UNIVERSIDADE DE BRASÍLIA

CENTRO DE DESENVOLVIMENTO SUSTENTÁVEL

PROGRAMA DE PÓS-GRADUAÇÃO EM DESENVOLVIMENTO SUSTENTÁVEL

Mestrado Profissional em Gestão e Política de Ciência Tecnologia e Inovação (C,T\&l)

O Processo de Acompanhamento e Avaliação das Transferências Voluntárias de Recursos do CNPq em Parceria com as FAP

Aluna: Rudes Lima Freitas

Orientadora: Profa. Dra. Maria Carlota de S. Paula 
Freitas, Rudes Lima.

O Processo de Acompanhamento e Avaliação das Transferências Voluntárias de Recursos do CNPq em Parceria com as FAP.I Rudes Lima Freitas. 154 p.

(UnB-CDS, Mestre, Gestão e Política de C\&T, 2014).

Dissertação de Mestrado. Centro de Desenvolvimento Sustentável, Universidade de Brasília, Brasília.

1. Ciência e Tecnologia 2. Transferências Voluntárias de Recursos da União 3. Acompanhamento e Avaliação 4. Fundações Estaduais de Amparo à Pesquisa. I. Universidade de Brasília-CDS.

É concedida à Universidade de Brasília permissão para reproduzir cópias desta dissertação e emprestar ou vender tais cópias somente para propósitos acadêmicos e científicos. A autora reserva outros direitos de publicação e nenhuma parte desta dissertação de mestrado pode ser reproduzida sem a autorização por escrito da autora.

Rudes Lima Freitas 


\title{
O Processo de Acompanhamento e Avaliação das Transferências Voluntárias de Recursos do CNPq em Parceria com as FAP
}

\author{
Rudes Lima Freitas
}

Dissertação de Mestrado submetida ao Centro de Desenvolvimento Sustentável da Universidade de Brasília, como parte dos requisitos necessários para a obtenção do Grau de Mestre em Desenvolvimento Sustentável, área de concentração em Gestão e Política de Ciência e Tecnologia, opção Profissional.

Aprovada por:

Maria Carlota de Souza Paula, Doutora (Universidade de Brasília-CDS) (Orientadora)

Isabel Teresa Gama Alves, Doutora (Examinador Interno)

Roberto Muniz de Carvalho Barretto, Doutor (Examinador Externo)

Brasília-DF, Outubro / 2014 
"E você aprende que realmente pode suportar... Que realmente é forte, e que pode ir muito mais longe...

Depois de pensar que não se pode mais. E que realmente a vida tem valor e que você tem valor diante da vida!" (W. SHAKESPEARE) 
Dedico este trabalho ao meu valoroso pai "in memorian", a minha mãe e a minha irmã sempre presentes em todos os momentos da minha vida e em especial quando eu mais precisei. Ao meu esposo e filhos pela compreensão da minha ausência sempre presente nesse período de grande labor mental. 


\section{AGRADECIMENTOS}

Agradeço em primeiro lugar ao meu Deus que me fortalece; me sustenta e me dá a direção e o caminho, todos os dias.

À minha família, especialmente ao Rozembelde, Gabriel e Lucas pela compreensão dos meus momentos quase insanos.

Ao CNPq pela oportunidade de aperfeiçoar os meus conhecimentos na confiança de retorno à Casa.

Às companheiras de longa jornada Lili - que possibilitou o meu ingresso no mestrado -, Tânia, Cristina, Eneida, Odete e Zê (aposentada) pela confiança de todas e por sempre acreditarem em meu potencial, toda a minha gratidão.

Ao Professor Ivan Rocha toda a minha gratidão, pela sua amabilidade, presteza e disponibilidade, pelo aprendizado que me proporciona sempre, tanto em nível acadêmico quanto pessoal.

À todos os professores do Curso de Mestrado In Company e aos colaboradores nas pessoas do Genismares e Antônio (da Secretaria do CDS), sempre atentos.

Aos colegas de curso pelo companheirismo, força e pelos momentos de descontração e em especial a Robertinha e Zanela, pelo meu sentimento de pertencimento e familiaridade junto aos dois.

Á minha orientadora Professora Doutora Maria Carlota pela aceitação em orientar, dedicação e paciência mantidas durante todo o tempo e pelo primor na orientação.

À Professora Lilian pelo carinho, dedicação e incentivo, sempre presentes e muito necessários, que me foram de grande valia.

Devo agradecimento especial ao Prof. Dr. Ricardo Félix pelo acompanhamento institucional, pelas discussões e sugestões, desde o início da formatação do projeto de pesquisa, fornecendo informações, suporte e apoio no decorrer da pesquisa realizada.

Aos colegas da CGNAC nas pessoas da Dra Ana Paula e Éderson Mantoan.

Aos colegas do SEDOC Roberto Muniz, Jânio, Fatinha, Paulo e também aos demais pela colaboração, busca e identificação de bibliografia e documentos do CNPq.

Aos colegas da Auditoria Interna do CNPq, em especial a Jack e a Andréia, pela colaboração contínua.

Ao Josenaldo Ferreira pela ajuda fundamental no manuseio dos Sistemas SIAFI, SIGEF e SIPC.

Em especial a Romúzia, pela paciência e presteza, que tornou as minhas tabelas e gráficos apresentáveis.

E a todos os outros colegas aqui não nominados, mas lembrados, que de alguma forma, apoiaram e fizeram parte dessa minha caminhada. 


\section{RESUMO}

O objetivo desta dissertação foi o de analisar e compreender como é realizado o processo de Acompanhamento e Avaliação das Transferências Voluntárias de Recursos da União, descentralizados por meio do CNPq às Fundações Estaduais de Amparo à Pesquisa (FAP). Buscamos identificar os mecanismos para incentivar o estabelecimento da pesquisa e desenvolvimento em regiões com maiores proporções de desigualdades e ainda sem a infraestrutura necessária para se utilizar da ciência e tecnologia, visando o alcance do desenvolvimento regional. Políticas federais de interiorização da ciência e tecnologia editadas de forma planejada e estruturada, entre outras, tiveram o seu início há mais de duas décadas no país. Em políticas mais recentes, foram introduzidos novos instrumentos, como a descentralização de recursos federais e de seus programas e projetos, que eram de execução prioritária do Estado-Nação e que foram descentralizadas para outros entes da Federação. Foram analisados os procedimentos e rotinas utilizados pelo $\mathrm{CNPq}$ para a transferência de recursos da União e os mecanismos de acompanhamento, monitoramento e avaliação dos recursos transferidos por meio de parcerias institucionais com as Fundações de Amparo à Pesquisa (FAP). Foram examinados processos de concessão internos ao CNPq, e os procedimentos frente às exigências legais, a efetividade desse procedimento. Foram realizadas entrevistas com técnicos e gestores do CNPq, comprometidos com a execução e gestão das transferências voluntárias e realizada uma pesquisa junto às FAP que recebem essas transferências.

Palavras-chave: Ciência e Tecnologia; Transferências Voluntárias de Recursos da União; Acompanhamento e Avaliação; Fundações Estaduais de Amparo à Pesquisa. 


\begin{abstract}
The aim of this study was to analyze and understand how the Evaluation of Voluntary Transfer of Union Resources is carried out, decentralized by CNPq to the State Foundations for Research Support (FAP). We sought to identify mechanisms to promote the establishment of research and development in areas with higher proportions of inequalities and still without the necessary infrastructure to use science and technology, aimed at achieving regional development. Federal policies of internalization of science and technology edited in a planned and structured way, among others, were initiated in the country more than two decades ago. In more recent policies, new instruments were introduced, such as the decentralization of federal funds and its programs and projects, which were of priority implementation to the State-Nation and that were decentralized for other entities of the Federation. Procedures and routines used by CNPq for the transfer of federal funds and monitoring mechanisms were analyzed, as well as the monitoring and evaluation of the resources transferred through institutional partnerships with the State Foundations for Research Support (FAP). CNPq's internal granting process were examined, and the procedures to face legal requirements, as well as the effectiveness of this procedure. Interviews were conducted with staff and managers from CNPq, committed to the implementation and management of the voluntary transfers and a survey to the FAP receiving such transfers.
\end{abstract}

Key words: Science and Technology; Voluntary Transfer of Union Resources; Monitoring and Evaluation; State Foundations for Research Support. 


\section{LISTA DE QUADROS}

Quadro 1 Instituições, Instrumentos de Fomento e Diretrizes da PCT no Brasil no período de 1950 a 2014

Quadro 2 Alguns marcos de Políticas Públicas de Combate às Desigualdades Regionais no Brasil -1988 a 2014

Quadro 3 Organização institucional das FAP nos estados 58

Quadro 4 Legislação que regula as Transferências Voluntárias da União 73

$\begin{array}{lll}\text { Quadro } 5 \text { Critérios para contrapartidas estaduais } & 75\end{array}$

$\begin{array}{lll}\text { Quadro } 6 & \text { Conceitos Abordados } & 77\end{array}$

Quadro 7 Composição dos recursos descentralizados para as FAP $\quad 84$

Quadro 8 Evolução do Monitoramento e Avaliação das Parcerias e Convênios do CNPq com as 104 FAP, $2003-2013$

Quadro 9 Consolidado das respostas dos representantes das FAP ao Questionário 


\section{LISTA DE GRÁFICOS}

Gráfico 1 Pesquisadores cadastrados no diretório dos grupos de pesquisa do CNPq por unidade da 42 federação, 2010

Gráfico 2 Dispêndios dos governos estaduais em Ciência e Tecnologia (C\&T), em valores de 2011, 44 por atividade, 2000-2011

Gráfico 3 Dispêndios dos governos estaduais em Ciência e Tecnologia (C\&T), por região, 2010-2011 45

Gráfico 4 Distribuição percentual dos dispêndios dos governos estaduais aplicados em Ciência e 46 Tecnologia (C,T\&l), por unidade da federação (UF)

$\begin{array}{lll}\text { Gráfico } 5 & \text { Recurso orçamentário das FAP } & 47\end{array}$

$\begin{array}{llr}\text { Gráfico } 6 & \text { Recurso Financeiro das FAP } & 67\end{array}$

Gráfico 7 Recursos Constitucionais gerais destinados à CT\& 81

Gráfico 8 Recursos Descentralizados pelo CNPq, por meio de Transferências Voluntárias, às FAP, 82 no período de 2003 a 2013

Gráfico 9 Recursos Financeiros Descentralizados às FAP 


\section{LISTA DE TABELAS}

Tabela 1 Percentual dos DispEmdios em Pesquisa e Desenvolvimento (P\&D) dos governos estaduais em relac;::ao as suas receitas totais, 2000-2012

Tabela 2 Recursos Descentralizados pelo CNPq 2003-2013 


\section{LISTA DE FIGURAS}

Figura 1 Índice de Desenvolvimento Humano nas Regiões Brasileiras - 2013

Figura 2 Ciclos das Políticas Públicas Regionais $\quad 35$

Figura 3 Divisão percentual dos Fundos de Financiamento 36

Figura 4 Percentual dos Fundos de Financiamento entre as regiões brasileiras 36

Figura $5 \quad$ Eixos de Sustentação da ENCTI $\quad 55$

Figura 6 Macrofluxo da Descentralização de Créditos pelo CNPq às FAP 110

Figura 7 Definição de diretrizes para a descentralização de Créditos pelo CNPq às FAP 111

Figura $8 \quad$ Cadastramento dos convênios com as FAP no SICONV 112

$\begin{array}{lll}\text { Figura } 9 & \text { Fluxo para a Firmatura de Convênio do CNPq com as FAP } & 113\end{array}$

$\begin{array}{lll}\text { Figura } 10 & \text { Fluxo da Execução de Convênio do CNPq com as FAP } & 114\end{array}$ 


\section{LISTA DE ABREVIATURAS E SIGLAS}

\begin{tabular}{|c|c|}
\hline ACTC & Atividades Científicas e Técnicas Correlatas \\
\hline$A C$ & Análise de Conteúdo \\
\hline ADTEN & Fundo de Desenvolvimento Tecnológico \\
\hline AgilFAP & Ambiente de Gestão de Informação e Logística \\
\hline BID & Banco Interamericano de Desenvolvimento \\
\hline BIRD & Banco Mundial \\
\hline C\&T\&l & Ciência, Tecnologia e Inovação \\
\hline CA & Comitês de Assessoramento \\
\hline CAPES & Coordenação de Aperfeiçoamento de Pessoal de Nível Superior \\
\hline CATC & Comissão de Assessoramento Técnico-Científico \\
\hline CCT & Conselho de Ciência e Tecnologia \\
\hline CD & Conselho Deliberativo \\
\hline CGCIN & Coordenação Geral de Cooperação Internacional \\
\hline CGSAU & Coordenação Geral do Programa de Pesquisa em Saúde \\
\hline CGEE & Centro de Gestão e Estudos Estratégicos \\
\hline CGNAC & Coordenação Geral de Cooperação Nacional \\
\hline CGU & Controladoria Geral da União \\
\hline CIDE & Contribuição de Intervenção no Domínio Econômico \\
\hline $\mathrm{CNI}$ & Confederação Nacional da Indústria \\
\hline CNPq & Conselho Nacional de Desenvolvimento Científico e Tecnológico \\
\hline CONECIT & Conselho Estadual de Ciência e Tecnologia \\
\hline CONFAP & Conselho Nacional de Fundações Estaduais de Amparo à Pesquisa \\
\hline CONSECT & Conselho Nacional de Secretários Estaduais para assuntos de C\&T\&I \\
\hline CORPAM & Comissão Coordenadora Regional de Pesquisa na Amazônia \\
\hline CPCT & Centro de Estudos em Política Científica e Tecnológica \\
\hline $\mathrm{CsF}$ & Programa Ciência sem Fronteiras \\
\hline DABS & Diretoria de Ciências Agrárias, Biológicas e da Saúde \\
\hline DCOI & Diretoria Cooperação Institucional \\
\hline DCR & Programa de Desenvolvimento Científico Regional \\
\hline DEHS & Diretoria de Engenharias, Ciências Exatas e Humanas e Sociais \\
\hline DEX & Diretoria Executiva \\
\hline DGP & Diretório do Grupo de Pesquisas do CNPq \\
\hline DGTI & Diretoria de Gestão e Tecnologia da Informação \\
\hline DNER & Departamento Nacional de Estradas e Rodagens \\
\hline DNIT & Departamento Nacional de Infraestrutura de Transportes \\
\hline FACEPE & Fundação de Amparo à Ciência e Tecnologia do Estado de Pernambuco \\
\hline FAP & Fundação Estadual de Amparo à Pesquisa \\
\hline FAPDF & Fundação de Apoio à Pesquisa do Distrito Federal \\
\hline FAPEAL & Fundação de Amparo à Pesquisa do Estado de Alagoas \\
\hline FAPEAM & Fundação de Amparo à Pesquisa do Estado do Amazonas \\
\hline FAPEG & Fundação de Amparo à Pesquisa do Estado de Goiás \\
\hline FAPEMA & Fundação de Amparo à Pesquisa e ao Desenvol. Cien. e Tecnol. do Maranhão \\
\hline FAPEMAT & Fundação de Amparo à Pesquisa do Estado de Mato Grosso \\
\hline FAPEMIG & Fundação de Amparo à Pesquisa do Estado de Minas Gerais \\
\hline FAPEP & Fundação de Amparo à Pesquisa do Estado da Paraíba \\
\hline FAPERGS & Fundação de Amparo à Pesquisa do Estado do Rio Grande do Sul \\
\hline FAPERJ & Fundação Carlos Chagas de Amparo à Pesquisa do Estado do Rio de Janeiro \\
\hline FAPERN & Fundação de Apoio à Pesquisa do Estado do Rio Grande do Norte \\
\hline FAPES & Fundação de Apoio à Ciência e Tecnologia do Espírito Santo \\
\hline FAPESB & Fundação de Amparo à Pesquisa do Estado da Bahia \\
\hline FAPESC & Fundação de Amparo à Ciência e Tecnologia do Estado de Santa Catarina \\
\hline FAPESP & Fundação de Amparo à Pesquisa do Estado de São Paulo \\
\hline FAPT & Fundação de Amparo à Pesquisa do Estado do Tocantins \\
\hline $\mathrm{FCO}$ & Fundo Constitucional de Financiamento do Centro-Oeste \\
\hline FINEP & Agência Brasileira da Inovação \\
\hline FNAS & Fundo Nacional de Assistência Social \\
\hline FNDCT & Fundo Nacional de Desenvolvimento Científico e Tecnológico \\
\hline FNE & Fundo Constitucional de Financiamento do Nordeste \\
\hline FNO & Fundo Constitucional de Financiamento do Norte \\
\hline FNS & Fundo Nacional de Saúde \\
\hline FORPESq & Fórum Nacional das Fundações, Fundos e Entidades de Amparo à Pesquisa \\
\hline FPE & Fundo de Participação dos Estados e Distrito Federal \\
\hline FPEX & Fundo de Cooperação pela Exportação de Produtos Industrializados \\
\hline
\end{tabular}




\begin{tabular}{|c|c|}
\hline FUNCAP & Fundação Cearense de Apoio ao Desenvolvimento Científico e Tecnológico \\
\hline FUNDEB & $\begin{array}{l}\text { Fundo de Manutenção do Desenvolvimento da Educação Básica e de Valorização de } \\
\text { Profissionais da Educação }\end{array}$ \\
\hline FUNDECT & $\begin{array}{l}\text { Fundação de Apoio ao Desenvolvimento do Ensino, Ciência e Tecnologia do Estado do } \\
\text { Mato Grosso do Sul }\end{array}$ \\
\hline FUNTAC & Fundação de Tecnologia do Estado do Acre \\
\hline FUNTEC & Fundo Estadual de Ciência e Tecnologia \\
\hline GOCNAE & Grupo da Comissão Nacional de Atividades Espaciais \\
\hline IBGE & Instituto Brasileiro de Geografia e Estatística \\
\hline IBICT & Instituto Brasileiro de Informação em Ciência e Tecnologia \\
\hline ICT & Institutos de Ciência e Tecnologia \\
\hline $\mathrm{IDH}$ & Índice de Desenvolvimento Humano \\
\hline IEL & Instituto Euvaldo Lodi \\
\hline IES & Instituições de Ensino Superior \\
\hline IN & Instrução Normativa \\
\hline INCT & Institutos Nacionais de Ciência e Tecnologia \\
\hline IPEA & Instituto de Pesquisa Econômica Aplicada \\
\hline IPI & Imposto sobre Produto Industrializado \\
\hline IR & Imposto de Renda \\
\hline LDO & Lei de Diretrizes Orcamentárias \\
\hline LOA & Lei Orcamentária Anual \\
\hline $\mathrm{MCTI}$ & Ministério da Ciência, Tecnologia e Inovação \\
\hline MEC & Ministério da Educação \\
\hline NATI & Núcleo de Assessores em Tecnologia e Inovação \\
\hline OBTV & Ordem Bancária das Transferências Voluntárias \\
\hline OCDE & Organização para Cooperação e Desenvolvimento Econômico \\
\hline OSCIP & Organizações da Sociedade Civil de Interesses Públicos \\
\hline P\&D & Pesquisa e Desenvolvimento \\
\hline PAINT & Plano Anual de Atividades de Auditoria Interna \\
\hline PCE & Programa Ciência na Escola \\
\hline PEC & Proposta de Emenda Constitucional \\
\hline PIB & Produto Interno Bruto \\
\hline $\mathrm{PIBIC}$ & Programa Institucional de Bolsas de Iniciação Científica \\
\hline PIBITI & Programa Institucional de Bolsas de Iniciação Tecnológica \\
\hline PICC & Plataforma Integrada Carlos Chagas \\
\hline $\mathrm{PL}$ & Projeto de Lei \\
\hline PMA & Política de Monitoramento e Avaliação de Políticas Públicas de C\&T\&I \\
\hline PNDR & Política Nacional de Desenvolvimento Regional \\
\hline PPP & Programa Primeiros Projetos \\
\hline PROESTADO & Programa de Apoio aos Governos Estaduais \\
\hline PRONEM & Programa de Apoio a Núcleos Emergentes de Pesquisa \\
\hline PRONEX & Programa de Apoio a Núcleos de Excelência \\
\hline RAINT & Relatório Anual de Atividades de Auditoria Interna \\
\hline RHAE & Programa de Formação de Recursos Humanos em Áreas Estratégicas \\
\hline SAREM & Secretaria de Articulação com os Estados e Municípios \\
\hline SDCT & Secretaria de Estado para o Desenvolvimento da Ciência e Tecnologia \\
\hline SEBRAE & Serviço Brasileiro de Apoio às Micro e Pequenas Empresas \\
\hline SECTI & Secretaria de Estado de Ciência, Tecnologia e Inovação \\
\hline SEINFRA & Secretaria de Estado de Infraestrutura de Manaus \\
\hline SEMATEC & Secretaria de Meio-Ambiente, Ciência e Tecnologia \\
\hline SENAI & Serviço Nacional de Aprendizagem Industrial \\
\hline SEPLAN & Secretaria de Estado do Planejamento e Desenvolvimento \\
\hline SEPLAN/PR & Secretaria de Planejamento da Presidência da República \\
\hline SEPRM & Serviço de Prêmios \\
\hline SESI & Serviço Social da Indústria \\
\hline SESPI & Suporte à Propriedade Intelectual \\
\hline SFC & Sistema Federal de Controle \\
\hline SIAFI & Sistema Integrado de Administração Financeira do Governo Federal \\
\hline SICONV & Sistema de Gestão de Convênios e Contratos de Repasse \\
\hline SIPC & Sistema Integrado de Prestação de Contas \\
\hline SNDCT & Sistema Nacional de Ciência Tecnologia e Inovação \\
\hline STN & Secretaria do Tesouro Nacional \\
\hline SUDENE & Superintendência de Desenvolvimento do Nordeste \\
\hline TCU & Tribunal de Contas da União \\
\hline
\end{tabular}




\section{SUMÁRIO}

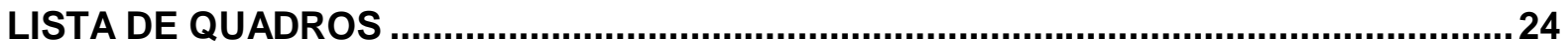

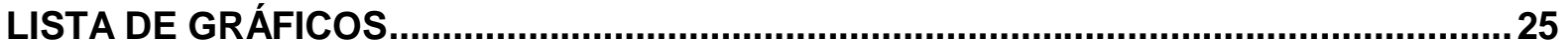

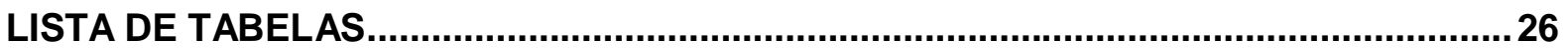

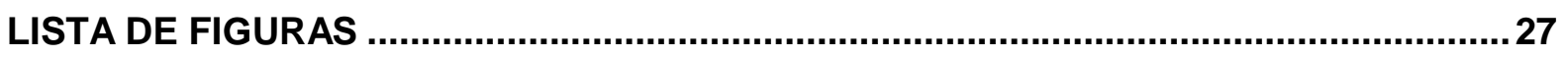

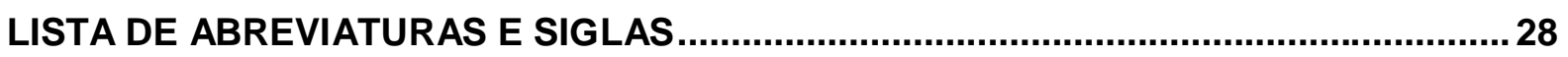

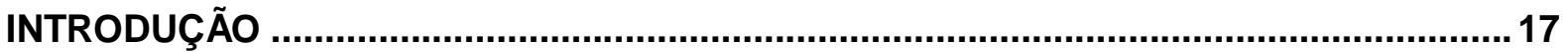

1 CIENCIA, TECNOLOGIA E REGIÕES NO BRASIL: antecedentes e contexto de fortalecimento do propósito de desconcentração ...................................................... 22

1.1 INSTITUCIONALIZAÇÃO DA CIÊNCIA E TECNOLOGIA NO BRASIL ........................22

1.2 CONCENTRAÇÃO DA CIÊNCIA E DA TECNOLOGIA NAS REGIÕES BRASILEIRAS

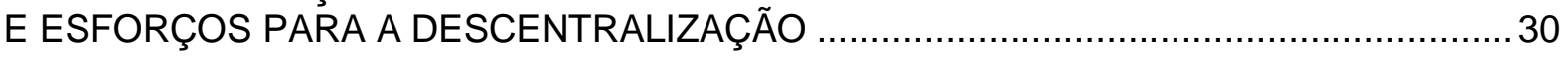

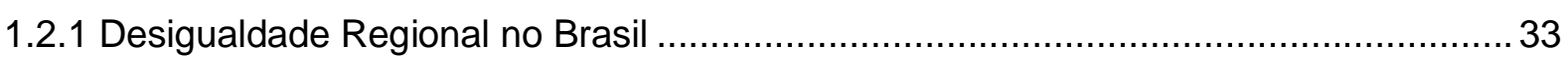

1.2.2 CT\&I no quadro das desigualdades regionais ..................................................... 40

1.2.3 Política de CT\&I e Descentralização Regional no Brasil ........................................ 48

2 A DESCENTRALIZAÇÃO DE RECURSOS DA UNIÃO PARA CIÊNCIA, TECNOLOGIA E INOVAÇẪO ....................................................................................56

2.1 AS FUNDAÇÕES ESTADUAIS DE AMPARO À PESQUISA OU SECRETARIAS DE ESTADO DA CIÊNCIA E TECNOLOGIA E AS TRANSFERÊNCIAS VOLUNTÁRIAS DE

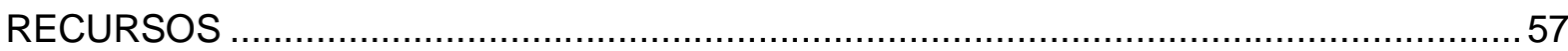

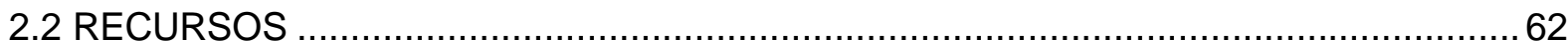

2.3 EVOLUÇÃO DA LEGISLAÇÃO DAS TRANSFERÊNCIAS VOLUNTÁRIAS DA UNIÃO 69 3 AS PARCERIAS ENTRE O CNPq E AS FUNDAÇÕES DE AMPARO À PESQUISA

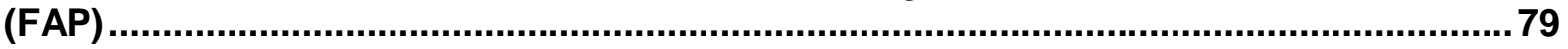

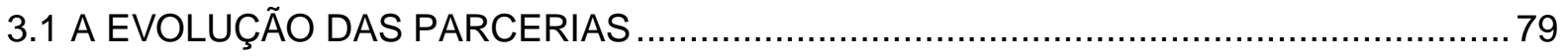

3.2 DEFINIÇÃO E PADRONIZAÇÃO DE ROTINAS PARA AS TRANSFERÊNCIAS

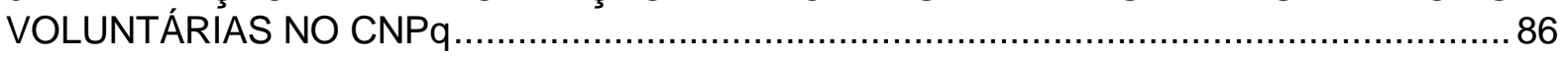

3.2.1 Mecanismos e Processos Decisórios para as Transferências Voluntárias .................. 91

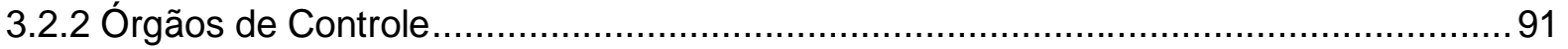

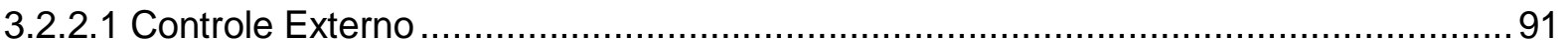

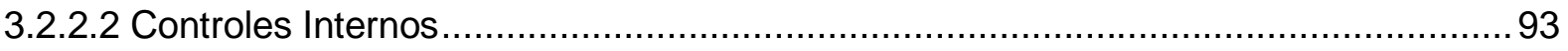

4 MONITORAMENTO E AVALIAÇÃO DAS TRANSFERÊNCIAS VOLUNTÁRIAS NO

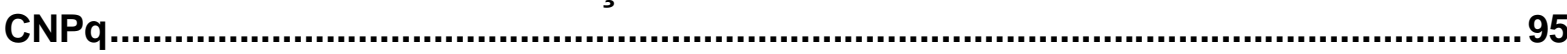

4.1 MONITORAMENTO E AVALIAÇÃO DAS TRANSFERÊNCIAS VOLUNTÁRIAS EM C\&T: uma visão geral

4.2 EVOLUÇÃO DO MONITORAMENTO \& AVALIAÇÃO DAS TRANSFERÊNCIAS

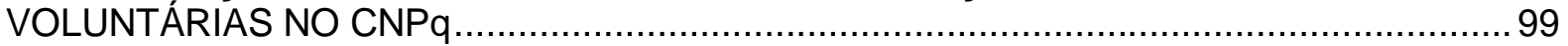

4.4. CONSULTA AO CNPq E ÀS FAP E OS RESULTADOS ALCANÇADOS ..................115 
4.4.1 Metodologia da Consulta

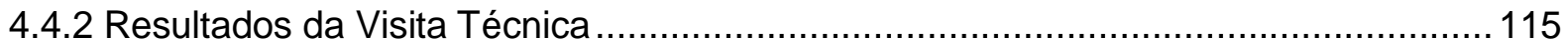

4.4.4 Resultados da Aplicação do Questionário......................................................... 117

4.4.4.1 Resultados do questionário aplicado às FAP .................................................. 117

4.4.4.2 Respostas das FAP às questões abertas.................................................. 118

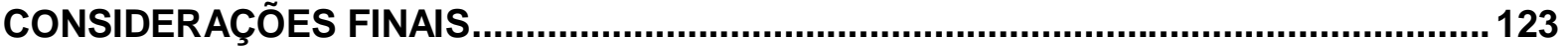

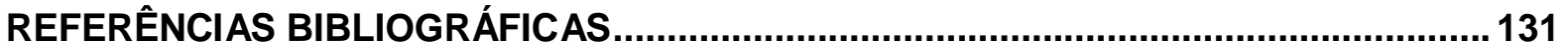

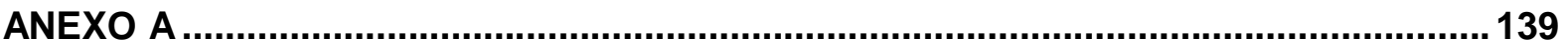

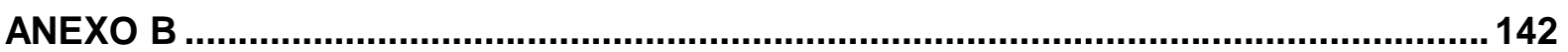

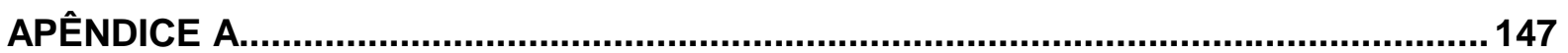

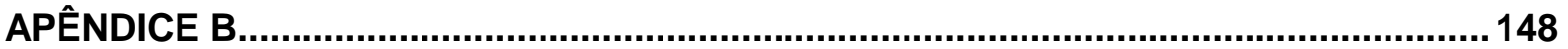

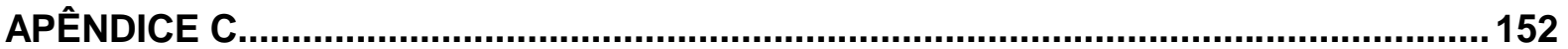





\section{INTRODUÇÃO}

Esta dissertação tem como objetivo analisar a estratégia de gestão e os instrumentos utilizados pelo Conselho Nacional de Desenvolvimento Cientifico e Tecnológico (CNPq) para realizar o acompanhamento e avaliação (A\&A) dos repasses efetuados por esse Conselho às Fundações de Amparo à Pesquisa (FAP) existentes no País. Os recursos são provenientes da União e repassados na forma de transferências voluntárias.

O portal do Tesouro Nacional assim define transferências voluntárias: "são os recursos financeiros repassados pela União aos Estados, Distrito Federal e Municípios em decorrência da celebração de convênios, acordos, ajustes ou outros instrumentos similares cuja finalidade é a realização de obras e/ou serviços de interesse comum e coincidente às três esferas do Governo." A Lei de Responsabilidade Fiscal entende por transferência voluntária "a entrega de recursos correntes ou de capital a outro ente da Federação, a título de cooperação, auxílio ou assistência financeira, que não decorra de determinação constitucional, legal ou os destinados ao Sistema Único de Saúde."

A transferência de recursos da União às FAP se insere em um conjunto de políticas públicas que, embora tenham feito parte das decisões políticas do governo federal anterior a 2003, foram, também, objeto de proposições feitas pela comunidade científica. A partir de 2003, o CNPq decidiu, por meio do seu Conselho Deliberativo, assinar termos de convênio com a maioria das FAP em atividade, para cumprir uma decisão de Estado que visava, em última análise, a diminuição das desigualdades regionais no campo de C\&T\&l. A implementação e execução dessa política caberiam, principalmente, ao $\mathrm{MCTI}$, por intermédio do CNPq.

Neste estudo buscou-se compreender os processos implementados nessa tarefa de operacionalizar a descentralização de recursos da União, observando as suas forças e fraquezas, e apontando o aperfeiçoamento dos processos internos do CNPq.

A sistemática de repasse foi analisada, também, sob o ponto de vista do atendimento à legislação federal que regula a adoção dessas transferências e dos trâmites para o alcance dos resultados esperados, propostos nos convênios firmados entre o CNPq e as FAP e no planejamento institucional do CNPq. Essa análise se fez por meio do estudo dos processos de acompanhamento e avaliação realizados pelo $\mathrm{CNPq}$, das ações descentralizadas de programas e projetos do governo federal nos estados, nos municípios e no Distrito Federal. 
Como elemento contextual, foi preciso também compreender a mudança institucional necessária em decorrência dos esforços de descentralização da C\&T, destacando-se a incorporação das FAP ao processo histórico de constituição da política científica e tecnológica no Brasil, como instrumento de fomento à pesquisa e desenvolvimento regionais, à formação de recursos humanos e de capacitação tecnológica para o atendimento às necessidades regionais. As transferências voluntárias de recursos da União, criadas com vistas a fortalecer a descentralização de recursos e as ações de desenvolvimento regional no campo da C\&T\&l, dentre outros instrumentos de políticas de Estado, tornaram-se possíveis a partir de uma nova configuração institucional e de infraestrutura, tanto nos Estados, nos Municípios e no Distrito Federal, como na estrutura do CNPq.

No cerne das expectativas do processo de descentralização de recursos e de ações de ciência e tecnologia está a perspectiva do desenvolvimento do País em sua totalidade, visto ser o Brasil um país de proporções continentais, onde as políticas públicas nem sempre conseguem alcançar todas as distintas regiões que o compõem. Nesse sentido, as transferências voluntárias constituem um instrumento mediante o qual o Estado brasileiro busca a articulação, convergência e coordenação de diversas iniciativas de fomento que visam ao desenvolvimento socioeconômico regional, conduzidas por órgãos públicos, empresas privadas e organizações da sociedade civil sem fins lucrativos.

O CNPq, como órgão do Governo Federal - assim como a Agência Brasileira de Inovação (FINEP) e a Coordenação de Aperfeiçoamento de Pessoal de Nível Superior (CAPES) - utilizam essas transferências às FAP ou às Secretarias Estaduais de C\&T\&l, mediante parcerias oficializadas por meio de convênios, com a finalidade de descentralizar recursos financeiros da União para a aplicação regional em pesquisa e desenvolvimento em ciência e tecnologia. A Portaria Interministerial n 507/2011, em seu Art. 8º é o documento legal que qualifica os partícipes para a "realização de atividades, por meio de convênio ou termo de parceria, com entidades públicas ou privadas, sem fins lucrativos, para a execução descentralizada de projetos."

Em 25 de junho de 2003, o Conselho Deliberativo (CD) do CNPq, em sua $125^{\mathrm{a}}$ Reunião, definiu a estratégia e a exigência formal de instrumentos mediante as quais o repasse de recursos aos estados, municípios e ao Distrito Federal, deveria ser efetivado.

As atividades de acompanhamento e avaliação, além de permitirem uma melhor visualização do atendimento do objeto e das metas do instrumento acordado, constituem 
uma exigência legal dos órgãos de controle federal. Ao longo desse trabalho, buscou-se mostrar como o CNPq tem realizado o acompanhamento e a avaliação das transferências voluntárias de recursos.

Visando demonstrar não apenas os procedimentos, mas também as bases das ações do CNPq, a pesquisa buscou responder, primeiramente, a algumas perguntas mais afetas ao caráter político e estratégico das atividades que têm viabilizado as transferências voluntárias, a saber: Quais são os critérios do CNPq para decidir sobre a viabilidade de transferências para uma FAP? Como se dá o processo de definição de prioridades? ${ }^{1}$

Outro conjunto de questões que se buscou responder refere-se à gestão realizada pelo CNPq, com vistas a compreender a sistemática de A\&A das transferências voluntárias: Como está estruturado o processo de transferências voluntárias? Como está estruturado o A\&A dessas transferências dentro do CNPq? Quais são as normas e regras adotadas pelo CNPq para a realização do A\&A? Se existem normas internas elas têm-se mostrado adequadas para realizar o A\&A desse tipo de instrumento? O CNPq possui estrutura física ou de pessoal adequada para realizar o A\&A? É necessária uma estrutura distinta para esse fim? As normas dos órgãos de controle são adequadas ou suficientes para realizar o A\&A, em conformidade com as necessidades do CNPq - em virtude das especificidades do campo de ciência e tecnologia? Como são realizados os procedimentos de aplicabilidade dos recursos pelas FAP e, consequentemente, da prestação de contas dos recursos recebidos?

Quanto aos resultados do A\&A, pergunta-se: Tem sido possível identificar se as transferências têm apresentado resultados que respondem ao esperado ou previsto pelos órgãos centrais que descentralizam recursos da União? O A\&A realizado possibilita às FAP e ao CNPq melhorar os seus métodos e práticas de gestão do apoio concedido?

Para a realização deste estudo foram utilizadas as fontes de dados do CNPq, como documentos e relatórios de gestão institucional e relatórios de gestão das áreas técnicas envolvidas nos processos de transferências voluntárias de recursos da União realizadas por este Conselho; os sistemas eletrônicos de fomento do CNPq; do Serviço de Documentação e Arquivo, Centro de Memória; e-fomento; Sistema Integrado de Prestação de Contas (SIPC); sítio do CNPq e de outros órgãos, como: SICONV; SIAFE; sítios das FAP; sítio do

\footnotetext{
${ }^{1}$ Como é a abordagem do CNPq junto às FAP, relativamente à identificação e definição das prioridades regionais? As FAP têm autonomia na definição das prioridades para a pesquisa regional ou obedecem a determinações de instâncias superiores? Qual o papel do CNPq nesse processo de definição das prioridades?
} 
CONFAP; do MCTI; do TCU; da CGU; SigFap; SigMCTI; SigPlan. Foram também realizadas entrevistas com gestores e técnicos do CNPq envolvidos com a descentralização de recursos da União às FAP, assim como visita a uma FAP.

Junto às FAP, foram aplicados questionários de pesquisa semiestruturados, dirigidos aos representantes das FAP que estiveram presentes no CNPq no período de 06 a 07 de maio de 2014, participando da II Oficina de Gestão de Convênios.

Com vistas à apresentação dos resultados deste trabalho, estruturou-se esta dissertação em quatro capítulos, além desta introdução e das considerações finais.

O primeiro capítulo busca apresentar, como pano de fundo, uma breve revisão histórica sobre os esforços brasileiros para a descentralização da ciência e tecnologia no Brasil. Para isso, aborda a institucionalização da ciência e tecnologia no País, destaca aspectos diretamente relacionados à concentração da C\&T\&l nas regiões brasileiras e aos esforços de descentralização da Política de Fomento à Ciência, Tecnologia e Inovação. São destacados os fatores que privilegiaram a concentração regional da ciência e tecnologia em algumas regiões e, por outro lado, buscou-se verificar o que levou o Estado brasileiro a criar políticas públicas que viabilizassem ações para diminuir a desigualdade regional. Recentemente foram criados instrumentos para uniformizar ações e procedimentos do fomento à C\&T\&l no Brasil, como as transferências voluntárias, com uma legislação destinada a atender a todas as regiões, independentemente de sua infraestrutura em P\&D, da capacitação de recursos humanos para a P\&D ou das necessidades regionais locais em P\&D.

O segundo capítulo trata de forma mais específica dessa descentralização de recursos da União para ciência, tecnologia e inovação, das Fundações Estaduais de Amparo à Pesquisa ou das Secretarias de Estado da Ciência e Tecnologia e das transferências voluntárias de recursos. No aspecto institucional - FAP ou Secretarias de C\&T - abordamse momentos históricos da criação dessas instituições, assim como a sua incorporação na agenda política federal e, especificamente, os processos da política e do fomento à C\&T; da necessidade de o Estado se instrumentalizar para disciplinar a forma de operacionalização do novo modelo de fomento de ciência e tecnologia, ou seja, a execução de programas nacionais descentralizados para os estados e a evolução da legislação das transferências voluntárias da União. 
No capítulo três são apresentadas as articulações entre o CNPq e as FAP, no que se refere às transferências voluntárias. Em primeiro lugar, um tópico aborda a evolução das parcerias e as exigências legais para que se viabilizassem as transferências voluntárias; são apresentados alguns dos principais programas do CNPq que foram descentralizados às FAP. Elencam-se os programas executados pelo CNPq e FAP na forma de transferências voluntárias; apresenta-se a normatização para uniformizar e definir ações e procedimentos para as transferências voluntárias por parte do CNPq. Nesse capítulo, destaca-se também o papel das instâncias de negociação, tais como o CONFAP, CONSECTI, o Fórum Nacional das Fundações, Fundos e Entidades de Amparo à Pesquisa (Forpesq), criados com o propósito de fazer a interface entre todas as FAP e as instituições governamentais para a captação de recursos financeiros e a discussão para a proposição de melhorias nas políticas regionais. São exploradas, ainda, mudanças institucionais e de políticas, nos estados, que possibilitaram a efetivação dessas parcerias com as Fundações de Amparo à Pesquisa.

No capítulo quatro são abordados o histórico dos procedimentos e os instrumentos utilizados pelo CNPq para realizar o acompanhamento, monitoramento e avaliação das transferências voluntárias, e consequentemente, a aplicação do montante desses recursos transferidos às FAP, no período compreendido para esse estudo, que é de 2003 a 2013. Quais os modelos utilizados pelo CNPq e pelas FAP para realizar esses procedimentos de acompanhamento, monitoramento e avaliação, assim como os resultados advindos da descentralização de recursos da União às FAP para o desenvolvimento da pesquisa regional. A importância da aferição desses resultados de pesquisas e a criação de indicadores próprios para ciência e tecnologia, vêm ao encontro do que é proposto pelo Estado e esperado pelos cidadãos brasileiros, quanto à transparência, à aplicabilidade de recursos e ao retorno das pesquisas como produtos ou processos à comunidade. Assim como, são apresentadas as bases da pesquisa realizada junto ao CNPq e às FAP e os resultados encontrados.

Nas considerações finais apresenta-se o resumo dos resultados deste estudo, que serviram de base para formular sugestões ao CNPq visando aperfeiçoar a gestão das transferências voluntárias, de modo particular quanto ao monitoramento, acompanhamento e avaliação. Foram relatadas as percepções da autora no decorrer da pesquisa quanto à gestão institucional do CNPq e à forma de execução das atividades realizadas pelos seus técnicos e gestores, não só quanto à gestão das transferências voluntárias, mas também quanto ao que tem sido cobrado pelos órgãos de controle interno e externos, para a observância e cumprimento da legislação pertinente. 


\section{CIENCIA, TECNOLOGIA E REGIÕES NO BRASIL: antecedentes e contexto de fortalecimento do propósito de desconcentração}

\subsection{INSTITUCIONALIZAÇÃO DA CIÊNCIA E TECNOLOGIA NO BRASIL}

Veremos neste item, em rápida revisão, como a questão regional se manifestou ao longo do tempo na política de CT\&I e que papel as medidas de descentralização, como as transferências voluntárias, exerceram ou podem exercer na busca de fortalecimento da ciência e tecnologia em todas as regiões.

Segundo o documento da Secretaria da Ciência e Tecnologia ${ }^{2}$ (1990), as mais importantes iniciativas para a institucionalização da ciência e tecnologia no Brasil tiveram lugar ainda no século XIX e no início do século XX. Merece destaque o estabelecimento da Escola de Minas de Ouro Preto e do Instituto Agronômico de Campinas em 1887; do Instituto Butantã em 1899, para a fabricação de soros antiofídicos, do Instituto Oswaldo Cruz, em 1901 - transformado em pouco tempo em referência internacional para a medicina tropical -; a criação da Academia Brasileira de Ciências em 1916 e, sobretudo, o surgimento da primeira Universidade moderna, a Universidade de São Paulo (USP), em 1934.

Essa mesma fonte aponta ainda que a criação dessas instituições não resultou de uma política deliberada de promoção do desenvolvimento científico e tecnológico do País, mas sim de respostas do Estado a desafios reais, impostos, principalmente, por necessidades das áreas de saúde, higiene e de problemas agrícolas ou, no caso da USP, a uma política específica para o fortalecimento do Estado de São Paulo, incentivada pelas suas elites agrárias e industriais contra o centralismo da União, após a revolução de 1930. (BRASIL, 1990, p. 1)

Montoyama (2000) afirma que, já no Período Republicano, alguns intelectuais brasileiros começaram as primeiras iniciativas de discussão sobre a situação da ciência no País. Essas ações tiveram forte influência da situação europeia no final do século XIX e princípios do século XX. São Paulo estava à frente das discussões, e se esforçava para montar uma infraestrutura capaz de enfrentar os desafios de uma nova era marcada pela Revolução Técnico-Científica ou Segunda Revolução Industrial. A institucionalização da C\&T no Brasil, nas palavras do autor, teve a sua gênese a partir "de episódios esparsos e

\footnotetext{
${ }^{2}$ O MCT, criado em 15 de março de 1985, havia sido transformado, nesse momento, em Secretaria da Ciência e Tecnologia, para depois tornar-se Ministério.
} 
nem sempre expressivos, marcados por iniciativas importantes". (MONTOYAMA, 2000, p. 18)

$\mathrm{Na}$ verdade, iniciativas para a institucionalização de uma política de ciência e tecnologia no Brasil começaram a esboçar-se no pós-guerra, principalmente a partir dos anos 50 do século $\mathrm{XX}$, quando o Estado passou a apoiar atividades científicas e tecnológicas de forma sistemática. Com um processo paulatino, as atividades dessa área passaram a ter mais espaço na agenda nacional e na de alguns estados de maior desenvolvimento econômico, que passaram a ser, por isso mesmo, os mais beneficiados pelos apoios públicos nesse campo, considerando a capacidade instalada e os níveis de avanço que apresentavam.

Para Montoyama (2000), o primeiro impulso deu-se em 1947, com a inserção, na Constituição do Estado de São Paulo, do preceito de se destinar, pelo menos, 0,5\% da arrecadação estadual para o amparo à pesquisa. No entanto, esse esforço se concretizaria apenas a partir de 1962, quando foi criada a Fundação de Amparo à Pesquisa do Estado de São Paulo (FAPESP), iniciativa que representou o início da instalação das Fundações de Amparo à Pesquisa (FAP) ${ }^{3}$ no Brasil. (MONTOYAMA, 2000, pp. 18-30; DIAS, 1990, p. 88)

Além das instituições citadas acima, um importante exemplo de instrumento foi a destinação de $0,5 \%$ da arrecadação do Estado de São Paulo para a pesquisa no estado. 0 processo de institucionalização de uma política de ciência e tecnologia no Brasil começou a esboçar-se apenas no pós-guerra, sendo marcada por períodos distintos. (SCT/PR,1990, p. 1)

Um marco importante nesse processo de institucionalização da ciência e tecnologia foi a criação do Conselho Nacional de Pesquisas (CNPq) ${ }^{4}$, em 1951, e da Campanha de Aperfeiçoamento de Pessoal de Nível Superior (CAPES) ${ }^{5}$, instituições voltadas para a capacitação de pessoal e para a formação e fortalecimento de grupos científicos no país, com a criação de instrumentos de fomento, como bolsas de estudos e auxílios à pesquisa.

Em 1964, foi criado o Fundo de Desenvolvimento Técnico Científico (FUNTEC). A partir daí, o Banco Nacional do Desenvolvimento Econômico (BNDE) recebeu a

\footnotetext{
3 "FAP - Fundações Estaduais de Amparo à Pesquisa - fundações de fomento à pesquisa, organizadas no âmbito de vários estados brasileiros e que compõem o sistema nacional de C\&T" (ROCHA NETO, 1996).

${ }^{4}$ Em 1974, a Lei № 6.129, de 6 de Novembro de 1974, transforma o "Conselho Nacional de Pesquisas" em "Conselho Nacional de Desenvolvimento Científico e Tecnológico, preserva-se a sigla CNPq.

${ }^{5}$ Hoje Coordenação de Aperfeiçoamento do Pessoal de Nível Superior. Preserva-se a sigla CAPES.
} 
incumbência de financiar atividades de pesquisa e desenvolvimento e de formar pessoal técnico para a empresa nacional. Em 1969 foi criada a Financiadora de Estudos e Projetos $\left(\right.$ FINEP) ${ }^{6}$ e, em 1971, o Fundo Nacional de Desenvolvimento Científico e Tecnológico (FNDCT), sob a administração da FINEP. (BRASIL, 1984, p. 6)

O Programa Estratégico de Desenvolvimento (PED) para o período de 1968 a 1970, definiu, explicitamente, o desenvolvimento científico e tecnológico como objetivo da política governamental. Esse Programa foi importante como elemento de viabilização da estratégia econômico-social do governo. Forte ênfase foi dada ao sistema de pós-graduação, bem como cresceu e diversificou-se a estrutura institucional de C\&T, para a qual se propôs um modelo de funcionamento sistêmico, o Sistema Nacional de Desenvolvimento Científico e Tecnológico (SNDCT). (BRASIL, 1990, p. 2)

Os esforços governamentais para institucionalizar o planejamento no País estenderam-se ao campo da ciência e tecnologia, sendo que o I Plano Nacional de Desenvolvimento (I PND), para o período de 1972 a 1974, inclui a área de Ciência e Tecnologia entre os "grandes objetivos nacionais". (BRASIL, 1984, p. 6) Posteriormente, foram editados os PND II e III.

Em consonância com os PND, foram elaborados Planos Básicos de Desenvolvimento Científico e Tecnológico (PBDCT). No primeiro deles, válido para o período de 1973 a 1974, foram detalhadas as ações para a constituição de sistemas setoriais no campo de C\&T, com os objetivos de:

1. Formular diretrizes gerais de pesquisa para cada área do conhecimento;

2. Elaborar programas setoriais específicos; e

3. Instituir estímulos ao entrosamento do Sistema Nacional de Desenvolvimento Científico e Tecnológico - SNDCT com o setor privado, a fim de proporcionar a este último indicação sobre suas prioridades e seus objetivos. (BRASIL, 1990, p. 7)

O II PBDCT, referente ao período de 1975 a 1979, indicava programas e projetos prioritários para o Sistema Nacional de Desenvolvimento Científico e Tecnológico. Formulado sob a coordenação do CNPq, esse plano mantinha as principais diretrizes estabelecidas no I PBDCT e incorporava as prioridades fixadas no II PND. (BRASIL, op. cit. p. $7-8)^{7}$

\footnotetext{
${ }^{6}$ A partir de 27 de janeiro de 2014, chamada Agência Brasileira da Inovação (Finep).

7 Entretanto, os investimentos previstos no II PND somente seriam possíveis mediante o financiamento e o endividamento externo, e a consequência foi a deterioração da capacidade de financiamento do setor público na
} 
De forma a efetivar o conceito de coordenação horizontal de C\&T dentro do governo federal, criou-se, no CNPq, o Conselho Científico e Tecnológico (CCT), como órgão normativo superior da área, para acompanhar a execução do II PBDCT.

Em 1980, o III PBDCT, para o período de 1980 a 1985, foi elaborado sob a coordenação direta do CCT. A elaboração das Ações Programadas, dentro do III PBDCT, propiciaria certo alinhamento das ações públicas setoriais em torno dos objetivos propostos (BRASIL, op. cit., pp. 3-4), muito embora se saiba que este Plano não chegou a concretizarse.

O III PND (1980 a 1985) foi interrompido já no segundo semestre de 1980, quando o país começava a sofrer as consequências de forte crise econômica internacional e o governo federal, alegando que a instabilidade econômica impedia qualquer programação de mais longo prazo, passou a governar com medidas de curto e curtíssimo prazo. (GIACOMONI, 1996 apud MATOS, 2002, p. 69)

A década de 1980, embora nominada como "a década perdida", não deixou de mostrar avanços em C\&T, como mostra o Quadro 1 (p. 29), que lista sete instituições e instrumentos de fomento criados na década, e o Quadro 3 (pp. 58 a 59) que mostra a criação de quatro fundações de amparo à pesquisa nos estados. Destaca-se, até 1984, a elaboração das Ações Programadas, das Ações e Perspectivas (não efetivamente implementadas) e a criação do PADCT, que funcionou como o grande programa estruturador e financiador da pesquisa, no momento em que o País passava por forte crise econômica e política.

Em 15 de março de 1985, primeiro dia da Nova República ${ }^{8}$, foi criado o Ministério de Ciência e Tecnologia - atual MCTI. Na segunda metade da década, foram também estruturadas as Secretarias em Áreas Estratégicas, foi implementado o PADCT e criado o Programa de Formação de Recursos Humanos em Áreas Estratégicas (RHAE), em 1987, entre outras ações e, em 1988, foi promulgada a Constituição Federativa do Brasil, primeira Carta Constitucional a incluir um capítulo sobre C\&T e que deu o norte para outras ações de forte impacto no desenvolvimento brasileiro, incluindo aspectos relevantes para o desenvolvimento regional e local.

\footnotetext{
década de 80, uma vez que se socializaram todos os custos do II PND (aumento nos gastos sem criar mecanismos adequados de financiamento). (Matos, 2002, p. 66)

${ }^{8} \mathrm{Na}$ realidade, o ministério havia sido criado em 1967, mas não chegou a ser efetivamente estabelecido.
} 
A promulgação da Constituição da República Federativa do Brasil, em 05 de outubro de 1988, trouxe em seu bojo - Artigo 218 - dispositivo com destaque para a responsabilidade do Estado frente à ciência e à tecnologia nacionais, no qual se estabelece o incentivo e o apoio a esse campo como atividades de Estado. Na íntegra, este artigo reza:

Art. 218 - O Estado promoverá e incentivará o desenvolvimento científico, a pesquisa e a capacitação tecnológicas.

$\S 1^{0}$ - A pesquisa científica básica receberá tratamento prioritário do Estado, tendo em vista o bem público e o progresso das ciências.

$\S 2^{\circ}{ }_{-}$A pesquisa tecnológica voltar-se-á preponderantemente para a solução dos problemas brasileiros e para o desenvolvimento do sistema produtivo nacional e regional. (grifo da autora)

§ 30- O Estado apoiará a formação de recursos humanos nas áreas de ciência, pesquisa e tecnologia, e concederá aos que delas se ocupem meios e condições especiais de trabalho.

$\S 4^{\circ}$ - A lei apoiará e estimulará as empresas que invistam em pesquisa, criação de tecnologia adequada ao País, formação e aperfeiçoamento de seus recursos humanos e que pratiquem sistemas de remuneração que assegurem ao empregado, desvinculada do salário, participação nos ganhos econômicos resultantes da produtividade de seu trabalho.

$\S 5^{\circ}$ - É facultado aos Estados e ao Distrito Federal vincular parcela de sua receita orçamentária a entidades públicas de fomento ao ensino e à pesquisa científica e tecnológica.

Entre os instrumentos então criados para o planejamento e financiamento à ciência e tecnologia, destacam-se os Planos Plurianuais (PPA). Para Matos (2002), foi de fundamental importância a inserção de texto constitucional específico relacionado ao planejamento e à institucionalização da ciência e da tecnologia no Estado brasileiro, pois logrou repercussão legítima em todo o território nacional. O processo de organização dos sistemas estaduais de C\&T foi iniciado em vários Estados, com a criação de Fundações Estaduais de Amparo à Pesquisa. (MATOS, op. cit., pp. 76-77)

$\mathrm{Na}$ década de 90, continuou o incentivo aos instrumentos de fomento e às diretrizes da Política Nacional de Ciência, Tecnologia e Inovação, destacando-se a continuidade do Programa de Apoio ao Desenvolvimento Científico e Tecnológico (PADCT) II e III e o fortalecimento da pesquisa científica e tecnológica com a consolidação da legislação aplicada ao setor. Foram criadas Secretarias de C\&T e Fundações de Amparo à Pesquisa nos estados. Houve aumento do montante de recursos para C\&T (hoje, o orçamento estimado para a área gira em torno de $1,2 \%$ do Produto Interno Bruto). Instalou-se uma rede de Institutos Nacionais de Ciência e Tecnologia, que substituíram os Institutos do Milênio e foi elaborado um plano nacional de C\&T, como eixo orientador da política de Estado. (VIDEIRA, 2010, pp.11 a 32) 
As regiões Norte, Nordeste e Centro-Oeste passaram a receber recursos financeiros públicos para ciência e tecnologia, de forma sistemática, a partir da promulgação da Carta Magna de 1988, por meio da descentralização de recursos via CNPq e outras agências de fomento, como a FINEP e a CAPES, além de receberem, também, repasses de recursos financeiros do FNDCT. Antes disso, eram realizados repasses financeiros esporádicos, em menor proporção e de forma não sistemática. Com a criação das Secretarias de Estado de Ciência e Tecnologia nos estados e das Fundações de Amparo à Pesquisa (FAP), passaram a ser tais instituições grandes responsáveis pela descentralização de recursos federais, como parte do processo de desconcentração dos recursos destinados à ciência e a tecnologia.

Em 2000 foram criados os Fundos Setoriais; em 2004, a Lei de Inovação; em 2005, a Lei do Bem, isso para mencionar algumas das iniciativas que contribuíram para fortalecer o sistema de C\&T e, de modo particular, fortalecer a inovação como parte do mesmo e tornála um dos componentes da política de C\&T.

Em 2011 foi proposto um novo marco legal para a área de C\&T\&l, por meio do Projeto de Lei $n^{\circ} 2.127 / 2011$ - ainda em tramitação no Congresso Nacional -, que visa estabelecer normas de regulamentação para as atividades de C\&T\&l no Brasil. Esse projeto de lei objetiva regulamentar os artigos "218 e 219 da Constituição Federal brasileira, ao instituir o Código Nacional de Ciência, Tecnologia e Inovação, com vistas à capacitação e ao alcance da autonomia tecnológica e ao desenvolvimento industrial do País".

Nas palavras de ARBIX (2007),

[...] ocorreu grande transformação das atividades de ciência e tecnologia, com a formulação de políticas integradas, envolvendo setores produtivos, Estado e centros de pesquisa tecnológica. Nas últimas décadas essas instituições tiveram uma redefinição e participação importante, procurando sintonizar o país àquilo que se praticava nas economias avançadas. Lembrando que esse caminho somente começou a ser palmilhado, restando ainda muito que percorrer, pois o Brasil continua um país com economia periférica, mas esforços estão sendo feitos na busca dessa convergência. (ARBIX, 2007apud ANDRADE, 2011, p. 299)

Em 01/04/2014, foi aprovada na Câmara Federal a Proposta de Emenda Constitucional (PEC) 290/2013, que altera o texto da Constituição Federal para dar novo tratamento ao segmento de C\&T\&l.

Pretende ela:

- renomear o Capítulo IV do Título VIII da Carta, introduzindo o termo "inovação", de se modificar o caput do art. 218 e de se introduzir um 
parágrafo único ao art. 219, reforçando a participação do Estado no estímulo à tecnologia de ponta; e

- alterar a redação do $\S 1^{\circ}$ do art. 218 , retirando do texto atual a expressão "básica" e inserindo a expressão "tecnologia", em virtude da separação vislumbrada entre ciência básica e pesquisa tecnológica, pois diversas linhas de pesquisa "pura" têm potencial para desdobrar-se em novas soluções para o setor produtivo.

A PEC 290/2013 apresenta-se com o objetivo de

criação de oportunidades de integrar instituições de pesquisa tecnológica e empresas inovadoras em um sistema nacional, alcançando as esferas federal, estadual e municipal, como forma de aliar os esforços de financiamento e de coordenação do desenvolvimento tecnológico e das atividades de extensão tecnológica. (PEC, 290/2013)

O Quadro 1 (p. 29) mostra, em ordem cronológica, a partir de 1950 e chegando a 2014 - a título de informação -, os fatos mais relevantes no processo de institucionalização da C\&T no Brasil, conforme descrito ao longo deste tópico: a criação de instituições de C\&T e de outros organismos que vieram a ter papel importante nesse campo, como o CNPq, a CAPES, a FINEP, o BNDE, o PROTEC e alguns institutos de pesquisa; o planejamento das ações da área a partir da década de 60 e a ampliação de instrumentos de fomento na década de 1970 - como o FNDCT - e a busca de organização do SNDCT.

No próximo tópico 1.2 serão abordados os temas concentração e descentralização da ciência e tecnologia nas regiões brasileiras, assim como os aspectos históricos que, associados, influenciaram esse modelo, dando lugar à disparidades regionais. 
Quadro 1 - Instituições, Instrumentos de Fomento e Diretrizes da PCT no Brasil no período de 1950 a 2014

\begin{tabular}{|c|c|c|}
\hline Décadas & Anos & Instrumentos de Fomento e Diretrizes da Política de C\&T\&I \\
\hline \multirow{4}{*}{50} & 1951 & Conselho Nacional de Desenvolvimento Científico e Tecnológico - CNPq \\
\hline & 1951 & Coordenação de Aperfeiçoamento de Pessoal de Nível Superior - CAPES \\
\hline & 1952 & Banco Nacional de Desenvolvimento Econômico - BNDE \\
\hline & 1952 & Programa de Expansão Tecnológica - PROTEC \\
\hline \multirow{3}{*}{60} & 1964 & Fundo de Desenvolvimento Técnico Científico - FUNTEC \\
\hline & 1967 & Programa Estratégico de Desenvolvimento - PED \\
\hline & 1969 & I Plano Nacional de Desenvolvimento - I PND \\
\hline \multirow{8}{*}{70} & 1971 & Financiadora de Estudos e Projetos - FINEP \\
\hline & 1971 & Fundo Nacional de Desenvolvimento Científico e Tecnológico - FNDCT \\
\hline & 1973-74 & Plano Básico de Desenvolvimento Científico e Tecnológico - I PBDCT \\
\hline & 1974 & Conselho Científico e Tecnológico - CCT \\
\hline & 1975 & Sistema Nacional de Desenvolvimento Científico e Tecnológico - SNDCT \\
\hline & $1975-79$ & II Plano nacional de Desenvolvimento - II PND \\
\hline & 1976 & II Plano Básico de Desenvolvimento Científico e Tecnológico - II PBDCT \\
\hline & 1979-85 & III Plano Nacional de Desenvolvimento - III PND \\
\hline \multirow{7}{*}{80} & $1980-85$ & Plano de Desenvolvimento Científico e Tecnológico - III PBDCT \\
\hline & 1981 & Sistemas Estaduais de Ciência e Tecnologia - SECT \\
\hline & 1984 & Programa de Apoio ao Desenvolvimento Científico e Tecnológico - I PADCT \\
\hline & 1985 & Ministério de Ciência e Tecnologia - MCT \\
\hline & $1986-89$ & I Plano Nacional de Desenvolvimento da Nova República - I PND/NR \\
\hline & 1988 & Constituição da República Federativa do Brasil \\
\hline & 1989 & $\begin{array}{l}\text { Constituições Estaduais } \\
\text { Fundações Estaduais de Amparo à Pesquisa - FAP }\end{array}$ \\
\hline \multirow{2}{*}{90} & 1991 & Programa de Apoio ao Desenvolvimento Científico e Tecnológico - II PADCT \\
\hline & 1996 & Programa de Apoio ao Desenvolvimento Científico e Tecnológico - III PADCT \\
\hline \multirow{5}{*}{00} & 2000 & Fundos Setoriais \\
\hline & 2004 & Lei de Inovação \\
\hline & 2005 & Lei do Bem \\
\hline & 2011 & $\begin{array}{l}\text { Código Nacional de Ciência, Tecnologia e Inovação - Projeto de Lei nº 2.177, de 2011. Em } \\
\text { tramitação - Maio/2014. }\end{array}$ \\
\hline & 2014 & PEC 290/2013, aprovada na Câmara dos Deputados em 01/04/2014. \\
\hline
\end{tabular}

Fonte: Elaborado pela autora a partir da pesquisa bibliográfica e documental. 


\subsection{CONCENTRAÇÃO DA CIÊNCIA E DA TECNOLOGIA NAS REGIÕES BRASILEIRAS E ESFORÇOS PARA A DESCENTRALIZAÇÃO}

Neste tópico serão tratados os aspectos que, associados, influenciaram a concentração da ciência e tecnologia pelas regiões brasileiras e, posteriormente, circundaram os esforços na busca de uma descentralização equilibrada. A importância do estudo desse tema se prende à gênese da formação do povo brasileiro e da divisão territorial, de proporção continental, do Brasil em regiões e principalmente do desenvolvimento alcançado por cada região. Hoje, das cinco regiões brasileiras, as que se destacam como as de maior desenvolvimento econômico, social, industrial e no campo da ciência e tecnologia, são as regiões Sudeste e Sul.

Nas últimas décadas tem-se dado atenção especial para promover uma desconcentração do apoio à CT\&l - visando maior e melhor distribuição espacial de recursos repassados pelo Estado brasileiro -, bem como à descentralização de ações, mobilizando-se diversos atores regionais, com vistas a colaborar para o desenvolvimento regional e o fortalecimento do SNDCT. (CGEE, 2010, p. 9)

Antes, porém, de analisar esses movimentos, aos quais se vinculam diretamente as transferências voluntárias - o foco deste estudo -, considera-se importante destacar alguns conceitos e manifestações do fenômeno da concentração, de forma a entender melhor o processo histórico que levou às ações e instrumentos atuais para o enfrentamento desse problema. Assim, este item discorrerá sobre as várias políticas de Estado que foram criadas visando minimizar as desigualdades regionais e inter-regionais brasileiras.

A concentração/desconcentração refere-se à distribuição espacial das ações de instituições do governo federal, no foco deste estudo, na área de C\&T\&l.

Segundo o CGEE (2010), o processo de desconcentração se define pelas:

[...] iniciativas da União (ministérios, empresas públicas, institutos de tecnologia etc.) ou dos estados e municípios, que levam a uma maior dispersão espacial de seus programas de CT\&l, sem que necessariamente estejam associadas a processos de descentralizaçãa ${ }^{9}$ ou a alguma forma de articulação estratégica, institucional ou operacional específica entre essas instâncias da Federação. (CGEE, op.cit, p.11-13)

9 Descentralização se refere à distribuição de funções entre diferentes níveis de governo (federal, estaduais e municipais) e entre esses níveis e instituições do setor privado. (CGEE, 2010, p.11-13) 
A desconcentração diferencia-se da descentralização. Esta última refere-se à distribuição de funções e responsabilidades entre níveis de governo e de instituições. De acordo com as definições de CGEE (2010, p. 12), possui duas dimensões analíticas:

1- a descentralização da responsabilidade pela execução das políticas ou programas; e

2- a descentralização da autoridade decisória sobre essas políticas pode compartilhar competências e autoridade decisória com os órgãos de governo (federal, estadual e municipal)

O processo de descentralização tem impacto na expansão dos recursos do Sistema Nacional de CT\&I, na medida em que, em geral, exige contrapartidas das unidades federativas.

Barros (1999) chama a atenção para a necessidade de, também, conceituar o que se entende por região, no contexto das regiões brasileiras, visto que seu uso é bastante diversificado e muitas vezes impreciso. Diz "tratar-se de um espaço geográfico cuja delimitação, por fins de ação administrativa do Estado, passa a contar com amplo reconhecimento". Além disso, para fins de ações governamentais, utilizam-se, também, as noções de regiões, macrorregiões e microrregiões. (BARROS, 1999, p.22)

Adota-se nesta dissertação a classificação regional feita pelo Instituto Brasileiro de Geografia e Estatística (IBGE), das cinco macrorregiões: Norte, Nordeste, Centro-Oeste, Sudeste e Sul.

Além desses aspectos conceituais, vale a pena lembrar que não só o Brasil tem se preocupado com a descentralização da C\&T. Carvalho da Silva (2000) afirma que países desenvolvidos tendem cada vez mais a descentralizar a sua capacidade de produzir conhecimento e formar recursos humanos, criando condições para que todas as suas regiões se beneficiem. Cita como exemplo a França, que, a partir dos anos 80, vem descentralizando suas ações e seu sistema de ciência, tecnologia e inovação o qual, atualmente, pode ser descrito como um processo de delegação às instituições de pesquisa, às agências encarregadas dos grandes programas, às diversas regiões e aos programas da Organização para Cooperação e Desenvolvimento Econômico (OCDE). (CARVALHO DA SILVA, 2000, p. 62)

Segundo esse autor, a descentralização das atividades em P\&D, em nível nacional, é um modelo possível de ser alcançado, já tendo ocorrido na Alemanha. Acrescenta que o modelo alemão poderia ser adaptado ao Brasil e poderia ampliar a capacidade própria de pesquisa, inovação e competitividade, em cada região, visto estar mais de dois terços do 
sistema de ciência e tecnologia concentrada na região Sudeste. (BUNDSBERICHT FORSCHUNG, 1996 apud CARVALHO DA SILVA, op.cit. 62). Evidentemente, não é possível a aplicação automática do modelo, considerando as marcantes diferenças entre os dois países. Porém, talvez algumas lições poderiam ser assimiladas.

Rodrigo Simões et. al apontam um número razoável de estudos que propõem distribuir espacialmente os gastos com P\&D, dentro de seus respectivos países, constituindo uma "geografia da inovação". Falam sobre as assimetrias regionais e registram que a OCDE destaca a necessidade de políticas públicas de inovação dirigidas a diminuir as disparidades regionais. (RODRIGO SIMÕES, et. al. p. 159)

Para esses autores, as disparidades internas de desenvolvimento das regiões administrativas dos países têm crescido e exigido a definição de políticas públicas que estimulem a inovação e a competitividade econômica. Mesmo no bloco da OCDE importantes assimetrias regionais dentro dos países foram constatadas, sendo que $4 \%$ das macrorregiões mais ricas responderam por um terço do crescimento da região no período de 1995 a 2005. Por sua vez, 13\% das regiões contribuem com 50\% dos dispêndios em pesquisa e desenvolvimento (P\&D) do bloco. (OCDE, 2011; AUDRETSCH \& FELDMAN, 1996; RODRIGO SIMÕES)

Apesar de não fazer parte da OCDE, o Brasil aparece em seu relatório de 2011 como um dos países que estão ganhando mais espaço no quadro da inovação mundial por descentralizar poderes para os estados, nas políticas e recursos da área de ciência, tecnologia e inovação (C\&T\&l), criando agendas que consideram as políticas para "estimular a competitividade e o crescimento em áreas periféricas", como forma de tentar diminuir os desequilíbrios regionais. (OCDE, 2011, p. 21)

Esse relatório destaca que esse processo está remodelando as relações políticas, principalmente, no âmbito regional e afetando os países,

.ampliando a necessidade de ações locais e regionais para identificar fontes endógenas de crescimento;

.desafiando os agentes locais a manter, na região, recursos humanos capacitados e capacidades de produção;

.abrindo oportunidades para organização de pesquisa e produção além das fronteiras; e

.estimulando a mobilidade de talentos, permitindo maior colaboração internacional. (OCDE, 2011, p. 21) 
A OCDE finaliza o estudo com algumas recomendações que poderiam contribuir na construção de ações de descentralização em política de ciência e tecnologia, tais como:

- Criar políticas que possibilitem o desenvolvimento regional;

- Buscar eficiência nas políticas de inovação e coordenação em todos os níveis de governo; e

- As políticas de estratégias regionais de inovação devem: definir, monitorar e avaliar o sucesso; áreas econômicas de interesse, não apenas as regiões administrativas; reconhecer o papel da região nas complexas redes globais de apoio à inovação, e aproveitar melhor as experiências do setor privado e fundos de apoio. (OCDE, 2011)

Apontados os conceitos e feitas essas considerações iniciais, passa-se a ver como, efetivamente, se manifesta a desigualdade regional no Brasil e, a seguir, como ela condiciona as disparidades em CT\&l, ao mesmo tempo em que os investimentos e avanços nesse campo são vistos como importantes componentes do processo de desenvolvimento regional.

\subsubsection{Desigualdade Regional no Brasil}

A despeito de todo um aparato legal de políticas públicas visando diminuir as desigualdades entre as regiões brasileiras, o crescimento da economia não conseguiu reduzir significativamente as desigualdades regionais do Brasil. As regiões Norte, Nordeste e Centro-Oeste, ainda mantêm índices sociais e econômicos bem inferiores aos do restante do país.

O Instituto de Pesquisa Econômica Aplicada (IPEA) ${ }^{10}$ realizou um estudo que mostra poucos avanços na redução das disparidades entre 1995 e 2008. Informa que ocorreu uma leve desconcentração da atividade econômica no Brasil, mas muito longe de ameaçar a composição estadual do Produto Interno Bruto (PIB) que o país tinha em 1995.

As desigualdades e diferenças regionais são de toda ordem, ainda mais se somadas à dimensão continental do Brasil, suas diferentes culturas locais, passando pela monumental diferença socioeconômica, financeira, educacional e política. Diante desse fato, o EstadoNação encontra inúmeros obstáculos à proposição de políticas públicas que se façam valer e levem efetivo benefício à população moradora dos lugares distantes das grandes metrópoles. (BARROS, 1999; RÜCKERT, 2004)

10 http://www.brasil.gov.br/economia-e-emprego/2010/12/desigualdade-regional-quase-nao-mudou-em-13-anosdiz-ipea 
O Brasil, apesar de ter passado por grandes mudanças nas últimas décadas, continua marcado por elevados níveis de desigualdades regionais. Enquanto a região Nordeste cuja população corresponde a $28 \%$ da população do país - detém apenas $13 \%$ do Produto Interno Bruto (PIB) brasileiro, a região Sudeste alcança 57\% do PIB, com $43 \%$ da população do país. Verificam-se elevados níveis de desigualdades inter-regionais de renda per capita, desigualdades que persistem e, muitas vezes, ampliam-se, quando se analisam indicadores como o Índice de Desenvolvimento Humano (IDH). (CAVALCANTE, 2011)

O Atlas do Desenvolvimento Humano 2013 indica que o Índice de Desenvolvimento Humano nas regiões brasileiras alcançou os seguintes níveis percentuais: no Sul, 65\%; no Centro-Oeste, 57\%; no Sudeste, 52\%; no Norte, 50\% e no Nordeste, $61 \%$. Essa diferenciação nos percentuais ratifica a grande disparidade no desenvolvimento regional e a necessidade de se criar políticas governamentais voltadas para o desenvolvimento dessas regiões menos favorecidas.

Figura 1 - Índice de Desenvolvimento Humano nas Regiões Brasileiras - 2013

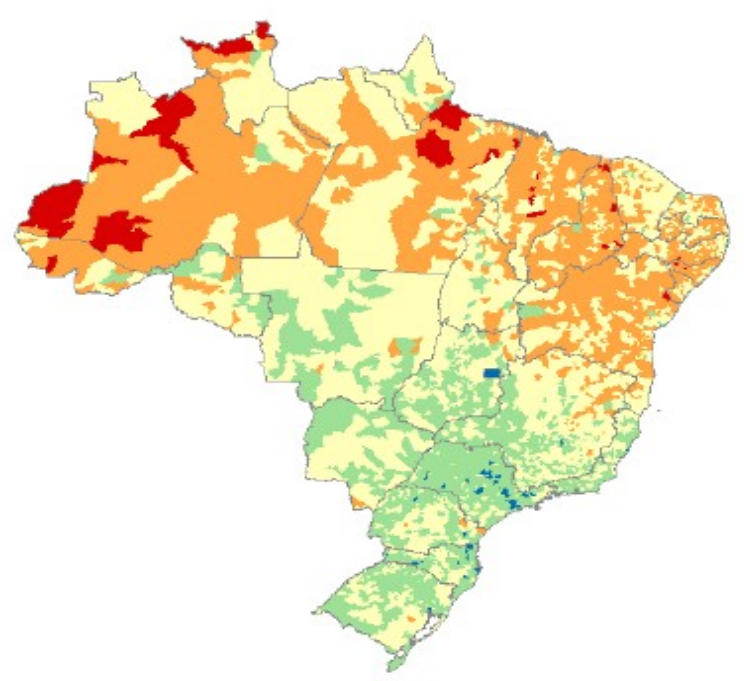

LEGENDA

De, $0,300-1$

$0,700-0,799$
$0,900-0,699$

$0,600-0,699$

$0,000-0,499$

Fonte: http://www.atlasbrasil.org.br/2013/ e Programa das Nações Unidas para o Desenvolvimento (PNUD) http://www.pnud.org.br/IDH/Atlas2013.aspx?indiceAccordion=1\&li=li_Atlas2013. 
Visando minorar esse quadro, muitas ações governamentais foram propostas ao longo do tempo. Segundo Diniz e Crocco (2006, apud SENRA 2011), as políticas públicas regionais se alteraram ao longo dos períodos históricos. Para esses autores, quatro fases moldaram distintamente as políticas regionais brasileiras: Nacional-Desenvolvimentista, Desenvolvimentista-Militar, Neoliberal e Neodesenvolvimentista. (DINIZ \& CROCCO, 2006, p. 10 apud SENRA, 2011, p. 3)

Figura 2 - Ciclos das Políticas Públicas Regionais

\section{FASES IDENTIFICADAS}
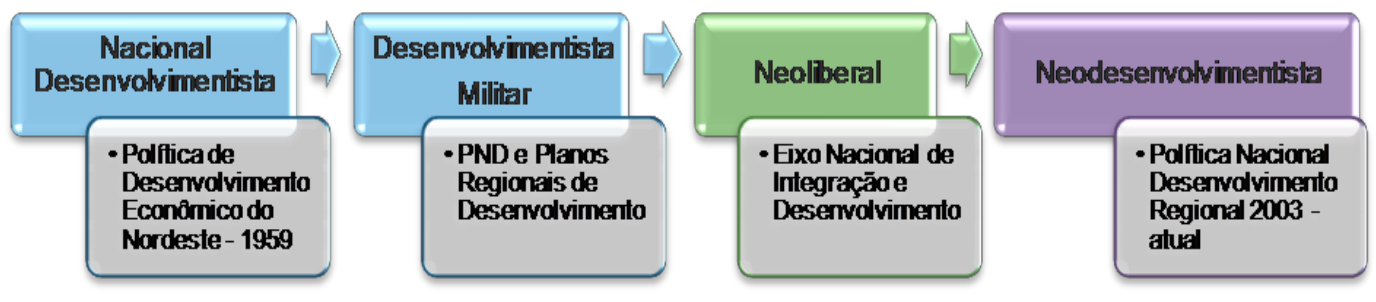

Fonte: SENRA, 2011. Adaptado.

Nessas fases identifica-se o incentivo governamental "à produção, ampliação do papel indutor do desenvolvimento pelo Estado e a melhor distribuição de suas intervenções no território, combinadas com a tendência à convergência de renda entre as regiões", como apontado no Plano Plurianual (PPA) 2012-2015, com perspectivas positivas para o crescimento do nível de atividade e o alcance de uma configuração regional da economia menos desigual até 2015. (PPA, 2012-2015, p. 52)

Pode-se citar como o primeiro esforço governamental sistematizado, em 1956, o Plano de Metas, com objetivo eminentemente setorial, com a previsão de construção de Brasília e da rodovia Belém-Brasília, visando à interiorização do desenvolvimento brasileiro; em 1959, a criação da Superintendência de Desenvolvimento do nordeste (SUDENE) e, depois, o fortalecimento da Superintendência do Plano de Valorização Econômica da Amazônia (SPVEA), transformada, em 1966, na atual SUDAM.

Entre as políticas e instrumentos criados a partir da Constituição Federal de 1988, destacam-se os Fundos de Financiamento que se respaldaram na Lei 7.827/1989, que destinava $3 \%$ de toda a arrecadação com Imposto sobre Produto Industrializado (IPI) e Imposto de Renda (IR), para as áreas Norte, Nordeste e Centro Oeste, com o objetivo de contribuir para o desenvolvimento econômico e social dessas Regiões. Para tanto 
regulamenta o art. 159, inciso I, alínea c, da Constituição Federal de 1988, a criação de fundos denominados como Fundo Constitucional de Financiamento do Norte (FNO); o Fundo Constitucional de Financiamento do Nordeste (FNE) e o Fundo Constitucional de Financiamento do Centro-Oeste (FCO), cuja abrangência e destinação percentual regional é mostrada nas Figuras 2 e 3. (BRASIL, 1989)

Figura 3 - Divisão percentual dos Fundos de Financiamento

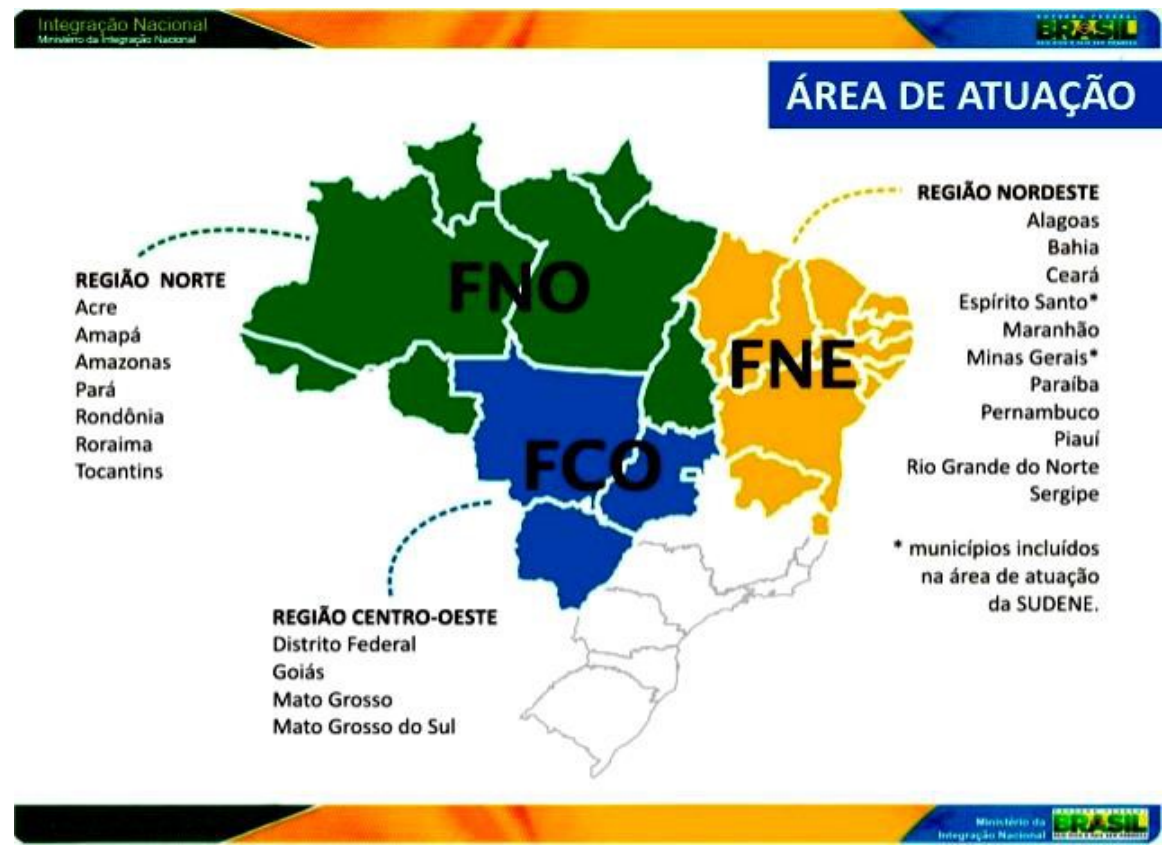

Fonte: Ministério da Integração Nacional, 2012.

Figura 4 - Percentual dos Fundos de Financiamento entre as regiões brasileiras

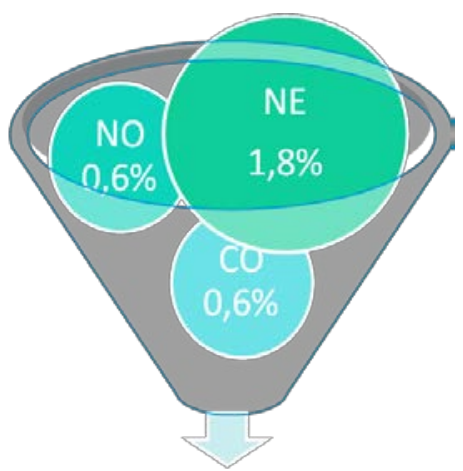

Fundos de Financiamento

Fonte: Construção própria a partir da Lei 7.827/1989. 
No Quadro 2 são mostradas algumas das principais ações, no âmbito das políticas regionais desenvolvidas no país, nos anos 90 e 2000 - portanto, nas duas últimas fases apontadas acima -, seus objetivos e os respectivos marcos legais que permitiram a construção e a institucionalização de política voltada para a diminuição dos desequilíbrios regionais brasileiros.

Quadro 2- Alguns marcos de Políticas Públicas de Combate às Desigualdades Regionais no Brasil - 1988 a 2014

\begin{tabular}{|c|c|c|}
\hline Ano & Ações/Marcos Legais & Objetivo ou Missão \\
\hline 1988 & Constituição Federativa do Brasil. & $\begin{array}{l}\text { Art. } 3^{\circ} \text { III - erradicar a pobreza e a } \\
\text { marginalização e reduzir as desigualdades } \\
\text { sociais e regionais. }\end{array}$ \\
\hline 1998 & $\begin{array}{l}\text { Lançamento do Estudo dos Eixos Nacionais de } \\
\text { Integração e Desenvolvimento - Estudo } \\
\text { contratado em } 1997 \text { pelo Ministério do } \\
\text { planejamento Orçamento e Gestão e pelo } \\
\text { Banco Nacional de Desenvolvimento } \\
\text { Econômico e Social (BNDES), para inserção no } \\
\text { Plano Plurianual (PPA) 2000-2003. }\end{array}$ & $\begin{array}{l}\text { Viabilizar o desenvolvimento econômico e } \\
\text { social, a integração nacional e } \\
\text { internacional, o aumento da } \\
\text { competitividade sistêmica da economia e } \\
\text { a redução das disparidades regionais } \\
\text { (CAGNIN \& LIMA, 2009) }\end{array}$ \\
\hline 1998 & $\begin{array}{l}\text { Lançamento do documento intitulado "Critérios } \\
\text { Básicos para Caracterização de Mesorregiões } \\
\text { Diferenciadas", pela Secretaria Especial de } \\
\text { Políticas Regionais - SPRE, criada pela Lei no } \\
\text { 9.649, de 27.05.98, vinculada ao Ministério do } \\
\text { Planejamento, constando o Programa do } \\
\text { Desenvolvimento Sustentável de Mesorregiões } \\
\text { Diferenciadas (FERREIRA \& MOREIRA, } \\
\text { 2007,p. 355). }\end{array}$ & $\begin{array}{l}\text { Elevar a qualidade de vida da população } \\
\text { residente em } 11 \text { microrregiões } \\
\text { selecionadas no território nacional por } \\
\text { meio de instrumentos e recursos que } \\
\text { assegurem ações de desenvolvimento } \\
\text { sustentável, especialmente, projetos de } \\
\text { produção com geração de emprego e } \\
\text { renda, provisão de infraestrutura produtiva } \\
\text { e elevação das condições sociais básicas } \\
\text { (FERREIRA \& MOREIRA, op. cit). }\end{array}$ \\
\hline 1999 & $\begin{array}{l}\text { Criação do Ministério da Integração Nacional, } \\
\text { mediante transferência das competências da } \\
\text { Secretaria Especial de Políticas Regionais, por } \\
\text { meio da Medida Provisória no } 1.911 \text {, de } \\
\text { 28.07.1999, convertida em Lei no } 10.683 \text {, de } \\
\text { 28/05/2003. }\end{array}$ & $\begin{array}{l}\text { Promover o desenvolvimento sustentável } \\
\text { e a integração das regiões menos } \\
\text { dinâmicas, estimulando a diversa base } \\
\text { social, econômica, ambiental e cultural do } \\
\text { país e a equidade de oportunidades com } \\
\text { vistas à redução das desigualdades } \\
\text { regionais. }\end{array}$ \\
\hline 2003 & $\begin{array}{l}\text { Formulação e divulgação do documento } \\
\text { intitulado "Política Nacional de Desenvolvimento } \\
\text { Regional", que se constituiu em proposta para } \\
\text { discussão elaborada pelo Ministério da } \\
\text { Integração Nacional, em dezembro de } 2003 \text {. }\end{array}$ & $\begin{array}{l}\text { Discutir políticas amplas } \\
\text { desenvolvimento regional. }\end{array}$ \\
\hline
\end{tabular}




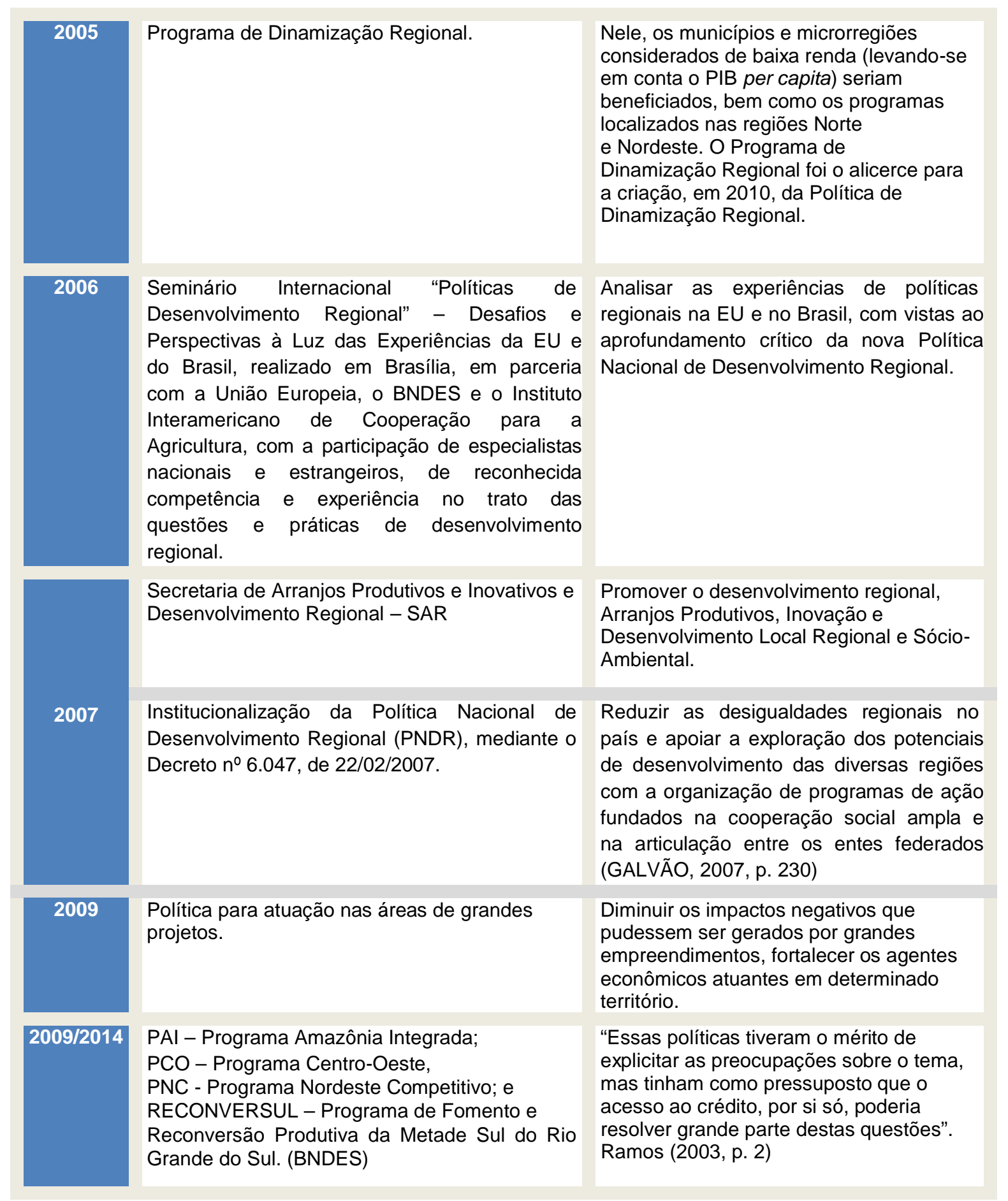

Fonte: Elaborado pela autora a partir da bibliografia consultada.

Galvão (2004) afirma que a nova fase de preocupações com a questão dos desequilíbrios regionais no Brasil foi, de certa forma, inspirada na União Europeia, de onde se extraiu o modelo para ser aplicado no caso brasileiro. 
Políticas nesse sentido têm sido propostas, como exemplo a Nova Política Nacional de Desenvolvimento Regional - PNDR II (2012), que em sua apresentação já aborda a gravidade das desigualdades regionais:

O Brasil se tornou, a partir de 2011, a sexta maior economia do globo, mas continua sendo um dos países mais desiguais do mundo, tanto em termos sociais como regionais. Mesmo no âmbito do Norte e do Nordeste, registram-se desigualdades intrarregionais gritantes. (PNDR II, 2012, p. 5)

A política regional fora retomada de forma mais densa a partir de 2003 , com o lançamento da proposta da Política Nacional de Desenvolvimento Regional, pelo Ministério da Integração Nacional (PNDR II), institucionalizada em 2007. Essa política explicita dois objetivos primordiais: reverter a trajetória das desigualdades regionais e explorar os potenciais endógenos da diversa base regional brasileira. (PNDR II, op.cit, p. 10)

A PNDR II contrapõe-se a programas isolados de desenvolvimento:

Objetivos

I - Sustentar uma trajetória de reversão das desigualdades inter e intrarregionais, valorizando os recursos endógenos e as especificidades culturais, sociais, econômicas e ambientais; e

II - Criar condições de acesso mais justo e equilibrado aos bens e serviços públicos no território brasileiro, reduzindo as desigualdades de oportunidades vinculadas ao local de nascimento e moradia.

Princípios

1) Transparência nos objetivos, nos processos e resultados;

2) Monitoramento e avaliação das políticas;

3) Competitividade-equidade;

4) Participação da sociedade civil;

5) Respeito e valorização da diversidade territorial e do meio ambiente;

6) Combinação entre políticas "de baixo para cima" e políticas "de cima para baixo", e atenção às políticas transversais;

7) Parceria público-privada; e

8) Respeito aos princípios e pactos federativos, a fim de possibilitar a participação efetiva das várias escalas de governo na execução da PNDR II. (PNDR II, op.cit, p. 14-15)

Essa política é a manifestação mais recente de um processo que teve um marco importante com a Constituição Federal de 1988, inclusive no que se refere aos instrumentos para respaldar ações com vista à mitigação das disparidades regionais. 
O Plano Plurianual (PPA, 2012-2015) destaca que o desenvolvimento regional, até 2015

[...] será orientado pelo crescimento da demanda doméstica, promovendo o crescimento econômico do conjunto das regiões brasileiras, sendo o fator mais importante para a expansão do investimento nos próximos anos. Isso oferecerá impactos relativos superiores nas regiões Norte, Nordeste e Centro-Oeste. (PPA, op.cit., p. 52)

As políticas públicas buscam privilegiar o desenvolvimento regional, objetivo que, por longo tempo, não mereceu grande relevância, dado que as políticas não contemplavam o atendimento aos problemas regionais, causados pela desigualdade entre as regiões. No campo da ciência e tecnologia também não foi diferente, embora tenha ocorrido um desenvolvimento proporcional à infraestrutura técnico-científica instalada de cada região. Assim, as regiões com melhor infraestrutura instalada tinham maior capacidade técnicocientífica e maior foi o seu desenvolvimento, o que contribuiu para gerar um distanciamento maior e na mesma proporção entre elas.

\subsubsection{CT\&I no quadro das desigualdades regionais}

O crescimento desigual deu lugar, também, à concentração do saber científico. Albuquerque e Rocha Neto (2005, p.21) atribuem à questão econômica papel determinante para as desigualdades regionais em C\&T\&l. Essa desigualdade está presente na maioria das regiões, em maior ou menor grau, e o Estado brasileiro viu-se instado a propor ações políticas em níveis que fossem ao encontro desses desequilíbrios visando minorar os seus impactos regionais locais.

Barros (1999) também destaca que a regionalização e centralização da ciência e tecnologia nas regiões Sudeste e Sul não foi uma ação deliberada, e sim característica das condições econômicas de produção dessas regiões, visto que, principalmente, as regiões Norte e Nordeste tinham a sua economia baseada em produção e exportação de matérias primas, oriundas da extração mineral e vegetal, não exigindo para isso qualquer qualificação ou saber científico para a sua execução. (Barros, 1999, op. cit.) Nas palavras desse autor,

[...] essa concentração da ciência e tecnologia pode ser observada como decorrente das disparidades geográficas do Brasil e do próprio desenvolvimento econômico, social, científico e tecnológico que ocorreu entre as regiões brasileiras e que pode ser constatado pelos fatos históricos que marcaram o desenvolvimento do país, em especial as regiões Norte e Nordeste. (BARROS, op.cit. p.23)

Portanto, a abordagem dos temas concentração e descentralização da política de ciência e da tecnologia pelas regiões brasileiras necessita levar em consideração que o 
Brasil é um país extremamente heterogêneo e marcado por desigualdades regionais que não teriam as suas necessidades atendidas de forma unânime ou igualitária, com uma política única que abrangesse todo o país. Assim, torna-se necessário que algumas questões sejam observadas quando da planificação e da formulação de políticas públicas, como a questão econômica das regiões, as diferenças culturais intrínsecas ao seu povo, as necessidades para o atendimento da geografia local, visando uma melhor compreensão sistêmica da realidade do país, no momento da definição das prioridades inseridas nas políticas públicas.

Para Cagnin e Da Silva (1987), a planificação de programas dirigidos às áreas da ciência e tecnologia e regiões geográficas consideradas carentes ou para as quais um desenvolvimento mais acelerado traria como resultados benefícios mais imediatos para a sociedade, poderia atenuar as diferenciações e desigualdades inter-regionais, por meio da pesquisa e do desenvolvimento científico local. (CAGNIN e DA SILVA, 1987, p. 13)

Buscando melhorar esse quadro e melhor gerir políticas regionais, em 1980, a Secretaria Geral da Secretaria de Planejamento da Presidência da República (SEPLAN/PR), por meio da Portaria SG/05/80, de 23/06/80, autorizou a Secretaria de Articulação com os Estados e Municípios (SAREM), conjuntamente com o CNPq - que à época era vinculado à Presidência da República e principal órgão formulador da Política Nacional de Ciência e Tecnologia - a elaborar um diagnóstico da função ciência e tecnologia (C\&T) no País, com o fim de compatibilizar as ações em desenvolvimento nos Estados, Distrito Federal e Territórios, com as diretrizes previstas do III PBDCT. Esse diagnóstico resultou em um Relatório Técnico elaborado por Analistas do CNPq e da SAREM, que apontou:

- a pulverização das atividades de C\&T;

- o desconhecimento, pelo Órgão central de C\&T, da extensão das ações desenvolvidas em cada estado ou mesmo quais eram os temas desenvolvidos;

- que vários estados já contavam com os seus sistemas de ciência e tecnologia implementados e estruturados, mesmo que de forma incipiente;

- as ações desenvolvidas não tinham vinculação com uma Política Nacional voltada para o desenvolvimento cientifico e tecnológico;

- a necessidade premente de treinamento e capacitação de recursos humanos; e

- a ausência de infraestrutura capaz de suportar uma rede de C\&T.

Esse diagnóstico balizou ações com o objetivo de promover a desconcentração da ciência e tecnologia, como se verá à frente. Antes disso, serão mostrados alguns dados adicionais que contribuem para compreender a concentração em CT\&l no Brasil. 
Como demonstração da desigualdade regional no setor de pesquisa em ciência, tecnologia e inovação no Brasil, pode-se tomar, entre outros aspectos, a distribuição dos grupos de pesquisa nacionais pelas regiões brasileiras. Segundo informações colhidas no Diretório do Grupo de Pesquisas (DGP) do CNPq, conforme censo de 2010, calculados por 100 mil habitantes. O número de doutores aparece no Sudeste com mais de 65.500 pesquisadores, com $45 \%$ do total, enquanto que o Norte tem 8.400 pesquisadores cadastrados, com $6 \%$ do total. Somadas, as regiões Sul e Sudeste, chegam a 96.397 mil pesquisadores, enquanto que a soma das outras três regiões fica em 48.750 mil pesquisadores cadastrados no DGP, alcançando o percentual de $34 \%$. Os dados totais estão representados no Gráfico 1.

Gráfico 1 - Pesquisadores cadastrados no Diretório dos Grupos de Pesquisa do CNPq por Unidade Da Federação, 2010

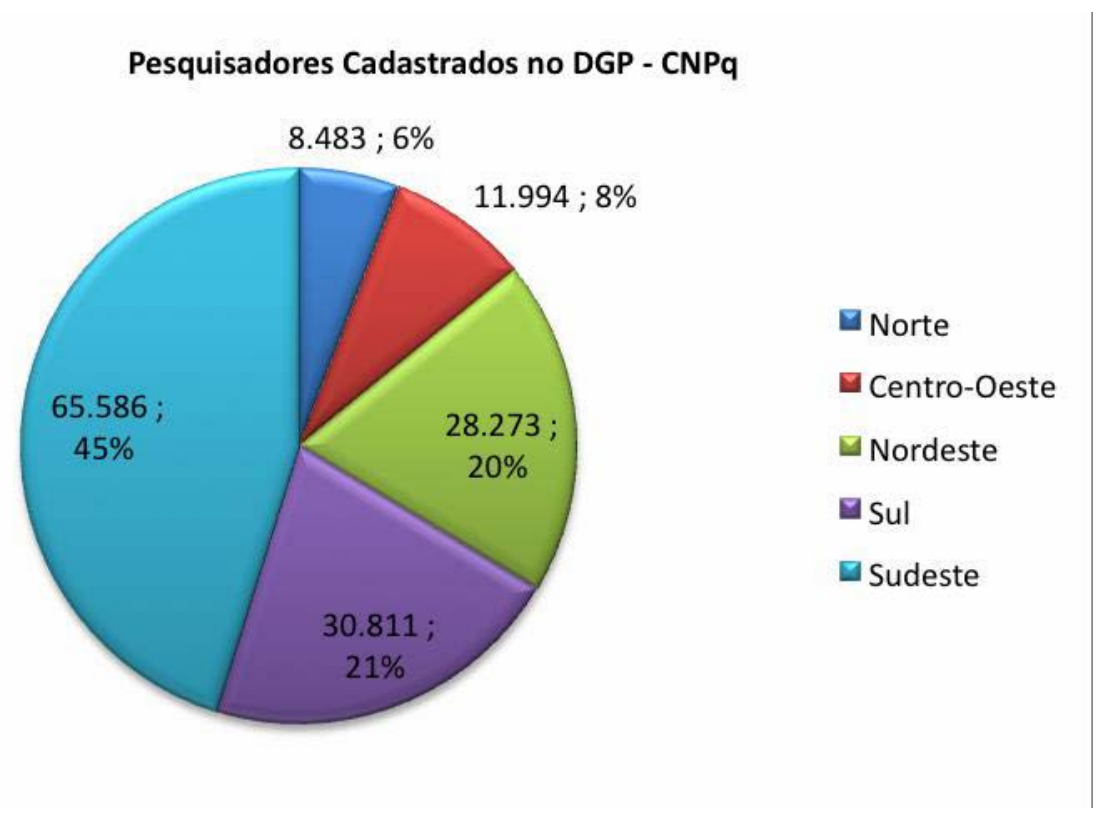

Fonte: DGP/CNPq, 2014.

Outro aspecto que pode demonstrar essas desigualdades são os percentuais concedidos pelos estados brasileiros para a pesquisa e desenvolvimento regionais. $O$ detalhamento é demonstrado na Tabela 1.

A Tabela 1 mostra os percentuais dos dispêndios em pesquisa e desenvolvimento (P\&D) dos governos estaduais, em relação às suas receitas totais, no período de 20002012. O que se observa, relativamente, ao demonstrado na Tabela 1, no período de análise é que houve leve variação dos dispêndios dos governos estaduais em ciência e tecnologia, apresentando um decréscimo de 0,95\%, do total dos investimentos aplicados em P\&D. 
Pode-se observar, também, certo aumento gradativo em determinadas regiões a partir de 2003, quando foi instalada a maioria das Fundações de Amparo à Pesquisa (FAP), nos Estados da Federação.

Por outro lado, a despeito das disparidades dos investimentos em ciência e tecnologia e indicadores de C\&T, de que a região Sudeste poderia estar recebendo um fluxo maior de recursos para aplicação em P\&D, o que é plenamente verdadeiro, nota-se, entretanto, que os percentuais totais de recursos financeiros dos governos estaduais aplicados decresceram comparativamente aos anos anteriores. Como exemplo, vejam-se os dispêndios de 2000 a 2012, que vieram caindo de $1,63 \%$ para $1,55 \%$, no período observado, como demonstra a Tabela 1: Sudeste $(0,87 \%)$, Nordeste $(1,4 \%)$, Sul $(1,81 \%)$, Norte $(3,71 \%)$ e Centro-Oeste (27\%). Apesar de se apresentarem com o maior montante percentual de recursos aplicados as regiões Norte e Centro-Oeste, foram as regiões que, percentualmente, aplicaram menor aporte de recursos, no período compreendido entre 2000-2012, comparativamente às outras regiões.

Tabela 1 - Percentual dos dispêndios em Pesquisa e Desenvolvimento (P\&D) dos governos estaduais em relação às suas receitas totais, 2000-2012

(em percentual)

\begin{tabular}{|c|c|c|c|c|c|c|c|c|c|c|c|c|c|}
\hline $\begin{array}{l}\text { Regiões e } \\
\text { Unidades da } \\
\text { Federação }\end{array}$ & 2000 & 2001 & 2002 & 2003 & 2004 & 2005 & 2006 & 2007 & 2008 & 2009 & 2010 & 2011 & 2012 \\
\hline Total & 1,63 & 1,72 & 1,55 & 1,44 & 1,22 & 1,19 & 1,12 & 1,38 & 1,33 & 1,36 & 1,37 & 1,52 & 1,55 \\
\hline Norte & 0,07 & 0,06 & 0,07 & 0,08 & 0,05 & 0,17 & 0,25 & 0,21 & 0,24 & 0,20 & 0,20 & 0,17 & 0,26 \\
\hline Nordeste & 0,30 & 0,44 & 0,37 & 0,44 & 0,37 & 0,41 & 0,36 & 0,48 & 0,40 & 0,36 & 0,34 & 0,42 & 0,42 \\
\hline Sudeste & 2,95 & 3,03 & 2,84 & 2,50 & 2,03 & 1,94 & 1,82 & 2,25 & 2,19 & 2,18 & 2,22 & 2,53 & 2,58 \\
\hline Centro-Oeste & 0,01 & 0,01 & 0,02 & 0,03 & 0,11 & 0,09 & 0,08 & 0,14 & 0,22 & 0,31 & 0,31 & 0,21 & 0,27 \\
\hline Sul & 0,54 & 0,72 & 0,58 & 0,59 & 0,75 & 0,79 & 0,74 & 0,87 & 0,77 & 1,07 & 1,02 & 0,97 & 0,98 \\
\hline
\end{tabular}

Fonte: MCTI, 2014

Atualizada em: 26/05/2014.

O Gráfico 2, abaixo, apresenta o percentual dos dispêndios em pesquisa e desenvolvimento (P\&D) dos governos estaduais no período de 2000 a 2012. Observa-se o destaque da Região Sudeste que se mantém com níveis percentuais mais elevados desde o ano de 2000, em comparação às outras regiões. O ano de 2001 foi o de maior investimento estadual em P\&D, com 3,03\% percentuais em relação às suas receitas totais, aplicados pela 
Região Sudeste, que computou ao longo desse período de análise, os níveis mais altos de investimentos em $P \& D$, relativamente aos outros estados da federação. Em contrapartida no ano de 2006 o percentual de investimento da Região Sudeste foi de 1,82\% em relação às suas receitas totais, o mais baixo desse período de análise. A partir de 2007 os percentuais voltam a elevar-se, mas com pequenas oscilações percentuais.

A Região Sul se apresenta em segundo lugar no investimento estadual em P\&D, apresentando em 2009 o seu maior percentual 1,07, também em relação às suas receitas totais de dispêndios em pesquisa e desenvolvimento. A Região Centro-Oeste aparece em último lugar, apresentando um percentual médio de 0,15\% de dispêndio anual em pesquisa e desenvolvimento, abaixo mesmo das Regiões Norte e Nordeste. Importante notar que o somatório dos 12 anos observados, relativos a Região Centro-Oeste, correspondem a $1,81 \%$, das suas receitas totais investidas em P\&D, equivalentes ao menor percentual investido pela Região Sudeste, no mesmo período de estudo.

Gráfico 2 - Percentual dos dispêndios em Pesquisa e Desenvolvimento (P\&D) dos governos estaduais 2000-2012

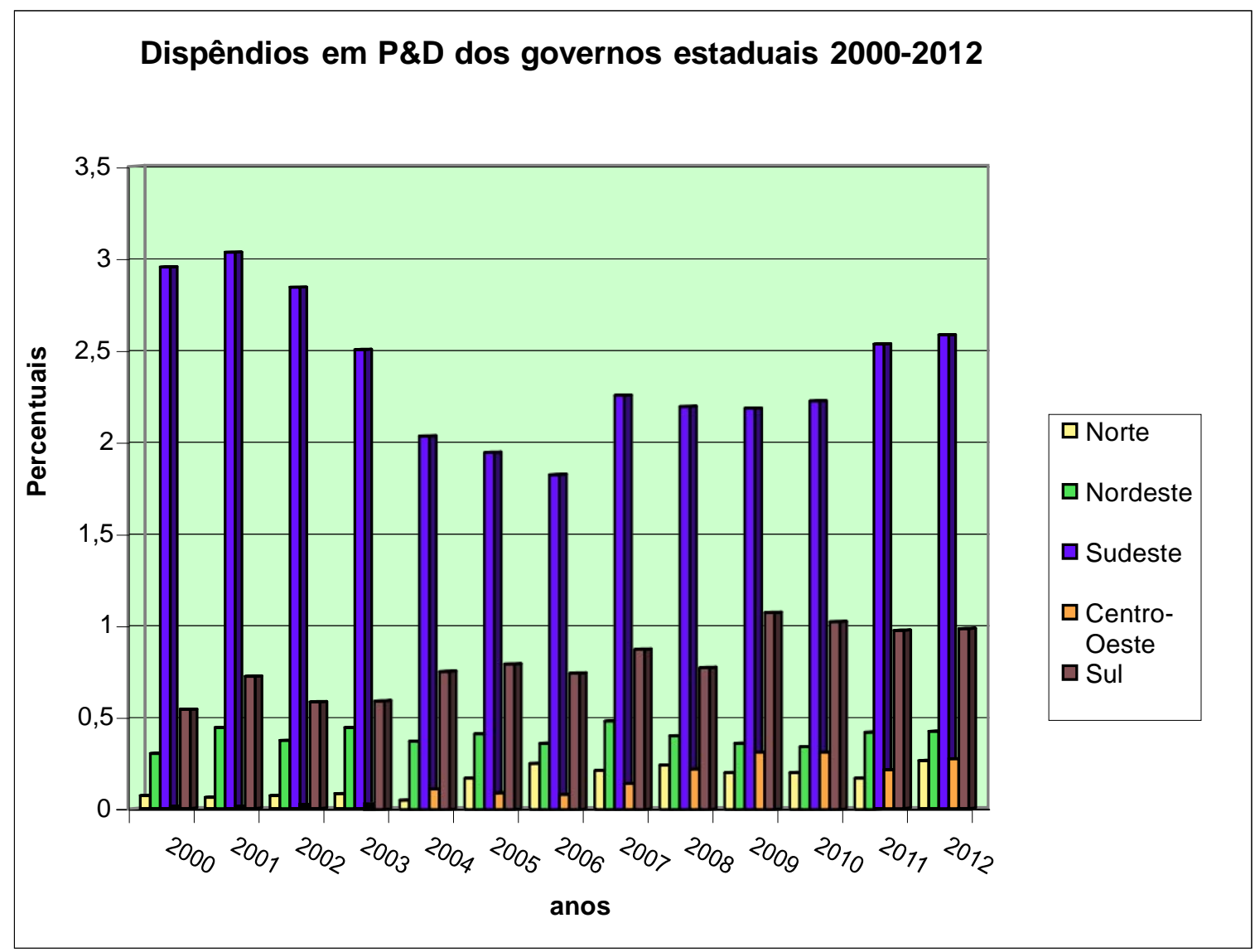

Fonte: MCTI, 2014

Atualizada em: 26/05/2014.

Gráfico elaborado pela autora. 
No Gráfico 3 aparecem os dispêndios dos governos estaduais em ciência e tecnologia, por categoria de investimentos. Pode-se observar que têm aumentado a partir de 2006 e estão concentrados, em primeiro lugar, em ciência e tecnologia, com o maior montante; em segundo lugar, em pesquisa e desenvolvimento ${ }^{11}$ e em terceiro, nas atividades científicas e técnicas correlatas $^{12}$, com discreta queda em 2010 e 2011, distribuídas nas regiões brasileiras.

Gráfico 3 - Dispêndios dos governos estaduais em ciência e tecnologia (C\&T), em valores de 2011, por atividade, 2000-2011

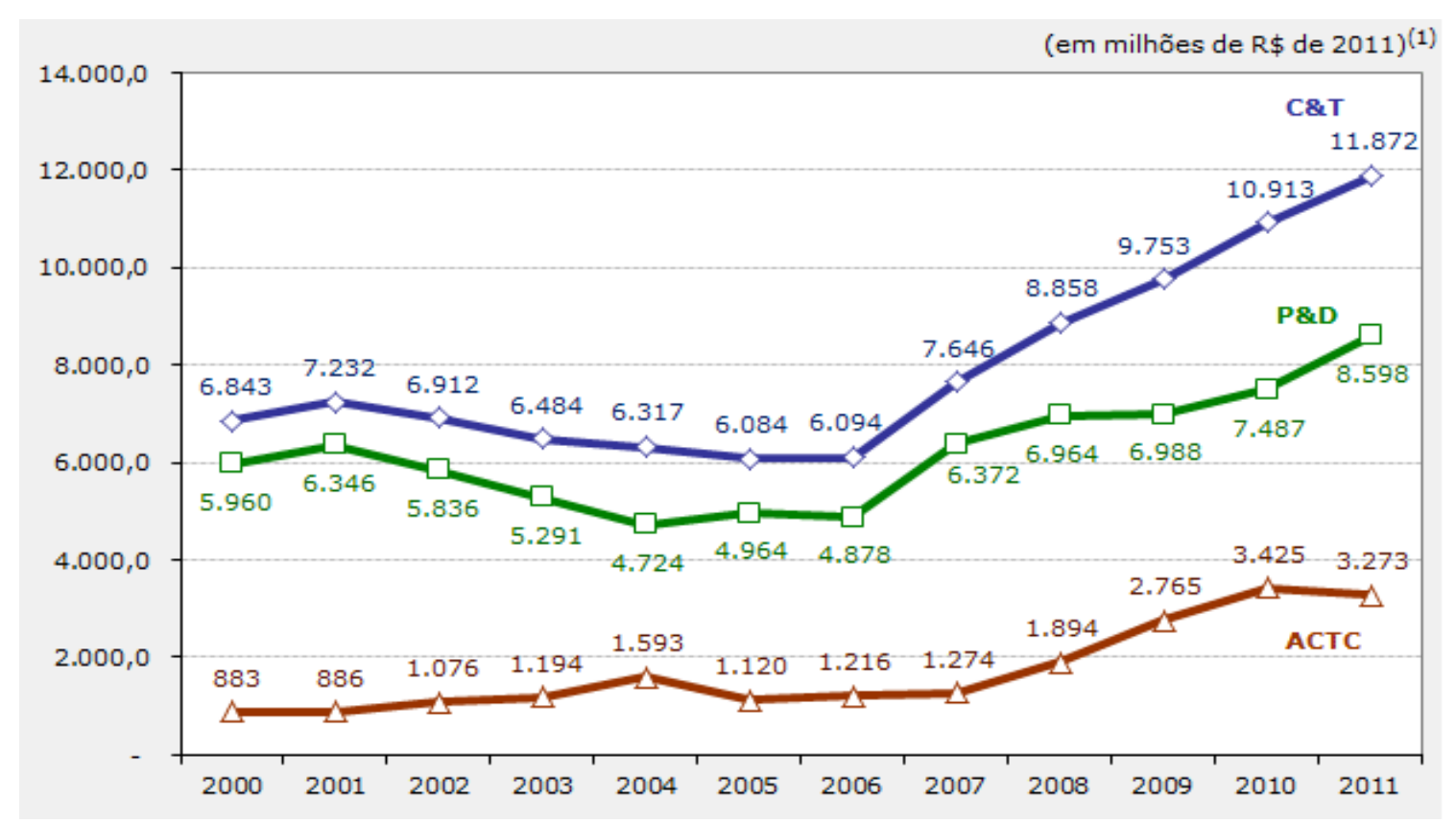

Fonte: MCTI, 2014.

No entanto, ao verificar os dados por regiões, Gráfico 4, observa-se claramente a grande disparidade entre os recursos aplicados por estado. A região Sudeste se destaca das demais Unidades da Federação no que se refere ao volume de investimentos em C\&T\&l, apresentando, inclusive, forte aumento de dispêndios a partir de 2006, reforçando sua posição de maior destaque em relação às outras regiões, cuja posição mudou de forma mais discreta nos últimos dez anos, apesar de as políticas editadas pelo governo federal, terem o objetivo de incrementar a proporção de investimentos em C\&T e diminuir as disparidades regionais.

\footnotetext{
${ }^{11}$ P\&D: Pesquisa e Desenvolvimento.

${ }^{12}$ ACTC: atividades científicas e técnicas correlatas.
} 
Gráfico 4 - Dispêndios dos governos estaduais em ciência e tecnologia por região, 20102011

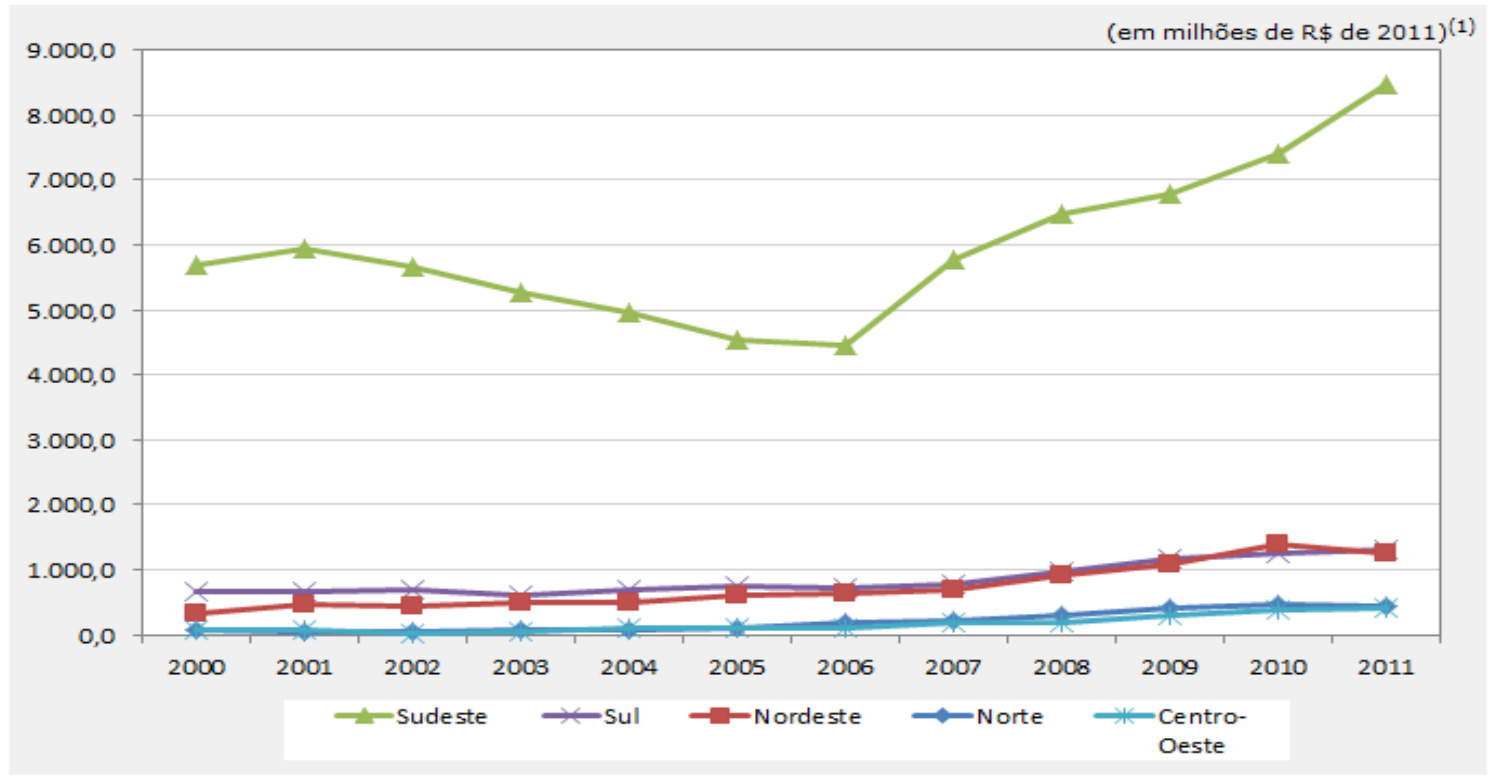

Fonte: MCTI, 2014.

No Gráfico 5, os dados mostram que São Paulo $(72,9 \%)$ se destaca das demais Unidades da Federação no que se refere aos investimentos em C\&T\&l, seguido pelo Rio de Janeiro (7,0\%), Paraná $(5,1 \%)$ e Minas Gerais com (3,9\%). As Unidades da Federação localizadas nas Regiões Sudeste - com a liderança de São Paulo - e Sul, apresentam os maiores dispêndios em ciência e tecnologia, sendo clara a disparidade regional existente no Brasil quanto a essas aplicações. Da Região Nordeste, destaca-se o estado da Bahia, com 2,3\% de investimento em P\&D. 
Gráfico 5 - Distribuição percentual dos dispêndios dos governos estaduais aplicados em Ciência e Tecnologia (C,T\&l), por unidade da federação (UF)

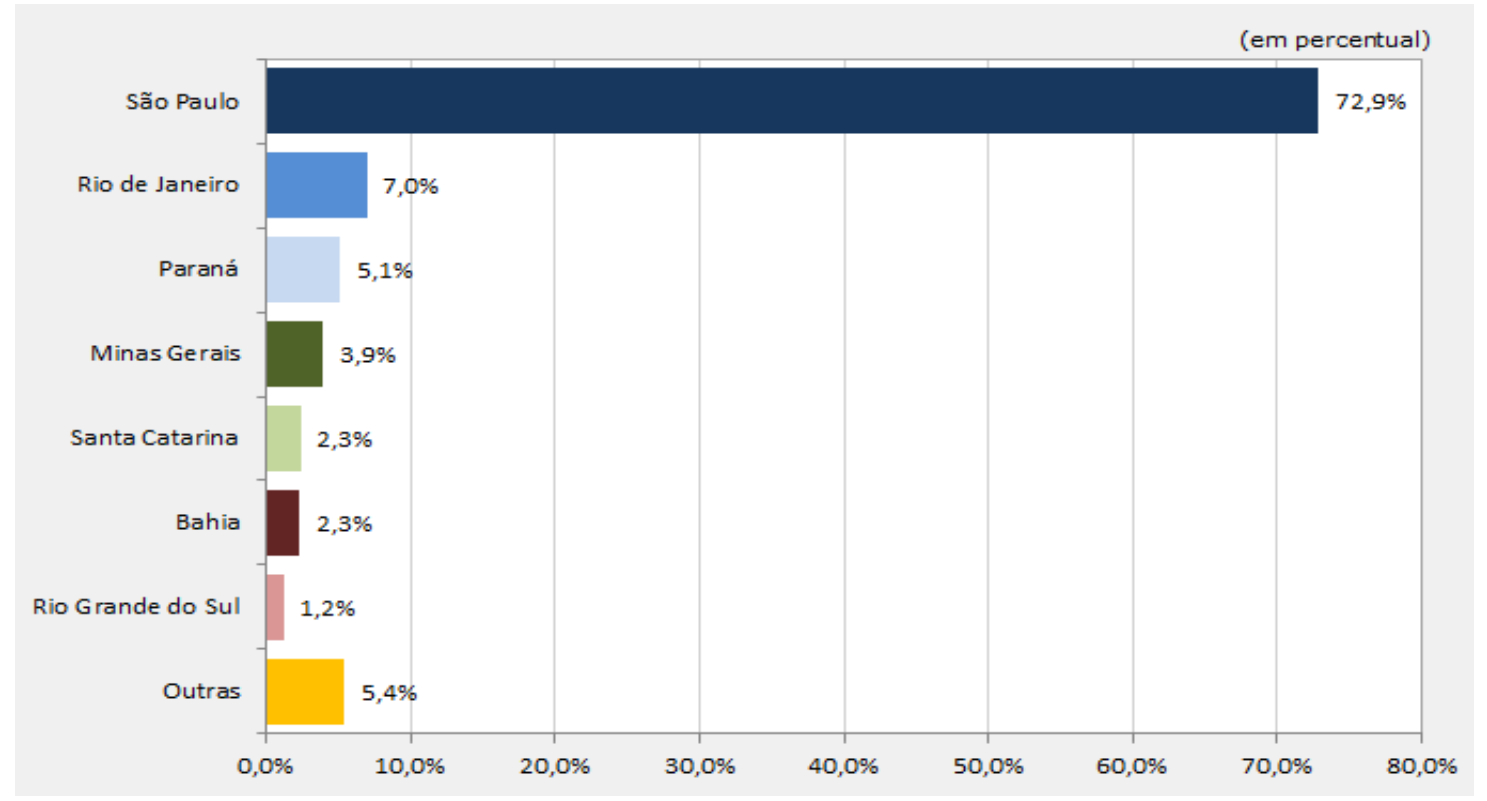

Fonte: MCT, 2014

Atualizada em: 04/10/2013.

A região sudeste lidera também quanto ao percentual de fomento federal concedido para o desenvolvimento de pesquisa e desenvolvimento na área de ciência e tecnologia, assim como o estado de São Paulo é o estado da federação que mais participa com recursos financeiros, como demonstrado nos Gráficos 2, 3, 4 e 5 (pp. 43 a 47). Essa situação se configura dessa forma visto o modelo adotado desde o início da formação da comunidade científica regional. Pois as discussões sobre o desenvolvimento em C\&T partiram das comunidades aristocratas, basicamente de São Paulo, que entendiam a necessidade de um modelo de desenvolvimento e que investimentos seriam necessários para esse fim. Como parte desse investimento enviavam os seus filhos à Europa para estudarem e retornarem com novas ideias para serem implementadas no Brasil. Esse fator também foi contribuindo para que São Paulo já fosse se configurando como o maior centro metropolitano do País.

Fica, também, caracterizada a alta participação percentual no fomento em ciência e tecnologia pela Fundação Estadual de Amparo à Pesquisa do Estado de São Paulo (FAPESP), que teve a sua instalação diferenciada pelo apoio financeiro recebido, se mantendo sempre à frente das outras FAP, que tiveram a sua instalação algum tempo depois, como demonstrado no Quadro 3 (pp. 58 a 59). 
O estudo do CGEE ressalta que, paralelamente ao processo de descentralização, vem também avançando as iniciativas de desconcentração, vinculadas à área de C\&T, de instituições do governo federal. Essas iniciativas constituem não só um fator de desenvolvimento regional, mas também um indutor de processos de descentralização de ações na área CT\&I, na medida em que aumenta o potencial local de clientela dos programas federais e estaduais de fomento. (CGEE, op. cit., p.38)

Como demonstrado na Tabela 1 as unidades federativas - estaduais e municipais vêm aumentando a sua participação nos gastos em C\&T em relação ao total das receitas dos estados, possibilitando o desenvolvimento industrial e de serviços, sendo essas ações de participações dos entes federativos, articulados ou não com o governo federal. Essa participação cada vez mais recorrente leva aos "incentivos de nova geração" (fiscais, financeiro, etc.), cuja ênfase é a promoção da competitividade e do ambiente regional de negócios, fortalecendo as ações na área de C\&T\&l. Essas ações advêm de instituições federais (FINEP, CNPq, BNDES, etc.), estaduais (SECT, FAP, etc.), do setor privado (SEBRAE, Federação de Indústrias, etc.), ICT e empresas inovadoras. (THEIS \& DAGNINO, 2008; ALBUQUERQUE e ROCHA NETO (2005; Barros, 1999)

\subsubsection{Política de CT\&I e Descentralização Regional no Brasil}

Neste item será abordada a descentralização regional como um dos focos do fomento à ciência, tecnologia e inovação, suas políticas e instrumentos, e a necessidade de o Estado redimensionar a forma de planificação e execução da política de ciência e tecnologia no Brasil, com vistas a minimizar essas disparidades regionais e maximizar o processo de descentralização e desconcentração.

Albuquerque e Rocha Neto (2005), chamam a atenção para a relevância estratégica do planejamento de Governo no tocante ao desenvolvimento de regiões e localidades dentro do país, tendo por base a descentralização das atividades de ciência e tecnologia em duas vertentes centrais:

-Possibilidades de contribuição para a sustentabilidade, pelo aproveitamento adequado de recursos disponíveis (escassos ou abundantes), em uma perspectiva de médio ou longo prazo; e

-Identificação das possibilidades/limitações para o acompanhamento do progresso técnico em áreas/tecnologias portadoras de futuro: tecnologias de informação, biotecnologias, logística, meio ambiente, gestão de recursos hídricos e outras. (ALBUQUERQUE e ROCHA NETO, 2005 apud VELOSO e NOGUEIRA, 2006, p. 2) 
Carvalho da Silva (2000) diz que para reverter a situação de desigualdade entre as regiões brasileiras, cabe ao Estado a formulação de uma política nacional de ciência e tecnologia para o desenvolvimento, de forma a criar condições para que todas as regiões do país possam gerar novos conhecimentos e incorporá-los ao seu sistema produtivo e, dessa forma, contar com uma força de trabalho com as qualificações necessárias para desempenhar essa função. Trata-se de um esforço que deve ser prolongado e persistente, para tornar possível criar as condições que permitam o enfrentamento de diversos desafios, à medida que eles surjam, e não apenas improvisar medidas de emergência quando os desafios aparecem. (CARVALHO DA SILVA, 2000, p. 64)

Segundo esse mesmo autor, o Brasil já conta com instrumentos que the permitem descentralizar a política de ciência e tecnologia em apoio à inovação e ao desenvolvimento, atendendo às condições e oportunidades em cada região. As fundações e fundos de amparo à pesquisa são componentes dessa política desde que se thes assegurem a autonomia e a regularidade na transferência de recursos. A função básica desses agentes é apoiar a pesquisa e a pós-graduação por meio de bolsas e auxílios para pesquisa e intercâmbio científico em todas as áreas do conhecimento, independentemente da sua aplicação imediata, tendo como base as qualificações do proponente e o mérito e a viabilidade da proposta como condição, para formar uma infraestrutura de pesquisa e recursos humanos suficientemente atualizados e diversificados para dar suporte aos esforços em apoio ao desenvolvimento. (CARVALHO DA SILVA, op. cit., p. 71)

Afirma, também, o referido autor, que ao governo federal cumpre formular e desenvolver uma política de ciência e tecnologia, bem como dos segmentos representativos da sociedade. Em grande parte o sucesso dessa política depende de como as fundações e fundos estaduais possam cumprir a parte que lhes compete na promoção do desenvolvimento local. Sem prejuízo da autonomia, a integração com ações e programas do governo federal, deverá ser intensificada tanto na execução quanto no financiamento, neste caso quando os recursos locais não forem suficientes para atender às ações prioritárias em apoio ao desenvolvimento científico e tecnológico regional. (CARVALHO DA SILVA, op. cit., p. 72)

Cavalcante et. al. (2007) indicam que a formulação de políticas de CT\&l em nível subnacional pode ser compreendida a partir da análise de dois conjuntos de fatores:

-de um lado, as alternativas disponíveis vis-à-vis as diferentes realidades sobre as quais se pretende intervir, que delimitam as alternativas possíveis; e 
-de outro, os múltiplos interesses associados à escolha das prioridades entre as alternativas tornam o processo mais complexo e menos linear. (CAVALCANTE et. al., 2007, p. 138)

No documento "Ciência, Tecnologia e Inovação para o Desenvolvimento Nacional", editado pelo MCTI, traz em seu bojo a configuração da política para C\&T\&l, prevista no Plano de Ação 2007-2010/MCTI, inicia sua apresentação declarando que, "a ciência, a tecnologia e a inovação são questões de Estado, que ultrapassam os governos e devem ser tratadas como compromissos que se transferem de um período governamental para outro". Como função do Estado a planificação da função de ciência, tecnologia e inovação pode ser idealizada por períodos mais longos, sem que se possa descontinuá-la de modo fácil pelo mandar de governos distintos. (BRASIL, 2006, p. 9)

O Estado brasileiro, já desde longa data, se preocupa com a questão referente à regionalização e interiorização da ciência e tecnologia no Brasil. As políticas recentes tendem à flexibilização das ações de governo, dando oportunidade de compartilhamento e multidimensionalidade do poder nas tomadas de decisões (RAFFESTIN, 1993; BECKER, 1983, 1988 apud RÜCKERT)

De acordo com o diagnóstico das iniciativas levadas a efeito no início dos anos 80 , estavam entre elas a instalação das representações regionais do CNPq - Agências Regionais -, para o assessoramento às atividades regionais nesse campo. Assim, foram instaladas agências em São Paulo, Fortaleza, Rio Grande do Sul e Rio de Janeiro, visando minorar a distribuição espacial da C\&T\&I nas regiões brasileiras. (CNPq, 1980)

As regiões Centro-Oeste, Norte e Nordeste necessitam de maior investimento relativo para a consolidação de seus sistemas científicos e tecnológicos por meio de recursos de ciência e tecnologia, identificando-se a necessidade de medidas para a integração do Sistema Nacional de Ciência e Tecnologia brasileiro, dado o elevado grau de diferenciação inter-regional. Nesse sentido, Marcelino e Vasconcelos (1984) já indicavam que para a efetivação do Sistema Nacional seria necessário promover a sua descentralização e implantar Sistemas Estaduais de desenvolvimento em ciência e tecnologia, a partir de uma ação indutora do governo federal. (MARCELINO E VASCONCELOS, 1984, pp.37-38)

Pode-se citar como exemplo dos esforços do Estado em contribuir para consolidar os sistemas científicos e tecnológicos nas regiões Centro-Oeste, Norte e Nordeste, o Programa de Desenvolvimento de Áreas Integradas do Nordeste Polonordeste; o Programa de Polos Agropecuários e Agrominerais da Amazônia (Poloamazônia); o Programa de Áreas Integradas do Centro-Oeste (Polocentro); em 1972, a criação do Programa do Trópico 
Úmido (PTU), para a região Norte, e em 1974, o Programa do Trópico Semiárido (PTSA), para a região Nordeste, que tinha como objetivo, segundo constou do Decreto $n^{\circ} 74.911 / 74$ da Presidência da República:

coordenar e estimular a contribuição da ciência e tecnologia ao desenvolvimento econômico e social da região semiárida do Nordeste, e ao adequado conhecimento e controle de suas características ecológicas (BRASIL, 1974, apud BARROS, op.cit., p.45).

O PTSA funcionou de 1976 até 1982 na sede da SUDENE, sob a coordenação desta e do CNPq, promovendo a articulação interinstitucional no Brasil e fora dele e, ainda, por meio de ações de fomento que abrangiam auxílios à pesquisa, apoio a teses, congressos e reuniões em instituições de pesquisa e universidades da região nordeste. (BARROS, op. cit., p. 45)

Barros (1999) destaca outros programas que buscaram apoiar e incentivar o desenvolvimento científico e tecnológico da região Nordeste, a exemplo do Programa de Desenvolvimento Científico e Tecnológico para o Nordeste (PDCT-NE) - executado com recursos do CNPq e do Banco Mundial (BID) e dos Sistemas Estaduais de C\&T\&I (SECT) -, e ainda o Programa Norte de Pós-Graduação - PNPG. (BARROS, op. cit., p. 48)

Esse autor reporta, ainda, que a partir de 1986, foi realizado um trabalho de articulação interinstitucional, entre as agências de fomento, com o objetivo de aumentar a competência da região Norte, em termos de mestres e doutores em áreas consideradas prioritárias pela Comissão Coordenadora Regional de Pesquisa na Amazônia (CORPAM): saúde e nosologia, agropecuária, sócio-economia, populações humanas e meio ambiente. (BARROS, op. cit., p. 50)

As Agências Regionais de C\&T, vinculadas ao CNPq, representavam as tentativas de estruturação do setor de C\&T\&l, com a função de permitir a identificação e indução, pelos estados, de programas e ações na área de C\&T\&l, direcionadas a possibilitar o engajamento regional, em busca do desenvolvimento científico e tecnológico. Essa tentativa de estruturação do setor de C\&T\&l tinha como pressuposto o desenvolvimento econômico regional, dando ênfase às peculiaridades locais que pudessem gerar diferenças positivas para a diminuição das desigualdades sociais e regionais, buscando auferir soluções para os problemas específicos e pontuais de cada uma das cinco macrorregiões brasileiras. (BARROS, op.cit., p. 51)

Entretanto, durante o segundo período do Governo Collor, em 1991, essas Agências Regionais de C\&T foram fechadas e promovida a desarticulação do setor de C,T\&l. Foi 
durante o Governo Collor que ocorreu: a) extinção das agências regionais do CNPq; o desmonte institucional e o esvaziamento do fomento das Unidades de C,T\&l das Superintendências de Desenvolvimento (SUDENE e SUDAM); c) drástica redução e contingenciamento dos orçamentos do CNPq e do FNDCT. (SICSÚ \& BOLAÑO, 2006)

Em nível federal, como forma de estimular a descentralização, a FINEP criou, em 1995, o Programa de Apoio aos Governos Estaduais (PROESTADO), com recursos do Fundo de Desenvolvimento Tecnológico (ADTEN). Esse programa tinha a finalidade de contribuir para o desenvolvimento de infraestrutura de pesquisa nos estados por meio de empréstimos às Fundações de Apoio à Pesquisa, Secretarias de C\&T ou outras instituições voltadas para o desenvolvimento tecnológico. (BARROS, op.cit., p. 96)

A proposta da CAPES, da FINEP e do CNPq foi a de realizar ações de descentralização em parceria com as fundações de amparo e de apoio à pesquisa e as Secretarias Estaduais de C\&T, instituições mais próximas das necessidades locais e mais capacitadas para identificá-las. Assim as definições de diretrizes e prioridades eram elaboradas em conjunto, repassando recursos para as fundações e as secretarias que, em contrapartida, deveriam captar mais recursos de outras fontes. A grande inovação, contudo, coube à deliberação sobre o quê, como e o quanto compartilhar com as instituições locais, assim como o acompanhamento das ações conjuntas. (BARROS, op.cit., p.103)

Percebe-se um esforço do aparelho do Estado em buscar manter o alinhamento das políticas públicas editadas pelo governo federal, para a regionalização e interiorização da ciência e tecnologia nas regiões brasileiras e a devida adequabilidade dessas políticas à cada região. Isto é, a mesma política não comporta aplicação em todas as regiões. Nesse sentido, as políticas necessitam guardar certa flexibilidade e adequação à sua aplicação de forma assertiva em cada região. (INCTI 2012-2015; CGEE, 2010)

Na perspectiva do CGEE (2010) os esforços visando ao aumento da capacidade regional para a estruturação institucional do processo de descentralização do fomento em CT\&I, no Brasil, são relativamente recentes e têm por base a articulação das seguintes iniciativas:

a criação dos fundos setoriais de C\&T, em nível federal, a partir de 1997;

a organização institucional dos estados na área de C\&T\&I (fundos estaduais de C\&T\&I, FAP, outros), em particular após a Constituição Federal de 1988;

a definição de programas de fomento do governo federal, compartilhados com os estados e instituições do setor privado; 
a desconcentração na área de C\&T\&l de forma articulada com instituições dos governos estaduais ou de prefeituras municipais ampliando os processos de descentralização;

a ampliação de dotações e da dispersão de ativos tecnológicos nas diversas regiões ou localidades brasileiras;

a expansão da capacitação dessas regiões na área de CT\&l; e

o aumento do potencial local da clientela dos programas federais de fomento, descentralizados ou não. (CGEE, op.cit. p. 37)

Os Fundos Setoriais de ciência e tecnologia geraram grande expectativa de impulso para o seguimento de ciência e tecnologia brasileira, visto que possibilitaram uma nova fonte de recursos para a aplicação em C\&T e contam com as contribuições incidentes sobre o faturamento de empresas e/ou sobre o resultado de empresas concessionárias que exploram recursos naturais pertencentes à União. (FINEP, 2014)

O sítio da FINEP - Inovação e Pesquisa ressalta a importância desses fundos para a área de C\&T\&l brasileira, pois representam o estabelecimento de um novo padrão de financiamento para o setor, sendo um mecanismo inovador de estímulo ao fortalecimento do sistema de C\&T nacional. Eles têm como objetivo garantir a estabilidade de recursos para a área e criar um novo modelo de gestão, com a participação de vários segmentos sociais, além de promover maior sinergia entre as universidades, centros de pesquisa e o setor produtivo. (FINEP, op. cit., 2014)

Acrescenta, ainda, que os Fundos Setoriais constituem um valioso instrumento da política de integração nacional, pois pelo menos $30 \%$ dos seus recursos são obrigatoriamente dirigidos às Regiões Norte, Nordeste e Centro-Oeste, promovendo a desconcentração das atividades de CT\&l e a consequente disseminação de seus benefícios. Sendo os recursos dos Fundos Setoriais, em geral, aplicados em projetos selecionados por meio de chamadas públicas, cujos editais são publicados nos portais da FINEP e do CNPq. (FINEP, op. cit., 2014)

No âmbito federal, a política de C\&T\&l mais recente se expressa por meio da Estratégia Nacional de Ciência, Tecnologia e Inovação (ENCTI), para o período de 2012 2015, que reflete a vontade política de dar continuidade aos pactos até agora feitos entre Estado e instituições de P\&D. Como descrito nesse documento,

[“...] a crescente interlocução entre Governo Federal, Estados e Municípios, agências de fomento, institutos de pesquisa, universidades e empresas, 
elevou a consolidação institucional do sistema de C\&T\&l a um novo patamar". [...] "apresenta um sistema de governança sistêmico que conta com ferramentas mais eficazes de acompanhamento e avaliação dos resultados e maior integração entre as políticas, instrumentos e agências". (ENCTI, 2012 - 2015, p.11)

A ENCTI 2012-2015 combina uma abordagem seletiva estritamente ligada com o apoio ao desenvolvimento da produção; compromisso de aumentar a qualidade e a massa crítica de recursos humanos capacitados; e crescente foco na dimensão regional. Também se destaca o apoio do Ministério da Ciência, Tecnologia e Inovação (MCTI) para a criação de leis de inovação nos estados brasileiros que possam constituir uma base legal própria, em que as ações locais de inovação possam ser estimuladas. (ENCTI, 2012 - 2015, p.11). Conforme o Balanço das Atividades Estruturantes do MCTI, 2011, as metas fixadas na ENCTI são ousadas e ambiciosas, mas essenciais para o desenvolvimento da política de C\&T, no longo prazo.

A ENCTI destaca a questão regional nos seguintes eixos de sustentação para a área de C\&T:

- Superação da pobreza e redução das desigualdades sociais e regionais,
pois apesar dos avanços obtidos nos últimos anos, a erradicação da pobreza
extrema e a redução das desigualdades sociais e regionais existentes
continuam a ser alguns dos principais desafios brasileiros. (grifos da
autora)

-A construção de agendas regionais de tecnologia e inovação alinhadas com as iniciativas federais, a interiorização dos centros de pesquisa e de formação de recursos humanos e o tratamento adequado das diferenças regionais na formulação e implementação de políticas nacionais são parte essencial das iniciativas que pretendam reduzir as disparidades de renda, de capacidade tecnológica e de condições de vida e de trabalho, tanto entre regiões como no interior de cada região. (grifos da autora)

- No tocante às desigualdades regionais, o grande esforço de desconcentração empreendido no último governo alterou a distribuição espacial dos programas de pós-graduação, assim fortalecendo as regiões Norte, Nordeste e Centro-Oeste na formação de mestres e doutores. (grifos da autora) (ENCTI, 2012 - 2015, p. 40)

A Figura 5 mostra a C\&T\&I colocada como eixo estruturante do desenvolvimento sustentável na ENCTI, bem como a questão regional entre os desafios a enfrentar nesse processo. 


\section{EIXOS DE SUSTENTAÇÃO DA ENCTI}

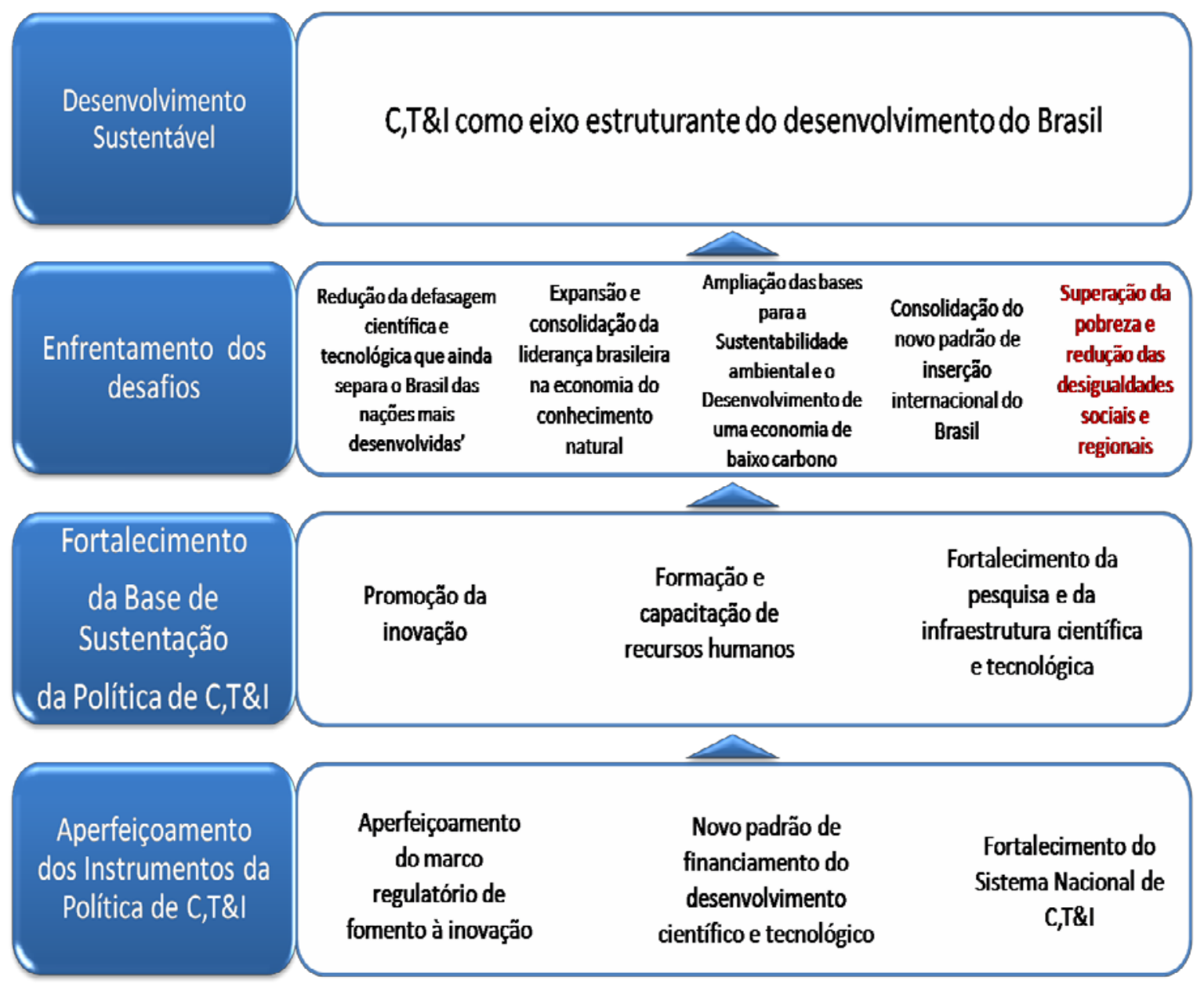

Fonte: MCTI, ENCTI - 2012 - 2015. Destaque da autora. 


\section{A DESCENTRALIZAÇÃO DE RECURSOS DA UNIÃO PARA CIÊNCIA, TECNOLOGIA E INOVAÇÃO}

Diante da necessidade de o Estado rever a forma de execução da Política de Ciência e Tecnologia no Brasil, com vistas a minimizar as disparidades regionais e maximizar o processo de descentralização ou desconcentração dos recursos financeiros destinados ao desenvolvimento científico e tecnológico, foram também criados instrumentos de fomento à C\&T\&I com vistas a atender esses propósitos.

Nesse processo, ocorreram fatos importantes no quadro nacional de CT\&l, e também foram necessárias mudanças internas às agências, como o CNPq, para acompanhar a demanda e a condução dos programas e projetos executados e ou apoiados. Entre essas mudanças, destaca-se a gestão compartilhada, decorrente das parcerias firmadas entre 0 CNPq e as FAP, por exemplo.

Como visto no item 1.1, a partir da promulgação da Constituição Federal de 1988, foi possível realizar, de forma sistemática, as transferências voluntárias da União aos entes federativos para a execução de programas e projetos nacionais descentralizados, em virtude do texto constitucional possuir capítulo específico tratando da matéria. Esses procedimentos de transferências já ocorriam, mas em menor número até o ano de 2003, quando o CNPq passou a firmar convênios com a maioria das FAP, já instaladas nessa época, descentralizando não só os recursos financeiros, mas também as ações a serem executadas em cumprimento à determinação federal.

Houve, também, a descentralização, por parte do CNPq, de algumas de suas tradicionais atividades de fomento - como o lançamento de editais nacionais e a seleção de projetos de pesquisa. A partir de 2003 , os estados passaram a realizar as chamadas públicas, por meio de edital, sob a tutoria do CNPq. Mesmo havendo legislação que permitia esse procedimento desde 1997, essas atividades eram, até 2003, restritas ao CNPq, como o eram outras ações de fomento à C\&T\&l.

Serão detalhados no próximo tópico os novos procedimentos do CNPq quanto à descentralização dos recursos financeiros da União às FAP. 


\subsection{AS FUNDAÇÕES ESTADUAIS DE AMPARO À PESQUISA OU SECRETARIAS DE ESTADO DA CIÊNCIA E TECNOLOGIA E AS TRANSFERÊNCIAS VOLUNTÁRIAS DE RECURSOS}

A primeira fundação de amparo à pesquisa a ser instalada do país foi a Fundação de Amparo à Pesquisa do Estado de São Paulo (FAPESP), formalmente criada em 1960, pela Lei Orgânica 5.918, de 18 de outubro de 1960. A FAPESP começou a funcionar em 1962 (Decreto 40.132, de 23 de maio de 1962), cumprindo o que fora previsto na Constituição Estadual de 1947, que determinou a transferência de 0,5\% da arrecadação estadual para ser aplicado em pesquisa e desenvolvimento no estado. Valor esse que foi ratificado na Constituição Federal de 1988. O governo estadual destinou à nova Fundação, no momento em que ela começou a funcionar, uma dotação inicial de US\$ 2,7 milhões para a formação de um patrimônio rentável, fato que contribuiu para o bem-sucedido modelo da FAPESP. Essa definição de um orçamento próprio para a Fundação, baseado no percentual do total da receita tributária do Estado - posteriormente elevado para 1\%, pela Constituição Estadual de 1989 - foi o grande diferencial que viabilizou a FAPESP como um organismo autônomo de apoio à pesquisa e uma das principais agências de fomento à pesquisa científica e tecnológica do País.

Após a criação da FAPESP em 1960, foram instaladas outras Fundações de Amparo, cita-se como exemplo a Fundação de Amparo à Pesquisa do Estado do Rio Grande do Sul (FAPERGS), em 1964, e a Fundação de Amparo à Pesquisa do Estado do Rio de Janeiro (FAPERJ), em 1980.

Contudo, foi a partir da promulgação da Constituição Federal de 1988, que as funções dessa nova instância administrativa, no sistema de ciência e tecnologia foram consolidadas e as parcerias entre o CNPq e as fundações estaduais de fomento à pesquisa fortalecidas, visando ao incremento das ações regionais. Nesse sentido, outros Estados da Federação se sentiram motivados a se adequarem para exercer os preceitos constitucionais relativos à descentralização de recursos da União aos Estados, Municípios e ao Distrito Federal. Nessa década, foram instaladas quatro FAP e, na década de 90, outras oito. Já na década de 2000, treze FAP foram instaladas, conforme demonstrado no Quadro 3. 


\section{Quadro 3 - Organização institucional das FAP nos estados}

\begin{tabular}{|c|c|c|c|c|c|c|c|c|}
\hline $\mathbf{N}^{\circ}$ & $\begin{array}{l}\text { Ano de } \\
\text { Criação }\end{array}$ & Denominação & UF & $\begin{array}{l}\text { SIGLAS } \\
\text { FAP }\end{array}$ & Marco legal & $\begin{array}{l}\% \text { de } \\
\text { repasse }\end{array}$ & Vínculo & $\begin{array}{c}\text { Autonomia } \\
\text { Financeira } \\
\text { e } \\
\begin{array}{c}\text { Administrat } \\
\text { iva }\end{array}\end{array}$ \\
\hline 1. & 1960 & $\begin{array}{l}\text { Fundação de Amparo à } \\
\text { Pesquisa do Estado de } \\
\text { São Paulo. }\end{array}$ & SP & FAPESP & $\begin{array}{l}\text { Lei Orgânica } 5.918 \text {, } \\
\text { de } 18 / 10 / 1960 \text {. } \\
\text { Decreto } 40.132 \text {, de } \\
23 / 05 / 1962 \text {. }\end{array}$ & $2 \%$ & $\begin{array}{l}\text { Secretaria de } \\
\text { Desenvolvimento } \\
\text { Econômico, Ciência e } \\
\text { Tecnologia do Governo } \\
\text { do Estado de São Paulo. }\end{array}$ & Sim \\
\hline 2. & 1964 & $\begin{array}{l}\text { Fundação de Amparo à } \\
\text { Pesquisa do Estado do } \\
\text { Rio Grande do Sul. }\end{array}$ & RS & FAPERGS & $\begin{array}{l}\text { Lei Estadual } \mathrm{N}^{\circ} \\
4.920 \text {, de } 31 / \\
12 / 1964 .\end{array}$ & $1,5 \%$ & $\begin{array}{l}\text { Secretaria de Estado de } \\
\text { Ciência e Tecnologia. }\end{array}$ & Sim \\
\hline 3. & 1980 & $\begin{array}{l}\text { Fundação Carlos } \\
\text { Chagas de } \\
\text { Amparo à Pesquisa do } \\
\text { Estado do Rio de } \\
\text { Janeiro. }\end{array}$ & RJ & FAPERJ & $\begin{array}{l}\text { Decreto } n^{\circ} 3.290 \text {, } \\
\text { de } 16 / 06 / 1980\end{array}$ & $2 \%$ & $\begin{array}{l}\text { Secretaria de Estado de } \\
\text { Ciência e Tecnologia. }\end{array}$ & Sim \\
\hline 4. & 1985 & $\begin{array}{l}\text { Fundação de Amparo à } \\
\text { Pesquisa do Estado de } \\
\text { Minas Gerais. }\end{array}$ & MG & FAPEMIG & $\begin{array}{l}\text { Lei Delegada no }{ }^{\circ} 10 \text {, } \\
\text { de } 28 / 08 / 1985 \text {. }\end{array}$ & $1 \%$ & $\begin{array}{l}\text { Secretaria de Estado de } \\
\text { Ciência, Tecnologia e. } \\
\text { Ensino Superior. }\end{array}$ & Sim \\
\hline 5. & 1987 & $\begin{array}{l}\text { Fundação } \\
\text { Tecnologia do } \\
\text { do Acre. }\end{array}$ & $A C$ & FUNTAC & $\begin{array}{l}\text { Lei } n^{\circ} 871, \quad \text { de } \\
24 / 09 / 1987 .\end{array}$ & $1 \%$ & $\begin{array}{l}\text { Secretaria de Estado de } \\
\text { Ciência, Tecnologia e. } \\
\text { Meio Ambiente. }\end{array}$ & Sim \\
\hline 6. & 1989 & $\begin{array}{l}\text { Fundação de Amparo à } \\
\text { Ciência e Tecnologia } \\
\text { do Estado de } \\
\text { Pernambuco. }\end{array}$ & PE & FACEPE & $\begin{array}{l}\text { Lei } n^{\circ} 10.401 \text {, de } \\
26 / 12 / 1989 \text {. }\end{array}$ & $1 \%$ & $\begin{array}{l}\text { Secretaria de Ciência, } \\
\text { Tecnologia e Meio } \\
\text { Ambiente. }\end{array}$ & Sim \\
\hline 7. & 1990 & $\begin{array}{l}\text { Fundação de Amparo à } \\
\text { Pesquisa do Estado de } \\
\text { Alagoas. }\end{array}$ & $\mathrm{AL}$ & FAPEAL & $\begin{array}{lcr}\text { Lei } & \text { Complementar } \\
\mathrm{n}^{\circ} & 5, & \text { de } \\
27 / 09 / 1990 . & \end{array}$ & $2 \%$ & $\begin{array}{l}\text { Secretaria de Ciência, } \\
\text { Tecnologia e Inovação. }\end{array}$ & Sim \\
\hline 8. & 1990 & $\begin{array}{l}\text { Fundação de Amparo à } \\
\text { Pesquisa do Estado de } \\
\text { Mato Grosso. }\end{array}$ & MT & FAPEMAT & $\begin{array}{l}\text { Lei } n^{\circ} 6.612 \text {, de } \\
21 / 12 / 1994 \text {. }\end{array}$ & $0,5 \%$ & $\begin{array}{l}\text { Secretaria de Estado de } \\
\text { Ciência e Tecnologia. }\end{array}$ & Sim \\
\hline 9. & 1991 & $\begin{array}{l}\text { Fundação Cearense de } \\
\text { Apoio ao } \\
\text { Desenvolvimento } \\
\text { Científico } \\
\text { Tecnológico. }\end{array}$ & CE & FUNCAP & $\begin{array}{l}\text { Lei } n^{\circ} 11.752 \text {, de } \\
12 / 11 / 1990 .\end{array}$ & $2,0 \%$ & $\begin{array}{l}\text { Secretaria de Ciência e } \\
\text { Tecnologia do Ceará. }\end{array}$ & Sim \\
\hline 10. & 1992 & $\begin{array}{l}\text { Fundação de Amparo à } \\
\text { Pesquisa do Estado da } \\
\text { Paraíba. }\end{array}$ & PB & FAPEP & $\begin{array}{l}\text { Lei } n^{\circ} 5.624 \text {, de } \\
\text { 06/07/1992. }\end{array}$ & $2,5 \%$ & 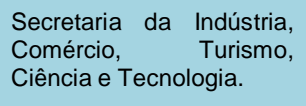 & Sim \\
\hline 11. & 1992 & $\begin{array}{l}\text { Fundação de Apoio à } \\
\text { Pesquisa do Distrito } \\
\text { Federal. }\end{array}$ & DF & FAPDF & $\begin{array}{l}\text { Lei No } 347 \text {, de } \\
\text { 04/11/1992. }\end{array}$ & $2 \%$ & $\begin{array}{l}\text { Secretaria de Estado } \\
\text { para o Desenvolvimento } \\
\text { da } \\
\text { Ciência e Tecnologia - } \\
\text { SDCT. }\end{array}$ & Sim \\
\hline 12. & 1993 & $\begin{array}{l}\text { Fundação de Amparo à } \\
\text { Pesquisa do Estado do } \\
\text { Piauí. }\end{array}$ & $\mathrm{PI}$ & FAPEPI & $\begin{array}{l}\text { Lei } n^{\circ} 4.664 \text {, de } \\
\text { 20/12/1993. }\end{array}$ & $1 \%$ & $\begin{array}{l}\text { Secretaria de } \\
\text { Desenvolvimento } \\
\text { Econômico e Tecnologia. }\end{array}$ & Sim \\
\hline 13. & 1998 & $\begin{array}{l}\text { Fundação de Apoio ao } \\
\text { Desenvolvimento do } \\
\text { Ensino, Ciência e } \\
\text { Tecnologia do Estado } \\
\text { do Mato Grosso do Sul. }\end{array}$ & MS & FUNDECT & $\begin{array}{l}\text { Lei } n^{\circ} 1.860 \text {, de } \\
03 / 07 / 1998 .\end{array}$ & $0,5 \%$ & $\begin{array}{l}\text { Secretaria de Estado de } \\
\text { Meio Ambiente, do } \\
\text { Planejamento, } \\
\text { da Ciência e Tecnologia } \\
\text { do Estado de Mato } \\
\text { Grosso do Sul. }\end{array}$ & Sim \\
\hline 14. & 1999 & $\begin{array}{l}\text { Fundação de Apoio à } \\
\text { Pesquisa e à Inovação } \\
\text { Tecnológica do Estado } \\
\text { de Sergipe. }\end{array}$ & SE & FAPITEC & $\begin{array}{l}\text { Lei 5.771, de } \\
\text { 12/12/2005. }\end{array}$ & $0,5 \%$ & $\begin{array}{l}\text { Secretaria Estadual da } \\
\text { Indústria, do Comércio e } \\
\text { da Ciência e Tecnologia } \\
\text { - SEICTEC. }\end{array}$ & Sim \\
\hline 15. & 2000 & $\begin{array}{l}\text { Fundação Araucária de } \\
\text { Apoio } \\
\text { Desenvolvimento ao } \\
\text { Científico } \\
\text { Tecnológico do } \\
\text { Paraná. }\end{array}$ & PR & $\begin{array}{c}\text { Fundação } \\
\text { Araucária. } \\
\text { Instituição } \\
\text { Privada. }\end{array}$ & $\begin{array}{l}\text { Decreto } 4.684 \text {, de } \\
12 / 08 / 1998 .\end{array}$ & $2 \%$ & $\begin{array}{l}\text { Secretaria de Estado de } \\
\text { Ciência, Tecnologia e } \\
\text { Ensino Superior. }\end{array}$ & Sim \\
\hline 16. & 2001 & $\begin{array}{l}\text { Fundação de Amparo à } \\
\text { Pesquisa do Estado da } \\
\text { Bahia. }\end{array}$ & BA & FAPESB & $\begin{array}{l}\text { Lei 7.888, } \\
27 / 08 / 2001 \text {. }\end{array}$ & $1 \%$ & $\begin{array}{l}\text { Secretaria de Ciência, } \\
\text { Tecnologia e Inovação. }\end{array}$ & Sim \\
\hline 1 & 2002 & $\begin{array}{l}\text { Fundação de Amparo à } \\
\text { Pesquisa do Estado do } \\
\text { Amazonas. }\end{array}$ & AM & FAPEAM & $\begin{array}{l}\text { Lei N. } 2.743 \text {, } \\
\text { 10/07/2002. }\end{array}$ & $1 \%$ & $\begin{array}{l}\text { Secretaria de Estado } \\
\text { de } \\
\text { Ciência e Tecnologia. }\end{array}$ & Sim \\
\hline
\end{tabular}




\begin{tabular}{|c|c|c|c|c|c|c|c|c|}
\hline 18. & 2003 & $\begin{array}{l}\text { Fundação de Apoio à } \\
\text { Pesquisa do Estado do } \\
\text { Rio Grande do Norte. }\end{array}$ & $\mathrm{RN}$ & FAPERN & $\begin{array}{l}\text { Complementar } n^{\circ} \\
257, \text { de } 14 / 11 / 2003\end{array}$ & $1 \%$ & $\begin{array}{l}\text { Secretaria de Estado } \\
\text { do Desenvolvimento } \\
\text { Econômico. }\end{array}$ & $\begin{array}{l}\quad \text { Não } \\
\text { Controladori } \\
\text { a-Geral do } \\
\text { Estado }\end{array}$ \\
\hline 19. & 2003 & $\begin{array}{lr}\text { Fundação de } & \text { Amparo a } \\
\text { Pesquisa e } & \text { ao } \\
\text { Desenvolvimento } & \\
\text { Cientí́ico } & \text { e } \\
\text { Tecnológico } & \text { do } \\
\text { Maranhão. } & \end{array}$ & MA & FAPEMA & $\begin{array}{l}\text { Lei } \text { Complementar } \\
\mathrm{n}^{\circ} \quad 060, \quad \text { de } \\
31 / 01 / 2003 .\end{array}$ & $0,5 \%$ & $\begin{array}{l}\text { Secretaria de Estado da } \\
\text { Ciência, Tecnologia, } \\
\text { Ensino Superior e } \\
\text { Desenvolvimento } \\
\text { Tecnológico. }\end{array}$ & Sim \\
\hline 20. & 2004 & $\begin{array}{l}\text { Fundação de Apoio à } \\
\text { Ciência e Tecnologia } \\
\text { do Espírito Santo. }\end{array}$ & ES & FAPES & $\begin{array}{l}\text { Lei } \begin{array}{c}\text { Complementar } \\
n^{\circ} \quad 290, \quad \text { de } \\
23 / 06 / 2004 .\end{array}\end{array}$ & $0,5 \%$ & $\begin{array}{l}\text { Secretaria de Estado de } \\
\text { Ciência e Tecnologia. }\end{array}$ & Sim \\
\hline 21. & 2005 & $\begin{array}{l}\text { Fundação de Amparo à } \\
\text { Pesquisa e Inovação } \\
\text { do Estado de Santa } \\
\text { Catarina. }\end{array}$ & $\mathrm{SC}$ & FAPESC & $\begin{array}{l}\text { Lei Complementar } \\
\text { n }^{\circ} 284 \text {, de } 28 \text { de } \\
\text { fevereiro de } 2005 \text {. }\end{array}$ & $1 \%$ & $\begin{array}{l}\text { Secretaria de Estado do } \\
\text { Desenvolvimento } \\
\text { Econômico Sustentável. }\end{array}$ & Sim \\
\hline 22. & 2005 & $\begin{array}{l}\text { Fundação de Amparo à } \\
\text { Pesquisa do Estado de } \\
\text { Goiás. }\end{array}$ & GO & FAPEG & $\begin{array}{l}\text { Lei 15.472, de } \\
\text { 12/12/2005. }\end{array}$ & $0,5 \%$ & $\begin{array}{l}\text { Secretaria de Estado da } \\
\text { Educação, Ciência e. } \\
\text { Tecnologia. }\end{array}$ & Sim \\
\hline 23. & 2007 & $\begin{array}{l}\text { Fundação Amazônia } \\
\text { Paraense de Amparo à } \\
\text { Pesquisa. }\end{array}$ & PA & FAPESPA & $\begin{array}{l}\text { Lei Complementar } \\
\text { n }^{\circ} 061 / 2007, \text { de } 24 \\
\text { de julho de } 2007 .\end{array}$ & $1 \%$ & $\begin{array}{l}\text { Secretaria Especial } \\
\text { de Estado de } \\
\text { Infraestrutura e Logística } \\
\text { para o Desenvolvimento } \\
\text { Sustentável. }\end{array}$ & Sim \\
\hline 24. & 2009 & $\begin{array}{l}\text { Fundação de Amparo à } \\
\text { Pesquisa do Estado do } \\
\text { Amapá (Fundação } \\
\text { Tumucumaque). }\end{array}$ & $\mathrm{AP}$ & FAPEAP & $\begin{array}{l}\text { Lei, } 1.438 \text { de } 30 \text { de } \\
\text { dezembro de } 2009 .\end{array}$ & $\begin{array}{c}\text { Não } \\
\text { informado. }\end{array}$ & $\begin{array}{l}\text { Secretaria de Estado da } \\
\text { Ciência e Tecnologia. }\end{array}$ & Sim \\
\hline 26. & 2011 & $\begin{array}{l}\text { Fundação Rondônia de } \\
\text { Amparo ao } \\
\text { Desenvolvimento das } \\
\text { Ações Científicas e } \\
\text { Tecnológicas e a } \\
\text { Pesquisa do Estado de } \\
\text { Rondônia. }\end{array}$ & RO & FAPERO & $\begin{array}{l}\text { Lei n. } 2.528 \text {, de } 25 \\
\text { de julho de } 2011 \text {. }\end{array}$ & $0,5 \%$ & $\begin{array}{l}\text { Vinculada à } \\
\text { Governadoria do Estado }\end{array}$ & Sim \\
\hline 26. & 2011 & $\begin{array}{l}\text { Instituto de Amparo à } \\
\text { Ciência, Tecnologia e } \\
\text { Inovação do Estado de } \\
\text { Roraima. }\end{array}$ & RR & IACTI-RR & $\begin{array}{l}\text { LEI } N^{\circ} 815 \text { DE } 7 \\
\text { DE JULHO DE } \\
2011 .\end{array}$ & $\begin{array}{c}\text { \% Não } \\
\text { informado }\end{array}$ & $\begin{array}{l}\text { Secretaria de Estado do } \\
\text { Planejamento e } \\
\text { Desenvolvimento } \\
\text { SEPLAN. }\end{array}$ & Sim \\
\hline 27. & 2011 & $\begin{array}{l}\text { Fundação de Amparo à } \\
\text { Pesquisa do Estado do } \\
\text { Tocantins. }\end{array}$ & TO & FAPT & $\begin{array}{l}\text { Lei Complementar } \\
\text { n. } 71 \text {, criada em } 31 \\
\text { de março de } 2011 .\end{array}$ & $0,5 \%$ & $\begin{array}{l}\text { Secretaria Estadual de } \\
\text { Ciência e Tecnologia e } \\
\text { ao Conselho Estadual de } \\
\text { Ciência e Tecnologia. }\end{array}$ & Sim \\
\hline
\end{tabular}

Fonte: Elaborado pela autora.

Última data de verificação no sitio das FAP: 10.08.2013.

As Fundações Estaduais de Amparo à Pesquisa têm como finalidade apoiar projetos de pesquisa, ensino e extensão e de desenvolvimento institucional, científico e tecnológico. Seus grandes eixos de atuação são:

a) fomentar as pesquisas científicas e tecnológicas e a inovação;

b) formar recursos humanos qualificados para as pesquisas; $\mathrm{e}$

c) fomentar a interação entre os centros geradores do conhecimento e os setores economicamente produtivos. (CONFAP, 2014)

As FAP têm como missão induzir e incentivar a pesquisa e inovação que visem ao desenvolvimento do Município, do Estado e finalmente do País. E têm como atribuições para o cumprimento de sua missão o financiamento de pesquisas por meio de bolsas; a contribuição para solidificar grupos de pesquisa científica e tecnológica; a promoção da 
integração entre os setores produtivos e instituições de ensino e pesquisa; a realização de eventos de caráter científico e/ou tecnológico; a realização de intercâmbios entre pesquisadores brasileiros e estrangeiros e, também, a divulgação científica dos resultados das pesquisas realizadas. (CONFAP, op. cit. 2014)

As Fundações de Amparo à Pesquisa possuem capacidades diferenciadas de ação, dependendo das políticas dos governos estaduais, mas todas possuem um potencial de atuação muito grande nos estados, o que é fundamental para buscar um desenvolvimento equilibrado das pesquisas científicas e tecnológicas das regiões.

O processo de instalação das FAP não ocorreu segundo um formato único nem se deu de forma simultânea no tempo, com todas as unidades da federação implementando as suas fundações ao mesmo tempo, pois, como dito anteriormente, ocorreram fatores intervenientes como diferentes atores locais, capacidades técnicas e operacionais próprias, interesses políticos e proatividade inovativa distintas.

De todas as FAP, a que desde a sua instalação possui, até hoje, maior organicidade, regularidade, sistematicidade e capacidade de investimento, é a FAPESP, considerando-se o modelo político aplicado à sua criação e a posição altamente participativa tanto do estado de São Paulo, como também da comunidade cientifica que foi formada no estado.

Pode-se depreender, após consulta em várias fontes13 que, na instância estadual e regional, as FAP vêm desempenhando um papel estratégico no processo de descentralização das ações federais de fomento, seja do ponto de vista técnico, seja operacional, reforçando a execução local da pesquisa e desenvolvimento.

As FAP, além de serem eixos de alinhamento entre as políticas de C\&T\&l dos governos federal e estadual, mesmo considerando a necessidade de flexibilidade e adaptação de programas federais às diferentes realidades locais, vêm contribuindo para dar maior capilaridade local a esse processo e para o aumento dos recursos aplicados no Sistema Nacional de C\&T\&I, via o aporte de contrapartidas, até mesmo em nível internacional, no caso de algumas FAP. (CGEE, 2010; CONFAP, 2014; BRASIL, 2006; SECT)

\footnotetext{
${ }^{13}$ (CGEE, 2010; ENCTI 2012-2015; MCTI; Relatórios de Gestão CNPq)
} 
No bojo do processo de descentralização, o MCTI

ampliou a capacidade das FAP de mobilizar os recursos de contrapartidas das instituições conveniadas (públicas e privadas) e aumento do potencial multiplicador de suas aplicações diretas no fomento da C\&T\&l. A exigência de relações estruturadas e compartilhadas entre as FAP e instituições do setor privado torna forte tanto as FAP quanto as instituições parceiras, política e operacionalmente, e se tornam importantes aliadas para assegurar a autonomia e a estabilidade de alguns programas das FAP e dessas instituições. (CGEE, op. cit., p. 93)

O estudo do CGEE ressalta que

paralelamente ao processo de descentralização, vêm também avançando as iniciativas de desconcentração, vinculadas à área de C\&T, de instituições do governo federal. Essas iniciativas constituem não só um fator de desenvolvimento regional, mas também um indutor de processos de descentralização de ações na área de CT\&I, na medida em que aumenta o potencial local de clientela dos programas federais e estaduais de fomento. (CGEE, op. cit., p.38)

Em conformidade com as condições de cada acordo entre os estados e as FAP, são definidos os percentuais de repasse, pelos estados, para a sua FAP ou instituição estadual responsável pela execução das ações na área de ciência e tecnologia.

Outro ponto a ser considerado, e que demonstra as diferenças entre as FAP, é a vinculação institucional, que nem sempre é feita junto à Secretaria de Estado de Ciência e Tecnologia, mas junto a outras Secretarias Estaduais.

Todas as FAP possuem caráter jurídico público, com exceção da Fundação Araucária de Apoio ao Desenvolvimento Científico e Tecnológico do Paraná, que possui o seu caráter jurídico privado.

A maioria das FAP está vinculada à Secretaria de Estado de Ciência e Tecnologia do seu estado, e possuem autonomia financeira e administrativa, exceto a Fundação de Apoio à Pesquisa do Estado do Rio Grande do Norte, que se vincula à Controladoria Geral do Estado e não possui autonomia financeira e administrativa. Todas essas informações relativas a cada FAP podem ser observadas no Quadro 3 (apresentado acima nas pp 58 e 59), que trata da organização institucional das FAP nos estados.

Para que as parcerias com as FAP pudessem ser executadas, tornou-se necessário que o Estado se instrumentasse ou editasse medidas que pudessem disciplinar a forma de operacionalização de um modelo novo de fomento para o segmento de ciência e tecnologia. Essa instrumentalização compreende todos os entes partícipes da relação com o governo 
federal, quanto à execução de programas nacionais descentralizados para os estados. Nesse sentido, foram editados normativos que compreendem elementos que devem vigorar em uma relação estreita entre o Estado e os gastos públicos, assim como a transparência que deve guardar cada ação realizada pelas partes.

\subsection{RECURSOS}

Como exemplos da operacionalização financeira de todas as parcerias firmadas pelo CNPq junto às FAP, por meio da firmatura de convênios, optou-se pela demonstração dos valores repassados, mediante as transferências voluntárias, para a execução descentralizada dos Programas PPP e PRONEX, por serem programas que mantêm regularidade na publicação de seus editais de chamadas públicas e que recebem somas vultosas para a execução de projetos, no âmbito desses dois programas.

Os dados foram extraídos do Sistema Integrado de Prestação de Contas (SIPC), do CNPq e os valores considerados para o cômputo das transferências voluntárias foram os valores efetivamente transferidos às FAP, para a execução desses dois programas supra mencionados.

Desde o ano de 2000, os investimentos do CNPq vêm sendo realizados de acordo com os programas e as ações estabelecidas nos Planos Plurianuais (PPA) do Governo Federal.

A partir de 2003, os recursos totais destinados ao Fomento à Pesquisa apresentam um comportamento ascendente em quase todo o período de análise deste estudo, impulsionados, principalmente, pelas modalidades de Auxílio à Pesquisa, que incluíram grande parte dos recursos dos Fundos Setoriais.

No âmbito dos convênios e parcerias, os recursos geridos pelo CNPq têm apresentado acréscimo de ano a ano, mesmo que em percentuais menores em relação aos anos anteriores. Alguns dos fatores explicativos desse acréscimo são:

1) A vigência da Lei $n^{\circ} 10.524$, de $25 / 07 / 2002$, segundo a qual a função 'ciência e tecnologia' passou a fazer parte do grupo daquelas não contingenciáveis;

2) A ampliação e consolidação dos vários fundos setoriais em operação, criados com a finalidade específica de aumentar o aporte de recursos para o financiamento da atividade científico-tecnológica nacional, em setores especialmente selecionados, em função de sua importância estratégica para o desenvolvimento do País; e 
3) Aumento de recursos previstos na Lei de Diretrizes Orçamentárias (LDO), com valores significativos para a área de ciência e tecnologia. (MCTI, 2014) $)^{14}$

No período de 2003 a 2013, o CNPq descentralizou para as FAP executarem os convênios firmados no âmbito dos Programas PPP e PRONEX, e segundo demonstrativos do SIPC/CNPq, o montante de $\mathrm{R} \$ 410.451 .438,44$ (quatrocentos e dez milhões, quatrocentos e cinquenta e um mil, quatrocentos e trinta e oito reais e quarenta e quatro centavos), foram repassados à todas as Unidades da Federação, com execução pelas Fundações de Amparo, dos referidos Programas descentralizados, como demonstrado na Tabela 2, a seguir: 
Tabela 2: Recursos descentralizados pelo CNPq às FAP para execução dos Programas PPP e PRONEX - 2003-2013

\begin{tabular}{|c|c|c|c|c|c|c|c|c|}
\hline \multicolumn{9}{|c|}{ Soma dos Valores CNPq / Anos } \\
\hline Programa & Região & 2003 & 2005 & 2006 & 2008 & 2010 & 2013 & Total Global \\
\hline \multirow[t]{5}{*}{ PPP } & $\mathrm{CO}$ & $\mathrm{R} \$ 724.000,00$ & & $\mathrm{R} \$ 2.400 .000,00$ & $\mathrm{R} \$ 2.000 .000,00$ & $\mathrm{R} \$ 2.000 .000,00$ & $\mathrm{R} \$ 8.600 .000,00$ & $\mathrm{R} \$ 15.724 .000,00$ \\
\hline & $\mathrm{N}$ & $\mathrm{R} \$ 2.642 .323,12$ & & $\mathrm{R} \$ 5.980 .000,00$ & $\mathrm{R} \$ 5.440 .000,00$ & $\mathrm{R} \$ 4.690 .000,00$ & $\mathrm{R} \$ 3.701 .000,00$ & $\mathrm{R} \$ 22.453 .323,12$ \\
\hline & NE & $\mathrm{R} \$ 2.171 .022,00$ & & $\mathrm{R} \$ 3.780 .000,00$ & $\mathrm{R} \$ 3.657 .500,00$ & $\mathrm{R} \$ 8.746 .250,00$ & & $\mathrm{R} \$ 18.354 .772,00$ \\
\hline & S & $\mathrm{R} \$ 3.302 .000,00$ & & $\mathrm{R} \$ 3.100 .000,00$ & $\mathrm{R} \$ 1.400 .000,00$ & $\mathrm{R} \$ 2.422 .500,00$ & $\mathrm{R} \$ 2.000 .000,00$ & $\mathrm{R} \$ 12.224 .500,00$ \\
\hline & SE & $\mathrm{R} \$ 7.852 .000,00$ & & $\mathrm{R} \$ 4.500 .000,00$ & $\mathrm{R} \$ 2.250 .000,00$ & $\mathrm{R} \$ 13.000 .000,00$ & & $\mathrm{R} \$ 27.602 .000,00$ \\
\hline PPP Total & & R\$ 16.875.345,12 & & R\$ 19.760.000,00 & $\mathrm{R} \$ 14.747 .500,00$ & $\mathrm{R} \$ \mathbf{3 0 . 8 5 8 . 7 5 0 , 0 0}$ & $\mathrm{R} \$ 14.301 .000,00$ & R\$ 96.542.595,12 \\
\hline \multirow[t]{5}{*}{ PRONEX } & $\mathrm{CO}$ & $\mathrm{R} \$ 3.960 .000,00$ & & & $\mathrm{R} \$ 21.499 .996,00$ & $\mathrm{R} \$ 1.000 .000,00$ & $\mathrm{R} \$ 7.000 .000,00$ & $\mathrm{R} \$ 33.459 .996,00$ \\
\hline & $\mathrm{N}$ & $\mathrm{R} \$ 1.280 .000,00$ & & $\mathrm{R} \$ 3.640 .000,00$ & $\mathrm{R} \$ 31.826 .000,00$ & $\mathrm{R} \$ 5.000 .000,00$ & $\mathrm{R} \$ 8.000 .000,00$ & $\mathrm{R} \$ 49.746 .000,00$ \\
\hline & $\mathrm{NE}$ & $\mathrm{R} \$ 6.374 .400,00$ & $\mathrm{R} \$ 7.468 .800,00$ & $\mathrm{R} \$ 15.288 .800,00$ & $\mathrm{R} \$ 20.983 .847,32$ & $\mathrm{R} \$ 6.600 .000,00$ & $\mathrm{R} \$ 10.100 .000,00$ & $\mathrm{R} \$ 66.815 .847,32$ \\
\hline & $S$ & $\mathrm{R} \$ 9.900 .000,00$ & & $\mathrm{R} \$ 8.750 .000,00$ & $\mathrm{R} \$ 36.500 .000,00$ & $\mathrm{R} \$ 4.700 .000,00$ & $\mathrm{R} \$ 3.000 .000,00$ & $\mathrm{R} \$ 62.850 .000,00$ \\
\hline & SE & $\mathrm{R} \$ 25.000 .000,00$ & & $\mathrm{R} \$ 34.100 .000,00$ & $\mathrm{R} \$ 27.437 .000,00$ & $\mathrm{R} \$ 10.500 .000,00$ & $\mathrm{R} \$ 4.000 .000,00$ & $\mathrm{R} \$ 101.037 .000,00$ \\
\hline PRONEX Total & & $\mathrm{R} \$ 46.514 .400,00$ & $\mathrm{R} \$ 7.468 .800,00$ & $\mathrm{R} \$ \mathbf{6 1 . 7 7 8 . 8 0 0 , 0 0}$ & $\mathrm{R} \$ 138.246 .843,32$ & R\$ 27.800.000,00 & $\mathrm{R} \$ 32.100 .000,00$ & $\mathrm{R} \$ 313.908 .843,32$ \\
\hline Total Global & & R\$ 63.389.745,12 & R\$ 7.468.800,00 & R\$ 81.538.800,00 & R\$ 152.994.343,32 & $\mathrm{R} \$ 58.658 .750,00$ & $\mathrm{R} \$ 46.401 .000,00$ & $\mathrm{R} \$ 410.451 .438,44$ \\
\hline
\end{tabular}

Fonte: SIPC/CNPq, 2014. Elaboração da autora. 
A Tabela 2 apresenta a distribuição regional dos recursos da União descentralizados para as FAP, pelo CNPq, no âmbito do PPP e do PRONEX. Para a execução de projetos do Programa PPP, em dez anos, foi transferido o montante de R $\$ 96.542 .595,12$ (noventa e seis milhões, quinhentos e quarenta e dois mil, quinhentos e noventa e cinco reais e doze centavos); no caso do PRONEX, um programa consolidado e de excelência, no mesmo período, as transferências foram da ordem de $\mathrm{R} \$ 313.908 .843,32$ (trezentos e treze milhões, novecentos e oito mil, oitocentos e quarenta e três reais e trinta e dois centavos).

No período de estudo, demonstrado na Tabela 2, para a execução dos Programas PPP e PRONEX, em virtude da publicação de editais, manteve-se certa regularidade na descentralização dos recursos transferidos a todas as regiões. Observa-se que, no ano de 2005, somente aparece a transferência de recursos para o PRONEX/NE, correspondente à publicação de editais e recursos específicos. No mesmo ano, não foram publicados editais ou transferidos recursos do CNPq para outras regiões, embora as FAP tenham continuado a execução de projetos, que já se encontravam implementados, utilizando dos recursos de outras fontes parceiras.

A região Nordeste veio a se destacar apenas no ano de 2013, com a descentralização de $\mathrm{R} \$ 10.100 .000,00$ (dez milhões e cem mil reais) para a execução de projetos no âmbito do Programa PRONEX.

De acordo com o Relatório de Gestão 2013, do CNPq, observa-se que no ano de 2005 e 2013, não houve regularidade habitual nas transferências voluntárias às $F A P$, o que se pode verificar pelos números expressos na Tabela 2. Na verdade, os recursos destinados ao CNPq, em geral, têm sofrido restrições e quedas. Nessas condições, no ano de 2013 tomouse a decisão estratégica de priorizar a racionalização nos processos de implementação dos convênios com as fundações de amparo por falta de recursos. Neste caso, racionalização significa, segundo o Relatório, priorizar alguns projetos e diminuir a implementação dos convênios com as fundações de amparo, por falta de recursos financeiros. Em torno de $10 \%$, do total da demanda qualificada (projetos submetidos e reconhecidos como meritórios) não são apoiados por insuficiência de recursos orçamentários do CNPq. Nesse quadro, as demais parcerias realizadas pelas FAP, são importantes para manter as atividades. Assim, as ações e a meta física prevista foi cumprida no exercício de 2013. (Relatório de Gestão do CNPq, 2013, p.26)

No entanto, apesar desse quadro situacional, a meta estabelecida para cumprimento até 2015 é a de ampliar, de 3.500 para 10 mil o número de projetos de pesquisa apoiados 
pelo CNPq, no ambito da execuc;:;ao das parcerias com as FAP. Nesse sentido o CNPq tem o prop6sito de firmar, com entidades estaduais, 42 convenios de cooperac;:ao para o fomento a projetos de pesquisa, dentro do periodo 2012-2015, visando promover o equilibrio entre as regi6es do pais, buscando cumprir uma das metas previstas na ENCTI 2012-2015. 
Convênios Pronex/PPP - 2003 a 2013

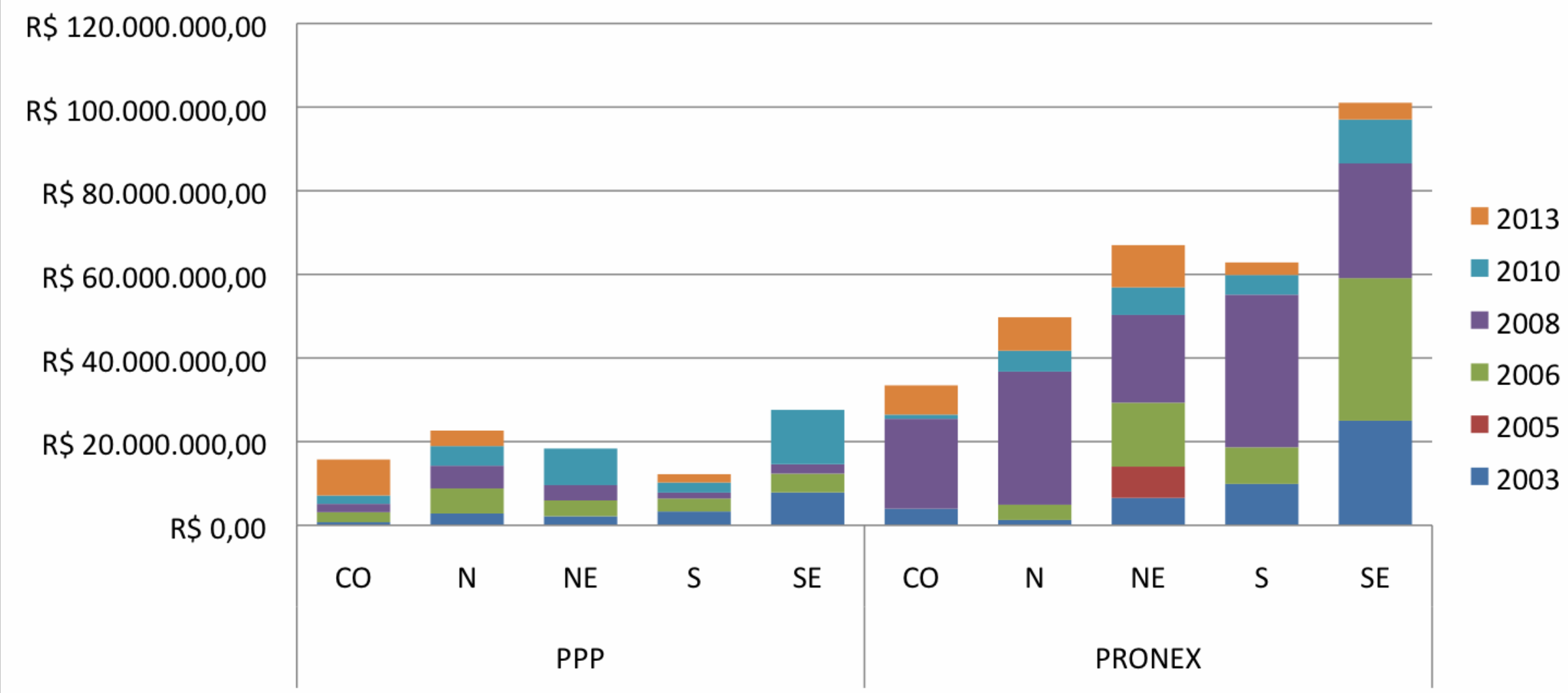

Fonte: SIPC/CNPq, 2014. Elaboração da autora. 
A região Sudeste recebe os repasses por meio de convênios e aparece como liderança nesse recebimento de recursos. Essa predominância da região Sudeste aparece com 56,9\%, em média, dos valores repassados pelo CNPq às FAP, segundo Relatório de Gestão do CNPq 2013. (CNPq, 2013)

O Estado de São Paulo detém, historicamente, cerca da metade dos recursos da região Sudeste, e o estado do Rio de Janeiro, um pouco mais de $1 / 3$, ficando, juntos, com 82,4\% dos recursos dessa região. Em seguida ao Sudeste aparecem, em média, no ranking dos recursos totais transferidos nesses dez anos, as regiões Sul (16,9\%), Nordeste (15\%), Centro-Oeste $(7,2 \%)$ e Norte (3,9\%). A implementação de programas regionais e os repasses às FAP estaduais, entre outras iniciativas do CNPq, alteraram discretamente os percentuais de distribuição regional dos recursos: diminuíram no Sudeste e no Sul e aumentaram nas demais regiões. (CNPq, 2011)

No próximo tópico se abordará a edição de medidas legais para a execução descentralizada de recursos federais, por meio das transferências voluntárias da União, e como se deu a evolução dessa legislação para atender as necessidades que foram identificadas a partir de sua execução, tendo em vista ser um modelo relativamente novo no aparato do Estado. 


\subsection{EVOLUÇÃO DA LEGISLAÇÃO DAS TRANSFERÊNCIAS VOLUNTÁRIAS DA UNIÃO}

Para concretizar a cooperação entre os entes federativos, a União executa transferências constitucionais, legais e voluntárias, que deverão ser utilizadas com eficácia e eficiência no atendimento dos interesses públicos.

O governo federal adotou a descentralização por delegação ou por colaboração, que acontece entre os entes federativos e entre os privados. Surgem daí os atos administrativos unilaterais, os bilaterais e os multilaterais, destacados, entre outros, os convênios. (BITTENCOURT, 2012, apud ARENA e TEIXEIRA, 2011)

A Constituição Federal de 1988, em seu artigo 23, enumera as competências comuns da União, dos Estados, do Distrito Federal e dos Municípios. Em 2006, foi editada a Emenda Constitucional $\mathrm{n}^{\circ} 53$, de 19.12.2006, que previu a elaboração de leis complementares para disciplinar a cooperação entre os entes, com a finalidade de atender às necessidades da população.

A Constituição Federal disciplina três modalidades de transferências:

.as constitucionais previstas em seu artigo 159, que definem a distribuição dos recursos provenientes da arrecadação de tributos federais ou estaduais, aos Estados, Distrito Federal e Municípios nos prazos legalmente estabelecidos, e buscam trazer regularidade e previsibilidade nas finanças ao facilitar o planejamento e controle das contas públicas ${ }^{15}$.

.as legais são as transferências de recursos financeiros com destinação pré-estabelecida, sem a utilização de acordos ou contratos. Estão previstas em leis específicas que determinam a forma de habilitação, a transferência, a aplicação dos recursos e o modo da prestação de contas ${ }^{16}$.

.as voluntárias são as transferências realizadas pelos órgãos e entidades da administração pública federal para órgãos ou entidades públicas ou

\footnotetext{
15 As principais são: de Participação dos Estados e Distrito Federal (FPE); Fundo de Participação dos Municípios (FPM); Fundo de Cooperação pela Exportação de Produtos Industrializados (FPEX); Fundo de Manutenção do Desenvolvimento da Educação Básica e de Valorização de Profissionais da Educação (FUNDEB) e Imposto Sobre a Propriedade Territorial Rural (ITR), dentre outras.(BRASIL, 1988)

${ }^{16}$ Podem ser automáticas, em que os repasses são efetuados em contas específicas: Programa Nacional de Alimentação Escolar (PNAE), Programa Dinheiro Direto da Escola (PDDE). Podem ainda ser processadas fundo a fundo, onde os recursos são transferidos diretamente dos fundos federais para fundos da esfera estadual, municipal ou do Distrito Federal. São programas específicos como, por exemplo, os que envolvem as áreas de saúde do Fundo Nacional de Saúde (FNS) ou assistência social, Fundo Nacional de Assistência Social (FNAS).
} 
privadas sem fins lucrativos, para a execução de programas, projetos e atividades de interesse recíproco que envolvam a transferência de recursos.

Os principais exemplos de transferências voluntárias são os convênios e termos de cooperação celebrados entre as instituições federais, municipais, estaduais ou privadas.

Como esta dissertação tem o seu foco nas transferências voluntárias da União, será tratada a legislação específica sobre o tema.

A Instrução Normativa (IN) no 01, de 15 de Janeiro de 1997, da Secretaria do Tesouro Nacional, foi o março legal que disciplinou a celebração de convênios de natureza financeira para fins de execução descentralizada de Programa de Trabalho de responsabilidade de órgão ou entidade da Administração Pública Federal, direta ou indireta. Em outras palavras, foi a legislação que regulou a descentralização dos recursos financeiros da União para os Estados, Municípios e Distrito Federal.

A Lei n 8666/93, conhecida como a "lei de licitação", em seu artigo 116 também disciplina a transferência de recursos da União, por instituir o processo de licitação pública para a aquisição de bens de capital, consumo e a construção de obras públicas. Disciplina os gastos públicos enumerando as informações mínimas que devem ser observadas para a celebração de "convênios, acordos, ajustes e outros instrumentos congêneres celebrados por órgãos e entidades da Administração", demarcando os limites para a celebração dos convênios pela Administração Pública. Os convênios administrativos são os acordos firmados por pessoas administrativas entre si, ou entre elas e particulares, objetivando interesses comuns, mas que se pautem pelo respeito às normas legais e, principalmente, estejam alicerçados no interesse público. Essa lei possui bastante amplitude para disciplinar as transferências voluntárias da União.

A partir de 2004, foram definidos critérios diferenciados de aporte de contrapartidas dos estados, conforme especificado na Carta de Salvador ${ }^{17}$. Levou-se em consideração a dimensão das economias de cada estado e a localização nas diferentes regiões brasileiras, adotando-se a Carta de Salvador como parâmetro para disciplinar os percentuais de participação financeira de cada estado. Também em 2004, o MCTI passou a adotar a Carta de Salvador como referência para definir os critérios diferenciados de aporte de contrapartida dos estados.

\footnotetext{
${ }^{17}$ Of. FÓRUM No 297 / 04, Salvador, 15.06.2004. (ANEXO A, pág. 141)
} 
Por conseguinte, o Estado busca, com a edição de legislação específica, disciplinar, regulamentar e implementar propostas distintas e específicas de acordo com as condições de cada região, para viabilizar e amenizar a grande ocorrência de desequilíbrio econômico e social entre as regiões brasileiras. Nesse sentido, edita medidas voltadas para viabilizar a descentralização de recursos financeiros que possam, inclusive, gerar condições de competitividade entre as regiões.

O Decreto $n^{\circ} 6.170 / 2007$ dispôs, em seu art. $1^{\circ}, \S^{\circ}, \mathrm{II}$, :

II - sobre as normas relativas às transferências de recursos da União mediante convênios e contratos de repasse.

A Portaria Interministerial $n^{\circ} 507$, de 24 de novembro de 2011, editada conjuntamente pelo MPOG, Ministério da Fazenda e CGU, disciplinou o Decreto $n^{\circ}$ 6.170/2007, na forma que segue:

[...] regula os convênios, os contratos de repasse e os termos de cooperação celebrados pelos órgãos e entidades da Administração Pública Federal com órgãos ou entidades públicas ou privadas sem fins lucrativos para a execução de programas, projetos e atividades de interesse recíproco, que envolvam a transferência de recursos financeiros oriundos do Orçamento Fiscal e da Seguridade Social da União.

Essa Portaria foi editada em substituição à Portaria 127/2008, que teve como principais modificações os Artigos 51 a 55, que foram acrescidos à Portaria 507/2011 e inovou também com a inclusão dos Artigos 65 a 71, que tratam, em seu Capítulo $V$, do Acompanhamento e da Fiscalização da execução dos convênios, dos contratos de repasse e dos termos de cooperação celebrados pelos órgãos e entidades da Administração Pública Federal. Busca maior controle sobre as transações financeiras com recursos da União, oferecendo maior transparência dos gastos públicos.

Os principais exemplos de transferências voluntárias são os convênios, acordos, ajustes ou outros instrumentos similares, como os contratos de repasse. As transferências voluntárias são os recursos financeiros descentralizados pela União aos estados, Distrito Federal e municípios, em decorrência da celebração desses instrumentos, cuja finalidade seja a realização de obras e/ou serviços de interesse comum e coincidente aos partícipes. 


\section{E segundo a Lei de Responsabilidade Fiscal (LRF), ${ }^{18}$ a Transferência Voluntária é}

"a entrega de recursos correntes ou de capital a outro ente da Federação, a título de cooperação, auxílio ou assistência financeira, que não decorra de determinação constitucional, legal ou os destinados ao Sistema Único de Saúde."

A descentralização de recursos por meio de transferências voluntárias do governo federal tornou-se mais transparente com a implementação do Portal de Convênios do Governo Federal (SICONV), em 2008, por intermédio do qual passou a ser obrigatório o registro de todos os atos relativos a execução de convênios, contratos de repasse e termos de parceria. O desenvolvimento desse sistema foi motivado a partir de fiscalizações empreendidas pelo Tribunal de Contas da União (TCU), no ano de 2006,

[...] que identificaram fragilidades nos controles das transferências voluntárias da União. No mesmo ano foi expedida determinação ao Ministério do Planejamento, Orçamento e Gestão para que fossem tomadas providências no sentido de sanar distorções e tornar o processo das transferências voluntárias da União menos frágeis, de forma, também, que pudessem dar transparência dessas transações realizadas. (TCU, 2013)

Visando à melhoria das informações prestadas pelo SICONV e à necessidade de simplificar a forma de acesso às suas informações, está sendo proposto o SICONV Gerencial, que

é uma proposta para o acesso livre às Transferências Voluntárias da União - TVU, que foi desenvolvida com o intuito de facilitar o acesso aos dados do SICONV pelos cidadãos e a outras esferas de Governo. Essa nova ferramenta propõe atender a grande demanda de acesso diário à base de dados do SICONV. [...] o SICONV Gerencial permitirá a seleção de temas bastante específicos, com a inclusão de filtros para realizar as consultas e o download de interesses restritos. Além das consultas já existentes nos Extratores de Dados, futuramente serão adicionadas novas consultas referentes à execução financeira. (SICONV, 2013)

O Quadro 4 mostra a evolução da legislação que regula a transferência voluntária da União, estando nele relacionadas todas as leis que servem de base para orientar a firmatura de instrumentos de parceria e a efetiva execução das TVU.

18 A Lei de Responsabilidade Fiscal (LRF) estabelece normas de finanças públicas voltadas para a responsabilidade na gestão fiscal que pressupõe a ação planejada e transparente, em que se previnem riscos e corrigem desvios capazes de afetar o equilíbrio das contas públicas, mediante o cumprimento de metas de resultados entre receitas e despesas e a obediência a limites e condições no que tange a renúncia de receita, geração de despesas com pessoal, da seguridade social e outras, dívidas consolidada e mobiliária, operações de crédito, inclusive por antecipação de receita, concessão de garantia e inscrição em Restos a Pagar. (Lei Complementar $n^{\circ} 101$, de 4 de maio de 2000.) 


\section{Quadro 4 - Legislação que regula as Transferências Voluntárias da União}

\begin{tabular}{|c|c|}
\hline Legislação sobre transferência voluntária & Assuntos \\
\hline Lei $n^{\circ} 1.493$, de 13 de dezembro de 1951. & $\begin{array}{l}\text { - Dispõe sobre o pagamento de auxílios e subvenções } \\
\text { concedidos em virtude de lei, decreto, tratado ou } \\
\text { convênio, para atender a ônus ou encargos assumidos } \\
\text { pela União para com instituições públicas, autárquicas } \\
\text { ou semi-estatais. }\end{array}$ \\
\hline Lei Federal no 4.320/64. & $\begin{array}{l}\text { - Estabelece normas gerais sobre orçamentos, possui } \\
\text { várias determinações importantes para a celebração e } \\
\text { a execução de convênios e contratos de repasse. }\end{array}$ \\
\hline Constituição Federal de 1988, artigo 241e a EC 19. & $\begin{array}{l}\text { - A redação estabelecida pela Emenda Constitucional } \\
\text { no }^{\circ} 19 / 98 \text { faz alusão aos convênios como instrumentos } \\
\text { destinados à transferência de encargos, serviços, } \\
\text { pessoal e bens essenciais à continuidade dos serviços } \\
\text { transferidos. }\end{array}$ \\
\hline Plano Plurianual (PPA). & $\begin{array}{l}\text { - A Constituição da República exige das esferas de } \\
\text { governo o planejamento no tocante às ações e } \\
\text { despesas. A gestão planejada passa pelo Plano } \\
\text { Plurianual, que deve conter a previsão das grandes } \\
\text { obras e os programas de duração continuada. }\end{array}$ \\
\hline Lei de Diretrizes Orçamentárias (LDO). & $\begin{array}{l}\text { - Estabelece as condições gerais para a realização de } \\
\text { transferências voluntárias e celebração de convênios. }\end{array}$ \\
\hline Lei Orçamentária Anual (LOA). & $\begin{array}{l}\text { - Prevê a receita e a autorização de despesas para } \\
\text { cada exercício fiscal, que corresponde ao ano civil. }\end{array}$ \\
\hline $\begin{array}{l}\text { Instrução Normativa STN N. }{ }^{\circ} 01 \text {, de } 15 \text { de janeiro de } \\
1997 .\end{array}$ & $\begin{array}{l}\text { - Trata da celebração (assinatura de termo de } \\
\text { convênio) e da execução de convênio de natureza } \\
\text { financeira, da execução descentralizada de Programa } \\
\text { de Trabalho de responsabilidade de órgão ou entidade } \\
\text { da Administração Pública Federal, direta ou indireta. }\end{array}$ \\
\hline Lei n. ${ }^{\circ}$ 9.452, de 20 de março de 1997. & $\begin{array}{l}\text { - Notificação da liberação de recursos federais às } \\
\text { Câmaras municipais, aos partidos políticos, aos } \\
\text { sindicatos de trabalhadores e às entidades } \\
\text { empresariais. }\end{array}$ \\
\hline Lei Complementar nº 101/2000, artigo 25. & $\begin{array}{l}\text { - Lei de Responsabilidade Fiscal (LRF): traz um } \\
\text { capítulo específico sobre as transferências voluntárias. } \\
\mathrm{O} \text { artigo } 25 \text { e } \delta \S \text { condiciona as transferências } \\
\text { voluntárias à existência de dotação específica, dentre } \\
\text { outros. }\end{array}$ \\
\hline $\begin{array}{l}\text { Decreto } 6.170 \text {, de } 25 \text { de julho de } 2007 . \\
\text { Alterações no Decreto: } \\
\checkmark \quad \text { Decreto } n^{\circ} 6.619 / 2008 \\
\text { Decreto } \text { n }^{\circ} 6.497 / 2008 \\
\checkmark \quad \text { Decreto } n^{\circ} 6.428 / 2008 \\
\checkmark \quad \text { Decreto } n^{\circ} 6.329 / 2007 \text { - Altera o art. } 19 . \\
\checkmark \quad \text { Decreto } n^{\circ} 8.180 \text {, de } 30 \text { de dezembro de } \\
2013 .\end{array}$ & $\begin{array}{l}\text { - Dispõe sobre as normas relativas às transferências } \\
\text { de recursos da União mediante convênios e contratos } \\
\text { de repasse. }\end{array}$ \\
\hline $\begin{array}{l}\text { Instrução Normativa TCU No } 56 \text {, de } 5 \text { de dezembro } \\
\text { de } 2007 \text {. }\end{array}$ & $\begin{array}{l}\text { - Instauração e organização de tomada de contas } \\
\text { especial. }\end{array}$ \\
\hline $\begin{array}{l}\text { Portaria Interministerial, } n^{\circ} 24 \text {, de } 19 \text { de fevereiro de } \\
2008 \text {. }\end{array}$ & $\begin{array}{l}\text { - Arquivamento dos processos de convênios ou } \\
\text { contratos de repasse. }\end{array}$ \\
\hline $\begin{array}{l}\text { Portaria Interministerial-MP/MF/CGU, } \mathrm{n}^{\circ} 127 \text {, de } 29 \text { de } \\
\text { maio de } 2008 \text {. } \\
\text { Alterações na Portaria: } \\
\quad \checkmark \text { Portaria Interministerial } \mathrm{n}^{\circ} \quad 23 \text {, de } 19 \text { de } \\
\quad \begin{array}{l}\text { Janeiro de } 2010 . \\
\checkmark \text { Portaria Interministerial } \mathrm{n}^{\circ} \quad 534 \text {, de } 30 \text { de } \\
\quad \text { dezembro de } 2009 .\end{array}\end{array}$ & $\begin{array}{l}\text { - Execução do Decreto } 6.170 \text { - estabelece normas } \\
\text { para as transferências de recursos da União mediante } \\
\text { convênios e contratos de repasse. }\end{array}$ \\
\hline
\end{tabular}




\begin{tabular}{|c|c|}
\hline 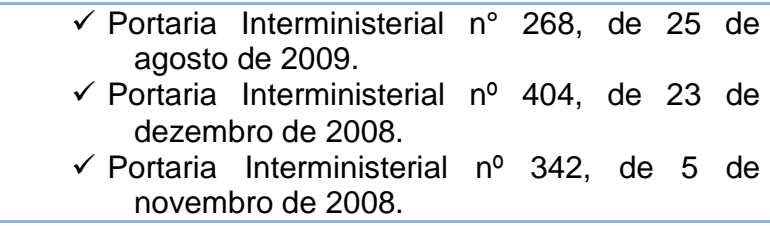 & \\
\hline $\begin{array}{l}\text { Portaria Interministerial, } n^{\circ} 165 \text {, de } 20 \text { de junho de } \\
2008 \text {. }\end{array}$ & - Instauração da Comissão Gestora do SICONV. \\
\hline $\begin{array}{l}\text { Portaria Interministerial } N^{0} 507 \text {, de } 24 \text { de novembro } \\
\text { de 2011. (MPOG - Min. Fazenda - CGU) }\end{array}$ & $\begin{array}{l}\text { - regula os convênios, os contratos de repasse e os } \\
\text { termos de cooperação celebrados pelos órgãos e } \\
\text { entidades da Administração Pública Federal com } \\
\text { órgãos ou entidades públicas ou privadas, sem fins } \\
\text { lucrativos, para a execução de programas, projetos e } \\
\text { atividades de interesse recíproco, que envolvam a } \\
\text { transferência de recursos financeiros oriundos do } \\
\text { Orçamento Fiscal e da Seguridade Social da União. }\end{array}$ \\
\hline $\begin{array}{l}\text { Lei } n^{\circ} 12.919, \text { de } 24 \text { de dezembro de } 2013 \text {, artigo. } 1^{\circ} \\
\text { inciso IV. }\end{array}$ & $\begin{array}{l}\text { - Trata das diretrizes para a elaboração e execução da } \\
\text { Lei Orçamentária para } 2014 \text {. }\end{array}$ \\
\hline Decreto $n^{\circ} 8.180$, de 30 de dezembro de 2013 . & $\begin{array}{l}\text { - Regulamenta os convênios, contratos de repasse e } \\
\text { termos de execução descentralizada celebrados pelos } \\
\text { órgãos e entidades da administração pública federal } \\
\text { com órgãos ou entidades públicas ou privadas sem } \\
\text { fins lucrativos, para a execução de programas, } \\
\text { projetos e atividades que envolvam a transferência de } \\
\text { recursos ou a descentralização de créditos oriundos } \\
\text { dos Orçamentos Fiscais e da Seguridade Social da } \\
\text { União. }\end{array}$ \\
\hline
\end{tabular}

Fonte: Elaboração da autora a partir da legislação consultada.

Essa forma de apoio descentralizado direcionado às instituições estaduais voltadas à promoção do desenvolvimento científico e tecnológico, trouxe outra dimensão aos programas do Governo Federal voltados para o apoio e o desenvolvimento regional em C\&T\&I. No CNPq, as parcerias formalizadas, que implicam na contrapartida de recursos financeiros por parte das FAP, fazem com que o esforço que antes era feito de forma unilateral pelo CNPq, passe, também, a contar com os recursos dos estados, no interesse conjunto da diminuição das desigualdades regionais no campo da C\&T\&l.

Para tanto, em reunião realizada em Salvador, nos dias 14 e 15 de junho de 2004, pelas entidades componentes do Fórum Nacional de Secretários Estaduais para Assuntos de Ciência e Tecnologia, pelo Fórum Nacional das Fundações de Amparo à Pesquisa e pelas FAP, foram propostas novas ações e critérios que foram adotados entre o MCTI e os estados para dinamizar os significativos avanços obtidos nessa relação, entre os estados e a União, com a efetivação dos convênios firmados em 2003, por meio do documento nominado Carta de Salvador (ANEXO A, p. 141).

A Carta de Salvador tem como pressuposto, além da continuidade e a ampliação das parcerias firmadas em 2003, a fixação de critérios diferenciados, por estado, adotando o 
estabelecimento de mecanismos de correção da realidade atual do estado, que deve ser entendida como ação afirmativa para a efetiva nacionalização do sistema de CT\&l.

A adoção desses critérios para contrapartidas (Quadro 5), leva-se em consideração o PIB, a base científica dos estados e busca, também, a necessária correção das desigualdades regionais existentes, na área C\&T\&I. O MCTI passou a adotar a Carta de Salvador a partir de 2004, para definir os critérios diferenciados de aporte de contrapartidas dos estados.

Quadro 5 - Critérios para contrapartidas estaduais

\begin{tabular}{|l|l|l|}
\hline \multicolumn{1}{|c|}{ Grupos } & \multicolumn{1}{|c|}{ Unidades da Federação } & \multicolumn{1}{c|}{ Critério } \\
\hline Grupo A & SP & $\begin{array}{l}\text { Contrapartida do Estado na proporção } \\
\text { de } 1 \times 1 \text { de aporte do MCT }\end{array}$ \\
\hline Grupo B & MG, RJ, RS & $\begin{array}{l}\text { Contrapartida do Estado na proporção } \\
\text { de } 1 \times 1,5 \text { de aporte do MCT }=: 0,5\end{array}$ \\
\hline Grupo C & $\begin{array}{l}\text { AM, PA, CE, PE, BA, PB, DF,, GO, GO, MT } \\
\text { PR, SC e ES }\end{array}$ & $\begin{array}{l}\text { Contrapartida do Estado na proporção } \\
\text { de } 1 \times 2 \text { de aporte do MCT = :2 }\end{array}$ \\
\hline Grupo D & AP, AC, RO, RR, TO, PI, MA, RN, SE e AL & $\begin{array}{l}\text { Contrapartida do Estado na proporção } \\
\text { de } 1 \times 3 \text { de aporte do MCT = : 3 }\end{array}$ \\
\hline
\end{tabular}

Fonte: Of. FÓRUM Nº 297 / 04, Salvador, 15 de junho de 2004.

No âmbito federal, tanto os termos de execução descentralizada quanto os convênios, mais usualmente, servem como meios para promover a descentralização de ações e da gestão de recursos públicos federal, podendo os recursos serem repassados a entes públicos ou privados, a fim de executar os objetivos compartilhados por ambas as partes.

Os recursos financeiros vão inicialmente da União (FNDCT) para a instituição que efetivará o repasse (no caso desta análise, o CNPq), como orçamento geral, a fim de ser utilizado, especificamente, em programa federal. Caberá ao órgão ou entidade interessada no recebimento e na utilização desses recursos firmarem acordo ou convênio com o CNPq, obedecidas as normas legais que regulamentam a transferência de recursos federais às instituições conveniadas.

Entretanto, essas normas são gerais, para todas as transferências voluntárias. Não há legislação regulamentando a transferência voluntária com os fins específicos para as atividades de pesquisa e desenvolvimento em ciência e tecnologia, cabendo aos gestores públicos fazer a devida adequação, para melhor atender as especificidades do setor. Alguns aspectos diferenciados e particulares da área de C\&T\&l, não contemplados em legislação 
específica, podem dificultar a melhor gestão do processo de concessão, execução, monitoramento, e avaliação dos recursos financeiros da União, descentralizados por meio das transferências voluntárias.

No caso do CNPq, os dois modos mais utilizados para a realização de parcerias são os Acordos de Cooperação Técnica - recém-nomeados como Termos de Execução Descentralizada -, e os convênios, distinguindo-se ambos quanto à forma de execução do objeto pelos pactuantes e pelo fato de os convênios receberem repasses financeiros.

O CNPq e a contraparte definem se o objeto do acordo de parceria será realizado por meio de acordo de cooperação técnica ou convênio. Quando houver somente a cooperação técnica, não há transferência de recursos financeiros; na modalidade convênio, dá-se a transferência voluntária de recursos da União.

O Quadro 6 apresenta os conceitos e as principais diferenças entre os termos utilizados na execução descentralizada de ciência e tecnologia, com vistas a efetivar a transferência voluntária da União para os Estados, Municípios e Distrito Federal. Os conceitos estão de acordo com o Decreto $n^{\circ}$ 6.170, de 25 de julho de 2007, alterado pelo Decreto $\mathrm{n}^{\circ} 8.180$, de 30 de dezembro de 2013. 


\section{Quadro 6 - Conceitos Abordados}

\begin{tabular}{|c|c|}
\hline $\begin{array}{l}\text { Convênio Acordo, ajuste ou qualquer outro } \\
\text { instrumento que discipline a transferência de recursos } \\
\text { financeiros de dotações consignadas nos Orçamentos } \\
\text { Fiscais e da Seguridade Social da União e tenha como } \\
\text { partícipe, de um lado, órgão ou entidade da } \\
\text { administração pública federal, direta ou indireta, e, de } \\
\text { outro lado, órgão ou entidade da administração pública } \\
\text { estadual, distrital ou municipal, direta ou indireta, ou } \\
\text { ainda, entidades privadas sem fins lucrativos, visando } \\
\text { a execução de programa de governo, na realização de } \\
\text { projeto, atividade, serviço, aquisição de bens ou } \\
\text { evento de interesse recíproco. }\end{array}$ & $\begin{array}{l}\text { Transferência Voluntária } \\
\text { Entrega de recursos correntes ou de capital a outro } \\
\text { ente da Federação, a título de cooperação, auxílio ou } \\
\text { assistência financeira, que não decorra de } \\
\text { determinação constitucional, legal ou os destinados ao } \\
\text { Sistema Único de Saúde. De acordo com a Lei de } \\
\text { responsabilidade fiscal é vedada a realização de } \\
\text { transferências voluntárias para o ente que não } \\
\text { observe os dispositivos referentes aos impostos. }\end{array}$ \\
\hline $\begin{array}{l}\text { Interveniente } \\
\text { Órgão da administração pública direta e indireta de } \\
\text { qualquer esfera de governo, ou entidade privada que } \\
\text { participa do convênio para manifestar consentimento } \\
\text { ou assumir obrigações em nome próprio. }\end{array}$ & $\begin{array}{l}\text { Contrato de Repasse } \\
\text { Instrumento administrativo, de interesse recíproco, por } \\
\text { meio do qual a transferência dos recursos financeiros } \\
\text { se processa por intermédio de instituição ou agente } \\
\text { financeiro público federal, que atua como mandatário } \\
\text { da União. }\end{array}$ \\
\hline $\begin{array}{l}\text { Concedente } \\
\text { Órgão da administração pública federal direta ou } \\
\text { indireta, responsável pela transferência dos recursos } \\
\text { financeiros ou pela descentralização dos créditos } \\
\text { orçamentários destinados à execução do objeto do } \\
\text { convênio. }\end{array}$ & $\begin{array}{l}\text { Convenente } \\
\text { Órgão ou entidade da administração pública direta e } \\
\text { indireta, de qualquer esfera de governo, bem como } \\
\text { entidade privada sem fins lucrativos, com o qual a } \\
\text { administração federal pactua a execução de } \\
\text { programa, projeto/atividade ou evento mediante a } \\
\text { celebração de convênio. }\end{array}$ \\
\hline $\begin{array}{l}\text { Contratante } \\
\text { Órgão ou entidade da administração pública direta e } \\
\text { indireta da União que pactua a execução de programa, } \\
\text { projeto, atividade ou evento, por intermédio de } \\
\text { instituição financeira federal (mandatária) mediante a } \\
\text { celebração de contrato de repasse. }\end{array}$ & $\begin{array}{l}\text { Contratado } \\
\text { Órgão ou entidade da administração pública direta e } \\
\text { indireta, de qualquer esfera de governo, bem como } \\
\text { entidade privada sem fins lucrativos, com a qual a } \\
\text { administração federal pactua a execução de contrato } \\
\text { de repasse. }\end{array}$ \\
\hline $\begin{array}{l}\text { Acordo de Cooperacão Técnica } \\
\text { Instrumento por meio do qual é ajustado o Acordo de } \\
\text { Cooperação Técnica, não havendo a transferência de } \\
\text { recursos financeiros de órgão da Administração } \\
\text { Pública Federal direta, autarquia, fundação pública, ou } \\
\text { empresa estatal dependente, para outro órgão ou } \\
\text { entidade federal da mesma natureza. }\end{array}$ & $\begin{array}{l}\text { Termo de Execucão Descentralizada } \\
\text { Instrumento que ajusta a descentralização de crédito } \\
\text { entre órgãos e/ou entidades integrantes dos } \\
\text { Orçamentos Fiscal e da Seguridade Social da União, } \\
\text { para execução de ações de interesse da unidade } \\
\text { orçamentária descentralizadora e consecução do } \\
\text { objeto previsto no programa de trabalho, respeitada } \\
\text { fielmente a classificação funcional programática. }\end{array}$ \\
\hline
\end{tabular}

Fonte: Elaborado pela autora a partir da legislação consultada. Decreto $\mathrm{n}^{0}$ 6.170, de 25 de julho de 2007; Portaria Interministerial $n^{\circ} 127$, de 29 de maio de 2008, Portaria Interministerial n. ${ }^{\circ}$ 507/2011.

Portanto, ratifica-se que as políticas de Estado regulam as formas de vínculos que podem existir entre uma entidade administrativa e terceiros, no tocante à disciplina da transferência voluntária de recursos da União.

Por sua vez, as instituições e agências congêneres ao CNPq, possuem autonomia para fazer os seus ritos internos, de modo a melhor executar a sua missão, desde que não 
se sobreponha a nenhuma legislação federal que trate do assunto. Nesse sentido, o CNPq tem buscado propor inovações no que tange às relações institucionais com os diversos atores envolvidos na execução de sua missão, em primeiro lugar e, em segundo, no que se refere às partes envolvidas nas atividades da política de ciência e tecnologia, disciplinando os normativos que lhe cabem ou mesmo oferecendo contribuição na formulação de políticas.

No caso das parcerias entre o CNPq e as FAP, os recursos poderão ser oriundos, também das FAP, a partir de captação de recursos de origem da firmatura de outros convênios com instituições públicas ou privadas, ou até mesmo internacionais e do CNPq, bem como de outras fontes que se interessem em integrar uma parceria específica para a pesquisa e desenvolvimento. As aplicações dos recursos têm como princípio o de atender aos objetivos prioritários para os estados, permitindo uma melhor adequação à demanda local.

Essas parcerias entre o CNPq e as FAP serão abordadas com mais detalhes no Capítulo 3. 


\section{AS PARCERIAS ENTRE O CNPq E AS FUNDAÇÕES DE AMPARO À PESQUISA (FAP)}

\subsection{A EVOLUÇÃO DAS PARCERIAS}

O CNPq já formalizou parcerias com todos os estados e em todos há programas ou projetos em alguma fase de execução dos recursos oriundos das transferências voluntárias da União. As transferências voluntárias da União às FAP acontecem mediante a assinatura de convênios ou com registros legais para esse fim. A contraparte - FAP - deve possuir infraestrutura necessária e compatível com a proposta apresentada para a recepção dos recursos financeiros da União, além de oferecer contrapartida financeira para a execução nos percentuais previstos na Carta de Salvador (tópico tratado no capítulo 2) estipulados para cada estado e quando for o caso.

Com o objetivo de incrementar o fomento à pesquisa, os recursos disponibilizados pela União têm crescido nos últimos anos, principalmente em virtude do aporte financeiro dado pelos Fundos Setoriais e das parcerias com as Fundações Estaduais de Amparo à Pesquisa.

A maioria das FAP se desenvolveu bastante e tornou-se um eixo forte para o desenvolvimento da P\&D nos estados, em virtude de as FAP terem sido estimuladas para o trabalho conjunto nos estados e pela incorporação de alguns dos principais programas do governo federal, principalmente do CNPq, como o Programa de Apoio a Núcleos de Excelência (Pronex), incluindo suas redes Dengue e Malária; o Programa de Primeiros Projetos (PPP), destinado a jovens pesquisadores; o Programa de Apoio a Núcleos Emergentes de Pesquisa (Pronem); o Programa de Bolsas de Iniciação Científica Júnior (Pibic-Jr); o Programa de Bolsas de Desenvolvimento Científico Regional (DCR) e o Programa de Recursos Humanos em Áreas Estratégicas (Rhae-estados).

O CNPq, como parte das iniciativas para a descentralização da ciência e tecnologia, a partir de 2003, por meio de seu Conselho Deliberativo, firmou parcerias com as instituições estaduais responsáveis pela área de ciência e tecnologia, as - Fundações Estaduais de Amparo à Pesquisa (FAP) ou as Secretarias de Estado de Ciência e Tecnologia, para fortalecer o movimento de articulação conjunta entre o CNPq e as FAP.

Essas parcerias têm como objetivo a descentralização dos recursos e da gestão da ciência e tecnologia e a ampliação e consolidação da capacidade científica e tecnológica nos estados. 
Para o Professor Erney Felício Plessmann de Camargo, que presidiu o CNPq no período de 13 de fevereiro de 2003 a 21 de junho de 2007, "um dos mais importantes trabalhos criados em sua gestão foram as parcerias com as Fundações de Amparo à Pesquisas Estaduais, iniciadas em torno do Programa PRONEX, que estava sem recursos, e que conseguiu se sustentar por meio do copatrocínio de algumas das FAP". Afirma, também, que os programas acima mencionados foram adotados pela quase totalidade das FAP, trazendo-as para participar do cenário Nacional de Ciência e Tecnologia. Lembra, entretanto, da singular importância da atenção dada pelo CNPq, em parceria com as FAP, ao Programa de Desenvolvimento Científico Regional, que aportou recursos significativos às regiões Norte, Nordeste e Centro-Oeste, sem nenhum prejuízo aos recursos destinados às regiões Sul e Sudeste do país. (CNPq, 2011, p. 7)

O Anexo B (pág. 144) apresenta as bolsas em curso e os projetos em andamento, que ilustram a dimensão dessas parcerias estaduais. Houve uma ampliação substancial, de 2010 para 2013/14, do número de convênios firmados com as Fundações Estaduais de Amparo à Pesquisa, para apoio a projetos e ampliação das ações de fomento à inovação, com a participação cada vez maior do setor empresarial. (CNPq, 2014)

As FAP recebem a cada ano mais recursos financeiros, como demonstrado no Gráfico 9, e se tornam agências mais fortes, podendo ampliar o seu campo de ação nos estados. Em 2006, o orçamento computado pelo conjunto das FAP foi de aproximadamente $\mathrm{R} \$ 1,12$ milhão, e, em 2011, ocorreu o auge dos recursos recebidos, da ordem de $R$ \$ 2,24 milhões.

Os recursos definidos e referendados anualmente pela Lei de Diretrizes Orçamentárias (LDO), mostrados nos Gráficos 7 e 8 , para transferência às FAP, com a finalidade de utilização em ciência e tecnologia, sofreram um aumento gradativo, sendo o ano de 2010, o de maior previsão de repasse, seguido de queda nos anos de 2011 e 2012. 
Gráfico 7: Recursos Constitucionais gerais destinados à CT\&।

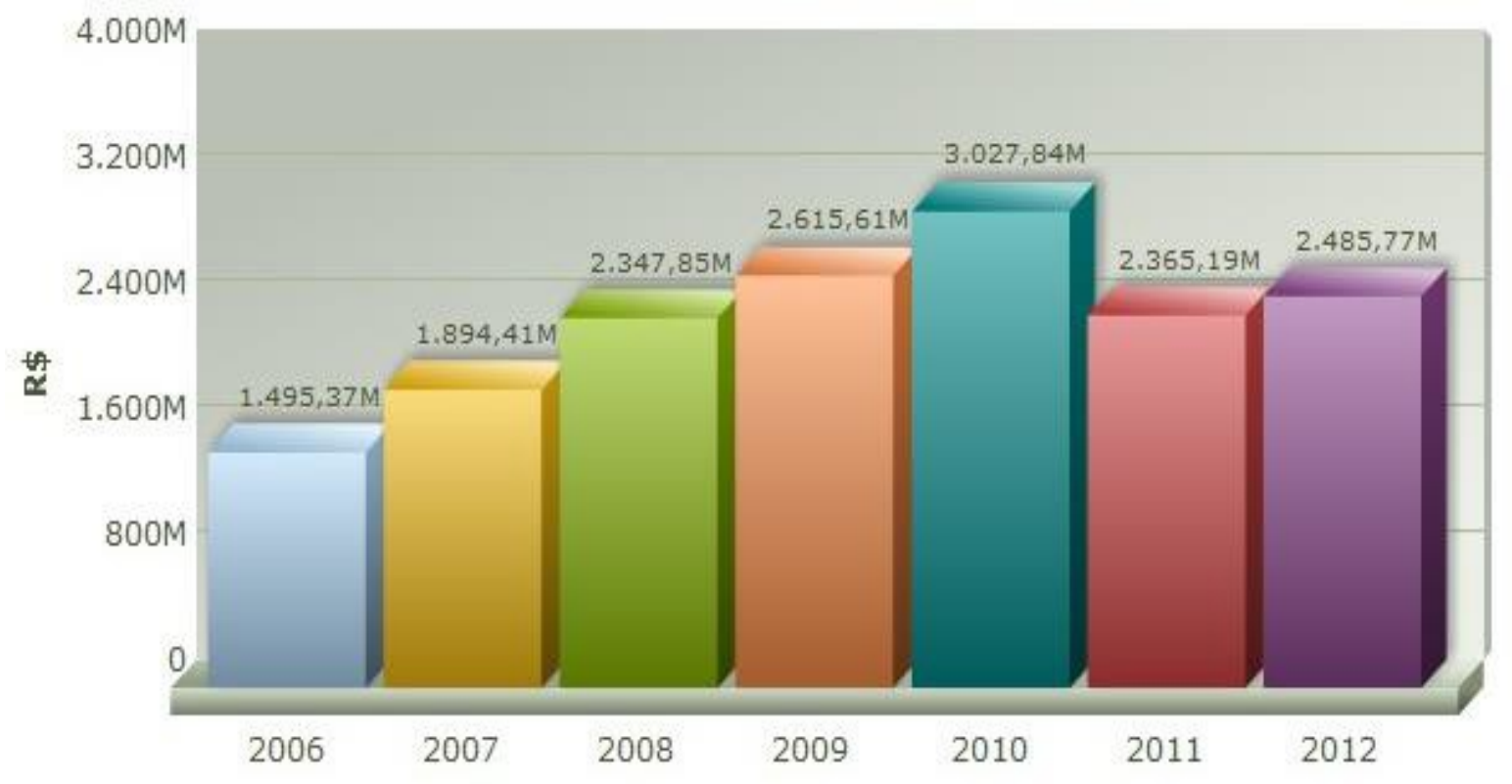

Fonte: SiFAPs, Sistema de Indicadores das FAP.

No Gráfico 8 é possível analisar o aumento dos recursos efetivamente recebidos pelas FAP e verificar que houve um aumento significativo do orçamento gerido pelo conjunto das FAP, no período de 2006 a 2012, apesar de se constatar uma discrepância entre o valor constitucional previsto no Gráfico 6, o orçamento reservado, conforme o Gráfico 7 e o de efetivo repasse, conforme o Gráfico 8. Os dados evidenciam, por exemplo, uma diferença para menor de $73,84 \%$, entre o valor previsto constitucionalmente (Gráfico 6) e o valor efetivamente recebido pelas FAP para aplicação em C\&T (Gráfico 8), no ano de 2012. 
Gráfico 8: Recursos orçamentários previstos para as FAP na LDO

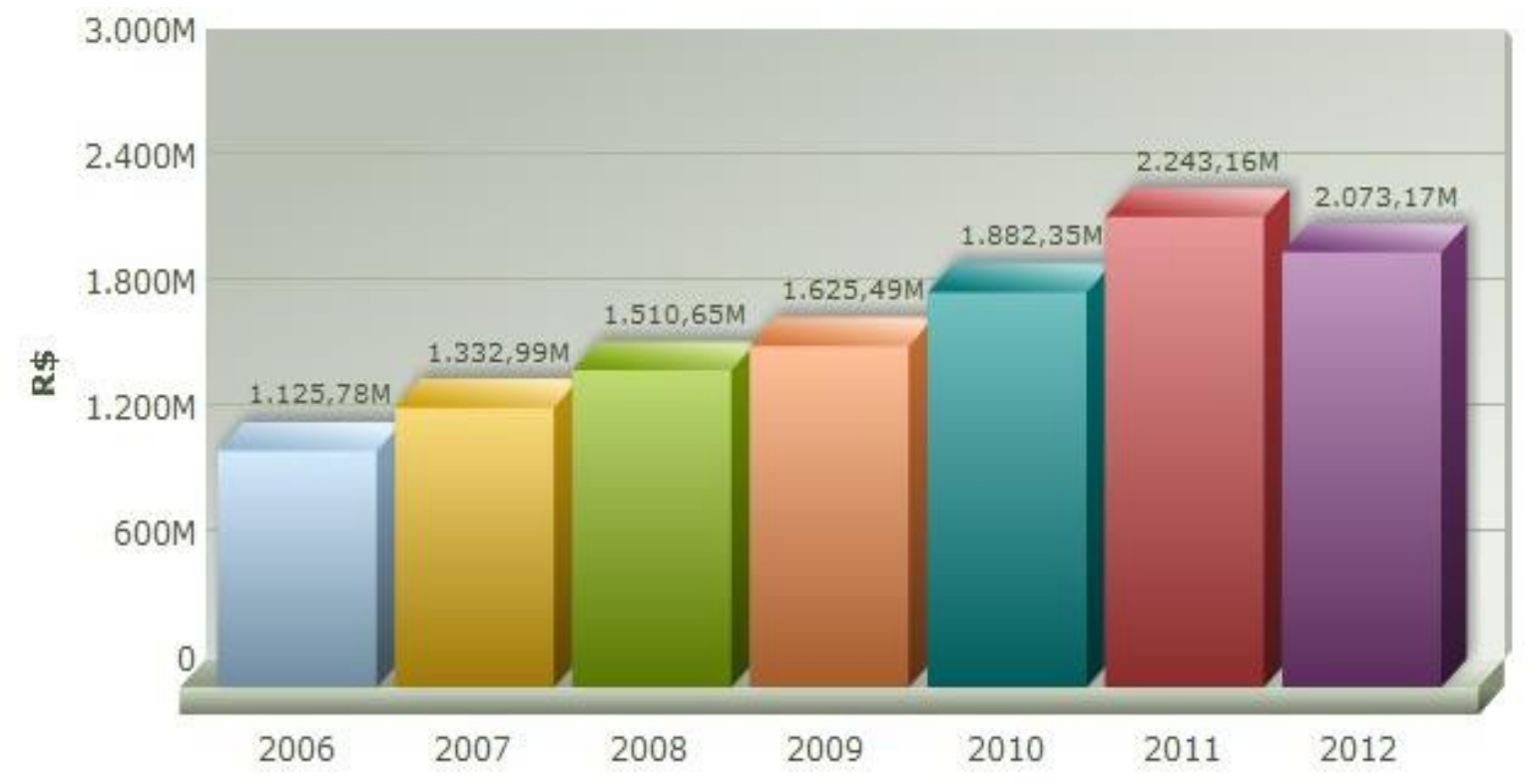

Fonte: SiFAPs, Sistema de Indicadores das FAP

O Gráfico 9 apresenta o somatório de todos os recursos declarados recebidos, efetivamente, pelo conjunto das FAP no período de 2006 a 2012. Observa-se uma função ascendente dos recursos disponibilizados às FAP para a execução das atividades descentralizadas de ciência e tecnologia nos estados. O percentual de aumento entre o ano de 2006 e o de 2012 foi de 184,15\%, gerando um aumento dos recursos da ordem de R\$ 947,39 ( novecentos e quarenta e sete milhões) reais. 
Gráfico 9: Recursos financeiros descentralizados às FAP

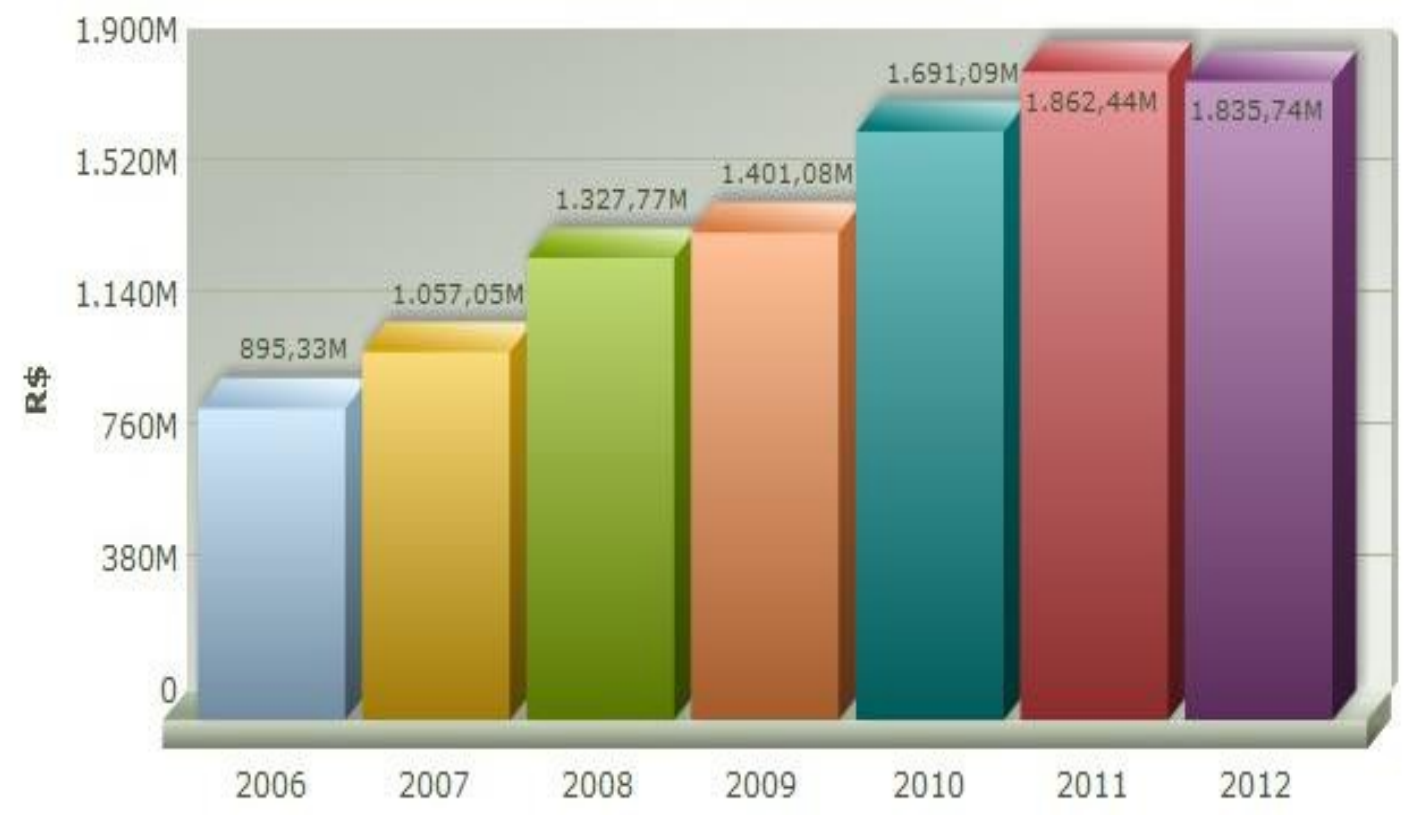

Fonte: SiFAPs, Sistema de Indicadores das FAP.

O Quadro 7 representa o conjunto de FAP que o CNPq mantém convênios ou acordos para a descentralização de recursos por meio das transferências voluntárias, individualizadas por programas em parceria com cada FAP e o número de Bolsas por Convênio; número de Bolsas por Acordo; Cota de bolsas; Projetos homologados e Empresas Contratadas no Programa RHAE-estado, apresentando, ainda, o cômputo dos valores de participação do CNPq, FNDCT e contrapartida das FAP, no período de 2010 a 2014. 
Quadro 7: Composição dos recursos descentralizados para as FAP

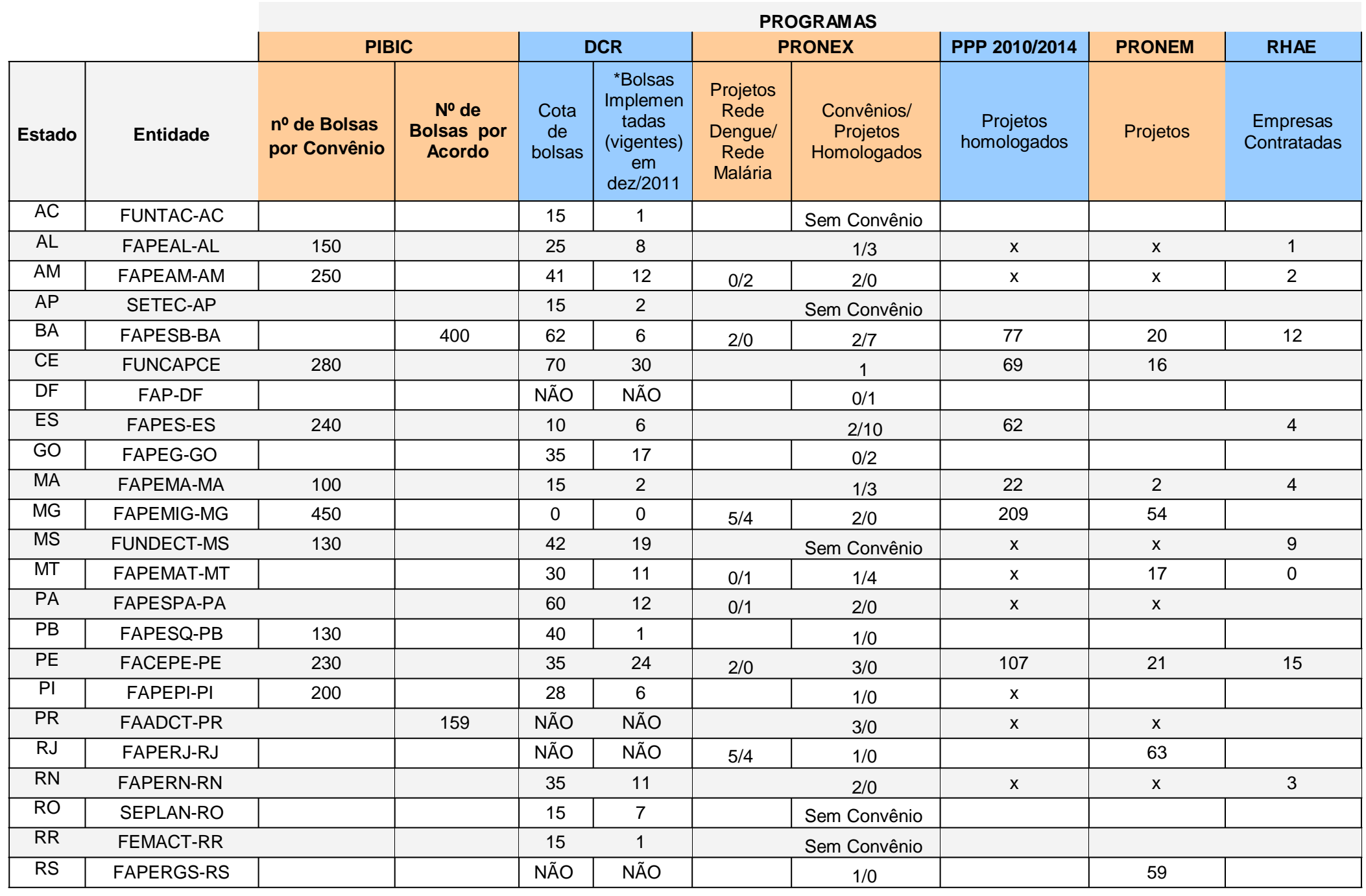




\begin{tabular}{|c|c|c|c|c|c|c|c|c|c|c|c|}
\hline SC & FAPESC-SC & & 140 & NÃO & NÃO & & $1 / 18$ & $x$ & $x$ & & \\
\hline SE & FAPITEC-SE & & 160 & 30 & 22 & & $1 / 0$ & 90 & $x$ & 2 & \\
\hline $\mathrm{SP}$ & FAPESP-SP & & & NÃO & NÃO & $1 / 4$ & $2 / 8$ & $x$ & & & \\
\hline TO & SEPLAN-TO & & & 15 & 0 & & $1 / 5$ & & & & \\
\hline & TOTAL & 2160 & 859 & 633 & 198 & $15 / 16$ & $34 / 58$ & 636 & 252 & 52 & TOTAL GERAL \\
\hline & $\begin{array}{c}\text { TOTAL } \\
\text { RECURSOS }\end{array}$ & $10.368 .000,00$ & $3.092 .400,00$ & & & & $323.474 .000,00$ & $60.975 .000,00$ & $91.000 .000,00$ & $16.298 .659,76$ & $505.208 .059,76$ \\
\hline & $\begin{array}{l}\text { RECURSOS DO } \\
\text { CNPq }\end{array}$ & & & & & & $203.401 .000,00$ & & & $10.865 .483,23$ & $214.266 .483,23$ \\
\hline & FNDCT & & & & & & & $37.600 .000,00$ & $58.700 .000,00$ & & $96.300 .000,00$ \\
\hline & $\begin{array}{c}\text { CONTRAPARTIDA } \\
\text { FAP }\end{array}$ & & & & & & & $23.300 .000,00$ & $32.300 .000,00$ & $5.433 .175,90$ & $61.033 .175,90$ \\
\hline
\end{tabular}

Fonte: CGNAC/CNPq, 2014. 


\subsection{DEFINIÇÃO E PADRONIZAÇÃO DE ROTINAS PARA AS TRANSFERÊNCIAS VOLUNTÁRIAS NO CNPq}

Os esforços empreendidos pelo Estado brasileiro para a efetivação das transferências voluntárias às FAP não compreendem somente o incremento financeiro, mas, também, um novo arranjo institucional. Todas as instâncias partícipes na execução da política de descentralização de programas de Estado estão presentes no esforço conjunto das agências públicas federais, em busca de um processo de adequação de modelo ou uniformização de ações e procedimentos que visam a eficiência e a eficácia na realização da pesquisa e do desenvolvimento regional. São atividades relativamente novas no contexto da ciência e tecnologia brasileiras e comportam ainda muitas melhorias em sua forma de operacionalização, pois ainda estão se construindo.

Esse avanço de entendimentos foi possibilitado, em parte, pela promulgação da Constituição Federativa de 1988. Os recursos e mecanismos destinados à aplicação em P\&D se deveram a um conjunto de políticas públicas implementadas para buscar reduzir ou minorar as desigualdades regionais, quer seja no âmbito social, econômico, ambiental e principalmente tecnológico, onde se observa ser consensual a importância do fomento em ciência e tecnologia, pesquisa e desenvolvimento para o desenvolvimento das nações.

A busca pelo aperfeiçoamento da legislação brasileira para a área de ciência, tecnologia e inovação é uma demanda que permeia discussões entre várias entidades ligadas à área, tanto em nível federal, como estadual ou municipal. Tanto que esse assunto tem sido a base para várias propostas no interesse de uniformizar ações e procedimentos do fomento nacional destinado ao desenvolvimento da ciência e tecnologia brasileira. Um exemplo prático é o resultado da $4^{\text {a }}$ Conferência Nacional de C\&T\&I (CNCTI), que, após reiteradas discussões, transformou-se em recomendações que apontam, sobretudo, para a necessidade de se fortalecer a interlocução e a interação com os atores envolvidos. Teve como resultado as sugestões compiladas no Livro Azul, publicação que traz consolidadas as propostas e os desafios para a política nacional de C\&T\&l.

Diante da quantidade e variedade de instrumentos governamentais, bem como da conflitante e, por vezes, ininteligível diversidade de regras que disciplinam procedimentos do fomento à C\&T\&l, o governo federal e instâncias representativas das FAP, buscam maneiras para simplificar os métodos, regras e uniformizar os procedimentos de execução da política de C\&T\&I. Para tanto, são realizadas reuniões, conferências, seminários com o intuito de discutir o tema e propor melhorias. 
O arcabouço legal vigente, muitas vezes, torna-se um empecilho tanto para os gestores do governo federal como para os pesquisadores da área de C\&T, quando se defrontam com situações que deveriam ser simples, como uma prestação de contas por recursos recebidos em forma de auxílio para a pesquisa e desenvolvimento.

Nesse sentido é que foram desenvolvidas ações visando à possibilidade de criação de diversificados mecanismos de articulação institucional e de comunicação entre os principais atores envolvidos na execução e na formação de arranjos que pudessem fortalecer e sistematizar a política de C\&T\&l.

No caso específico do CNPq, por orientação do Tribunal de Contas da União (TCU), iniciou-se a reformulação geral das instâncias que constituem a sua estrutura de governança. Essa reestruturação foi necessária tendo em vista que o CNPq possuía duas estruturas, uma formal e outra informal, sendo que esta última é a que atendia ao funcionamento do CNPq como um todo e mais especificamente, atendia também às atividades atinentes à gestão das parcerias institucionais.

A Coordenação Geral de Cooperação Nacional (CGNAC), subordinada à Diretoria de Cooperação Institucional (DCOI), tem como atribuição promover e participar das negociações de acordos e convênios de cooperação nos âmbitos federal, estadual e municipal, bem como coordenar, acompanhar e avaliar as atividades dos programas de cooperação nacional do CNPq. Para o cumprimento de sua missão, estão sob a sua orientação três coordenações técnicas: a Coordenação de Parcerias Estaduais (COPES); a Coordenação de Programas Acadêmicos (COPAD) e a Coordenação de Apoio a Parcerias Institucionais (COAPI).

Além da CGNAC, outra Coordenação Geral do CNPq também operacionaliza as atividades de transferência voluntária por meio de convênios, que é a Coordenação Geral do Programa de Pesquisa em Saúde (CGSAU), vinculada à Diretoria de Ciências Agrárias, Biológicas e da Saúde (DABS). É a CGSAU quem executa as atividades para a transferência voluntária em sua Coordenação do Programa de Pesquisa em Saúde (COSAU). A COSAU executa o Programa PPSUS em parceria com o Ministério da Saúde e as suas ações são basicamente similares às ações executadas pela CGNAC, na execução de convênios.

Importante esclarecer que desde a sua criação, em 2004, o Programa PPSUS é executado na Coordenação de Saúde. Nessa época ainda não havia a CGNAC. Entretanto, de acordo com o Art. 14 do Decreto $n^{\circ}$ 7.899, de 4 de fevereiro de 2013, que trata da 
estrutura interna do CNPq, onde subordina a CGSAU à DABS, não possui competência legal, dentro da estrutura do CNPq, para a firmatura e execução de convênios, à CGSAU estariam reservadas as atribuições estritamente técnicas, distantes de gestão, fiscalização de convênios. Por sua vez, o referido Decreto apresenta a CGNAC como área técnica competente para gerir todos os programas de cooperação nacional no âmbito do CNPq e realizar a execução de convênios, de acordo com o art. 14 do Decreto 7.899/2013

“Art. 14. À Diretoria de Cooperação Institucional compete:

I - promover e participar das negociações de acordos e convênios federais, estaduais, distritais ou municipais de cooperação nacional de caráter técnico-científico; e (destaque da autora)

II - promover e participar das negociações de acordos e convênios internacionais de cooperação técnico-científica e intercâmbio, no âmbito das ações e dos programas de fomento do $\mathrm{CNPq}$, em articulação com os Ministérios da Ciência, Tecnologia e Inovação, das Relações Exteriores e outros órgãos governamentais."

As atribuições da CGNAC, também, são reguladas pela Resolução Normativa (RN) 015/2007, onde diz ser competente para:

[...] promover e participar das negociações de acordos e convênios federais, estaduais, municipais ou distritais, de cooperação nacional de caráter técnico-científico, bem como coordenar, acompanhar e avaliar as atividades de cooperação técnico-científica, no âmbito dos programas cooperação nacional do CNPq."demonstrando mais uma vez a inviabilidade de coexirtir outra Coordenação Técnica com as mesmas atribuições, entretanto, sem as mesmas delegações competentes para a formalização e execução de convênios.

Quanto à efetivação financeira das transferências é realizada por meio da Coordenação de Gestão Orçamentária e Financeira (COFIN), responsável direta pela implementação das ações finalísticas de convênio.

As coordenações técnicas do CNPq envolvidas com as parcerias e repasses de recursos às FAP propuseram realizar, a partir do ano de 2012, um Pano Anual de Fiscalização, no qual foram inseridas a formalização e a fiscalização dos repasses para as FAP. Até então, ações de acompanhamento não haviam sido realizadas, mesmo fazendo parte do rol de medidas a serem cumpridas, previstas em legislação.

Esse plano foi implementado no ano de 2012 e teve a sua continuidade inserida nos planos de acompanhamento dos anos de 2013 e 2014. A CGNAC continua a fazer o acompanhamento e monitoramento conjunto as outras áreas técnicas, utilizando-se de planejamento anual. 
Essas coordenações realizam visitas técnicas sistemáticas de monitoramento às FAP para realizar o acompanhamento e orientar a execução dos convénios. A escolha das FAP a serem visitadas ocorre sob a forma de amostragem e incide também sobre aquelas que recebem maior volume de recursos. Essas áreas do CNPq realizam, no SICONV, um prévio levantamento dos processos a serem acompanhados/auditados, visando encontrar os desacordos legais ou administrativos, por ocasião de auditorias no SICONV. Essas FAP são definidas como potenciais para receberem as visitas do CNPq. Os desacordos observados são pontuados e indicadas as formas de correção de rumos, mediante Relatório de Visita Técnica, que são enviados às FAP, posteriormente, para providências.

Em 02 de maio de 2003, a Procuradoria Federal (PF) no CNPq fez publicar a Orientação Jurídica $n^{\circ}$ 001/2003, referente à celebração de convênios e instrumentos similares para a formalização do Processo Administrativo, a apreciação técnica e a avaliação da conveniência e oportunidade de uso desses instrumentos, observado o que disciplinam os arts. $6^{\circ}$ e $7^{\circ}$ da IN/STN no 01/97.

As orientações propostas por essa Procuradoria obedecem a dispositivos constantes de instrumentos legais que regulam os procedimentos de firmatura, execução, monitoramento e avaliação dos processos, levando-se em consideração as orientações normativas dos órgãos de controle interno e externos.

Vale lembrar que o CNPq já possuía norma interna, desde 1983, para regular a celebração de convênios. A Resolução Normativa (RN) 013/83 vigorou até 2007 e tinha o propósito claro de estabelecer condições gerais para a celebração de convênios em que houvesse a participação financeira dos convenentes. Disciplinava, também, tal normativa os direitos de Propriedade Intelectual dos autores; a firmatura; a execução do convênio; a prestação de contas, em que era exigida a apresentação da conciliação bancária, individualizada, dos saldos financeiros dos convênios com o CNPq e do saldo global dos convênios com outras instituições. Destacava a importância de se indicar as situações financeiras pendentes, identificando os convênios envolvidos nessas pendências.

Para a prestação de contas, a referida normativa exigia a apresentação dos relatórios: de execução financeira da parcela para efeito de recebimento da parcela subsequente; de execução técnica (de acordo com o Plano de Trabalho apresentado no ato da firmatura do convênio) e relatório final, de execução financeira e técnica, com prazo de apresentação de até 30 (trinta) dias contados do término de vigência do convênio. O responsável pelo monitoramento do convênio era o convenente incumbido da execução do convénio, que 
poderia designar prepostos para o acompanhamento da execução da avença. Já naquela época, em 1983, havia uma normatização interna no CNPq determinando os procedimentos a serem seguidos pelos partícipes, de forma bastante detalhada. Portanto, pode-se até considerá-la uma norma bastante eficaz e moderna.

Como já mencionado, instâncias de negociação foram criadas para mediar as negociações entre as instituições federais e as agências estaduais - FAP -, como o Conselho Nacional de Secretários para Assuntos de C\&T\&l (CONSECTI), que é uma entidade privada, sem fins lucrativos, fundada em $2005 \mathrm{com}$ a finalidade de representar as Secretarias de Ciência, Tecnologia e Inovação ou órgãos congêneres, nos Estados e no Distrito Federal. O CONSECTI tem por missão coordenar e articular os interesses comuns das Secretarias Estaduais de C\&T\&l e contribuir para o aperfeiçoamento da Política Nacional de Ciência, Tecnologia e Inovação, entre outros. (CONSECTI, 2013)

Foi também criado o Conselho das Fundações Estaduais de Amparo à Pesquisa (CONFAP), que é uma organização sem fins lucrativos e que tem por objetivo melhor articular os interesses das agências estaduais de fomento à pesquisa. Criado oficialmente em 2007. O CONFAP é o órgão negociador (pactuador) para a definição de valores a serem comprometidos pelas FAP junto ao CNPq e deste para com as FAP. (CONFAP, 2013) 


\subsubsection{Mecanismos e Processos Decisórios para as Transferências Voluntárias}

A negociação com vistas à transferência voluntária (TV) de recursos da União passa por discussões e acordos prévios. Nesse sentido, além das instituições federais, está envolvido o CONFAP, que traz informações e definições dos estados acerca das prioridades que foram definidas para o desenvolvimento local. Essa interlocução pode ser benéfica, porque contribui para melhorar a comunicação e negociação entre os diversos atores integrantes do sistema de C\&T\&l. O CONFAP tem a autorização para representar os interesses institucionais dos estados, por meio de seus membros indicados.

Quem faz essa interface pela definição de prioridades locais/regionais e para a definição de recursos a serem alocados às FAP são: os próprios presidentes das FAP, as Secretarias Estaduais de C\&T\&I, o CONFAP, representantes de universidades locais e também representantes do $\mathrm{MCTI}$. Pelo lado do CNPq, tem-se a sua Diretoria Executiva, Conselho Deliberativo e o seu Presidente.

\subsection{2 Órgãos de Controle}

Controle é uma forma de manter o equilíbrio na relação existente entre Estado e Sociedade, fazendo surgir daquele as funções que lhe são próprias, exercidas por meio dos seus órgãos, sejam estes ligados ao Executivo, Legislativo ou Judiciário. A Constituição Federal de 1988, a doutrina e a tradição republicanas preveem diversas instâncias de Controle Público, entre as quais se destacam os controles externo e interno. (TCU, 2014)

\subsubsection{Controle Externo ${ }^{19}$}

O controle externo está previsto nos artigos 70, 73 e 75 da Constituição Federal de 1988 e tem como titular originário o Poder Legislativo. Trata-se do controle sobre a totalidade da administração pública, exercido pelos que representam, por delegação, a sociedade politicamente organizada.

A execução dos mecanismos competentes para a implementação de convênios e outras formas de transferência voluntária da União tem possibilitado grande aprendizado por parte dos técnicos do CNPq. Verificou-se que na execução dessas parcerias com as FAP

\footnotetext{
${ }^{19} \mathrm{O}$ controle externo é definido "como a faculdade de vigilância, orientação e correção que um Poder, órgão ou autoridade exerce sobre a conduta funcional de outro". (HELY LOPES MEIRELES, Direito Administrativo Brasileiro, Malheiros, SP, 1993, p. 568)
} 
acontecem, por vezes, algumas dificuldades, principalmente na fase inicial da implementação de convênios, isso por desconhecimento ou falta de preparo técnico para a operacionalização dos instrumentos legais. Chama-se a atenção para o fato de que não há legislação específica para atender, plenamente, à execução de convênios na área de ciência e tecnologia, o que favorece conflitos de interpretação, quando se depara com um volume grande de leis, mas que não são específicas para reger a matéria, devendo para isso serem feitas adaptações que atendam às especificidades de C\&T\&l.

A cobrança por parte dos órgãos de controle passa pela orientação sobre a forma correta de proceder na execução das transferências voluntárias, em atendimento à legislação vigente, para que se evite retrabalho ou processos de tomada de contas especial que resultem na devolução dos recursos recebidos pela FAP ou pelo pesquisador, em virtude do não cumprimento da legislação pertinente.

Ao Tribunal de Contas da União (TCU), órgão de controle externo, regido pela sua Lei Orgânica $n^{\circ}$ 8.443, de 16 de julho de 1992, e nos termos da Constituição Federal, compete, entre outras atribuições, o estipulado em seu Capítulo I,

Art. $1^{\circ} \mathrm{I}$ - julgar as contas dos administradores e demais responsáveis por dinheiros, bens e valores públicos das unidades dos poderes da União e das entidades da administração indireta, incluídas as fundações e sociedades instituídas e mantidas pelo poder público federal, e as contas daqueles que derem causa a perda, extravio ou outra irregularidade de que resulte dano ao Erário.

A Secretaria Federal de Controle Interno (SFC) exerce as atividades de órgão central do sistema de controle interno do Poder Executivo Federal. Nesta condição, fiscaliza e avalia a execução de programas de governo, inclusive ações descentralizadas a entes públicos e privados, realizadas com recursos oriundos dos orçamentos da União; realiza auditorias e avalia os resultados da gestão dos administradores públicos federais; apura denúncias e representações; exerce o controle das operações de crédito; e, também, executa atividades de apoio ao controle externo. 


\subsubsection{Controles Internos ${ }^{20}$}

O controle interno está previsto nos artigos 70, in fine, e 74, da Carta Magna de 1988. Sua atuação tem por objetivo garantir que os níveis tático e operacional sigam a estratégia traçada e cumpram as decisões tomadas pelos administradores, observados os preceitos e limites impostos pela legislação. É efetivado por um órgão administrativo formalizado ou não no organograma das instituições.

As competências da Controladoria Geral da União (CGU) foram definidas pela Lei $n^{\circ}$ 10.683, de 28 de maio de 2003, e pelo Decreto no 8.109, de 17 de setembro de 2013.

A CGU também deve exercer, como órgão central, a supervisão técnica dos órgãos que compõem o Sistema Federal de Controle Interno e o Sistema de Correição e das unidades de ouvidoria do Poder Executivo Federal, prestando a orientação normativa necessária.

As competências da Auditoria Interna do CNPq foram estabelecidas inicialmente, e em caráter provisório, na Resolução Normativa (RN) 027/1990. Embora tenha sido editada provisoriamente, até que se concluísse a atualização do Manual de Organização do CNPq, está em pleno vigor. Em sentido provisório, foram transcorridos, até 2013, exatos 23 (vinte e três) anos. Essa RN tem como objetivo:

Garantir o pleno cumprimento da legislação vigente e das normas emanadas dos órgãos de Controle da União e do CNPq, inspecionar e avaliar a eficácia, suficiência e aplicação dos controles operacionais, contábeis e financeiros das unidades técnicas, administrativas e de pesquisa do CNPq, e assessorar a Administração no desempenho de suas funções, fornecendo-lhe avaliações, recomendações e comentários sobre as atividades auditadas. (RN 027/1990)

Entretanto, o Decreto $n^{\circ}$ 7.899, de 4 de fevereiro de 2013, que trata da estrutura interna do CNPq, subordina a Auditoria Interna à Presidência do CNPq e tem a sua competência descrita no

Art. 10. À Auditoria Interna compete acompanhar, orientar tecnicamente, fiscalizar e avaliar a gestão orçamentária, financeira, contábil, patrimonial e de recursos humanos, e acompanhar os trabalhos dos órgãos de controle interno e externo do CNPq.

\footnotetext{
${ }^{20}$ Controle interno: aquele exercido pela própria administração, no acompanhamento e revisão de seus atos e práticas administrativas.
} 
Esse tópico 3.2 serviu de base para a análise da definição e padronização das rotinas para as transferências voluntárias do CNPq, assim como medidas que devem ser acatadas pelo CNPq e órgãos parceiros na execução da política de ciência e tecnologia descentralizada aos estados, e a observância das normas dos órgãos de controle interno e externo para a melhor execução, monitoramento e obtenção de resultados destinados à sociedade.

No próximo capítulo serão apresentados os procedimentos administrativos para a realização do monitoramento e avaliação das transferências voluntárias, assim como as evoluções desses procedimentos e os valores transferidos, pelo CNPq, por meio dos convênios com as FAP. 


\section{MONITORAMENTO E AV ALIAÇÃO DAS TRANSFERÊNCIAS VOLUNTÁRIAS NO CNPq}

"Não se gerencia o que não se mede, não se mede o que não se define, não se define o que não se entende, não há sucesso no que não se gerencia".

William E. Deming

Frente à necessidade cada vez mais urgente de tornar transparentes aos cidadãos as ações do Estado brasileiro, têm sido estudadas propostas para a formulação de métricas para o aferimento de resultados obtidos e finalidades alcançadas com tais ações.

$\mathrm{Na}$ área da produção nacional do conhecimento, na qual o objeto desta dissertação se situa, encontra-se a mesma necessidade. O foco deste trabalho é, particularmente, as transferências voluntárias executadas pelo CNPq e cabe perguntar como esse órgão tem realizado a gestão dessas transferências. É esse o tema que tratará este Capítulo 4.

O capítulo está estruturado de forma a trazer, primeiramente, uma visão geral acerca de algumas definições sobre acompanhamento, monitoramento e avaliação para, depois, relatar como está estruturado o processo de acompanhamento e avaliação das transferências voluntárias executadas pelo CNPq e as perspectivas de gestão das parcerias observadas pelo CNPq e pelas convenentes.

\subsection{MONITORAMENTO E AVALIAÇÃO DAS TRANSFERÊNCIAS VOLUNTÁRIAS EM C\&T: uma visão geral}

O MCTI institucionalizou a política de Monitoramento e Avaliação por meio Plano Anual de Monitoramento e Avaliação (PMA), lançado em 2013. No ano anterior, o governo federal, no intuito de tornar públicas as suas ações na gestão e dar maior eficácia aos insumos para a formulação e o aprimoramento das políticas públicas, na forma de retroalimentação, publicou a Portaria $n^{\circ} 397$, de 05 de junho de 2012, que tem como objetivo

[...] Analisar, Monitorar e Avaliar as políticas, programas e ações executadas ou financiadas pelo Ministério, buscando o seu constante aperfeiçoamento e o alcance de seus objetivos com o menor custo possível.

A Portaria indica os seguintes Eixos Estruturantes:

Indicadores Nacionais de C\&T;

Estatísticas e indicadores sobre as políticas de C\&T\&l;

Indicadores básicos de monitoramento;

Indicadores sobre recursos investidos e público apoiado; 
Indicadores de resultado;

Acompanhamento e Avaliação;

Monitoramento gerencial;

Monitoramento analítico;

Avaliações de resultado/impactos; e

Estudos de linha de base.

Essa Portaria define a Comissão Permanente de Monitoramento e Avaliação (CPMA), como órgão colegiado responsável pela execução da Política de Monitoramento e Avaliação (M\&A), a quem outorga autonomia para definir quais políticas, programas e ações serão monitorados e avaliados, quais instrumentos serão utilizados e qual será a periodicidade das atividades de M\&A.

No sentido de uniformizar conceitos sobre o tema Monitoramento e Avaliação, serão apresentadas, a seguir, as considerações de alguns autores.

Francisco (2002) afirma que a avaliação de projetos tem como objetivo

justificar escolhas, controlar o desenvolvimento e auxiliar nos processos de decisão. É utilizada para fornecer subsídios tanto para as atividades administrativas como para as operacionais, direcionando-as à obtenção de melhores índices de eficácia, eficiência, relevância, e ainda de impactos positivos. A relevância diz respeito à importância dos objetivos, contrastando-os com outras necessidades. Os impactos referem-se aos efeitos sociais do projeto. (FRANCISCO, 2002, pp. 23-24)

Na visão de Costa e Castanhar (2003),

a avaliação somente é possível se o planejamento for consistente e uma maneira de se testar a consistência do planejamento é através da definição prévia da matriz lógica do programa. Esta começa pela identificação dos objetivos gerais e específicos, dos indicadores de performance, pelos quais o programa será avaliado, bem como a indicação das fontes de dados que serão usadas para as mensurações, comparações e análises necessárias. (COSTA e CASTANHAR, 2003, pp. 976-977)

Na perspectiva de Schwartzman (2002), a pesquisa e desenvolvimento é composta por atividades complexas e por resultados, na maioria das vezes, de longo prazo. $\mathrm{Na}$ avaliação dos resultados é necessário que se analise cada caso, levando-se em consideração suas particularidades. Por exemplo, grupos emergentes de pesquisa com grande promessa de qualidade não podem ser comparados, em termos de quantidade de produção, com grupos 
já estabelecidos; tecnologias incipientes, mas promissoras, não podem ser avaliadas em termos de seus resultados práticos de curto prazo (SCHWARTZMAN, 2002).

Na concepção dos autores M.C. de Souza Paula \& T.W. Sáenz (2001), a avaliação em C\&T compreende

\begin{abstract}
processos sistematizados de análise de políticas, programas, projetos ou atividades, de forma a instruir a tomada de decisão, nas fases de formulação e de implementação, bem como para verificar resultados e impactos, ao final e depois de algum tempo de terminada a ação. Vários fatores têm levado a que a avaliação se consolide como prática e cultura nos meios científicos e tecnológicos: a pressão social sobre os usuários de recursos públicos; a pressão de organismos financiadores - decorrente tanto do efeito da pressão social quanto das restrições físicas de recursos; as grandes expectativas colocadas sobre o trabalho científico e tecnológico, em termos da utilização de resultados e dos impactos na economia e na sociedade. A esse contexto se relaciona a necessidade de novas estratégias e metodologias de avaliação, adequadas às diversas atividades de C\&T e suas formas de organização. (SOUZA PAULA \& SÁENZ, 2001, p. 2)
\end{abstract}

Segundo Saravia (2010), as normas estabelecidas para o monitoramento e a avaliação da efetividade de políticas e programas referem-se a mensuração e a análise, a posteriori, dos efeitos produzidos na sociedade, pelas políticas públicas, especialmente no que diz respeito às realizações e às consequências previstas e não previstas. De posse dessas informações, espera-se que sejam estabelecidos parâmetros capazes de subsidiar o monitoramento permanente de um programa ou projeto, etapa em que, na sua opinião, consiste em

[...] processo sistemático de supervisão da execução de uma atividade (e de seus componentes), que têm como objetivo o de fornecer a informação necessária para introduzir eventuais correções a fim de assegurar a consecução dos objetivos estabelecidos. (SARAVIA, 2010, p.12)

Mesmo com as dificuldades inerentes à cultura da não avaliação ou da avaliação com sentido de punição, os esforços empreendidos foram tomando forma para que pudessem gerar, ainda que de forma incipiente, conceitos e modelos para realizar o acompanhamento e a avaliação de programas e projetos na área de ciência e tecnologia. Não somente foram definidos critérios por aqueles que se dedicaram aos estudos de avaliação, mas o Estado também o fez, quando aprovou a Emenda Constitucional no. 19, em 1998, que estabeleceu a adoção do Princípio da Eficiência, ou seja, não basta somente o controle, é necessária, também, a obtenção de resultados dos recursos públicos aplicados. 
A FAPESP (2008) afirma que

[...] a avaliação sistemática dos resultados da aplicação de recursos públicos em Ciência e Tecnologia tem se revelado ferramenta importante para subsidiar programas e orientar investimentos em pesquisa das maiores agências de fomento do país [...] é de suma importância o levantamento de dados, a sistematização das informações e a apuração de resultados dos diversos programas e modalidades de auxílios concedidos (FAPESP, 2008, p.15).

O PPA 2012-2015 traz em seu bojo tópico específico sobre monitoramento e avaliação, afirmando que:

[...] no contexto de uma política, plano ou programa, o conceito habitual de monitoramento consiste na observação contínua de uma dada realidade nos seus aspectos mais relevantes, no intuito de obter informações fidedignas e tempestivas. (destaques da autora)

[...] a avaliação é uma investigação aprofundada de uma determinada intervenção. Tanto o monitoramento quanto a avaliação, além de fornecerem informações para o aperfeiçoamento da ação governamental, são aliados essenciais para a articulação, o acompanhamento de transversalidades e territorialidades das políticas e, em última análise, para viabilizar as entregas de bens e serviços à população. (PPA, op. cit., p.123) (destaques da autora)

Com base nos conceitos apresentados no PPA 2012-2015, serão utilizados, a partir de agora, os termos "monitoramento" e "avaliação" para o estudo dos procedimentos adotados pelo CNPq, nas ações de transferências voluntárias da União às FAP. 


\subsection{EVOLUÇÃO DO MONITORAMENTO \& AVALIAÇÃO DAS TRANSFERÊNCIAS VOLUNTÁRIAS NO CNPq}

No CNPq, o aprendizado quanto à necessidade de se realizar o Monitoramento e a Avaliação das transferências voluntárias tem sido contínuo, levando a área técnica desse Conselho a se empenhar no estudo da legislação e na aplicação das normas previstas para regular os repasses voluntários da União, de forma a possibilitar o melhor acompanhamento e avaliação.

A motivação para esse aprendizado contínuo partiu não só do CNPq ou dos técnicos envolvidos, mas também da percepção, imputada pelos órgãos de controle interno e externo, da necessidade de se realizar um monitoramento adequado, capaz de sustentar a sua avaliação posterior. Essa é uma percepção da autora, adquirida por sua atuação nessa área do CNPq, e que teve a oportunidade de ratificá-la quando da realização de entrevistas no CNPq, bem como de constatá-la em processos nos quais ocorrem parcerias para as transferências voluntárias.

O monitoramento e a avaliação, além de atenderem ao cumprimento das normas legais, verificam, com vistas a tornar transparentes os resultados dessas transferências voluntárias, a efetividade das políticas e programas federais, estaduais e municipais de C\&T\&I. Essa avaliação continuada pode oferecer subsídios para referendar e viabilizar, ou não, a continuidade da parceria, do programa ou projeto e da consequente transferência de recursos financeiros.

Segundo o Centro de Gestão e Estudos Estratégicos (CGEE), a efetividade de políticas e programas são componentes estruturais dos processos de descentralização, na medida em que envolvem atribuições de responsabilidades de execução e delegação de autoridade decisória. No âmbito desse processo na área de C\&T, as ações de acompanhamento e avaliação tornam-se mais complexas, quando requerem práticas mais sofisticadas de coordenação federativa e público-privada, seja do ponto de vista técnico, institucional ou político. (CGEE, 2010, p. 96) Dessa forma, mesmo não tendo alcançado ainda o nível de equivalência exigido pelas normas, o CNPq vem buscando uma estreita relação com a legislação referente ao monitoramento e avaliação das ações envolvidas nas transferências voluntárias. Percebe-se a evolução desse intento quando da verificação dos procedimentos internos para a execução dessas transferências. 
Neste capítulo, onde se destaca o tema do monitoramento e da avaliação das transferências voluntárias, apresenta-se uma análise dos processos internos de área técnica do CNPq referentes à concessão de recursos da União, desde o ano de 2003.

No início da operacionalização das transferências, o CNPq já possuía norma interna vigente que disciplinava a matéria; entretanto, a mesma não foi observada e nem serviu de base a ser seguida para a formulação dos processos internos. Ao contrário, foram gerados novos conhecimentos e normativas frente à necessidade de implementar as atividades pertinentes à descentralização.

$\mathrm{Na}$ pesquisa documental realizada nos processos de transferência voluntária realizados pelo CNPq, observou-se que a proposta para a avaliação dos respectivos programas seguia o modelo apresentado pelas FAP, ou seja, as FAP procederiam à avaliação do projeto, levando em consideração os objetivos propostos no plano de trabalho apresentado. Constava dos processos físicos que o CNPq, por sua parte, poderia, a qualquer momento, realizar in loco a avaliação do projeto.

Ficou evidendiado, também, que algumas FAP realizariam anualmente um seminário no qual os coordenadores e bolsistas apresentariam os resultados do projeto e o plano de trabalho aprovados. Desses seminários ou workshop resultaria um Relatório Técnico Parcial e, ao final da execução do programa, um Relatório Técnico Final e um Relatório de Prestação de Contas, que seriam encaminhados ao CNPq. Técnicos do CNPq, quando liberados, participavam desses seminários. A participação de técnicos do CNPq não ocorria quando se iniciaram as transferências voluntárias, nem ocorrem agora em todas as etapas das atividades de avaliação que são realizadas, sob a alegação institucional de que faltam recursos destinados para esse fim.

No início da concessão das transferências voluntárias, em 2003, o CNPq não possuía nenhum modelo de monitoramento e avaliação desses instrumentos ${ }^{21}$. Essa lacuna deve ser destacada, ainda mais considerando-se que os convênios assinados pelos contratantes e publicados no Diário Oficial da União (DOU), continham cláusulas tratando, especificamente, da função acompanhamento e avaliação dos convênios por um Comitê de Gestão, instituído para esse fim.

\footnotetext{
${ }^{21}$ Em um dos processos analisados, observou-se que as atividades de monitoramento e avaliação foram propostas pela contraparte, a FAP.
} 
$\mathrm{Na}$ maioria dos processos consta, como parte dos procedimentos de monitoramento, somente o Espelho Financeiro do Processo e o Parecer Técnico emitido pela área técnica do $\mathrm{CNPq}$, relativos à conferência e ao cumprimento financeiro quanto às metas, etapas e fases do Plano de Trabalho acordadas entre os partícipes.

A maioria dos processos analisados também não apresentava nenhum Relatório Técnico Científico Parcial ou Final que condicionasse a continuidade dos repasses financeiros, ou a análise da aplicabilidade científica da transferência, documentos exigidos pela legislação vigente naquela época e que ainda prevalece.

Outro ponto a ser comentado é o fato de não constar também dos processos de transferências voluntárias nenhuma menção às possíveis ações do Comitê de Gestão relativas ao monitoramento e avaliação das atividades realizadas pelas FAP. Os processos não continham documentos, por qualquer das partes - CNPq ou FAP, que levassem em conta a cobrança de acompanhamento ou avaliação por parte do Comitê de Gestão ou, nem mesmo, continham alguma justificativa do próprio Comitê sobre a sua ausência no processo.

Pelo lado das FAP, consta dos processos informação de que as mesmas apresentariam Relatório Técnico de Acompanhamento e Avaliação em janeiro de cada ano, fazendo menção ao quantitativo de bolsas concedidas e aos recursos recebidos como transferências voluntárias da União, ou seja, apenas um relatório de caráter quantitativo, que não mencionava aspectos científicos da aplicabilidade dos recursos recebidos do CNPq. Os processos que trazem tais relatórios se limitam a apresentar os resultados quantitativos, quanto ao número de bolsas concedidas; de seminários realizados, mas não indicam os resultados qualitativos advindos da pesquisa, como, por exemplo, o que resultou da pesquisa; qual foi o produto ou processo obtido; que benefício trouxe para a comunidade regional, além de outros. Não foi constatada nenhuma manifestação nesse sentido.

No caso do Programa de Apoio a Núcleos de Excelência (PRONEX), também em 2003, o CNPq firmou parcerias com órgãos estaduais responsáveis pela área de ciência e tecnologia, as Fundações de Amparo à Pesquisa (FAP) ou Secretarias de Estado de Ciência e Tecnologia. Nesse caso, havia um modelo específico de acompanhamento e avaliação que já era utilizado pelo PRONEX, que atendia à diretriz de descentralização da produção do conhecimento nacional. Foram assinados convênios de cooperação que estabeleceram a provisão dos recursos financeiros para o programa em partes iguais, pelo CNPq e pela entidade local, entendida como FAP ou Secretaria de Estado de Ciência e Tecnologia, na qual o PRONEX estava instalado. 
Nesse caso, a FAP local passou a ser a responsável pela execução, monitoramento e avaliação dos projetos selecionados, cabendo ao CNPq a supervisão de todo o processo e a avaliação final da parceria, como uma avaliação ex-post.

Conforme dito anteriormente, o PRONEX já possuía uma cultura de acompanhamento e avaliação, materializada numa rotina que pode ser resumida como segue: As FAP encaminhavam ao CNPq um relatório de avaliação dos programas e projetos. Essas avaliações se davam mediante a participação de consultores externos, que realizavam uma avaliação presencial, apoiada na análise de relatórios parciais. Eram realizadas em seminários, com apresentações orais, além de painéis e pôsteres, visando assegurar maior abrangência e visibilidade da atuação dos diversos atores que participaram do programa.

Esse formato de Seminário de Avaliação ainda vigora e é válido para todos os programas nos quais as FAP têm parceria com o CNPq. Entretanto, nem todas as FAP possuem a cultura do monitoramento e da avaliação. Outro fator relevante que inviabiliza essa ação é a falta de infraestrutura física, financeira e de pessoal, segundo justificativa dos seus representantes, para a não realização dos procedimentos de avaliação.

Nos Seminários de Avaliação Final, além da avaliação oral e dos relatórios, são apresentados painéis aos consultores externos, responsáveis pelos relatórios de avaliação da execução do programa. A consolidação desses Seminários de Avaliação Final era encaminhada ao CNPq, juntamente com a prestação de contas físico-financeira, elementos suficientes para dar condições à área técnica do CNPq solicitar o arquivamento do processo, dando-o como quite junto ao CNPq e aos órgãos de controle.

A IN/STN no 01/97 destaca, no artigo $2^{\circ}$, a necessidade da elaboração e apresentação de um Plano de Trabalho detalhado, que deve ser analisado quando da submissão da proposta de solicitação de recursos. Esse Plano de Trabalho servirá como base para a realização do monitoramento e avaliação. A referida Instrução Normativa oferece um modelo a ser seguido, de modo a padronizar a forma de sua apresentação. Os convênios firmados sob a égide da IN/STN no 01/97, apresentavam cláusula específica quanto à apresentação de relatório técnico-científico e financeiro dos projetos financiados para viabilizar a prestação de contas junto ao CNPq. Os beneficiários finais prestam contas dos auxílios recebidos junto às FAP e estas, por sua vez, ao CNPq.

Observou-se, durante a análise dos processos anteriores a 2008, que quando havia a necessidade de se postergar a data final da vigência de um convênio, o procedimento era 
firmar um Termo Aditivo ao convênio inicial, mantidas as demais cláusulas sem alteração, o que acontecia mediante a apresentação de Relatório Técnico e de Prestação de Contas Parcial, justificando-se a necessidade e o novo período de vigência. É fato que, na maioria dos processos, não se encontram esses ritos formalizados. Essa rotina veio a ser modificada com a implementação do SICONV, em 2008, que é o sistema gerencial para o monitoramento das atividades executadas em programas com parcerias de órgãos do governo federal. Esse sistema não libera qualquer movimentação se todos os procedimentos e informações necessários não estiverem atualizadas e dentro das especificações exigidas pelo sistema SICONV. Esse sistema é alimentado tanto pelas FAP quanto pelo CNPq.

Com a criação do SICONV, por parte do Governo Federal, passou-se a exigir o mínimo de cumprimento da legislação pertinente às transferência voluntárias da União, como o acompanhamento, pelas partes envolvidas, por meio do lançamento de informações sobre os processos de concessão e o cumprimento das etapas previstas no plano de trabalho para a liberação de parcelas de recursos.

Como instrumento para monitoramento de convênios celebrados entre os órgãos públicos e outras instituições, públicas ou privadas, mediante a formalização de parceria, utiliza-se de modelo disponível no sítio do CNPq, que contém informações sobre os repasses e transferências de recursos financeiros efetuados, mediante a indicação dos links do Portal dos Convênios (SICONV) e da Página da Transparência Pública do CNPq. Esses são os mecanismos eletrônicos disponibilizados para o acesso aos dados relativos a essas ações.

Em 2012, a Instrução de Serviço (IS) 003/2012 veio regulamentar as atribuições e os prazos relacionados à prestação de contas técnica e financeira dos auxílios e bolsas concedidos pelo CNPq, no âmbito dos convênios.

Também a partir de 2012, o CNPq elaborou o seu primeiro Plano Anual de Fiscalização de Transferências Voluntárias, Acompanhamento e Avaliação dos Programas em Parceria com o CNPq, entre outras transferências voluntárias realizadas em nível nacional, inclusive indicando as instâncias decisórias de suas ações.

O Quadro 8 representa a forma esquemática e resumida da Evolução do Monitoramento e Avaliação das parcerias firmadas pelo CNPq mediante convênios, no período de 2003 a 2013, conforme relatado nos parágrafos anteriores. 
Quadro 8 - Evolução do Monitoramento e Avaliação das Parcerias e Convênios do CNPq com as FAP, 2003 - 2013

\begin{tabular}{|c|c|c|c|c|c|c|c|c|c|}
\hline 2003 & 2004 & 2006 & 2007 & 2008 & 2009 & 2010 & 2011 & 2012 & 2013 \\
\hline $\begin{array}{l}\text { - Grande número de } \\
\text { convênios firmados } \\
\text { nesse ano em virtude } \\
\text { de medida adotada } \\
\text { pela diretoria } \\
\text { Executiva do CNPq. } \\
\text { - Não configurada a } \\
\text { forma de } \\
\text { monitoramento de } \\
\text { avaliação pelo CNPq, } \\
\text { dos recursos } \\
\text { transferidos às FAP. }\end{array}$ & $\begin{array}{l}\text { Mo } \\
\text { realiza } \\
\text { por } \\
\text { workst } \\
\text { CNPq } \\
\text { - O C } \\
\text { de alc } \\
\text { workst } \\
\text { envolv } \\
\text { transfe } \\
\text { acordo } \\
\text { finance } \\
\text { - O C } \\
\text { relatór } \\
\text { pelas } \\
\text { de con }\end{array}$ & $\begin{array}{l}\text { toramento e } \\
\text { os por algumas c } \\
\text { eio de semin } \\
\text { ps que enviai } \\
\text { s resultados obtid } \\
\text { Pq participava, p } \\
\text { ns desses sem } \\
\text { ps, enviando } \\
\text { os no proces } \\
\text { ncias voluntár } \\
\text { com a dispo } \\
\text { a e de pessoal. } \\
\text { Pq basicamente } \\
\text { técnico apr } \\
\text { P e realizava a । } \\
\text { s financeiras. }\end{array}$ & $\begin{array}{l}\text { valiação } \\
\text { s FAP, } \\
\text { ios e } \\
\text { m ao } \\
\text { s. } \\
\text { vezes, } \\
\text { ários e } \\
\text { écnicos } \\
\text { o das } \\
\text { s, de } \\
\text { bilidade } \\
\text { colhia o } \\
\text { sentado } \\
\text { estação } \\
\end{array}$ & $\begin{array}{l}\text { - Implementação do } \\
\text { SICONV, em âmbito } \\
\text { Federal, que deu } \\
\text { maior visibilidade das } \\
\text { ações realizadas pelo } \\
\text { CNPq e instituições } \\
\text { convenentes. }\end{array}$ & $\begin{array}{l}\text { - Monito } \\
\text { visitas té } \\
\text { conforme } \\
\text { de pesso }\end{array}$ & $\begin{array}{l}\text { to juntc } \\
\text { on in loc } \\
\text { onibilide }\end{array}$ & $\begin{array}{l}\text { SICONV e } \\
\text { to às FAP, } \\
\text { nanceira e }\end{array}$ & $\begin{array}{l}\text { - Plano para a } \\
\text { realização do } \\
\text { monitoramento e } \\
\text { avaliação das } \\
\text { transferências } \\
\text { voluntárias. }\end{array}$ & $\begin{array}{l}\text { - Apesar dos esforços } \\
\text { do CNPq ainda não se } \\
\text { evoluiu para que se } \\
\text { tenha umsistema } \\
\text { específico para a } \\
\text { gestão de convênios } \\
\text { relativos às suas } \\
\text { transferências } \\
\text { voluntárias. } \\
\text { - Utiliza-se do SIAFE, } \\
\text { SIGEF; SICONV, } \\
\text { SigFap, Sigplan e de } \\
\text { visitas técnicas, in loco. } \\
\text {-Relatórios de } \\
\text { monitoramento de } \\
\text { avaliação recebidos das } \\
\text { FAP. }\end{array}$ \\
\hline
\end{tabular}

Fonte: Construído pela autora a partir da pesquisa documental. 
O Plano Anual de Fiscalização de Transferências Voluntárias, Acompanhamento e Avaliação dos Programas das Parcerias com o CNPq - 2012, previa, como principais ações, as seguintes:

1. Gestão da conformidade documental e processual:

$\checkmark$ Acompanhamento de julgamento de chamada (ex-ante);

$\checkmark$ Acompanhamento de avaliação de resultados (ex-post);

$\checkmark$ Visitas técnicas;

$\checkmark$ Oficinas de trabalho sobre a gestão de convênios; e

$\checkmark$ Tutoria às FAP.

2. Gestão da conformidade documental e processual (gestão interna):

$\checkmark$ Respeito à cadeia decisória;

$\checkmark$ Atendimento às premissas legais na composição de processos;

$\checkmark$ Atendimento às premissas legais na descentralização dos recursos; e

$\checkmark$ Monitoramento via SICONV e via PICC.

3. Acompanhamento de julgamento de chamadas e de seminários de avaliação de resultados:

$\checkmark$ Momentos para identificação de possíveis problemas na seleção e na execução dos programas descentralizados; $\mathrm{e}$

$\checkmark$ Visitas Técnicas.

Fonte: (Plano Anual de Fiscalização de Transferências Voluntárias, 2012).

Mesmo sendo um plano bem construído, que apontava o quantitativo de técnicos para realizar o acompanhamento; indicava a discriminação das despesas com diárias e passagens; as FAP a serem visitadas; e o montante de recursos federais a serem gastos com essas visitas, ele não foi completamente efetivado no ano de 2012. As ações remanescentes foram incorporadas aos planos de 2013 e 2014, para a sua finalização. Essa incompletude teve como justificativa o contingenciamento de recursos financeiros para esse fim e a falta de pessoal nas áreas técnicas do CNPq.

No sentido de melhorar e nivelar os entendimentos sobre os procedimentos de acompanhamento, monitoramento e avaliação, o CNPq encampou a proposta do MCTI, fazendo parte dos estudos para a Institucionalização da Política de Monitoramento e Avaliação de Políticas Públicas de C\&T\&l. 
Na busca de uma melhor gestão dos Programas de Cooperação Nacional, foi instituído, em março de 2012, um Grupo de Trabalho formado por representantes do CONFAP e servidores do CNPq, envolvendo todas as áreas afins às parcerias estabelecidas. Esse grupo foi criado com a missão de identificar pontos críticos e propor estratégias e soluções para o aperfeiçoamento dos instrumentos comuns e da prática de gestão articulada entre as instituições. Além disso, uma outra atividade importante foi o treinamento de 30 (trinta) servidores do quadro técnico do CNPq, na operacionalização do SICONV e, posteriormente, foi realizada a primeira edição de uma oficina de trabalho para capacitação de membros das FAP, para o uso do sistema SICONV. A oficina foi ministrada pelos próprios técnicos do CNPq, já capacitados. (CNPq, op.cit., pp. 18 a 22)

Também como forma de monitoramento das ações das transferências voluntárias, existe a necessidade de cumprimento do Plano Anual de Atividades de Auditoria Interna (PAINT), elaborado com base nos dispositivos constantes da instrução normativa do Sistema Federal de Controle (SFC) no 01, de 03/01/2007 e Instrução normativa SFC no 09 de 14/11/2007, que estabelecem o conteúdo do PAINT, e do item 13 do Capítulo $X$ do Manual do Sistema de Controle Interno do Poder Federal. O PAINT é remetido à CGU para a ratificação e, ao final dos procedimentos de monitoramento, consolida-se o Relatório Anual de Atividades de Auditoria Interna (RAINT). O RAINT também é remetido à CGU, que verifica a pertinência das informações ali contidas e da necessidade de verificação processual in loco, quando então uma equipe da CGU se desloca até ao CNPq para fazê-lo.

$\mathrm{Na}$ estrutura organizacional do CNPq não há área específica incumbida de proceder ao acompanhamento e à avaliação técnica das ações de concessão de transferência voluntária por meio de convênios. Está em processo de estudo e discussão interna a criação de instrumentos e mecanismos para subsidiar o acompanhamento e avaliação das atividades que envolvam a descentralização de ações e de recursos da União às FAP.

O CNPq tem buscado padronizar as rotinas e revisar as normativas dos programas e dos procedimentos na implementação e execução de parcerias. Nesse sentido foi constituído, pelo Presidente do CNPq, um Grupo de Trabalho (GT), conforme Portaria 169/2013, de 17 de maio de 2013, com o objetivo de analisar o fluxo da rotina; o Procedimento Operacional Padrão (POP) e procedimentos administrativos dos processos que envolvam Convênios, Protocolos de Intenções e Termos de Cooperação, no âmbito do CNPq, bem como apresentar minuta (ou minutas) de modelos, formulários, check-list, Instrução de Serviço (IS), e/ou Resoluções Normativas (RN). 
Ao referido GT foi dado o prazo inicial de 60 (sessenta) dias para a conclusão dos trabalhos. Entretanto, por meio da Portaria 259/2013, de 17 de julho de 2013, o Presidente do CNPq autorizou a prorrogação do prazo por mais 60 (sessenta) dias, a partir dessa data. Houve ainda outra solicitação de prorrogação, por mais 60 (sessenta) dias, a partir de 18 de setembro de 2013, feita pelo Grupo de Trabalho, pela Portaria 370 de 19/09/2013. Em novembro de 2013, o GT entregou ao Presidente do CNPq um relatório parcial das reuniões feitas e das sugestões de que o GT já dispunha, encerrando-se os trabalhos do ano, com o pedido de prorrogação para a entrega final do trabalho e informando que o início dos trabalhos se daria em março de 2014. Entre os componentes deste grupo está um membro da Procuradoria Federal (PF) do CNPq, para a discussão de um modelo capaz de sistematizar procedimentos de execução de convênios e outros. Em maio de 2014, foi publicada outra portaria, com alguns novos componentes do Grupo de Trabalho, com a mesma demanda da primeira portaria. O GT continua realizando as reuniões para levar a cabo as solicitações feitas pelo Presidente do CNPq.

Internamente no CNPq, o acompanhamento dos projetos e/ou ações relativos às transferências é realizado por meio de planilhas de acompanhamento, pelas áreas técnicas executoras. Os resultados subsidiam o acompanhamento das ações e/ou programas insertos no PPA, realizados a partir de registros sistemáticos e periódicos de informações sobre:

a) o cumprimento das metas físicas constantes do Sistema de Informações Gerenciais e de Planejamento (Sigplan), do Ministério do Planejamento, Orçamento e Gestão (MPO), em confronto com os gastos captados do Sistema Integrado de Administração Financeira do Governo Federal (Siafi);

b) as dificuldades enfrentadas, a situação em que se encontram as ações; os eventos críticos, e as restrições que se instalam; bem como as providências adotadas para superá-las; e

c) o cronograma físico e financeiro, com a aderência às metas previstas no PPA combinada com a execução mês a mês com base no sistema SIAFI.

Para o acompanhamento das ações de convênios e acordos, a legislação prevê a necessidade de se designar um servidor como fiscal ou gestor de convênio, para acompanhar a sua execução. O TCU diz em seu sítio que o princípio da segregação de funções é

[...] o princípio básico de controle interno essencial para a sua efetividade. Consiste na separação de atribuições ou responsabilidades entre diferentes pessoas, especialmente as funções ou atividades-chave de autorização, execução, atesto/aprovação, registro e revisão ou auditoria. (www.tcu.gov.br) 
Esse princípio explica, então, por que um gestor que assina um convênio não pode ser o mesmo que o acompanha, pois poderia incorrer em erros com mais facilidade do que outra pessoa que não participou da firmatura dos convênios ou acordos.

O princípio da segregação de funções decorre do princípio da moralidade (art. 37, da CF/88), e consiste da

necessidade de a Administração repartir funções entre os agentes públicos cuidando para que esses indivíduos não exerçam atividades incompatíveis umas com as outras, especialmente aquelas que envolvam a prática de atos e, posteriormente, a fiscalização desses mesmos atos.

Como visto anteriormente, não havia, basicamente, a avaliação ex-ante para a gestão de convênios relativos às transferências voluntárias, no período de 2003 a 2008. O CNPq operava com base nos relatórios técnicos e de prestação de contas que eram enviados pelas convenentes. Não havia, portanto, uma estrutura habitual de monitoramento da execução dos convênios. A avaliação era baseada na avaliação ex-post dos relatórios enviados pelas FAP.

Atualmente, para a realização da avaliação das parcerias, utilizam-se sistemas de informação como o SIAFI; visitas técnicas in loco; oficinas realizadas pelo CNPq ou pelas FAP; workshops promovidos pelas FAP para avaliação final de projetos, e, a partir de 2008, implementação do SICONV.

As Coordenações Técnicas do CNPq envolvidas com os processos de descentralização de recursos trabalham de forma integrada entre si, tendo em seus parceiros internos a colaboração para a realização da implementação e execução dos programas descentralizados. A CGNAC, a CGSAU, que opera o PPSUS, e a COFIN têm como objetivo buscar o alinhamento de ações para que sejam operacionalizados, de forma igualitária, os diferentes programas do CNPq. Para tanto, são realizadas oficinas expositivas com a participação de todos os parceiros envolvidos na execução dos programas, visando fortalecer as parcerias e uniformizar informações necessárias ao efetivo desenvolvimento dos programas nos estados.

A convergência das estratégias entre a forma de execução do CNPq e das FAP é extremamente importante, pois são programas nacionais descentralizados: recursos financeiros; a execução finalística; a priorização; a seleção; mas devem guardar as mesmas normativas e legalidade. É necessário que o modelo de execução dos programas que estão presentes em mais de um estado seja mantido e não haja divergências em sua forma de 
operacionalização. Para isso, é necessária a capacitação frequente das equipes técnicas, tanto do CNPq como das FAP, treinadas sob um objetivo comum, a boa execução dos recursos públicos descentralizados. (II Oficina de Gestão de Convênios, 2014)

Para visualizar, esquematicamente, o processo interno de execução das transferências voluntárias por meio dos convênios, são apresentados, a seguir, os fluxos dos processos, de acordo com o atual modelo operacionalizado pelas áreas técnicas. 


\subsection{FLUXOGRAMAS DA EXECUÇÃO DO PROCESSO DE DESCENTRALIZAÇÃO NO $\mathrm{CNPq}$}

O Macrofluxo representado pela Figura 6 mostra a função macro das etapas para a descentralização de créditos realizada pelo CNPq, quando da operacionalização das transferências voluntárias da União às FAP.

Figura 6: Macrofluxo da Descentralização de Créditos pelo CNPq às FAP

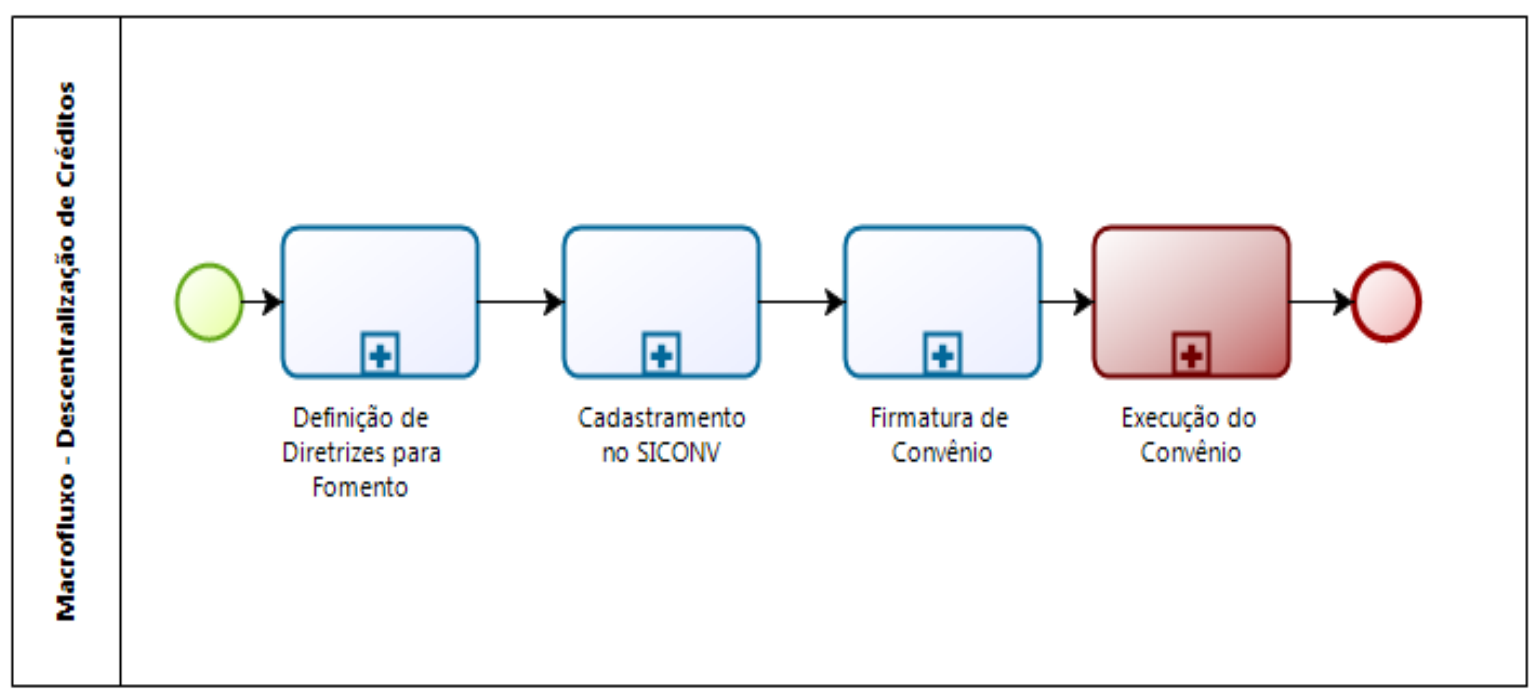

Fonte: Fluxo desenhado pela autora a partir de entrevistas/consultas nas áreas técnicas do CNPq. 
A Figura 7 apresenta o fluxo das instâncias representativas para a discussão e a definição de diretrizes para a descentralização de recursos financeiros da União.

Figura 7 - Definição de diretrizes para a descentralização de Créditos pelo CNPq às FAP

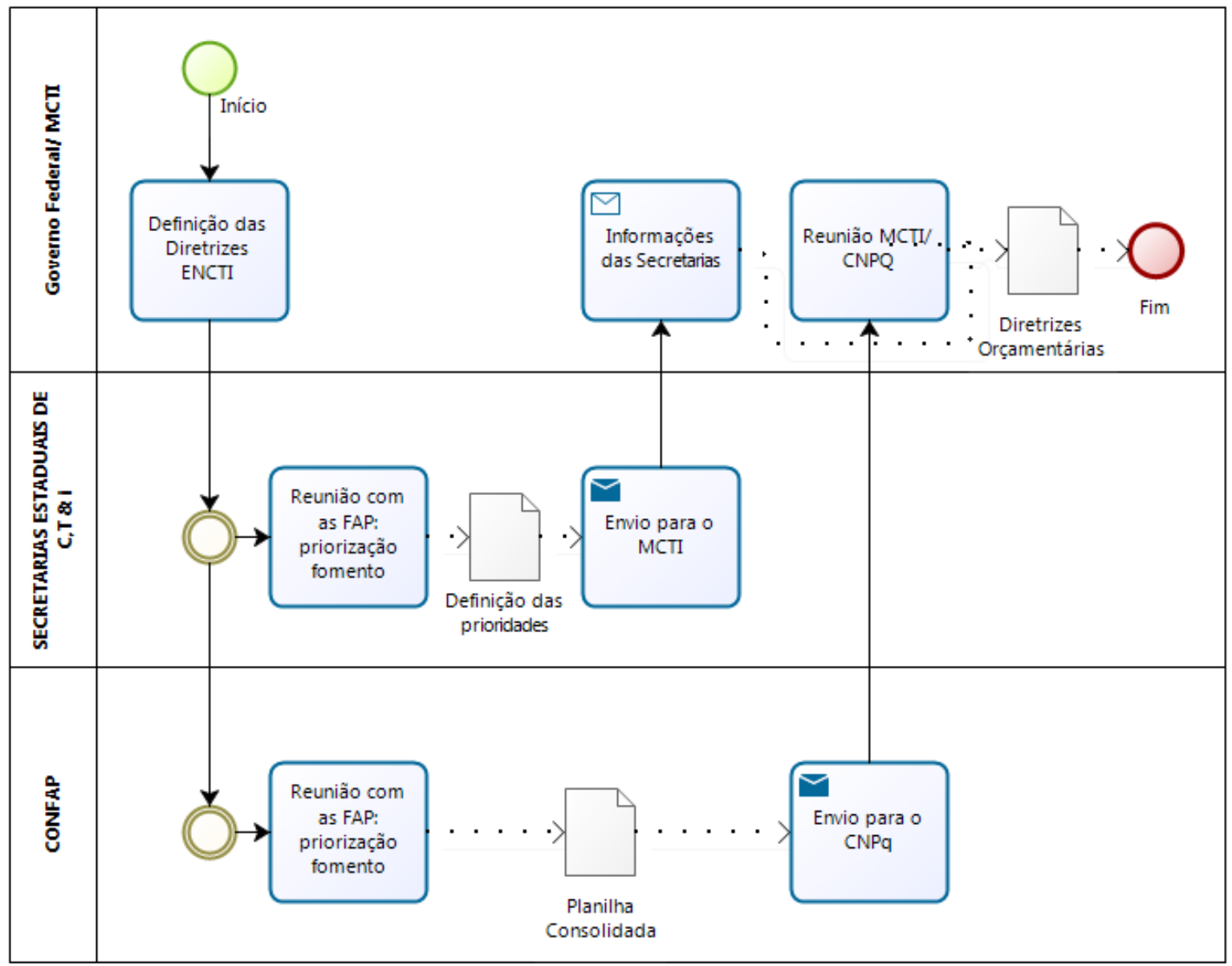

Fonte: Fluxo desenhado pela autora a partir de entrevistas/consultas nas áreas técnicas do CNPq. 
A Figura 8 representa o curso do cadastro do convênio e a tramitação do processo, no CNPq, para o cadastramento no SICONV.

Figura 8 - Cadastramento dos convênios com as FAP no SICONV

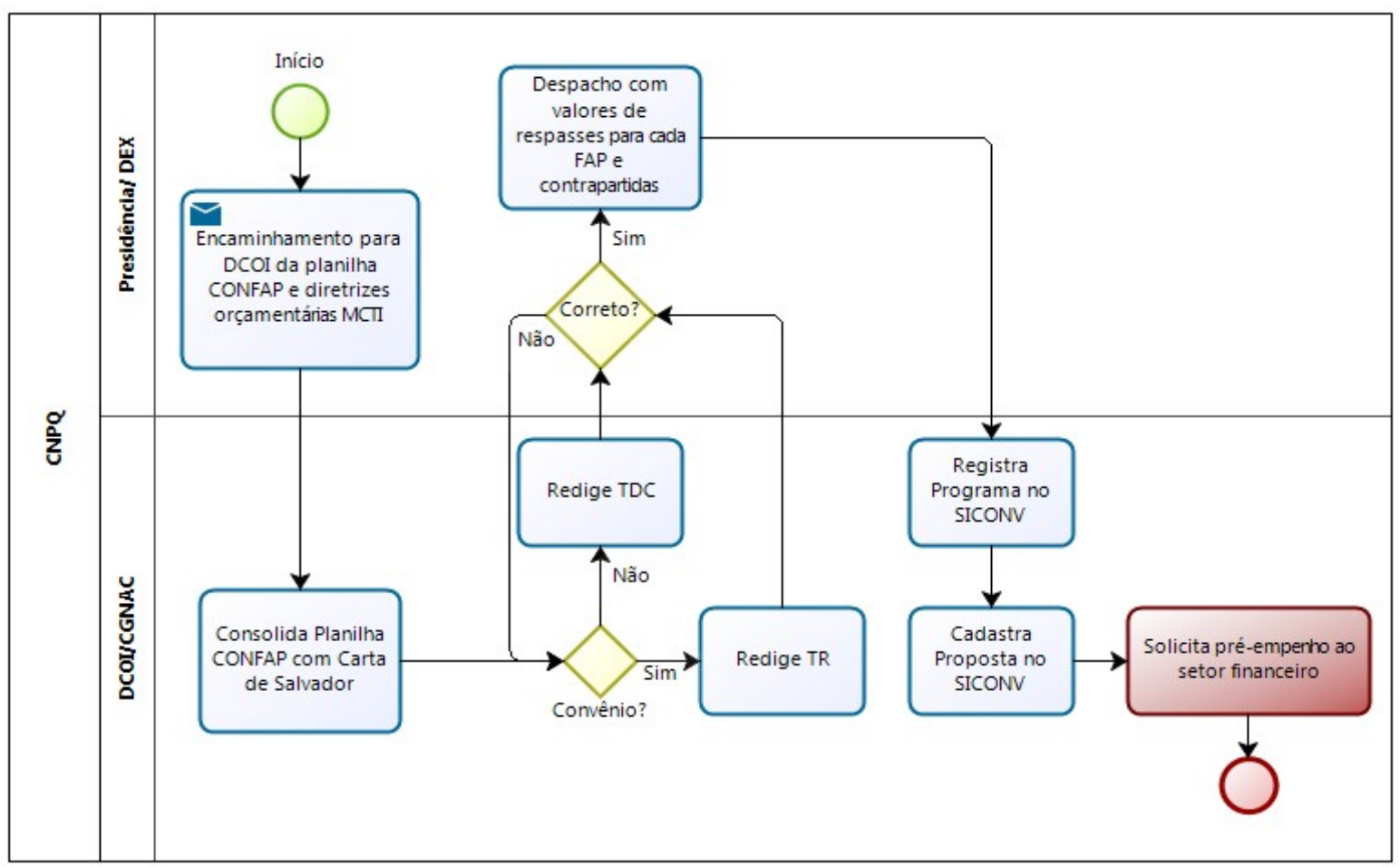

Fonte: Fluxo desenhado pela autora a partir de entrevistas/consultas nas áreas técnicas do CNPq. 
A Figura 9 apresenta os trâmites processuais no CNPq para a firmatura de convênio junto às FAP.

Figura 9 - Fluxo para a Firmatura de Convênio do CNPq com as FAP

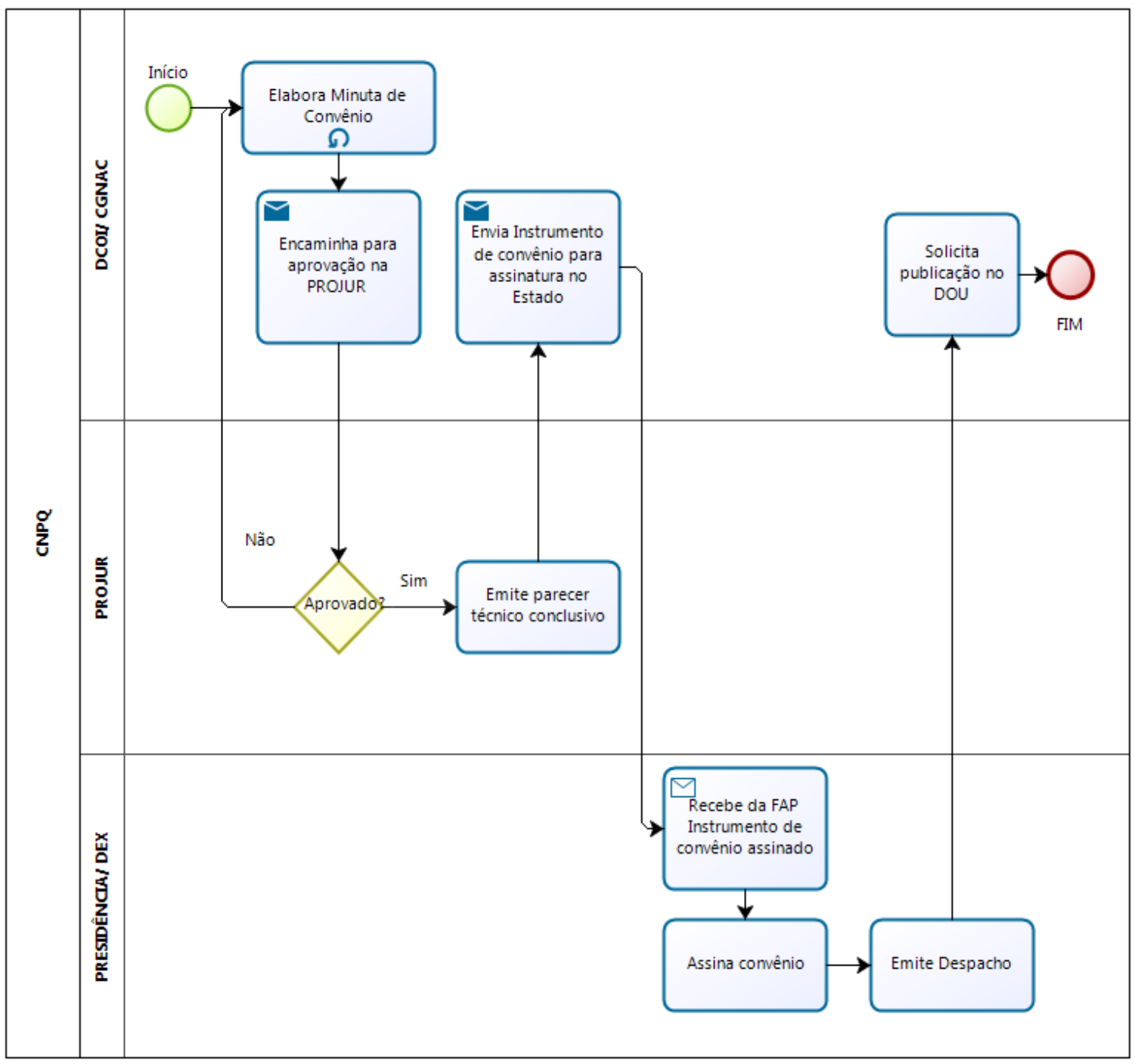

Fonte: Fluxo desenhado pela autora a partir de entrevistas/consultas nas áreas técnicas do CNPq. 
A Figura 10 mostra as funções a serem desempenhadas pelo CNPq e pela FAP para a execução de convênio, até a sua finalização com a análise da prestação de contas técnica e financeira.

Figura 10 - Fluxo da Execução de Convênio do CNPq com as FAP

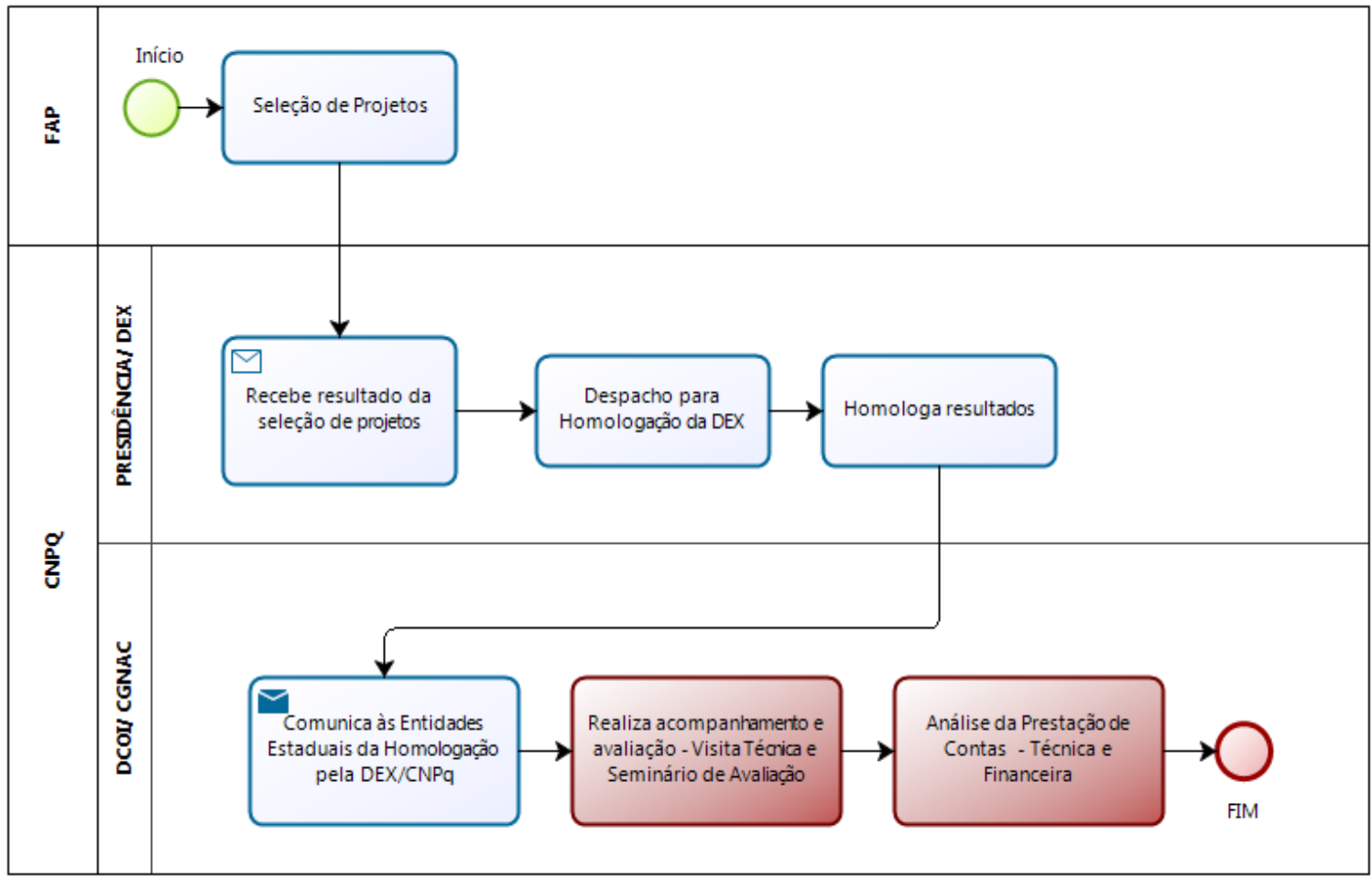

Fonte: Fluxo desenhado pela autora a partir de entrevistas/consultas nas áreas técnicas do CNPq.

No próximo item será abordado o método utilizado para a realização de consulta junto ao CNPq e às FAP, para se verificar como são realizados os procedimentos para a execução, monitoramento e avaliação dos recursos financeiros da União repassados pelo CNPq e recebidos pelas FAP, com o objetivo de induzir o investimento em pesquisa e desenvolvimento da ciência e tecnologia regional. 


\subsection{CONSULTA AO CNPq E ÀS FAP E OS RESULTADOS ALCANÇADOS}

A consulta junto aos principais atores das TV levadas a cabo pelo CNPq representantes das FAP e técnicos do CNPq - teve como objetivo verificar a importância dada por essas instituições à descentralização de recursos públicos da União às fundações de amparo, particularmente no que se refere à política de descentralização de recursos e ações federais implementadas no âmbito dessas fundações, para a área de ciência e tecnologia nos estados brasileiros.

\subsubsection{Metodologia da Consulta}

A consulta ao CNPq e às FAP se deu por meio das seguintes atividades: em primeiro lugar, entrevistas com os gestores e técnicos do CNPq envolvidos com a execução de convênios com as FAP para a realização de transferência voluntária de recursos da União; em segundo lugar, pela aplicação de questionário semi-estruturado a respresentantes de 14 FAP.

Também contribuíram para a obtenção de informações a consulta a relatórios técnicos e de gestão do CNPq e uma visita a uma FAP, aproveitando-se a oportunidade de uma viagem de serviço.

\subsubsection{Resultados da Visita Técnica}

No caso desta visita técnica, o foco das observações incidiu nos processos administrativos. Foram verificados os procedimentos adotados pelos técnicos da fundação na realização de sua missão como agência executora de C\&T\&l, tais como: pagamentos efetuados a terceiros; auxílios transferidos a pesquisadores; diárias e passagens; aquisição de equipamentos e instrumentos; componentes químicos necessários para a realização de pesquisa, além de outros. Em consequência, foram também observados os processos licitatórios e de tomada de preços para a aquisição dos bens de capital necessários à infraestrutura de P\&D, bem como documentos de convênios assinados com o CNPq e seus aditivos.

Nessa visita foi possível perceber certo receio dos técnicos da fundação em disponibilizar os seus documentos, que, a priori, haviam sido demandados para serem submetidos à análise. Inferiu-se que esse receio ocorreu não porque houvesse erro de qualquer instância, passível de ser evidenciado, mas sim pela incerteza das ações tomadas. Esse fato tem sua origem, possivelmente, no desconhecimento das regras e práticas previstas nas legislações que envolvem o mérito das funções desempenhadas 
pelas fundações. Não foi encontrado nenhum documento que comprovasse a realização de acompanhamento, monitoramento e avaliação das atividades de pesquisa junto aos pesquisadores. Os relatórios encontrados se ativeram à execução físico-financeira dos projetos a cargo da fundação. A equipe do CNPq teve a oportunidade de esclarecer algumas dúvidas de funcionários dessa FAP, relativas à legislação normatizadora, firmatura de convênios, execução da avença a serem adotadas. A partir dessa visita, os equívocos encontrados foram apontados no Relatório Técnico de Visitas e enviado à fundação, para as correções devidas.

Embora tenhamos participado de apenas uma visita, a equipe do CNPq realiza essas visitas e tivemos acesso aos relatórios de visitas técnicas e aos relatórios técnicos de outras fundações, recebidos pelo CNPq. Neste material, observou-se que esse receio dos técnicos da fundação em disponibilizar os seus documentos é um fato corriqueiro em muitas outras fundações. Dessa forma, as visitas técnicas podem ser um importante meio de transferir o conhecimento sobre a legislação e outros itens, a exemplo da FAP visitada.

Por sua vez, pelo manuseio e leitura de relatórios de visitas técnicas e relatórios técnicos de outras fundações, recebidos pelo CNPq, observou-se que esse é um fato corriqueiro em muitas outras fundações. Dessa forma, as visitas técnicas podem ser um importante meio de transferir o conhecimento sobre a legislação e outros itens, a exemplo da FAP visitada.

\subsubsection{Resultados das Entrevistas no CNPq}

No que se refere à consulta, em primeiro lugar, encontram-se as entrevistas com gestores e técnicos do CNPq envolvidos com a descentralização de recursos da União às FAP, em todos os níveis de execução. Foram realizadas 08 (oito) entrevistas, algumas gravadas, quando autorizadas, e quando não, foram feitas anotações, posteriormente conferidas com o respondente, ao final, para ratificar as respostas. Essas entrevistas foram de grande valia para o entendimento do funcionamento das rotinas das ações de descentralização de recursos pelo CNPq. Das oito entrevistas realizadas, 02 (dois) servidores se manifestaram contrários à descentralização de recursos para as FAP. Apresentaram como justificativa a pulverização dos recursos públicos destinados à C\&T\&l, incipiência ou ausência de capacitação ou preparo dos pesquisadores, do pessoal de apoio e principalmente da falta de infraestrutura para o suporte necessário à realização dos projetos de pesquisa e desenvolvimento. Outro fator apontado como negativo é a dificuldade de o CNPq acompanhar a execução dos recursos destinados às fundações. 
Para eles, essas transferências são desnecessárias como ponto de apoio regional para o desenvolvimento de C\&T.

\subsubsection{Resultados da Aplicação do Questionário}

A terceira parte da consulta foi a aplicação de questionário aos representantes de quatorze das vinte e sete FAP instaladas e que mantêm parceria com o CNPq, por meio de convênio ou acordo constituído. Esse questionário compunha-se de perguntas semiestruturadas, com perguntas abertas e fechadas, para obtenção de dados e de informações sobre a situação atual da gestão das FAP no que se refere às ações descentralizadas, bem como sobre a relação institucional mantida com o CNPq.

Esta pesquisa deve ser entendida como um estudo exploratório de caráter quantitativo e qualitativo. O retorno dos questionários aplicados foi de 51\% (cinquenta e um por cento) do total. A seguir, apresenta-se a consolidação e a análise dos resultados das respostas dos questionários aplicados às FAP, iniciando por aquelas nas quais as opções nos permitem uma consolidação quantitativa das respostas.

\subsubsection{Resultados do questionário aplicado às FAP}

Quadro 9: Consolidado das respostas dos representantes das FAP ao questionário

\begin{tabular}{|c|c|c|c|}
\hline $\mathbf{N}^{\circ}$ & Perguntas do Questionário & SIM & NÃO \\
\hline 1 & $\begin{array}{l}\text { A descentralização de recursos da União têm contribuído, efetivamente, para uma } \\
\text { descentralização regional efetiva das atividades de C\&T\&l? }\end{array}$ & 14 & 0 \\
\hline 2 & $\begin{array}{l}\text { Elas têm contribuído para um maior desenvolvimento científico e tecnológico de seu } \\
\text { Estado? }\end{array}$ & 14 & 0 \\
\hline 3 & $\begin{array}{l}\text { No caso da descentralização de recursos da União, esta FAP participa efetivamente da } \\
\text { escolha das prioridades para aplicação dos recursos? }\end{array}$ & 13 & 1 \\
\hline 5 & $\begin{array}{l}\text { Há participação de atores do poder público federal na escolha das prioridades } \\
\text { estaduais/regionais para aplicação dos recursos recebidos via descentralização de } \\
\text { recursos da União? De que forma? }\end{array}$ & 7 & 6 \\
\hline \multirow[t]{6}{*}{6} & $\begin{array}{l}\text { As parcerias e convênios com o CNPq têm contribuído para o aperfeiçoamento da } \\
\text { gestão do fomento por parte desta FAP? }\end{array}$ & 11 & 3 \\
\hline & \multicolumn{3}{|l|}{ 6.1. Este aperfeiçoamento da gestão é observado de que forma? } \\
\hline & (1) aperfeiçoamento de editais; & 9 & 5 \\
\hline & (2) processos de acompanhamento e avaliação de projetos mais sistemáticos; & 7 & 7 \\
\hline & (3) desenvolvimento de Acompanhamento e Avaliação das parcerias e convênios; & 8 & 3 \\
\hline & (4) outros. & 0 & 0 \\
\hline \multirow[t]{5}{*}{7} & Há avaliações de resultados e de impactos das parcerias com o CNPq? & & \\
\hline & (1) Em todos os casos & 7 & 2 \\
\hline & (2) Em alguns casos & 5 & 0 \\
\hline & (3) Não & 0 & 1 \\
\hline & (4) Em caso negativo ou de avaliação em apenas alguns casos, por que? & 0 & 0 \\
\hline 10 & $\begin{array}{l}\text { Os convênios e parcerias com o CNPq têm contribuído para o desenvolvimento } \\
\text { regional? }\end{array}$ & 13 & 1 \\
\hline
\end{tabular}

Fonte: Questionário aplicado pela autora às FAP. 
Nas questões de números 01 e 02, os respondentes foram unânimes em responder que a descentralização de recursos da União têm contribuído, efetivamente, para uma descentralização regional e efetiva das atividades de C\&T\&l e para um maior desenvolvimento científico e tecnológico de seu Estado. Esse fato pode ser creditado à efetividade dos esforços empreendidos para a descentralização de recursos e ações junto aos estados. Ratificou-se essa afirmativa na questão de número 10, na qual 13 (treze) respondentes disseram que os convênios e parcerias com o CNPq têm contribuído para o desenvolvimento regional.

Quanto à questão de número 03, 13 (treze) respondentes confirmaram que a FAP participa efetivamente da escolha das prioridades para a aplicação dos recursos descentralizados pela União. Somente em um caso, o representante da FAP respondeu que a sua fundação não participa das decisões para a escolha das prioridades regionais para a alocação dos recursos advindos da União. Apesar de ser um número pequeno de representantes de FAP - apenas uma entre os 14 respondentes, cerca de $7 \%$ - que indica não ter participação, isso significa que, no total, deve-se envidar esforços para que todas tenham um papel importante na escolha das prioridades. Afinal, elas são as instituições mais próximas e com melhor condições de conhecer as necessidades e demandas regionais e locais.

A seguir, encontram-se a apresentação e a análise das respostas àquelas perguntas abertas e com possibilidade de diferentes opções.

\subsubsection{Respostas das FAP às questões abertas}

À pergunta de número 4, que incidia sobre o processo de escolha de prioridades regionais ou estaduais, oito FAP responderam que realizam a escolha das prioridades por meio de seminários; comitês mistos com a Agência Federal concedente; oficinas, etc. Depreendeu-se que há a busca pela participação de outros atores para discussões e escolhas dessas prioridades regionais é frequente.

Quatro respondentes se referem à participação de instâncias do governo federal, estadual ou municipal nas escolhas das prioridades regionais, havendo também uma parcela de demanda espontânea da comunidade científica, das Instituições de Ensino Superior e das universidades. Foi afirmado por dois representantes das FAP, não haver muito critério quanto à concessão dos recursos. 
Essas formas de participação para a concessão de recursos das transferências voluntárias possam acarretar maior complexidade para a realização de monitoramento, acompanhamento e avaliação efetiva dos recursos concedidos. Aparece nas respostas que uma FAP não executa acompanhamento e avaliação nem dos impactos regionais ou estaduais do fomento concedido.

Observa-se que o CONFAP é a principal instituição que faz a interface de negociação entre as FAP e as instituições concedentes do governo federal.

\section{Respostas Questão 4: - Como se dá o processo de escolha das prioridades estaduais ou regionais?}

- Por meio de seminários; demanda do Estado em áreas do conhecimento prioritária; Se dá mediante as necessidades das pesquisadores das IES;

- $\quad$ Através de editais para pesquisadores, informando o valor a ser repassado;

- Conforme demanda espontânea e áreas de interesse do Estado; No lançamento de Editais visando o fomento à pesquisa científica e qualificação regional;

- Conforme demanda espontânea e áreas de interesse do Estado; No lançamento de Editais visando o fomento à pesquisa científica e qualificação regional;

- Com estratégicas de oficinas envolvendo gestores e pesquisadores e reunindo UnB, Embrapa e Universidade Católica para discutirem;

- Pelo Conselho Superior da Fundação e as respectivas secretarias de estado envolvidas;

- Através das reuniões do conselho, formado pelas instituições de ensino superior e os órgãos públicos de apoio e fomento ao desenvolvimento científico e tecnológico (seus representantes);

- $\quad$ No caso do PPSUS a secretaria de estado de saúde de MG prioriza as áreas temáticas do edital;

- $\quad$ Em seminários da Própria FAPESP e também nos comitês mistos da FAPESP com a Agência Federal concedente;

Primeiro no Edital depois propomos ao CNPq;

Através de Conselhos como o CONFAP e o CONCIT; e Por meio de encontros do PPA.

Na questão de número 5, quando perguntados se há participação de atores do poder público federal na escolha das prioridades estaduais ou regionais para a aplicação dos recursos recebidos da União, sete representantes de FAP responderam que Sim e seis responderam que Não. Isso leva à reflexão de que, pelo menos em 50\% das FAP, reconhece a participação do poder público nas escolhas de prioridades locais. Observado, principalmente, em casos onde há FAP ainda em processo de consolidação, em que se percebe bastante salutar essa participação do poder público nas escolhas de prioridades regionais.

Respostas Questão 5: Há participação de atores do poder público federal na escolha das prioridades estaduais/regionais para aplicação dos recursos recebidos via descentralização de recursos da União? De que forma?

- $\quad$ Não recebemos nenhuma prioridade do Governo Federal;

Procurando definir as áreas prioritárias para melhor aproveitamento dos projetos;

Através do CONFAP;

Já que os programas já são pré-estabelecidos, desta forma existem limitações formais e conceituais na utilização dos recursos, onde muitas vezes não estão alinhados com a realidade local das FAP e de certo modo inviabilizam ou reduz a ação local. O ministério da saúde participa da oficina de prioridades do PPSUS. Membros do Ministério da Saúde participam dos seminários presencialmente 
opinando e orientando a escolha dos temas indicados pelas Secretarias Estaduais sem a abrangência dos programas;

- $\quad$ Nos comitês mistos FAPESP + Agência Federal Concedente;

- $\quad$ Na escolha não, na aplicação sim. Reuniões e consultas;

- $\quad$ Através do CONFAP; e

- $\quad$ Por meio da emissão de convites para discutir sobre PPA.

Para a questão de número 06, onze representantes das FAP disseram que as parcerias e convênios com o CNPq têm contribuído para o aperfeiçoamento da gestão do fomento regional e local. Houve três abstenções.

Representantes de nove FAP afirmaram que esse aperfeiçoamento da gestão tem sido observado em lançamento de editais. Ou seja, a presença do CNPq tem sido vista de forma favorável nos estados.

Visando ao aperfeiçoamento da gestão, registraram-se sugestões de que o CNPq realize mais oficinas e treinamentos para funcionários das FAP; que haja possibilidade de mais interação do CNPq com as equipes das FAP; que o CNPq realize fiscalização, in loco, e mais amiúde dos convênios em execução; que o acompanhamento mais efetivo por parte do CNPq; que se realize mais fiscalização do fomento, pois na maioria dos convênios com as FAP, isso não é feito; que haja mais presença do CNPq nas avaliações dos projetos, desde o início até ao final de vigência dos convênios.

Respostas Questão 6.2: As parcerias e convênios com o CNPq têm contribuído para o aperfeiçoamento da gestão do fomento por parte desta FAP?

- Descentralização dos Recursos para todo o Estado, visando disponibilizar recursos de C\&T\&I para onde não existe;

- O CNPq poderia interagir mais com oficinas e treinamentos resultando em mais conhecimento com as parcerias das FAP;

- Realização de fiscalização dos fomentos;

- $\quad$ Acredito que seja um aprendizado mutuo, já que as leis normalmente não estão voltadas ao fomento;

- $\quad$ As oficinas de gestão de convênios permitindo a troca de experiências entre as FAP e o CNPq;

- Fundamenta a gestão; e

- Mais oportunidades para interação e capacitação entre as equipes.

Ainda sobre gestão, sete representantes de FAP responderam que a parceria com o CNPq tem sido importante para o aperfeiçoamento dos processos de acompanhamento e avaliação de projetos, de forma mais sistemática. E oito respondentes consideram pertinente o aprendizado com o CNPq no que se refere à gestão do Acompanhamento e Avaliação das parcerias e convênios.

À pergunta de número 07, sete respondentes disseram que a FAP realiza avaliações de resultados e de impactos das parcerias em execução com o CNPq, em todos os casos. 
Cinco FAP responderam que realizam avaliações de resultados e de impactos das parcerias em execução com o CNPq, em alguns casos e duas FAP não fazem nenhum tipo de avaliação, seja de resultados ou de impactos.

Respostas Questão 7.4: Há avaliações de resultados e de impactos das parcerias com o CNPq?

- Na maioria dos casos as FAP está realizando seminário de avaliação visando buscar o resultado e o impacto da pesquisa; e

- $\quad$ Existem avaliações por projetos, mas não de forma geral.

$\mathrm{Na}$ pergunta 8, sobre os resultados advindos da parceria com o CNPq os respondentes afirmaram ser bastante positiva essa relação de parceria para o desenvolvimento da pesquisa e desenvolvimento regional em ciência e tecnologia em seus estados, em todos os níveis que envolvem as atividades de pesquisa, como demonstrado pelas respostas mencionadas a seguir.

Respostas Questão 8: Quais os principais resultados que poderiam ser apontados?

- $\quad$ Aumento do financiamento de projetos lançados pela FAP;

- De forma geral, a cultura. Atualmente a população, principalmente científica, tem mais incentivos para se dedicar ao desenvolvimento de projetos;

- Fixação de pesquisadores em MG, bem como os resultados dos seus traalhos são aplicados no referido estado. Formação de recursos humanos (mestrado e doutorado, etc);

- Evolução das pesquisas para o SUS/Saúde, consolidação de núcleos de pesquisa, apoio a jovens pesquisadores;

- Execução total dos projetos, pois o estado tem um ganho significativo quando cada projeto tenha sido realizado conforme planejado;

- $\quad$ Crescimento institucional;

- Desenvolvimento de recursos humanos e desenvolvimento de pesquisas;

- $\quad$ Avaliação em maiores proporções;

- Melhor gestão dos Recursos;

- Desenvolvimento do setor científico e tecnológico do estado;

- $\quad$ Avanços positivos nas pesquisas no estado de MT;

- Desenvolvimento da pesquisa e do conhecimento em C\&T do estado; e

- Popularização e difusão do conhecimento.

Quanto aos impactos das atividades realizadas em decorrência da descentralização de recursos financeiros às FAP, 16 respostas foram recebidas, sendo mais de uma resposta por representante. Foram relatadas as melhorias tanto na promoção do fomento à pesquisa regional, no desenvolvimento de recursos humanos, na gestão dos recursos para aplicação em projetos de pesquisa prioritários para a região de influência de cada FAP, quanto no desenvolvimento regional na área de C\&T, conforme demonstram as respostas à Questão 9, agrupadas abaixo.

Respostas Questão 9: Cite pelo menos três aspectos que poderiam ser descritos como impactos das atividades desenvolvidas por meio da descentralização de recursos da União, no que se refere à gestão e aos avanços científicos e tecnológicos observados na área de influência desta FAP.

Maior aplicação dos recursos de C\&T no estado;

- Desenvolvimento regional de C\&T e difusão do conhecimento; 
- Fomento da pesquisa, melhora da qualidade da educação do estado e incentivo a pesquisa nos diversos ramos de ensino;

- $\quad$ Resultados positivos da pesquisa e parceria com as instituições de ensino;

- Foco dos investimentos em desenvolvimento regional, aproximação do estado e da academia e perspectiva de inovação tecnológica para o Estado;

- Pesquisas na área da saúde PPSUS tem avançado e os PRONEX tem apresentado bons resultados;

- $\quad$ Aplicação dos recursos nas prioridades do estado, oportunidade de promover o fomento à pesquisa regional:

- Desenvolvimento de recursos humanos;

- Maior organização da gestão de recursos, otimiza o uso dos recursos públicos e simplifica e agiliza os processos;

- $\quad$ Fortalecimento do sistema de C\&T\&l local, Reconhecimento da Agência como parceira da Agência Federal;

- Evolução das pesquisas nas áreas apoiadas;

- Gestão entre a FAP/CNPq amplia a participação dos pesquisadores com a descentralização dos recursos;

- $\quad$ Os resultados tem um impacto direto na sociedade mineira. Ex.: Projetos na área de saúde;

- Crescimento do interesse na atividade acadêmica e de pesquisa, envolvimento de agentes privados no fomento de forma mais efetiva; e

- Maior transparência na utilização dos recursos.

A análise das respostas da Questão 10, listadas a seguir, confirma que tem sido positiva a relação de parceria entre o CNPq e as FAP, contribuindo essa relação de parceria para o desenvolvimento regional, possibilitando maior abrangência de ação das FAP.

Respostas Questão 10: Os convênios e parcerias com o CNPq têm contribuído para o desenvolvimento regional?

- Maior abertura com as FAP para identificar as nuances regionais para aumentar a abrangência e o efetivo desenvolvimento científico e tecnológico, proporcionando a inclusão de regiões menos vislumbradas;

- Que continuasse ocorrendo as oficinas de gestão de convênios, principalmente com a utilização do SICONV, permitindo uma interação melhor, visando a transparência da gestão dos recursos;

- Visitas técnicas para conhecer a realidade local e as necessidades de apoio técnico;

- Simplificação e informatização dos procedimentos;

- $\quad$ O CNPq poderia dar mais ênfase ou seja ser mais próximo das FAP;

- $\quad$ Representação do CNPq em nível regional;

- Maior participação do CNPq nas avaliações do projeto do início ao fim; e

- $\quad$ Essa questão seria melhor respondida pela direção da FAPERGS.

Algumas respostas às consultas realizadas, tanto de representantes das FAP, quanto de representantes do CNPq, são coincidentes, entre as quais, que a gestão dos processos de transferências voluntárias carecem, na visão desses dois atores, de melhoria no método utilizado para monitoramento e avaliação; em ambos os casos, observaram-se recomendações para ampliar a participação do CNPq junto às FAP; requerem melhor interação entre as equipes; e reconhecem a necessidade de uniformização de informações para melhor gerir os processos de descentralização de recursos da União, de forma a trazer maior transparência à sociedade quanto aos gastos públicos em pesquisa e desenvolvimento nos estados. 


\section{CONSIDERAÇÕES FINAIS}

Este estudo teve por objetivo analisar a estratégia de gestão e os instrumentos utilizados pelo CNPq para realizar o acompanhamento e avaliação (A\&A) dos repasses efetuados às Fundações de Amparo à Pesquisa, por meio das transferências voluntárias da União.

Para que se pudesse compreender o estado da arte sobre esse tema do acompanhamento e avaliação das transferências voluntárias, foi importante realizar um estudo da retrospectiva histórica do processo de institucionalização da ciência e tecnologia no país. Verificou-se nesse estudo que houve, desde o início do processo, repercutidas confirmadas as desigualdades regionais no Brasil, que é uma questão estrutural.

Considerando o tema deste trabalho, deu-se ênfase, nessa retrospectiva, aos esforços para descentralização da ciência e tecnologia, no país, principalmente a partir dos anos 1980, tendo por base o pressuposto de minimizar as desigualdades entre as cinco regiões brasileiras por meio da pesquisa e desenvolvimento, voltada ao desenvolvimento regional, com foco nas prioridades regionais.

As FAP vieram estabelecer maior conectividade entre os estados, entidades federais e congêneres, tanto públicas quanto privadas, para a captação de recursos com vistas à execução da pesquisa e desenvolvimento. As FAP tornaram-se, então, instituições fortes, compreendidas no Sistema Nacional de Desenvolvimento Científico e Tecnológico do Brasil, muito embora haja grandes diferenças entre elas, algumas já consolidadas e outras ainda em processo de consolidação. As FAP se tornaram, então parceiras importantes de instituições como o CNPq.

Este estudo teve como foco analisar como se coloca o acompanhamento e avaliação no processo de gestão e descentralização financeira do CNPq às FAP. A apresentação dos dados e das informações coletadas no decorrer da pesquisa de campo, das entrevistas realizadas com gestores, técnicos do CNPq e das respostas ao questionário, aplicado aos representantes das FAP, embasaram as análises constantes dessa pesquisa e dos resultados encontrados.

Os resultados podem ser auferidos pela comparação entre o que foi proposto no planejamento para a realização da pesquisa na área de C\&T e os resultados efetivamente alcançados. Fator esse de maior complexidade quando se tratar de pesquisas que demandem maior prazo para a sua execução. Tanto mais complexa pode ser o seu 
processo de monitoramento e avaliação. Nesse sentido são muito importantes as avaliações de processo - durante - ou monitoramento continuado, que deve ser feito tanto pelas FAP quanto pelo CNPq. O CNPq realiza esse monitoramento por meio de visitas técnicas às FAP e estas também produzem relatórios técnicos parciais da evolução da execução dos projetos descentralizados e executados em parceria com o CNPq.

As transferências voluntárias dos recursos financeiros da União executadas pelo CNPq junto às FAP constituem um procedimento relativamente recente e que ainda necessita de alguns ajustes por parte dos legisladores, bem como de adequabilidade de gestão por parte dos executores do CNPq e parceiros. Para isso, é importante reunir as instâncias envolvidas em todos os níveis de execução e elaborar rotinas que possam ser entendidas e praticadas com eficiência, por todos. Essas articulações deveriam fazer parte do protocolo do convênio, sendo uma ação a ser realizada quando do monitoramento da execução dos programas e projetos desenvolvidos pelas FAP.

Um ponto importante a ser mencionado é a existência de uma visão quase consensual por parte dos gestores do CNPq que foram entrevistados pela autora, de que as FAP "não querem receber visitas técnicas do CNPq". Por sua vez, isso è contestado pelas FAP, de acordo com a pesquisa realizada junto as mesmas. Na verdade, o que os representantes das FAP expressaram é de que essas fazem questão da presença do CNPq e sugeriram, de modo inequívoco, que este Conselho participe mais dos processos de avaliação, do início ao final da execução do convênio; que faça visitas in loco; que Ihes propiciem mais treinamentos.

Em suma, pelas respostas recebidas, as FAP se mostraram interessadas em aprender mais sobre as melhores práticas de gestão para a execução de suas rotinas administrativas e demonstraram a preocupação em evitar erros. Ou seja, tem-se aí uma janela de oportunidade para que o CNPq fortaleça e solidifique a sua parceria junto às FAP.

Apesar de a prática do monitoramento e da avaliação não estarem presentes em algumas FAP, nada sugere, pelas respostas dadas ao questionário, que as ações de Estado não estejam sendo efetivas no cumprimento das metas de descentralização da pesquisa em ciência e tecnologia. Como ficou demonstrado nas estatísticas apresentadas nesta dissertação, os índices de investimentos estaduais em P\&D têm-se elevado, o que sugere impactos positivos em decorrência das ações pró-descentralização. No entanto, é certa a necessidade de indicadores e análises que demonstrem melhor esses impactos, bem como a consecução das metas. 
As três atividades utilizadas para a realização dessa pesquisa - visita técnica, entrevistas e aplicação de questionário - que conformaram a metodologia para a realização desta pesquisa foram complementares entre si, de modo a ratificar os resultados encontrados em cada uma das instâncias analisadas - gestores, técnicos do CNPq e representantes das FAP.

As questões que orientaram essa pesquisa foram satisfatoriamente respondidas. No primeiro bloco de perguntas, relativas ao caráter político e estratégico das atividades que têm viabilizado as transferências voluntárias para as FAP, foram identificados na pesquisa os critérios utilizados pelo CNPq, para a implementação dos projetos resultantes de editais de chamadas públicas para a execução das transferências voluntárias às FAP.

A definição e a publicação da nova estrutura física e arranjo institucional vieram ao encontro das necessidades de cumprimento legal, designando, portanto, área técnica que se responsabiliza pela análise e comprimento dos ritos para a descentralização de recursos e, também, de técnicos para a observação e análise dos diplomas legais envolvidos na contrapartida financeira ou de infraestrutura física e de pesquisa, em complementação aos recursos descentralizados, de acordo com a Carta de Salvador, que vige desde 2004.

Na pesquisa foi constatado que o CNPq não exerce o papel de indutor na escolha de prioridades regionais junto às FAP. Entretanto, na maioria dessas fundações, esse papel de indução é identificado pela presença do poder público federal ou estadual, representados pelas Secretarias de Estado de Ciência, Tecnologia e ás vezes o próprio Ministério da Ciência, Tecnologia e Inovação, no momento das escolhas das prioridades regionais pelos estados.

Quanto ao segundo conjunto de questões, atinentes à gestão dos procedimentos adotados pelo CNPq no monitoramento e avaliação das transferências voluntárias, verificou-se que não há um sistema informatizado específico dentro desse Conselho para esse fim. O que se identificou na pesquisa é que os técnicos responsáveis pela gestão de convênios constroem planilhas distintas para o acompanhamento dos convênios sob a sua responsabilidade. Essas planilhas estão instaladas em suas estações de trabalho, não sendo, portanto, um sistema aberto e de fácil acesso até mesmo pelos técnicos da própria área.

O CNPq não possui estrutura física ou de pessoal específico para realizar o monitoramento e a avaliação das transferências voluntárias. Justifica-se pela falta de 
recursos financeiros e humanos destinados a esse fim. Entretanto, acompanham a execução junto às FAP, na medida em as condições Ihes são disponibilizadas.

Os procedimentos de acompanhamento e avaliação dos convênios realizados pelas FAP, se compõem de seminários e workshops, com a presença de consultores ad hoc; em alguns desses eventos, técnicos do CNPq podem acompanhar os trabalhos de avaliação, se for possível a disponibilização de algum servidor da área técnica afeta à execução do projeto. Ao final desses eventos, as FAP consolidam os resultados e os enviam ao CNPq por meio de relatórios técnicos. Não se observam, porém, análises mais aprofundadas sobre esses resultados e possíveis subsídios para os processos de TV e para as políticas de descentralização. Seria também importante verificar e demonstrar os impactos dessas TV relacionando-as (ou não) aos avanços nos diversos estados que recebem as TV.

$\mathrm{O} \mathrm{CNPq}$ obedece às normas e regras adotadas pelos órgãos de controle, embora o faça de modo parcial. O CNPq não possui normas ou regras internas que sistematizem as ações inerentes às transferências voluntárias. Um Grupo de Trabalho foi designado pelo Presidente do CNPq para esse fim. Entretanto, os trabalhos, que tiveram início em maio de 2013, ainda não chegaram ao fim.

A legislação que regula as transferências voluntárias da União merece atenção importante. Em virtude das especificidades da área de ciência e tecnologia, as normas dos órgãos de controle não são adequadas ou suficientes para realizar o monitoramento e a avaliação, pois são bastante amplas e são as mesmas regras gerais utilizadas para todo o sistema federal. Inclusive o SICONV, apesar de ser um sistema criado com o propósito de tornar transparentes as ações do governo federal no tocante às suas transações financeiras, não atende às especificidades da área de C\&T, por estarem mais voltadas para as aquisições de bens, serviços, construção de estradas de rodagem, pontes e prédios públicos.

Por exemplo, é conflitante o fato de que, dentro do SICONV, o CNPq não possa visualizar algumas páginas de execução das TV pelas FAP e vice-versa. Visualiza-se o convênio somente após a conclusão do lançamento dos dados e de alguns módulos, o que ocorre, às vezes, somente ao final do processo de execução, podendo resultar em retrabalho em virtude de lançamentos indevidos e que poderiam ser evitados, se houvesse a possibilidade de acompanhamento, pelo CNPq, em tempo real. 
Ressalta-se a importância de gestões do CNPq, junto aos órgãos de criação e manutenção do SICONV, no sentido de se tornar mais amistoso esse Sistema para a área de ciência e tecnologia, com a customização do mesmo para atender às especificidades da C\&T\&I, em muito contribuiria para a melhoria da transparência da gestão de recursos transferidos voluntariamente pela União, caso deste estudo.

Consideram-se frágeis os procedimentos de execução dos recursos financeiros transferidos às FAP e por ela transferidos aos pesquisadores para a execução dos projetos de pesquisa e, consequentemente, quando da prestação de contas dos recursos recebidos pelos pesquisadores e pelas FAP, visto que para esse fim ainda não existe estruturado, no CNPq, rotinas para esse efeito. O estabelecimento dessas rotinas são o objeto de estudo do Grupo de Trabalho, constituído pelo Presidente do CNPq, como demonstrado neste estudo. Fica o CNPq sujeito aos relatórios técnicos e financeiros enviados pelas FAP para dar o processo de descentralização de recursos por encerrado.

O terceiro grupo de perguntas é relativo aos resultados efetivos das ações de transferências quanto à verificação do cumprimento dos objetivos propostos no plano de trabalho e se os resultados e metas, realmente foram alcançados quando da finalização do convênio. Esse tema é bastante controverso, daí a importância de o CNPq realizar o monitoramento continuado da execução financeira e do projeto de pesquisa, in loco, para a correção de rotas, se necessário for.

Observou-se a necessidade de maior discussão no CNPq sobre as legislações pertinentes sobre a discussão, definição, implementação, execução e monitoramento de convênios, fato que poderá ser muito útil para a formação de um senso comum quanto à melhor prática a ser adotada e quanto ao entendimento das hierarquias legais a serem obedecidas.

Como resultado geral depreendido das respostas dos representantes das FAP, é pertinente reapresentar aqui as sugestões que os mesmos propuseram, para o aperfeiçoamento da gestão dos convênios junto ao CNPq:

1. Maior abertura do CNPq junto às FAP para identificar as nuances regionais capazes de aumentar a abrangência e o efetivo desenvolvimento científico e tecnológico, proporcionando a inclusão de regiões menos vislumbradas;

2. Visitas técnicas para conhecer a realidade local e as necessidades de apoio técnico; 
3. Dar continuidade às oficinas de gestão de convênios, principalmente com a utilização do SICONV, o que permitiria uma interação melhor, visando à transparência da gestão dos recursos;

4. Representação do CNPq em nível regional;

5. Maior participação do CNPq nas avaliações do projeto do início ao fim de sua execução; e

6. Simplificação e informatização dos procedimentos administrativos.

Percebeu-se, também, grande esforço e preocupação de alguns dos técnicos e gestores para minimizar a ausência de rotinas internas que determinem responsabilidades e competências das áreas. Essa situação faz com que até o treinamento de novos servidores para a execução das tarefas se torne mais difícil, quase impossível, pois tem-se de despender grande tempo para explicar as rotinas, verbalmente. A ausência de rotinas impressas ficou comprovada em várias situações nas entrevistas. Quando se questionava: Qual é o seu trabalho? O que você faz? Onde está escrito o que você deve fazer?, a resposta era quase sempre "está na minha cabeça". Essa fala é muito impactante, pois para quem executa uma tarefa e não sabe exatamente qual a sua atribuição, não entende para que serve e qual é o resultado do seu trabalho para o CNPq, é bem possível que tenha o seu desempenho prejudicado e inibida a sua proatividade, não saber do impacto e da importância do seu trabalho no resultado final da missão do CNPq.

A ausência de um manual de normas e procedimentos é um complicador na gestão das rotinas de trabalho, principalmente porque, nos últimos cinco anos, está havendo grande rotatividade de servidores. Tanto pelo alto número de servidores concursados que tomam posse e não permanecem no cargo, pois buscam tomar posse em outro concurso público que oferece uma remuneração mais atraente, quanto pela quantidade de servidores antigos saindo como aposentados. Esses últimos causam maior prejuízo ao CNPq, pois levam consigo todo um know how adquirido durante anos de trabalho na função de técnicos e analistas de C\&T, sem deixar nenhum material escrito ou outro servidor treinado para assumir a sua função. E sabe-se: know how não se apreende de forma muito rápida.

O CNPq entende que não deve interferir na forma de execução das atividades das FAP. Cada Fundação tem a sua maneira de fazê-lo. Entretanto, avalia-se que seria pertinente a elaboração de um manual de rotinas que serviria de modelo a todas as FAP, possibilitando adaptações segundo a necessidade e a especificidade de cada FAP. Isso poderia propiciar diminuição de retrabalho aos funcionários das FAP e maior organicidade para os técnicos do CNPq, quando da realização de visitas técnicas. Entende-se que essa 
medida não seria uma interferência, mas uma orientação, que é um dos papéis do CNPq como gestor dos recursos descentralizados da União. Deve-se pensar que, em última instância, é a imagem do CNPq que aparece.

Foi perceptível certo anseio por parte de alguns dos gestores quanto à inexistência de instrumentos internos apropriados para auxiliar na gestão das parcerias com as FAP, visto ser a legislação federal, que regula o assunto, inapropriada para a área de C\&T\&l, por ser muito abrangente e destoar da área.

Sobre os processos de acompanhamento e avaliação como partes essenciais da gestão, ao início deste estudo percebeu-se certa desconfiança, por parte de alguns gestores e técnicos. Em nosso meio, falar em análise ou avaliação - ou qualquer sinônimo que possa ter o sentido de julgamento -, traz ainda, para muitos, a conotação de punição, e não a conotação do sentido pretendido, que é de se ter uma atitude institucional pró-ativa, que possibilite aproveitar as experiências para conhecimento fundamentado dos resultados das políticas, ações ou atividades, bem como possibilitar a correção rumos e procedimentos, quando esses se mostrem inadequados ou não efetivos para a realização das finalidades e objetivos estabelecidos.

Por outro lado, podemos afirmar que a grande maioria dos gestores viu nesta pesquisa a oportunidade ímpar de colaborar com o seu resultado, pois estavam diante da possibilidade de verem as informações sobre as transferências voluntárias reunidas, analisadas e consolidadas. Na verdade, esta foi a primeira iniciativa de estudo sobre o assunto. Suscitou-se o interesse, verbalizado no decorrer das entrevistas, de se ratificar o entendimento por parte do CNPq quanto às ações das FAP ou mesmo da possibilidade de implementar algumas sugestões advindas desta pesquisa, que pudessem agregar valor às ações já empreendidas pelo CNPq.

A adequação dos procedimentos de monitoramento e avaliação das transferências voluntárias de recursos da União, por parte do CNPq, poderá evitar a inconsistência dos relatórios gerados pelos sistemas de informações. Em muitos casos, os servidores têm sistemas de acompanhamento paralelo a que só eles têm acesso em suas estações de trabalho. Essa postura pode ocasionar falhas nos controles internos, as quais poderiam ser minimizadas pela disponibilização de um sistema que pudesse agregar todas as informações em um sistema único de dados. 
Outro fator que poderia melhorar o processo de monitoramento e avaliação seria a designação de um fiscal ou gestor interno de convênios - figura que é prevista em lei - que teria, efetivamente, a função de colaborador para a melhor execução do processo, observando lacunas e inconsistências com os normativos, pois operações realizadas fora dos normativos vigentes só acarretam notificações dos órgãos de controle e prejuízo à imagem do CNPq.

Sugere-se que, para a melhor gestão dos processos de transferência voluntária da União, tenham prioridade as normativas internas que disciplinam as transferências voluntárias; a criação dos fluxos das rotinas pertinentes; oferta de treinamento e capacitação para os técnicos do CNPq; reuniões frequentes com a equipe para uniformizar informações; demandar da área de informática que os sistemas utilizados sejam interligados, tornando mais fieis as informações produzidas e divulgadas ao público.

Observa-se que há bastante trabalho ainda por ser feito em vários níveis de ação e de estratégia para a continuidade e efetividade das políticas de descentralização da pesquisa em ciência e tecnologia, principalmente àquelas direcionadas a mitigar as desigualdades regionais nesse campo, como restou demonstrado nesse estudo. E sendo esse um dos eixos da Estratégia Nacional de Ciência e Tecnologia para o desenvolvimento nacional e erradicação da pobreza, pressupõe-se ser prioridade do CNPq sanar os descompassos ainda presentes, para a melhoria da gestão de convênios sob a sua responsabilidade.

Nesse sentido, é que frente aos estudos realizados e o conhecimento adquirido, espera-se poder contribuir com o CNPq nos processos de melhoria na gestão das transferências voluntárias relativas a descentralização de recursos da União às Fundações Estaduais de Amparo, para fomentar a execução da Política Nacional de Ciência e Tecnologia. Consequentemente, a expectativa é a de colaborar para a melhoria dos processos de acompanhamento, monitoramento e avaliação dos resultados advindos dessas ações de Estado. 


\section{REFERÊNCIAS BIBLIOGRÁFICAS}

ACADEMIA BRASILEIRA DE CIÊNCIAS. "Science in Brazil". Editora Rio de Janeiro-RJ, 2002.

AGÊNCIA BRASILEIRA DA INOVAÇÃO (FINEP). Fundos Setoriais. Brasília-DF. Disponível em:< http://www.finep.gov.br/pagina.asp?pag=fundos o que sao $>$ Acesso em: 23.09.2013 e 10.03.2014.

ALBUQUERQUE, Lynaldo Cavalcanti de; ROCHA, Ivan. Estudo do Desequilíbrio Econômico Inter-Regional: Ciência, Tecnologia e Regionalização: Brasília: Editora IBICT, 1994.

ALBUQUERQUE, Lynaldo Cavalcanti de; ROCHA NETO, Ivan. Ciência, Tecnologia e Regionalização: descentralização, inovação e tecnologias sociais. Editora Garamond. Rio de Janeiro, 2005.

ANDRADE, Jackeline Amantino de; MACÊDO, Caroliny Wanderley de. Ciência e Tecnologia para o Desenvolvimento Regional. Revista Política Pública, São Luís, v.16, n.1, p. 67-78, jan./jun. 2012.

ANPAD. XXXVI Encontro de 22 a 26 de 2012. Recursos de Convênio entre Fundações de Apoio e Universidades Federais no Brasil: um estudo dos acórdãos do Tribunal de Contas da União (TCU). Rio de Janeiro-RJ.

ANSELMO, Fabio Paceli (Coord.). Indicadores estaduais de ciência e tecnologia. Brasília: Ministério da Ciência e Tecnologia (MCT), 2003.

ANDRADE, Thales. As Elites Tecnológicas. Revista Política Hoje, Vol. 20, n.1, 2011,p. 299. ARBIX, G. Inovar ou inovar: a indústria brasileira entre o passado e o futuro, São Paulo: Editora Papagaio, 2007.

ARENA, Vilma Aparecida e TEIXEIRA, Rogério de Assis. As Transferências Voluntárias e o Siconv - Portal de Convênios. ANGHER, ANNE JOYCE. Vade Mecum; acadêmico de direito. 12 $2^{\mathrm{a}}$ Ed. São Paulo: Rideel, 2011.

ASSIS, Renato Aguiar. PRÉ-SAL: impasses e perspectivas. Salvador: Instituto dos Auditores Fiscais do Estado da Bahia-IAF, outubro (2013). Disponível em: <www.iaf.org.br>. Acesso em: 20.12.2013.

AZAMBUJA, D. Introdução à ciência política. Porto Alegre: Editora Globo, 1969, 411 p. BARBETTA, P. A. Estatística Aplicada às Ciências Sociais. $7^{\mathrm{a}}$ Ed. Florianópolis: Ed. UFSC, 2010.

BARROS, Fernando Antonio Ferreira de. Confrontos e Contrastes Regionais da Ciência e Tecnologia no Brasil. Editora Paralelo 15. Brasília: UnB, 1999.

BASTOS NETO, Murilo de Miranda. Manual Prático de Convênios Federais com ênfase no Sistema de Gestão de Convênios - SICONV. Brasília Editora, 2012, 980 p. 
BAUER MW, Gaskell G. Análise de conteúdo clássica: uma revisão. In: Bauer MW, Gaskell G. Pesquisa qualitativa com texto, imagem e som: um manual prático. 3a ed. Petrópolis (RJ): Vozes; 2002. p.189-217.

BITTENCOURT, Sidney. Manual de convênios administrativos, 2012. $2^{\mathrm{a}}$ Edição. Biblioteca Digital do Superior Tribunal de Justiça. Disponível em: http://bdjur.stj.jus.br/dspace/handle/2011/40060 Acesso em: 17.02.14.

BOBBIO, N. 1909 - Dicionário de Política I Norberto Bobbio, Nicola Matteucci e Gianfranco Pasquino; trad. Carmen C, Varriale et ai.; coord. trad. João Ferreira; rev. geral João Ferreira e Luis Guerreiro Pinto Cacais. Brasília: Editora Universidade de Brasília, 1․ ed., 1998. Vol. 1: 674 p. (total: 1.330 p.) Vários Colaboradores. Obra em 2v.

BONAVIDES, P. “Ciência Política”. São Paulo: Malheiros Editores, 15a Edição, 2008.

BRASIL. SECRETARIA DA CIÊNCIA E TECNOLOGIA/PR. A Política Brasileira de Ciência e Tecnologia: 1990/1995. 2ª Ed. Rev. Brasília: SCT, 1990. 126 p.: il.

BRASIL. PRESIDÊNCIA DA REPÚBLICA. II Plano Nacional de Desenvolvimento - 197579. Editora Brasília: Imprensa Oficial, 1974.

Lei $n^{0}$ 12.858, de 09 de setembro de 2013. Disponível em: <http://www.planalto.gov.br/CCIVIL 03/ Ato2011-2014/2013/Lei/L12858.htm>. Acesso em: 20.12.2013.

Lei $\mathrm{n}^{\circ}$ 7.827, de 27 de setembro de 1989. Disponível em:

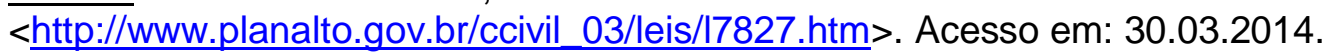

Lei $n^{\circ}$ 12.919, de 24 de dezembro de 2013. Elaboração e Execução da Lei Orçamentária de 2014 Disponível em: www.planalto.gov.br/ccivil_03/_Ato2011.../2013/Lei/L12919.htm>. Acesso em: 30.03.2014.

BRASIL. Desenvolvimento Regional para a Integração Nacional. Palestra apresentada durante o Fórum Nacional Consecti e Confap, realizada nos dias 12 e 13 de novembro/2012, em Macapá, pelo coordenador geral de Programas Sub-Regionais da Secretaria de Desenvolvimento Regional, Walber Santana Santos.

BRASIL. Secretaria de Planejamento/PR. III Plano Básico de Desenvolvimento Científico e Tecnológico 1980-85. Ação Programada em Ciência e Tecnologia. Editora Coronário Ltda. Brasília-DF: SEPLAN/CNPq, 1984.

BRASIL. MINISTÉRIO DA INTEGRAÇÃO NACIONAL (MI). Nova Política Nacional de Desenvolvimento Regional - PNDR II, 2012. Disponível em: $<$ http://www.integracao.gov.br/web/guest/nova-politica-nacional-de-desenvolvimentoregional>. Acesso em: 22/09/2013

BRASIL. MINISTÉRIO DA CIÊNCIA E TECNOLOGIA E INOVAÇÃO (MCTI). Plano De Ação 2007-2010: Ciência, Tecnologia e Inovação para o Desenvolvimento Nacional. BRASIL, MCTI, 2006.

PLANO DE AÇÃO MCTI 2007-2010: Resumo Executivo - Objetivos das 21 Linhas de Ação. BRASIL, MCTI, 2006. 
Estratégia Nacional de Ciência, Tecnologia e Inovação 2012 - 2015. Balanço das Atividades Estruturantes 2011. BRASIL, MCTI, 2012.

. MINISTÉRIO DA CIÊNCIA TECNOLOGIA E INOVAÇÃO. Estratégia Nacional de Ciência, Tecnologia e Inovação (ENCTI) - 2012-2015. Brasília, DF: MCTI, 2011.

BRASIL. MINISTÉRIO DO PLANEJAMENTO, ORÇAMENTO E GESTÃO. PLANO PLURIANUAL (PPA) 2007 - 2011 e 2012 - 2015. Brasília: MPOG, 2011.

BRASIL. TRIBUNAL DE CONTAS DA UNIÃO. Convênios e outros repasses. 4ª . Edição Brasília, DF, Secretaria-Geral de Controle Externo. TCU, 2013. 80 p.

CAGNIN, M.A.H. e DA SILVA, Darly Henriques. A Ação de Fomento na História do CNPq, Assessoria Editorial, Brasília, DF. MCT/CNPq,1987, p. 13.

CAREGNATO RCA, MUTTI, R.. Pesquisa Qualitativa: Análise de Discurso versus Análise de Conteúdo, 2006, Out-Dez; 15(4): 679-84.

CARGNIN, A. P. e LIMA, R. S. Desenvolvimento regional e governança: ação estatal e participação social. Textos para Discussão $n^{0} 59$. Fundação de Economia e Estatística FEE. Secretaria de Planejamento e Gestão. Governo do Estado do Rio Grande do Sul. Porto Alegre, março de 2009.

CARVALHO DA SILVA, Alberto. Descentralização em Política de Ciência e Tecnologia. Revista Estudos Avançados.Vol.14nº (39). São Paulo: SP, IEA-USP, 2000.

CASSIOLATO, J. E.; LASTRES, H. M. M. Globalização e inovação localizada: experiências de sistemas locais no Mercosul. 1ª Edição. Brasília: IBICT, 1999.

CASSIOLATO, J. E.; LASTRES, H. M. M. O foco em arranjos produtivos e inovativos locais de micro e pequenas empresas. In: LASTRES, H. M. M. et. al. (Org.). Pequena empresa: cooperação e desenvolvimento local. Editora Relume Dumará, Rio de Janeiro, 2003.

CASSIOLATO, J. E.; LASTRES, H. M. M. Sistemas de inovação: políticas e perspectivas. Parcerias estratégicas. Revista do Centro de Estudos Estratégicos do Ministério da Ciência e Tecnologia, v. 4, p. 144-153, 2000.

CARLOTA PEREZ AND LUC SOETE, "Catching up in technology: entry barriers and windows of opportunity", in Giovanni Dosi et. al., eds., Technical Change and Economic Theory, (London: Pinter Publishers, 1988), 458-479.

CAVALCANTE, LRMT et. al. Formulação de Políticas de Ciência, Tecnologia e Inovação em Nível Subnacional: Isomorfismo e Aderência às realidades Regionais. "Journal of technology management \& innovation. Research Group", Volume 2, Issue 2, p. 136147. 2007, ISSN: 0718-2724. Disponível em: <http://www.jotmi.org>. Acesso em: 30.09.2013.

CAVALCANTE, Pedro e NOGUEIRA, Ronaldo. Avaliação e monitoramento: Institucionalização na Gestão das Políticas Públicas do Governo Federal. Revista de Políticas Públicas e Gestão Governamental. Vol. 9 - No 1 Jan/Jun 2010.

CAVALCANTE, Luiz Ricardo. Desigualdades Regionais em Ciência, Tecnologia e Inovação (Ct\&l) no Brasil: Uma Análise de sua evolução recente. Texto para Discussão, 1574. IPEA, 2011. Rio de Janeiro-RJ, fevereiro de 2011. 
CAVARZAN, Gustavo Machado. Economia, Discurso e Poder: Os Bastidores Políticos do Segundo Plano Nacional de Desenvolvimento (II PND), PPG-História. UFRGS. v. 1, $\mathrm{n}^{0} 1$, 2008.

CENTRO DE GESTÃO E ESTUDOS ESTRATÉGICOS (CGEE). Descentralização do Fomento à Ciência, Tecnologia e Inovação no Brasil. Brasília, 2010.

CONSELHO NACIONAL DE DENSENVOÇLVIMENTO CIENTÍFICO E TECNOLÓGICO CNPq. Relatório de Gestão Institucional, 2003. Brasília-DF: CNPq.

Relatório de Gestão Institucional, 2004. Brasília-DF: CNPq.

Relatório Técnico dos Sistemas Estaduais de C\&T - PQ-0651/Nov/80.

. Diretório dos Grupos de Pesquisa no Brasil e Fomento do CNPq, AEI - Séries Históricas do Diretório dos Grupos de Pesquisa (DGP). Distribuição dos Grupos de Pesquisa segundo a região geográfica - 1993-2010. Brasília-DF: CNPq. Disponível em: <http://www.cnpq.br/estatisticas/sérieshistóricas.htm>. Acesso em 09.08.13.

.Executive Summary: Regional Policies, 2011, p. 19-23. Disponível em: <http://www.oecd.org/gov/regional-policy/47743581.pdf>. Acesso em: 12.09.2013.

DIAS, Rafael de Brito. Sessenta anos de política científica e tecnológica no Brasil. Campinas, SP. Editora da Unicamp, 2012.

FRANCISCO, Lourdes Terezinha dos Santos Tome. Indicadores para Avaliação de Resultados de Projetos de Pesquisa Científica e Tecnológica. 2002. 128f. Dissertação (Mestrado em Administração) - Universidade Federal do Rio Grande do Sul. Porto Alegre.

FUNDAÇÃO DE APOIO À PESQUISA DO ESTADO DE SÃO PAULO (FAPESP). Perfil e trajetória acadêmico-profissional de bolsistas da FAPESP. SÃO PAULO, 2008, p.15)

FURTADO, Celso. Formação Econômica do Brasil. São Paulo: Editora Companhia das Letras, 2007.

FURTADO, André Tosi. Novos Arranjos Produtivos, Estado e Gestão da Pesquisa Pública. Tecnociências. Revista Ciência e Cultura, nº 57. Vol. 1, pp.41 a 45. São Paulo, 2005.

GALVÃO, A. C. F. Política de Desenvolvimento Regional e Inovação: Lições para o Brasil da experiência europeia. Campinas, 2003. 272 p. Ed. Garamond. Rio de Janeiro, 2004.

GIL, Antônio Carlos. Como Elaborar Projetos de Pesquisa. Editora Atlas, 1996. São Paulo-SP.

GÜNTHER, H., Brito, S. M. O., \& Silva, M. S. M. M. (1989). Relação entrevistador entrevistado: Um exemplo de técnica de entrevista com grupos marginalizados: Meninos na rua. Psicologia: Reflexão e Crítica, 4 (1/2), 12-23.

GÜNTHER, H. \& Lopes, Jr., J. (1990). Perguntas abertas VS perguntas fechadas: Uma comparação empírica. Psicologia: Teoria e Pesquisa, 6, 203-213. 
GÜNTHER, Hartmut. Universidade de Brasília Pesquisa Qualitativa Versus Quantitativa. Psic.: Teor. e Pesq., Brasília, Mai-Ago 2006, Vol. 22 n. 2, pp. 201-210.

KONDO, Edson Kenji. Desenvolvendo Indicadores Estratégicos em Ciência e Tecnologia: as Principais Questões. Ciência da Informação, Brasília, v.27, n.2, p. 128133, maio/ago. 1998.

LEMOS, C. "Inovação na era do conhecimento", Parcerias Estratégicas, n. 08, p.157-179, 2000.

LEMOS, Dannyela da Cunha e CÁRIO, Silvio Antonio Ferraz. A Evolução das Políticas de Ciência e Tecnologia no Brasil e a Incorporação da Inovação. Conferência Internacional LALICS 2013 "Sistemas Nacionais de Inovação e Políticas de CTI para um Desenvolvimento Inclusivo e Sustentável", 11 e 12 de Novembro, 2013, Rio de Janeiro, Brasil.

LIVRO AZUL. $4^{a}$ Conferência Nacional de Ciência e Tecnologia. Política de Estado para ciência, tecnologia e inovação com vistas ao Desenvolvimento Sustentável. Brasil, 2010.

LONGO, Waldimir Pirró e. O Desenvolvimento Científico e Tecnológico do Brasil e suas Perspectivas Frente aos Desafios do Mundo Moderno. COLEÇÃO BRASIL: 500 ANOS, Vol II, Editora da Universidade da Amazônia, Belém (2000).

MARCELINO, G. F.; VASCONCELLOS, E. Barreiras e sugestões para a implantação dos sistemas estaduais de desenvolvimento científico e tecnológico. Revista de Administração de Empresas, v. 24, n. 4, p. 37-38, out./dez. 1984.

MARTINS, Humberto E. de Paula; CASTRO, Ariane B. de; SOUSA, Graciele de Fátima. Concentração Regional das Atividades de Ciência e Tecnologia (C\&T) no Brasil: Uma Análise Interestadual. XIII Encontro da Associação Nacional de Pós-Graduação e Pesquisa em Planejamento Urbano e Regional. 25 a 29 de Maio de 2009. Florianópolis Santa Catarina - Brasil.

MARQUES, M. B. Gestão, Planejamento e Avaliação de Políticas de Ciência e Tecnologia: hora de rever? Revista Ciência e Saúde Coletiva. Rio de Janeiro, v. 4, n. 2, p. 383-392, 1999.

MARTINS, Teonio Wellington. Transferências Voluntárias no Brasil: critérios para distribuição de recursos para os municípios e estados brasileiros. Especialização em Orçamento Público. ISC/TCU, 2010.

MATOS, Patrícia de Oliveira. Análise dos planos de desenvolvimento elaborados no Brasil após o II PND. Dissertação (mestrado) ESALQ/USP - Piracicaba, 2002. 184 p.

M.C. DE SOUZA PAULA \& T.W. SÁENZ. Elaboração, A \& A de Projetos: Conceitos Básicos e Instrumentos. Brasília-DF, 2001.

MONTOYAMA, Shozo et al. 500 Anos de C\&T no Brasil. Suplemento Especial, Fapesp Pesquisa, No.52, abril de 2000.

MINAYO, Maria Cecília de Souza (org.) Pesquisa Social: Teoria, método e criatividade. Editora Vozes Ltda, $7^{a}$ Edição (1997). Petropolis-RJ. 
MONTOYAMA, Shozo et. al. 500 Anos de C\&T no Brasil. Revista Pesquisa FAPESP, Suplemento Especial, № 52, Abril/2000.

NEVES, Clarissa Eckert Baeta. Institucionalização da pesquisa e sistemas decisórios. In: FRANCO, Maria Estela Dal Pai; MOROSINI, Marília Costa (Orgs.). Universidade e pesquisa: políticas, discursos e práticas. Passo Fundo: UPF , 1999.

Oficina de Gestão de Convênios, $2^{\mathrm{a}}$ : os pontos de vista jurídico, de monitoramento e de controladoria. Brasília, 06 e 7 de maio de 2014.

ORGANIZAÇÃO PARA COOPERAÇÃO E DESENVOLVIMENTO ECONÔMICO (OCDE). Asymmetries Regions. "OECD Reviews of Regional Innovation: Regions and Innovation Policy". Disponível em:<www.oecd.org/regional/regionsandinnovationpolicy $>$.

Acesso em:

05.09.2013

OHAYON, Pierre. Metodologia de avaliação "ex-post" de projetos de pesquisa em órgãos governamentais de coordenação de apoio à P\&D do Brasil e da França. 1985. Tese (Doutorado) - Universidade de São Paulo, Programa de Pós-Graduação em Administração/FEA, São Paulo-SP.

PEIXOTO, Fernanda Maciel. Painéis de indicadores Financeiros e Operacionais para Alocação de Recursos: o caso FAPEMIG. 2005. 335f. Dissertação (Mestrado em Administração). Universidade Federal de Uberlândia. Uberlândia-MG.

RIP, Arie, Desafios para a Avaliação de P\&D. University of Twente. ano 49, n. 2, abr./jun. 1998.

ROCHA NETO, I. Ciência, Tecnologia e Inovação: Conceitos Básicos. Brasília: SEBRAE/CNPq/ABIPTI. 1996.

RÜCKERT, ALDOMAR ARNALDO. Políticas territoriais, ciência \& tecnologia e a ação de atores locais e regionais. O Pólo de Modernização Tecnológica da Serra - Rio Grande do Sul - Bras, Sociologias, Porto Alegre, ano 6, nº 11, jan/jun 2004, p. 148-183. Disponível em: http://www.scielo.br/pdf/soc/n11/n11a08.pdf. Acesso em: 14.02.14

SANTOS, R. N. M.; KOBASHI, N. Y. Aspectos metodológicos da produção de indicadores em Ciência da Informação. In: ENCONTRO NACIONAL DE CIENCIA DA INFORMACAO (CINFORM): INFORMACAO, CONHECIMENTO E SOCIEDADE DIGITAL. 2005. Anais. Salvador: Universidade Federal da Bahia (UFBA). v. 1.

SARAVIA, Enrique. Introdução à Teoria da Política Pública. Publicações. Coletânea de Políticas Públicas - Vol.1, 2006. ENAP, Brasília-DF.

SBRAGGIA, Roberto. (1984) Avaliação do desempenho dos projetos em instituições de pesquisa: um estudo empírico dentro do setor de tecnologia industrial. Revista de Administração. v.19, n.1, jan - mar, p. 83-93.

SEADI, C.F.; FRACASSO, E.M.; SANTOS, L.T. Indicadores para avaliação de resultados de um projeto na área de materiais. 2003. Disponível em: www.presidentekennedy.br/recadm/edicao2/artigo0.pdf. Acesso em: 13.08.2014.

SCHWARTZMAN, Simon. A Pesquisa Científica e o Interesse Público. Revista Brasileira de Inovação. 2002. Disponível em: http://br.monografias.com/trabalhos. Acesso em: 
10.08.2014. 
SENRA, Kelson Vieira. Cinquenta Anos de Políticas Públicas Federais de Desenvolvimento Regional no Brasil. XIV Encontro Nacional da ANPUR, Maio de 2011. Rio de Janeiro - RJ - $\quad$ Brasil. Disponível em: http://www.anpur.org.br/revista/rbeur/index.php/anais/article/view/3649/3574 Acesso em:

17.02.14

SEVERINO, Antônio Joaquim. Metodologia do Trabalho Científico. Editora Cortez. São Paulo, 2000.

SICSÚ, A. B. e Lima; J. P. R. Regionalização das Políticas de C \&T: concepção, ações e propostas tendo em conta o caso do Nordeste. Revista Parcerias Estratégicas, MCTI/CGEE, no 13, p. 23-41. Dezembro, 2001.

SICSÚ, A. B.; BOLAÑO, C. R. S, Ciência, tecnologia e desenvolvimento regional. Revista Brasileira de Gestão e Desenvolvimento Regional, v. 3, n. 1, p. 23-50, jan./abr. 2007.

SILVA, Cylon Gonçalves e MELO, Lúcia Carvalho Pinto de (coord.). Ciência, Tecnologia e Inovação. Desafios para a sociedade brasileira. Livro Verde. Brasília: MCT e Academia Brasileira de Ciências, 2001.

SILVA, E. F. C. A emergência de um novo paradigma nas políticas de formação de recursos humanos em ciência e tecnologia no Brasil: Uma análise do Programa RHAE. Brasília, 1996. 160p. Dissertação. (Mestrado em Sociologia) - UnB, SOL.

SILVA, Rosa Eliane Dias Rodrigues. Ciência e Tecnologia nas Constituições Brasileiras. Da Vinculação de Receitas: O Caso das Fundações de Apoio à Pesquisa FAP. Dissertação de Mestrado (Desenvolvimento Sustentável), Universidade de Brasília Brasília: UNB, 2008.

SIMÕES, Rodrigo et. al. Revista Brasileira de Inovação. Volume 4, Número 1, Janeiro / Junho 2005.

STREET, Penny; BARKER, Katharine. Evaluating the impacts of buildings energy research in the UK Research Evaluation. Vol. 4, número 4, p. 171179. Dezembro, 1998.

THEIS, I. M. e DAGNINO, R. P. Política científica e tecnológica e desenvolvimento geográfico desigual no Brasil. In: VII Jornadas Latinoamericanas de Estudos Sociais da Ciência e da Tecnologia. Rio de Janeiro. Anais. Rio de Janeiro: ESOCITE 2008. Disponível em: < www.necso.ufrj.br/esocite2008/trabalhos/35925.doc> Acesso em: 21 out. 2013.

TENÓRIO, Fernando Guilherme. Cidadania e Desenvolvimento Local: casos brasileiros. IX Congreso Internacional del CLAD sobre la Reforma del Estado y de la Administración Pública, Madrid, España, 2 - 5 Nov. 2004.

TURINE, Marcelo A. S.; CARROMEU, Camilo; Márcio A.I da Silva; CAGNIN, Maria Istela. 10/06/2011. Revista Eletrônica de Jornalismo Científico. Artigo. Disponível em: < http://www.comciencia.br/comciencia/?section=8\&edicao=67\&id=851> Acesso em: 28.03.2014.

TURINE, Marcelo A. S.; CARROMEU, Camilo; DA SILVA, Márcio A.I; CAGNIN, Maria Istela. Gestão Pública Flexível e Ágil por meio do Sigfap. ComCiência no.129, Campinas 2011.

T. W. S. Sánchez; M. C. S. Paula. Ministério da Ciência, Tecnologia e Inovação: CGEE, Revista Parcerias Estratégicas, $n^{\circ}$ 13, 2001. Brasília, DF. 
VAINER. C. B. Fragmentação e projeto nacional: desafios para o planejamento. In: DINIZ, Clélio Campolina, (org.) Políticas de Desenvolvimento Regional: desafios e perspectivas à luz das experiências da União Europeia e do Brasil. Brasília, Editora da Universidade, 2007. pp. 103-130.

VELOSO, F. de A. Filho e NOGUEIRA, Jorge Madeira. O Sistema Nacional de Desenvolvimento Científico e Tecnológico e a Promoção Econômica de Regiões e Localidades no Brasil. Estudos Geográficos, Rio Claro, 4(2): 01-15 dezembro, 2006. Disponível em: www.rc.unesp.br/igce/grad/geografia/revista.htm Acesso em: 19.03.2014.

VIDEIRA, Antonio Augusto Passos. 25 anos de MCT: raízes históricas da criação de um ministério - Rio de Janeiro, RJ: Centro de Gestão e Estudos Estratégicos, 2010, 176 p.

VERONESE, A. A busca de um novo modelo de gestão para a ciência, tecnologia e inovação na política do MCT (1995-2002), RAP Rio de Janeiro 40(1):107-25, Jan./Fev. 2006.

WORTHEN, Blaine R.; SANDERS, James R.; FITZPATRICK, Jody L. Avaliação de Programas: concepções e práticas. Traduzido por Dinah de Abreu Azevedo. Editora Gente. São Paulo, 2004.

Sítios visitados

intranet.cnpq WWW.cnpq.br

WWW.mcti.gov.br WWW.sic

onv.gov.br http://censo2010.i

bge.gov.br

http://www.opovo.com.br/app/opovo/fortaleza/2012/04/28/noticiasjornalfortaleza

http://www.sefaz.am.gov.br

http://www.seinfra.am.gov.br http://www.transparencia

.am.gov.br/transpprd http://www2.e-

siga.am.gov.br/portal/page/portal/esiga

http://www.integracao.gov.br/web/guest/nova-politica-nacional-de-desenvolvimento-

regional. www.revistapoliticaspublicas.ufma.br/site. 


\section{ANEXO A}

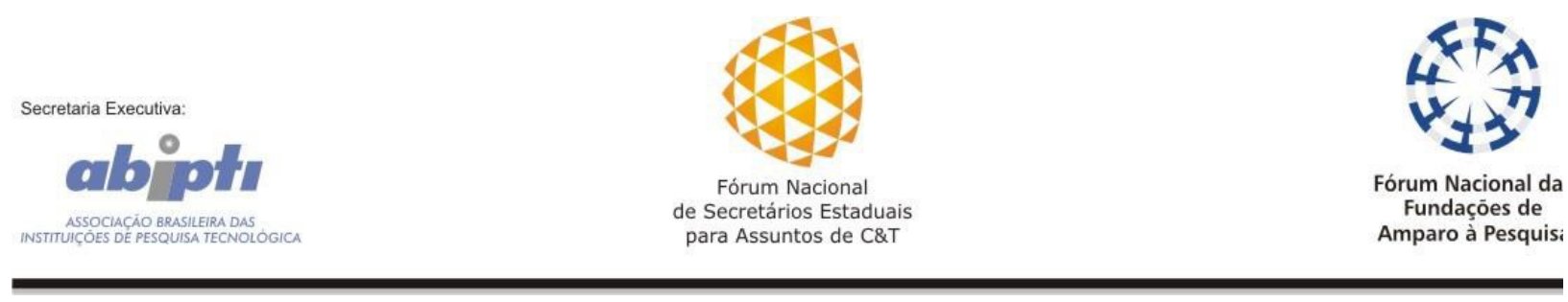

\section{Of. FÓRUM Nº 297 / 04}

Salvador, 15 de junho de 2004

\section{Exmo. Sr.}

\section{Ministro Eduardo Campos}

Reunidos na cidade de Salvador (BA), nos dias 14 e 15 de junho de 2004, o Fórum Nacional de Secretários Estaduais para Assuntos de Ciência e Tecnologia e o Fórum Nacional das Fundações de Amparo à Pesquisa aprovam a mensagem apresentada a seguir, com as seguintes considerações:

a realidade brasileira impõe medidas urgentes relativas ao desenvolvimento regional em Ciência e Tecnologia e a nacionalização dos recursos está estabelecida como eixo norteador do planejamento estratégico formulado pelo MCT;

a preservação do pacto federativo, no que diz respeito à Ciência e Tecnologia, passa pela implementação e consolidação de parcerias entre os Estados e a União;

o desenvolvimento do setor só se viabilizará com investimentos do governo federal, somados ao crescente interesse dos governos estaduais em promover o desenvolvimento local em CT\&l;

as parcerias entre a União e os Estados representam o crescimento significativo de recursos para o desenvolvimento em todo o território nacional e, no estabelecimento de tais parcerias, as desigualdades regionais devem ser levadas em conta e critérios devem ser fixados de forma a se constituírem como instrumento para a gradual superação das desproporções existentes;

a fixação de critério diferenciado por Estado, com estabelecimento de mecanismos de correção da realidade atual, deve ser entendida como ação afirmativa para a efetiva nacionalização do sistema de CT\&l;

os significativos avanços obtidos na relação entre os Estados e a União com a efetivação dos convênios firmados em 2003; e 
a solicitação, por fim, do Sr. ministro ao Fórum Nacional de Secretários Estaduais para Assuntos de CT\&l de formulação de novos critérios que possam ser adotados para a consolidação vitoriosa das parcerias com o MCT.

Nesse sentido, os fóruns de Secretários Estaduais e de FAPs vêm a V.Exa. propor as seguintes ações e critérios a serem adotados entre o MCT e os Estados:

1- $\quad$ Continuidade e ampliação das parcerias firmadas em 2003 e daquelas estabelecidas anteriormente, que possibilitaram aos Estados a execução de programas como o Prossiga, o Programa Nacional de Monitoramento do Tempo, Clima e Recursos Hídricos, a Rede Proteoma, o PPP, as bolsas de Desenvolvimento Científico Regional (DCR), o PAPPE, o PIBIC e o Pronex.

2- $\quad$ Apoio aos projetos estruturantes estaduais e/ou interestaduais apresentados pelas Unidades da Federação ao MCT, muitos sem resposta do MCT até o presente momento;

3- $\quad$ Contratação de novos convênios, especialmente no que se refere :

a) às ações de diversificação da matriz energética nacional, em especial ao Programa Nacional de Produção e Uso do Biodiesel;

b) à formação e fixação de recursos humanos avançados;

c) ao desenvolvimento tecnológico de Arranjos Produtivos Locais;

d) à constituição e consolidação de Parques Tecnológicos;

e) à capacitação tecnológica através de CVTs ou projetos semelhantes dos Estados;

f) à inclusão digital;

g) à difusão e popularização da ciência;

h) à constituição de novas incubadoras de empresas e consolidação das já existentes.

i) à geração de indicadores estaduais de Ciência e Tecnologia.

j) à estadualização de parcela dos recursos destinados à infra-estrutura em pesquisa através do fundo setorial CT-Infra.

k) à operacionalização do PADCT, em parceria com os Estados.

I) ao Programa de Desenvolvimento da Nanociência e da Nanotecnologia. 
4- Desburocratização e agilização na liberação dos recursos gerenciados pela Finep, mediante convênios com os Estados.

5- $\quad$ Participação dos fóruns nas ações relacionadas aos Institutos do Milênio.

6- $\quad$ Adoção dos seguintes critérios para contrapartidas, levando-se em consideração o PIB e a base científica dos Estados e a necessária correção das desigualdades existentes.

\begin{tabular}{|l|l|l|}
\hline Grupos & Unidades da Federação & Critério \\
\hline Grupo A & SP & Contrapartida do Estado na proporção \\
& de $1 \times 1$ de aporte do MCT \\
\hline Grupo B & MG, RJ, RS & Contrapartida do Estado na proporção \\
\hline Grupo C & $\begin{array}{l}\text { AM, PA, CE, PE, BA, PB, DF, } \\
\text { GO, MT, MS, PR, SC e ES }\end{array}$ & Contrapartida do Estado na proporção \\
& de $1 \times 2$ de aporte do MCT $=: 2$ \\
\hline Grupo D & AP, AC, RO, RR, TO, PI, MA, & Contrapartida do Estado na proporção \\
& RN, SE e AL. & de $1 \times 3$ de aporte do MCT $=: 3$ \\
\hline
\end{tabular}

Certos de contar com a atenção que historicamente esse Ministério tem dispensado aos Estados, renovamos nossos votos de estima e consideração.

Atenciosamente,

\section{Denise Carvalho}

Presidente

Fórum Nacional de Secretários Estaduais para Assuntos de CT\&I

\section{Jorge Bounassar Filho}

Presidente

Fórum Nacional das Fundações Estaduais de Amparo à Pesquisa 



\section{ANEXO B}

Programas executados pelo CNPq e FAP na forma de transferências voluntárias

\begin{tabular}{|c|c|c|c|c|}
\hline \multicolumn{5}{|c|}{ PARCERIAS DO CNPq } \\
\hline ID & REGIÃO & NOME & MODALIDADE & PROGRAMA/PROJETO \\
\hline 1 & Norte & AM Fundação de Amparo à Pesquisa do Estado do Amazonas - FAPEAM & Acordo & Instituto Nacional de Ciência e Tecnologia - INCT \\
\hline 2 & Norte & AM Fundação de Amparo à Pesquisa do Estado do Amazonas - FAPEAM & Convênio & $\begin{array}{c}\text { Promoção do Desenvolvimento Científico, Tecnológico e de Inovação na área de } \\
\text { Biocombustíveis no Estado do Amazonas }\end{array}$ \\
\hline 3 & Norte & AM Fundação de Amparo à Pesquisa do Estado do Amazonas - FAPEAM & Outras & Bolsas de Doutorado no País (GD) - Encomenda \\
\hline 4 & Norte & AM Fundação de Amparo à Pesquisa do Estado do Amazonas - FAPEAM & Outras & Programa de Formação de Doutores em Áreas Estratégicas - PDAEST \\
\hline 5 & Norte & AM Fundação de Amparo à Pesquisa do Estado do Amazonas - FAPEAM & Acordo & Desenvolvimento Científico Regional \\
\hline 6 & Norte & AM Fundação de Amparo à Pesquisa do Estado do Amazonas - FAPEAM & Convênio & Iniciação Científica Júnior - IC-Jr \\
\hline 7 & Norte & AM Fundação de Amparo à Pesquisa do Estado do Amazonas - FAPEAM & Convênio & $\begin{array}{c}\text { Programa de Infraestrutura para Jovens Pesquisadores - Programa Primeiros } \\
\text { Projetos }\end{array}$ \\
\hline 8 & Norte & AM Fundação de Amparo à Pesquisa do Estado do Amazonas - FAPEAM & Convênio & Programa de Apoio a Núcleos de Excelência \\
\hline 9 & Norte & AM Fundação de Amparo à Pesquisa do Estado do Amazonas - FAPEAM & Convênio & Programa de Apoio à Núcleos Emergentes \\
\hline 10 & Norte & ecretaria de Estado do Planejamento e Coordenação Geral & Convênio & $\begin{array}{l}\text { Programa de Infraestrutura para Jovens Pesquisadores - Programa Primeiros } \\
\text { Projetos }\end{array}$ \\
\hline 11 & Norte & RO Secretaria de Estado do Planejamento e Coordenação Geral & Acordo & Desenvolvimento Científico Regional \\
\hline 12 & Norte & RR Fundação Estadual do Meio Ambiente e Recursos Hídricos- FEMARH & Convênio & $\begin{array}{l}\text { Programa de Infraestrutura para Jovens Pesquisadores - Programa Primeiros } \\
\text { Projetos }\end{array}$ \\
\hline 13 & Norte & RR Fundação Estadual do Meio Ambiente e Recursos Hídricos- FEMARH & Acordo & Desenvolvimento Científico Regional \\
\hline 14 & Norte & AC Fundação Tecnologia do Estado do Acre - FUNTAC & Convênio & $\begin{array}{l}\text { Programa de Infraestrutura para Jovens Pesquisadores - Programa Primeiros } \\
\text { Projetos }\end{array}$ \\
\hline 15 & Norte & AC Fundação Tecnologia do Estado do Acre - FUNTAC & Acordo & Desenvolvimento Científico Regional \\
\hline 16 & Norte & PA Fundação Amparo à Pesquisa do Estado do Pará - FAPESPA & Acordo & Instituto Nacional de Ciência e Tecnologia - INCT \\
\hline 17 & Norte & PA Fundação Amparo à Pesquisa do Estado do Pará - FAPESPA & Acordo & Desenvolvimento Científico Regional \\
\hline 18 & Norte & PA Fundação Amparo à Pesquisa do Estado do Pará - FAPESPA & Outras & Apoio ao Edital FAPESPA - Redes de Pesquisa \\
\hline 19 & Norte & PA Fundação Amparo à Pesquisa do Estado do Pará - FAPESPA & Outras & Bolsas DTI - IC - Encomenda (Auxílio Individual) \\
\hline 20 & Norte & PA Fundação Amparo à Pesquisa do Estado do Pará - FAPESPA & Convênio & $\begin{array}{c}\text { Programa de Infraestrutura para Jovens Pesquisadores - Programa Primeiros } \\
\text { Projetos }\end{array}$ \\
\hline 21 & Norte & PA Fundação Amparo à Pesquisa do Estado do Pará - FAPESPA & Convênio & Programa de Apoio a Núcleos de Excelência \\
\hline 22 & Norte & PA Fundação Amparo à Pesquisa do Estado do Pará - FAPESPA & Convênio & Programa de Apoio à Núcleos Emergentes \\
\hline 23 & Norte & AP Secretaria de Estado da Ciência e Tecnologia - SETEC & Acordo & Desenvolvimento Científico Regional \\
\hline
\end{tabular}




\begin{tabular}{|c|c|c|c|c|}
\hline 24 & Norte & TO Fundação de Amparo à Pesquisa do Estado do Tocantins - FAPT & Convênio & $\begin{array}{l}\text { Programa de Infraestrutura para Jovens Pesquisadores - Programa Primeiros } \\
\text { Projetos }\end{array}$ \\
\hline 25 & Norte & TO Fundação de Amparo à Pesquisa do Estado do Tocantins - FAPT & Convênio & Desenvolvimento Científico Regional \\
\hline 26 & Norte & TO Fundação de Amparo à Pesquisa do Estado do Tocantins - FAPT & Convênio & Programa de Apoio a Núcleos de Excelência \\
\hline 27 & Nordeste & $\begin{array}{ll}\text { MA } & \text { Fundação de Amparo à Pesquisa e ao Desenvolvimento Científico e Tecnológico do } \\
\text { Maranhão - FAPEMA }\end{array}$ & Convênio & $\begin{array}{l}\text { Programa de Infraestrutura para Jovens Pesquisadores - Programa Primeiros } \\
\text { Projetos }\end{array}$ \\
\hline 28 & Nordeste & $\begin{array}{l}\text { MA Fundação de Amparo à Pesquisa e ao Desenvolvimento Científico e Tecnológico do } \\
\text { Maranhão - FAPEMA }\end{array}$ & Convênio & Programa de Apoio a Núcleos de Excelência \\
\hline 29 & Nordeste & $\begin{array}{l}\text { MA Fundação de Amparo à Pesquisa e ao Desenvolvimento Científico e Tecnológico do } \\
\text { Maranhão - FAPEMA }\end{array}$ & Acordo & Desenvolvimento Científico Regional \\
\hline 30 & Nordeste & $\begin{array}{ll}\text { MA } & \text { Fundação de Amparo à Pesquisa e ao Desenvolvimento Científico e Tecnológico do } \\
\text { Maranhão - FAPEMA }\end{array}$ & Convênio & Programa de Apoio à Núcleos Emergentes \\
\hline 31 & Nordeste & $\begin{array}{l}\text { MA Fundação de Amparo à Pesquisa e ao Desenvolvimento Científico e Tecnológico do } \\
\text { Maranhão - FAPEMA }\end{array}$ & Convênio & iniciação Científica Júnior - IC-Jr \\
\hline 32 & Nordeste & PI Fundação de Amparo à Pesquisa do Estado do Piauí - FAPEPI & Convênio & Iniciação Científica Júnior - IC-Jr \\
\hline 33 & Nordeste & PI Fundação de Amparo à Pesquisa do Estado do Piauí - FAPEPI & Acordo & Desenvolvimento Científico Regional \\
\hline 34 & Nordeste & PI Fundação de Amparo à Pesquisa do Estado do Piauí - FAPEPI & Convênio & 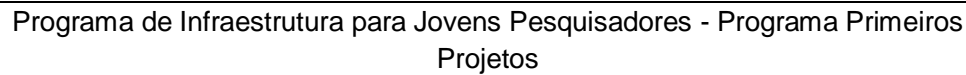 \\
\hline 35 & Nordeste & PI Fundação de Amparo à Pesquisa do Estado do Piauí - FAPEPI & Convênio & Programa de Apoio a Núcleos de Excelência \\
\hline 36 & Nordeste & CE Fundação Cearense de apoio ao Desenvolvimento Científico e Tecnológico - FUNCAP & Convênio & Iniciação Científica Júnior - IC-Jr \\
\hline 37 & Nordeste & CE Fundação Cearense de apoio ao Desenvolvimento Científico e Tecnológico - FUNCAP & Acordo & Desenvolvimento Científico Regional \\
\hline 38 & Nordeste & CE Fundação Cearense de apoio ao Desenvolvimento Científico e Tecnológico - FUNCAP & Convênio & $\begin{array}{c}\text { Programa de Infraestrutura para Jovens Pesquisadores - Programa Primeiros } \\
\text { Projetos }\end{array}$ \\
\hline 39 & Nordeste & CE Instituto Federal de Educação, Ciência e Tecnologia do Ceará - IFCE & Outras & Encomenda - Auxílio Individual \\
\hline 40 & Nordeste & CE Fundação Cearense de apoio ao Desenvolvimento Científico e Tecnológico - FUNCAP & Convênio & Programa Astronomia para todos \\
\hline 41 & Nordeste & CE Fundação Cearense de apoio ao Desenvolvimento Científico e Tecnológico - FUNCAP & Convênio & Programa de Apoio a Núcleos de Excelência \\
\hline 42 & Nordeste & CE Fundação Cearense de apoio ao Desenvolvimento Científico e Tecnológico - FUNCAP & Convênio & Programa de Apoio à Núcleos Emergentes \\
\hline 43 & Nordeste & RNFundação de Amparo à Pesquisa do Estado do Rio Grande do Norte - FAPERN & Acordo & Instituto Nacional de Ciência e Tecnologia - INCT \\
\hline 44 & Nordeste & RN Fundação de Amparo à Pesquisa do Estado do Rio Grande do Norte - FAPERN & Convênio & $\begin{array}{l}\text { Programa de Infraestrutura para Jovens Pesquisadores - Programa Primeiros } \\
\text { Projetos }\end{array}$ \\
\hline 45 & Nordeste & RN Fundação de Amparo à Pesquisa do Estado do Rio Grande do Norte - FAPERN & Acordo & Desenvolvimento Científico Regional \\
\hline 46 & Nordeste & RN Fundação de Amparo à Pesquisa do Estado do Rio Grande do Norte - FAPERN & Convênio & Programa de Apoio a Núcleos de Excelência \\
\hline 47 & Nordeste & RN Fundação de Amparo à Pesquisa do Estado do Rio Grande do Norte - FAPERN & Convênio & Programa de Apoio à Núcleos Emergentes \\
\hline 48 & Nordeste & PB Fundação de Apoio à Pesquisa do Estado da Paraíba - FAPESQ & Convênio & Programa de Apoio a Núcleos de Excelência \\
\hline 49 & Nordeste & PB Fundação de Apoio à Pesquisa do Estado da Paraíba - FAPESQ & Acordo & Desenvolvimento Científico Regional \\
\hline 50 & Nordeste & PB Fundação de Apoio à Pesquisa do Estado da Paraíba - FAPESQ & Convênio & Iniciação Científica Júnior - IC-Jr \\
\hline 51 & Nordeste & PE Fundação de Amparo à Ciência e Tecnologia do Estado e Pernambuco - FACEPE & Convênio & Iniciação Científica Júnior - IC-Jr \\
\hline
\end{tabular}




\begin{tabular}{|c|c|c|c|c|}
\hline 52 & Nordeste & PE Fundação de Amparo à Ciência e Tecnologia do Estado e Pernambuco - FACEPE & Convênio & $\begin{array}{c}\text { Programa de Infraestrutura para Jovens Pesquisadores - Programa Primeiros } \\
\text { Projetos }\end{array}$ \\
\hline 53 & Nordeste & PI Fundação Museu do Homem Americano - FUMDHAM & Outras & Fomento a Projetos de Fortalecimento da Capacidade Científica e Tecnológica \\
\hline 54 & Nordeste & PE Fundação de Amparo à Ciência e Tecnologia do Estado e Pernambuco - FACEPE & Acordo & Desenvolvimento Científico Regional \\
\hline 55 & Nordeste & PE Fundação de Amparo à Ciência e Tecnologia do Estado e Pernambuco - FACEPE & Convênio & Programa de Apoio a Núcleos de Excelência \\
\hline 56 & Nordeste & PE Fundação de Amparo à Ciência e Tecnologia do Estado e Pernambuco - FACEPE & Convênio & Programa de Apoio à Núcleos Emergentes \\
\hline 57 & Nordeste & AL Fundação de Amparo à Pesquisa do Estado de Alagoas - FAPEAL & Convênio & Iniciação Científica Júnior - IC-Jr \\
\hline 58 & Nordeste & AL Fundação de Amparo à Pesquisa do Estado de Alagoas - FAPEAL & Convênio & Programa de Apoio a Núcleos de Excelência \\
\hline 59 & Nordeste & AL Fundação de Amparo à Pesquisa do Estado de Alagoas - FAPEAL & Acordo & Desenvolvimento Científico Regional \\
\hline 60 & Nordeste & AL Fundação de Amparo à Pesquisa do Estado de Alagoas - FAPEAL & Convênio & $\begin{array}{l}\text { Programa de Infraestrutura para Jovens Pesquisadores - Programa Primeiros } \\
\text { Projetos }\end{array}$ \\
\hline 61 & Nordeste & AL Fundação de Amparo à Pesquisa do Estado de Alagoas - FAPEAL & Convênio & Programa de Apoio à Núcleos Emergentes \\
\hline 62 & Nordeste & $\begin{array}{l}\text { SE Fundação de Apoio à Pesquisa e à Inovação Tecnológica do Estado de Sergipe - } \\
\text { FAPITEC }\end{array}$ & Acordo & Iniciação Científica Júnior - IC-Jr \\
\hline 63 & Nordeste & $\begin{array}{l}\text { SE Fundação de Apoio à Pesquisa e à Inovação Tecnológica do Estado de Sergipe - } \\
\text { FAPITEC }\end{array}$ & Convênio & $\begin{array}{l}\text { Programa de Infraestrutura para Jovens Pesquisadores - Programa Primeiros } \\
\text { Projetos }\end{array}$ \\
\hline 64 & Nordeste & $\begin{array}{l}\text { SEE Fundação de Apoio à Pesquisa e à Inovação Tecnológica do Estado de Sergipe - } \\
\text { FAPITEC }\end{array}$ & Acordo & Desenvolvimento Científico Regional \\
\hline 65 & Nordeste & $\begin{array}{l}\text { SE Fundação de Apoio à Pesquisa e à Inovação Tecnológica do Estado de Sergipe - } \\
\text { FAPITEC }\end{array}$ & Convênio & Programa de Apoio a Núcleos de Excelência \\
\hline 66 & Nordeste & $\begin{array}{l}\text { SE Fundação de Apoio à Pesquisa e à Inovação Tecnológica do Estado de Sergipe - } \\
\text { FAPITEC }\end{array}$ & Convênio & Programa de Apoio à Núcleos Emergentes \\
\hline 67 & Nordeste & BA Fundação de Amparo à Pesquisa do Estado da Bahia - FAPESB & Convênio & $\begin{array}{c}\text { Programa de Infraestrutura para Jovens Pesquisadores - Programa Primeiros } \\
\text { Projetos }\end{array}$ \\
\hline 68 & Nordeste & BA Fundação de Amparo à Pesquisa do Estado da Bahia - FAPESB & Acordo & Desenvolvimento Científico Regional \\
\hline 69 & Nordeste & BA Fundação de Amparo à Pesquisa do Estado da Bahia - FAPESB & Convênio & Programa Astronomia para todos \\
\hline 70 & Nordeste & BA Fundação de Amparo à Pesquisa do Estado da Bahia - FAPESB & Convênio & Programa de Apoio a Núcleos de Excelência \\
\hline 71 & Nordeste & BA Fundação de Amparo à Pesquisa do Estado da Bahia - FAPESB & Convênio & Programa de Apoio à Núcleos Emergentes \\
\hline 72 & Nordeste & BA Fundação de Amparo à Pesquisa do Estado da Bahia - FAPESB & Acordo & Iniciação Científica Júnior - IC-Jr \\
\hline 73 & $\begin{array}{l}\text { Centro } \\
\text { Oeste }\end{array}$ & DF Fundação de Apoio à Pesquisa do Distrito Federal - FAP/DF & Convênio & Programa de Apoio a Núcleos de Excelência \\
\hline 74 & $\begin{array}{l}\text { Centro } \\
\text { Oeste }\end{array}$ & GOFundação de Amparo à Pesquisa do Estado de Goiás - FAPEG & Convênio & $\begin{array}{l}\text { Programa de Infraestrutura para Jovens Pesquisadores - Programa Primeiros } \\
\text { Projetos }\end{array}$ \\
\hline 75 & $\begin{array}{l}\text { Centro } \\
\text { Oeste }\end{array}$ & GOFundação de Amparo à Pesquisa do Estado de Goiás - FAPEG & Acordo & Desenvolvimento Científico Regional \\
\hline 76 & $\begin{array}{l}\text { Centro } \\
\text { Oeste }\end{array}$ & GOFundação de Amparo à Pesquisa do Estado de Goiás - FAPEG & Convênio & Programa de Apoio a Núcleos de Excelência \\
\hline
\end{tabular}




\begin{tabular}{|c|c|c|c|c|}
\hline 77 & $\begin{array}{l}\text { Centro } \\
\text { Oeste }\end{array}$ & MT Fundação de Amparo a Pequisa do Estado de Mato Grosso - FAPEMAT & Convênio & $\begin{array}{l}\text { Programa de Infraestrutura para Jovens Pesquisadores - Programa Primeiros } \\
\text { Projetos }\end{array}$ \\
\hline 78 & $\begin{array}{l}\text { Centro } \\
\text { Oeste }\end{array}$ & MT Fundação de Amparo a Pequisa do Estado de Mato Grosso - FAPEMAT & Acordo & Desenvolvimento Científico Regional \\
\hline 79 & $\begin{array}{l}\text { Centro } \\
\text { Oeste }\end{array}$ & MT Fundação de Amparo a Pequisa do Estado de Mato Grosso - FAPEMAT & Convênio & Programa de Apoio a Núcleos de Excelência \\
\hline 80 & $\begin{array}{l}\text { Centro } \\
\text { Oeste }\end{array}$ & MT Fundação de Amparo a Pequisa do Estado de Mato Grosso - FAPEMAT & Convênio & Programa de Apoio à Núcleos Emergentes \\
\hline 81 & $\begin{array}{l}\text { Centro } \\
\text { Oeste }\end{array}$ & \begin{tabular}{|l|l|} 
MS Fundação de Apoio ao Desenvolvimento do Ensino, Ciência e Tecnologia do Estado de \\
Mato Grosso do Sul - FUNDECT
\end{tabular} & Convênio & Iniciação Científica Júnior - IC-Jr \\
\hline 82 & $\begin{array}{l}\text { Centro } \\
\text { Oeste }\end{array}$ & $\begin{array}{l}\text { MS } \begin{array}{l}\text { Fundação de Apoio ao Desenvolvimento do Ensino, Ciência e Tecnologia do Estado de } \\
\text { Mato Grosso do Sul - FUNDECT }\end{array} \\
\end{array}$ & Acordo & Desenvolvimento Científico Regional \\
\hline 83 & $\begin{array}{l}\text { Centro } \\
\text { Oeste }\end{array}$ & $\begin{array}{l}\text { MS } \begin{array}{l}\text { Fundação de Apoio ao Desenvolvimento do Ensino, Ciência e Tecnologia do Estado de } \\
\text { Mato Grosso do Sul - FUNDECT }\end{array} \\
\end{array}$ & Convênio & $\begin{array}{l}\text { Programa de Infraestrutura para Jovens Pesquisadores - Programa Primeiros } \\
\text { Projetos }\end{array}$ \\
\hline 84 & $\begin{array}{l}\text { Centro } \\
\text { Oeste }\end{array}$ & $\begin{array}{l}\text { MS } \begin{array}{l}\text { Fundação de Apoio ao Desenvolvimento do Ensino, Ciência e Tecnologia do Estado de } \\
\text { Mato Grosso do Sul - FUNDECT }\end{array}\end{array}$ & Convênio & Programa de Apoio à Núcleos Emergentes \\
\hline 85 & Sudeste & MG Fundação de Amparo à Pesquisa do Estado de Minas Gerais - FAPEMIG & Acordo & Instituto Nacional de Ciência e Tecnologia - INCT \\
\hline 86 & Sudeste & MG Fundação de Amparo à Pesquisa do Estado de Minas Gerais - FAPEMIG & Convênio & $\begin{array}{l}\text { Programa de Infraestrutura para Jovens Pesquisadores - Programa Primeiros } \\
\text { Projetos }\end{array}$ \\
\hline 87 & Sudeste & MG Fundação de Amparo à Pesquisa do Estado de Minas Gerais - FAPEMIG & Convênio & Ciência, Tecnologia \& Inovação na Bacia do Rio Doce \\
\hline 88 & Sudeste & MG Fundação de Amparo à Pesquisa do Estado de Minas Gerais - FAPEMIG & Convênio & Programa Astronomia para todos \\
\hline 89 & Sudeste & MG Fundação de Amparo à Pesquisa do Estado de Minas Gerais - FAPEMIG & Convênio & Programa de Apoio a Núcleos de Excelência \\
\hline 90 & Sudeste & MG Fundação de Amparo à Pesquisa do Estado de Minas Gerais - FAPEMIG & Convênio & Programa de Apoio à Núcleos Emergentes \\
\hline 91 & Sudeste & MG Fundação de Amparo à Pesquisa do Estado de Minas Gerais - FAPEMIG & Convênio & Iniciação Científica Júnior - IC-Jr \\
\hline 92 & Sudeste & ES Fundação de Amparo à Pesquisa do Espírito Santo - FAPES & Convênio & Iniciação Científica Júnior - IC-Jr \\
\hline 93 & Sudeste & ES Fundação de Amparo à Pesquisa do Espírito Santo - FAPES & Convênio & Ciência, Tecnologia \& Inovação na Bacia do Rio Doce \\
\hline 94 & Sudeste & ES Fundação de Amparo à Pesquisa do Espírito Santo - FAPES & Acordo & Desenvolvimento Científico Regional \\
\hline 95 & Sudeste & ES Fundação de Amparo à Pesquisa do Espírito Santo - FAPES & Convênio & $\begin{array}{l}\text { Programa de Infraestrutura para Jovens Pesquisadores - Programa Primeiros } \\
\text { Projetos }\end{array}$ \\
\hline 96 & Sudeste & ES Fundação de Amparo à Pesquisa do Espírito Santo - FAPES & Convênio & Programa de Apoio a Núcleos de Excelência \\
\hline 97 & Sudeste & $\begin{array}{l}\text { RJ Fundação Carlos Chagas Filho de Amparo à Pesquisa do Estado do Rio de Janeiro - } \\
\text { FAPERJ }\end{array}$ & Acordo & Instituto Nacional de Ciência e Tecnologia - INCT \\
\hline 98 & Sudeste & $\begin{array}{l}\text { RJ Fundação Carlos Chagas Filho de Amparo à Pesquisa do Estado do Rio de Janeiro - } \\
\text { FAPERJ }\end{array}$ & Convênio & Programa de Apoio a Núcleos de Excelência \\
\hline 99 & Sudeste & $\begin{array}{l}\text { RJ Fundação Carlos Chagas Filho de Amparo à Pesquisa do Estado do Rio de Janeiro - } \\
\text { FAPERJ }\end{array}$ & Convênio & Programa de Apoio à Núcleos Emergentes \\
\hline 100 & Sudeste & SP Fundação de Amparo à Pesquisa do Estado de São Paulo - FAPESP & Acordo & Instituto Nacional de Ciência e Tecnologia - INCT \\
\hline
\end{tabular}




\begin{tabular}{|c|c|c|c|c|}
\hline 101 & Sudeste & SP Fundação de Amparo à Pesquisa do Estado de São Paulo - FAPESP & Convênio & $\begin{array}{c}\text { Programa de Infraestrutura para Jovens Pesquisadores - Programa Primeiros } \\
\text { Projetos }\end{array}$ \\
\hline 102 & Sudeste & SP Fundação de Amparo à Pesquisa do Estado de São Paulo - FAPESP & Outras & Programa de Apoio a Núcleos de Excelência \\
\hline 103 & Sudeste & SP Fundação de Amparo à Pesquisa do Estado de São Paulo - FAPESP & Convênio & Programa de Apoio a Núcleos de Excelência \\
\hline 104 & Sul & $\begin{array}{l}\text { PR } \begin{array}{l}\text { Fundação Araucária - Apoio ao Desenvolvimento Científico e Tecnológico do Paraná - } \\
\text { FAADCT }\end{array}\end{array}$ & Acordo & Iniciação Científica Júnior - IC-Jr \\
\hline 105 & Sul & $\begin{array}{l}\text { PR } \begin{array}{l}\text { Fundação Araucária - Apoio ao Desenvolvimento Científico e Tecnológico do Paraná - } \\
\text { FAADCT }\end{array}\end{array}$ & Convênio & $\begin{array}{c}\text { Programa de Infraestrutura para Jovens Pesquisadores - Programa Primeiros } \\
\text { Projetos }\end{array}$ \\
\hline 106 & Sul & $\begin{array}{ll}\text { PR } & \begin{array}{l}\text { Fundação Araucária - Apoio ao Desenvolvimento Científico e Tecnológico do Paraná - } \\
\text { FAADCT }\end{array}\end{array}$ & Convênio & Rede Aquífero Guarani / Serra Geral \\
\hline 107 & Sul & $\begin{array}{l}\text { PRR } \\
\begin{array}{l}\text { Fundação Araucária - Apoio ao Desenvolvimento Científico e Tecnológico do Paraná - } \\
\text { FAADCT }\end{array}\end{array}$ & Convênio & Programa de Apoio a Núcleos de Excelência \\
\hline 108 & Sul & 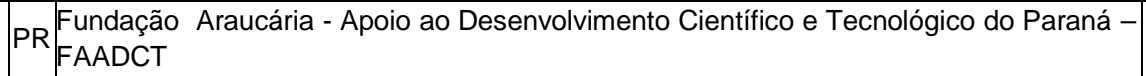 & Convênio & Programa de Apoio à Núcleos Emergentes \\
\hline 109 & Sul & $\begin{array}{l}\text { SC Fundação de Apoio à Pesquisa Científica e Tecnológica do Estado de Santa Catarina - } \\
\text { FAPESC }\end{array}$ & Acordo & Instituto Nacional de Ciência e Tecnologia - INCT \\
\hline 110 & Sul & $\begin{array}{l}\text { SC Fundação de Apoio à Pesquisa Científica e Tecnológica do Estado de Santa Catarina - } \\
\text { FAPESC }\end{array}$ & Acordo & Iniciação Científica Júnior - IC-Jr \\
\hline 111 & Sul & $\begin{array}{l}\text { SC Fundação de Apoio à Pesquisa Científica e Tecnológica do Estado de Santa Catarina - } \\
\text { FAPESC }\end{array}$ & Outras & $\begin{array}{l}\text { Sistema de Indicadores das Fundações Estaduais de Amparo à Pesquisa - } \\
\text { SIFAP'S }\end{array}$ \\
\hline 112 & Sul & $\begin{array}{l}\text { SC Fundação de Apoio à Pesquisa Científica e Tecnológica do Estado de Santa Catarina - } \\
\text { FAPESC }\end{array}$ & Convênio & Rede Aquífero Guarani / Serra Geral \\
\hline 113 & Sul & $\begin{array}{l}\text { SC } \begin{array}{l}\text { Fundação de Apoio à Pesquisa Científica e Tecnológica do Estado de Santa Catarina - } \\
\text { FAPESC }\end{array} \\
\end{array}$ & Convênio & Programa de Apoio a Núcleos de Excelência \\
\hline 114 & Sul & $\begin{array}{l}\text { SC Fundação de Apoio à Pesquisa Científica e Tecnológica do Estado de Santa Catarina - } \\
\text { FAPESC }\end{array}$ & Convênio & Programa de Apoio à Núcleos Emergentes \\
\hline 115 & Sul & $\begin{array}{l}\text { SC Fundação de Apoio à Pesquisa Científica e Tecnológica do Estado de Santa Catarina - } \\
\text { FAPESC }\end{array}$ & Convênio & $\begin{array}{c}\text { Programa de Infraestrutura para Jovens Pesquisadores - Programa Primeiros } \\
\text { Projetos }\end{array}$ \\
\hline 116 & Sul & RS Fundação de Amparo à Pesquisa do Estado do Rio Grande do Sul - FAPERGS & Convênio & Programa de Apoio a Núcleos de Excelência \\
\hline 117 & Sul & RS Fundação de Amparo à Pesquisa do Estado do Rio Grande do Sul - FAPERGS & Convênio & Programa de Apoio à Núcleos Emergentes \\
\hline 118 & Sudeste & SP Universidade Estadual de Campinas - UNICAMP & Convênio & Iniciação Científica Júnior - IC-Jr \\
\hline 119 & Sudeste & SP Universidade Estadual Paulista "Júlio de Mesquita Filho" - UNESP & Acordo & Iniciação Científica Júnior - IC-Jr \\
\hline
\end{tabular}

Fonte: www.cnpq.br 


\section{APÊNDICE A}

\section{MATRIZ DA ESTRUTURA LÓGICA DO PROJETO}

\begin{tabular}{|c|c|c|c|}
\hline $\begin{array}{l}\text { OBJETIVO GERAL } \\
\text { - Contribuir para a melhoria dos } \\
\text { instrumentos de acompanhamento e } \\
\text { avaliação e gestão de Programas no } \\
\text { âmbito das parcerias com as FAP. }\end{array}$ & \begin{tabular}{|l|} 
IMPACTO \\
- Melhoria na forma do \\
A\&A das parcerias no \\
contexto interno e externo ao \\
CNPq, possibilitando a rua \\
gestão estratégica, em \\
conformidade com seus \\
Dirigentes.
\end{tabular} & \begin{tabular}{|l|} 
- Verificar nos \\
Relatórios $\quad$ Técnicos \\
recebidos a incorporação das \\
sugestões.
\end{tabular} & $\begin{array}{l}\text { - Disposição dos Dirigentes } \\
\text { das FAP para o envio de } \\
\text { Relatórios Técnicos ao CNPq. } \\
\text { Disposição dos Dirigentes das } \\
\text { FAP e CNPq para adotarem } \\
\text { sugestões. }\end{array}$ \\
\hline $\begin{array}{l}\text { OBJETIVOS } \\
\text { ESPECÍFICOS/PROPÓSITOS } \\
1-\text { Identificar como acontecem as } \\
\text { relações institucionais entre o CNPq e } \\
\text { as FAP; } \\
2 \text { - Identificar quais as formas de } \\
\text { Acompanhamento e Avaliação - A\&A } \\
\text { utilizadas pelas FAP; } \\
3 \quad \text { - Analisar o processo de } \\
\text { acompanhamento e avaliação das } \\
\text { atividades em parceria entre o CNPq e a } \\
\text { FAP. } \\
4-\text { Identificar as formas de utilização } \\
\text { dos resultados do A\&A pelas partes } \\
\text { envolvidas. }\end{array}$ & \begin{tabular}{|l|} 
IMPACTO \\
Implementação de sugestões \\
de práticas de monitoramento \\
das parcerias no contexto \\
interno e externo ao CNPq, \\
visando o A\&A \\
da gestão das parcerias de \\
forma estratégica, de acordo \\
com os Dirigentes das FAP e \\
CNPq.
\end{tabular} & $\begin{array}{l}\text { - Realizar visitas técnicas } \\
\text { periódicas } \\
\text { para o acompanhamento e } \\
\text { avaliação. }\end{array}$ & 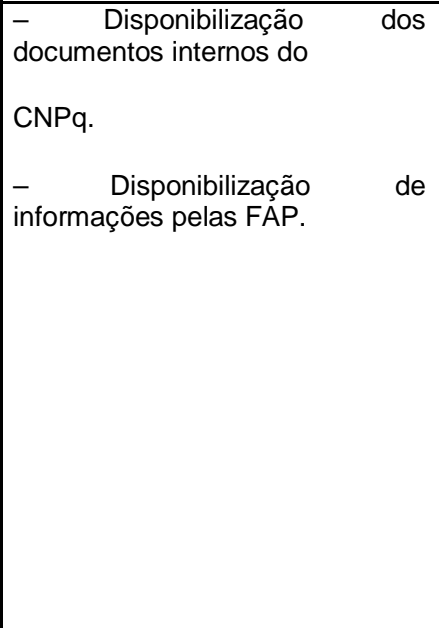 \\
\hline $\begin{array}{l}\text { RESULTADOS } \\
\text { Espera-se a incorporação das sugestões } \\
\text { derivadas da pesquisa para a melhoria } \\
\text { dos instrumentos de acompanhamento e } \\
\text { avaliação e gestão de convênios no } \\
\text { âmbito das parcerias do CNPq com as } \\
\text { FAP. }\end{array}$ & $\begin{array}{l}\text { PRODUTOS } \\
\text { Dissertação concluída. }\end{array}$ & \begin{tabular}{|lrr|}
\multicolumn{3}{|l|}{ - Base de dados do } \\
\\
CNPq; & Relatórios & Técnicos \\
enviados & pelas & FAP; \\
sistemas & eletrônicos & do \\
CNPq. & & \\
\end{tabular} & \begin{tabular}{|lll} 
- Aceitação & e apoio das \\
autoridades competentes. &
\end{tabular} \\
\hline $\begin{array}{l}\text { ATIVIDADES } \\
\text { 1-Revisão bibliográfica sobre gestão do } \\
\text { apoio à C,T\&l, relativo a } \\
\text { descentralização da C\&T\&I no Brasil, } \\
\text { sobre A\&A, sobre as ações do CNPq } \\
\text { com as FAP; } \\
\text { 2- Levantamento e análise de } \\
\text { documentos sobre o A\&A das parcerias } \\
\text { entre o CNPq e as FAP, relatórios de } \\
\text { gestão do CNPq, processos e relatórios } \\
\text { técnicos das parcerias; } \\
\text { 3- Levantamento histórico sobre a FAP e } \\
\text { suas iniciativas junto ao Governo do } \\
\text { Estado, seus modelos e práticas de A\&A } \\
\text { utilizadas; e } \\
\text { 4-Realização de entrevistas por meio de } \\
\text { questionário semiestruturado com os } \\
\text { gestores e técnicos do CNPq e, também, } \\
\text { junto aos gestores dos convênios nas } \\
\text { FAP, sobre o A\&A das parcerias. }\end{array}$ & $\begin{array}{l}\text { INSUMOS/RECURSOS } \\
\text { - Levantamento e análise de } \\
\text { documentos sobre o A\&A dos } \\
\text { convênios entre o CNPq e as } \\
\text { FAP. } \\
\text { - Entrevistas por meio de } \\
\text { questionário semiestruturado. }\end{array}$ & \begin{tabular}{lll|}
- & Processos & físicos dos \\
convênios & desenvolvidos \\
pelas FAP, no âmbito do \\
CNPq.
\end{tabular} & $\begin{array}{l}\text { Disponibilização dos } \\
\text { documentos internos do CNPq. } \\
\text { - Participação dos gestores } \\
\text { internos e externos de entrevista } \\
\text { por meio de questionário } \\
\text { semiestruturado. }\end{array}$ \\
\hline
\end{tabular}




\section{APÊNDICE B}

Prezado(a) Colega,

Estou terminando a minha pesquisa do Curso de Mestrado Profissional em Gestão e Política de Ciência Tecnologia e Inovação (C,T\&l), do Programa de Pós-Graduação Stricto Sensu da Universidade de Brasília - UnB, intitulada "O Processo de Acompanhamento e Avaliação da Descentralização de Recursos da União, descentralizados por meio do CNPq às Fundações Estaduais de Amparo à Pesquisa (FAP)". A proposta é a de analisar como são feitas as descentralizações de Recursos da União, pelo CNPq e de como são realizados o acompanhamento e a avaliação desse processo.

A sua colaboração é de fundamental importância como subsidio para a minha pesquisa e conclusão da dissertação de mestrado, incluindo sugestões que possibilitem aperfeiçoar a gestão de processos associados à descentralização de recursos financeiros, sendo este um dos aspectos da Missão e atuação do CNPq.

Nesse sentido, a resposta a todas as questões colocadas seria uma colaboração inestimável. Asseguro a V.Sas que as informações contidas neste instrumento somente serão utilizadas nesta pesquisa e nenhuma opinião, afirmação ou sugestão terá autoria declarada, salvo se devidamente autorizado pelo respectivo entrevistado.

Desde já agradeço a sua colaboração e solicito a gentileza em devolver o questionário até o dia 20.05.2014.

RUDES LIMA FREITAS

E-mail: rudes.freitas@cnpq.br ou rudeslimafreitas@gmail.com

Celular: ( 61) 9222-2531

Telefone: (61) 3211-9943 
Data:

\section{PERGUNTAS:}

1) Quais são as instâncias decisórias dentro do CNPq para a negociação e firmatura de convênios para a concessão de recursos mediante a descentralização de recursos da União?

Houve a necessidade de adaptação na Estrutura física do CNPq para o atendimento à legislação que regula a concessão de recursos mediante a descentralização de recursos da União às FAP?

$\operatorname{Sim}$

Não

Se sim, quais?

Sobre o papel das FAP no processo de negociação das parcerias e convênios

2) Quem define as prioridades para a pesquisa nos estados?

As FAP, de forma independente;

As FAP e o CNPq;

As FAP, o CNPq e outros financiadores, de acordo com os programas;

O CNPq, de forma independente; e

O CNPq e financiadores do respectivo programa.

COMENTARIOS

\section{Sobre o A\&A dos convênios e das Transferências}

3) O CNPq tem realizado acompanhamento e avaliação dos convênios e da descentralização de recursos da União?

Sim, desde o início das assinaturas dos convênios que ocorreram, basicamente a partir do ano de 2003

Sim, desde

Em alguns casos, dependendo do programa

Somente da descentralização de recursos da União (financeiro)

Não faz A\&A dos convênios e da descentralização de recursos da União (neste caso, pule para a pergunta número 11)

4) Quais os principais instrumentos utilizados para o A\&A?

Acompanhamento financeiro, de acordo com a legislação da descentralização de recursos da União; 
Acompanhamento técnico, de acordo com as normas e instrumentos do CNPq para todos os projetos que apoia;

Seminários e painéis para avaliação de projetos em conjunto com as FAP.

5) O CNPq define ou solicita às FAP a definição prévia de indicadores para acompanhamento dos projetos e verificação de resultados?

6) As normas internas do CNPq são adequadas para realizar o A\&A da descentralização de recursos da União?

\section{COMENTARIOS}

7) As normas dos órgãos de controle são adequadas para realizar o A\&A da descentralização de recursos da União?

\section{COMENTARIOS}

8) Até que ponto o A\&A realizado pelo CNPq permite respostas claras quanto à aplicação dos recursos e de ações descentralizados em regiões mais afastadas e com menor infraestrutura de P\&D?

\section{COMENTARIOS}

\section{Sobre a Gestão do A\&A e uso dos resultados}

9) O CNPq possui estrutura física ou de pessoal adequadas para realizar o A\&A?

10) Na sua opinião, seria necessária uma estrutura distinta para realizar o A\&A?

11) Existe um fiscal ou gestor de convênios designado pelo CNPq, para acompanhar os convênios, conforme legislação?

12) Como deveria ser feito o A\&A dos convênios no âmbito do CNPq?

Por área especifica responsável por A\&A

Por pessoas/equipes designadas em cada convênio

Por consultores externos, no caso do acompanhamento e avaliação técnica

\section{COMENTARIOS}

13) Esta Coordenação trabalha em parceria com outras áreas do CNPq?

$\operatorname{Sim}$

Não

14) O A\&A realizado (pelo CNPq ou pelas FAP) sobre os convênios e descentralização de recursos têm contribuído para o aperfeiçoamento desses instrumentos?

Não

$\operatorname{Sim}-$ como?

COMENTARIOS 
15) Na sua opinião, as parcerias e convênios com o CNPq contribuíram para que as FAP aprimorassem a gestão de convênios e a gestão do fomento em geral?

Não

Sim, Como?

COMENTARIOS

16) Do ponto de vista dos resultados dos projetos apoiados por meio das parcerias com o CNPq e da descentralização de recursos da União, há alguma avaliação sobre os impactos no desenvolvimento científico e tecnológico estadual ou regional?

Não conheço.

Sim.

Quais?

17) Cite três medidas ou procedimentos que, na sua opinião, deveriam ser implementados para aperfeiçoar o A\&A dos convênios e parcerias com as FAP e da descentralização de recursos da União. 


\section{Orientação Geral}

Prezado(a),

Estou terminando a minha pesquisa do Curso de Mestrado Profissional em Gestão e Política de Ciência Tecnologia e Inovação (C,T\&l), do Programa de Pós-Graduação Stricto Sensu da Universidade de Brasília - UnB, intitulada "O Processo de Acompanhamento e Avaliação da Descentralização de Recursos da União, descentralizados por meio do $\mathrm{CNPq}$ às Fundações Estaduais de Amparo à Pesquisa (FAP)". A proposta é a de analisar como são feitas as descentralizações de Recursos da União, pelo CNPq e de como são realizados o acompanhamento e a avaliação desse processo.

A sua colaboração é de fundamental importância como subsidio para a minha pesquisa e conclusão da dissertação de mestrado, incluindo sugestões que possibilitem aperfeiçoar a gestão de processos associados à descentralização de recursos financeiros, sendo este um dos aspectos da Missão e atuação do CNPq. Nesse sentido, a resposta a todas as questões colocadas seria uma colaboração inestimável.

Asseguro a V.Sas que as informações contidas neste instrumento somente serão utilizadas nesta pesquisa e nenhuma opinião, afirmação ou sugestão terá autoria declarada, salvo se devidamente autorizado pelo respectivo entrevistado.

Desde já agradeço a colaboração e solicito a sua gentileza em devolver o presente questionário até ao final do evento.

\section{RUDES LIMA FREITAS}

E-mail: rudes.freitas@cnpq.br ou rudeslimafreitas@gmail.com

Celular: ( 61) 9222-2531

Telefone: (61) 3211-9943 


\section{QUESTIONÁRIO DE PESQUISA DIRIGIDA AOS REPRESENTANTES DAS FUNDAÇÕES DE AMPARO À PESQUISA - FAP}

Data:

\begin{tabular}{|c|c|c|}
\hline $\mathrm{N}^{\mathrm{o}}$ & Perguntas & SimNão \\
\hline & $\begin{array}{l}\text { A descentralização de recursos da União têm contribuído, efetivamente, para uma } \\
\text { descentralização regional efetiva das atividades de C\&T\&I? }\end{array}$ & \\
\hline 2. & Elas têm contribuído para um maior desenvolvimento científico e tecnológico de seu Estado? & \\
\hline & $\begin{array}{l}\text { No caso da descentralização de recursos da União, esta FAP participa efetivamente da escolha } \\
\text { das prioridades para aplicação dos recursos? }\end{array}$ & \\
\hline \multicolumn{3}{|c|}{ 4. Como se dá o processo de escolha das prioridades estaduais ou regionais? } \\
\hline \multicolumn{3}{|c|}{$\begin{array}{l}\text { Há participação de atores do poder público federal na escolha das prioridade } \\
\text { estaduais/regionais para aplicação dos recursos recebidos via descentralização de recursos da } \\
\text { União? }\end{array}$} \\
\hline \multicolumn{3}{|c|}{ 5.1.De que forma? } \\
\hline \multirow[t]{3}{*}{6.} & $\begin{array}{l}\text { As parcerias e convênios com o CNPq têm contribuído para o aperfeiçoamento da gestão do } \\
\text { fomento por parte desta FAP? }\end{array}$ & \\
\hline & $\begin{array}{l}\text { 6.1. Este aperfeiçoamento da gestão é observado de que forma ? } \\
(\text { ) aperfeiçoamento de editais; } \\
\text { ( ) processos de acompanhamento e avaliação de projetos mais sistemáticos; } \\
\text { ( ) desenvolvimento de Acompanhamento e Avaliação das parcerias e convênios; } \\
\text { ( ) outros. }\end{array}$ & \\
\hline & \multicolumn{2}{|l|}{ 6.2. Observações quanto à contribuição para o aperfeiçoamento da gestão: } \\
\hline \multirow[t]{5}{*}{7.} & Há avaliações de resultados e de impactos das parcerias com o CNPq? & \\
\hline & 7.1. Em todos os casos & \\
\hline & 7.2. Em alguns casos & \\
\hline & 7.3. Não & \\
\hline & \multicolumn{2}{|l|}{ 7.4. Em caso negativo ou de avaliação em apenas alguns casos, por que? } \\
\hline 8. & Quais os principais resultados que poderiam ser apontados? & \\
\hline
\end{tabular}


9. Cite pelo menos três aspectos que poderiam ser descritos como impactos das atividades desenvolvidas por meio da descentralização de recursos da União, no que se refere à gestão e aos avanços científicos e tecnológicos observados na área de influência desta FAP.

9.1 .

9.2

9.3 .

10. Os convênios e parcerias com o CNPq têm contribuído para o desenvolvimento regional?

11. Que sugestões você daria para o aperfeiçoamento da gestão dos convênios com o CNPq?

Observações:

Nome do Respondente:

Função ou Cargo que exerce:

Nome da FAP: 